\begin{abstract}
UNIVERSIDADE DE SÃO PAULO - USP
ESCOLA DE ENGENHARIA DE SÃO CARLOS

DEPARTAMENTO DE ENGENHARIA ELÉTRICA E DE COMPUTAÇÃO

Programa de Pós-Graduação em Engenharia ElÉtrica
\end{abstract}

ANDRÉ SANCHES Fonseca SOBRINHO

\title{
DESENVOLVIMENTO DE UMA UNIDADE DE MEDIÇÃO FASORIAL OTIMIZADA PARA SISTEMAS DE DISTRIBUIÇÃO
}





\section{André Sanches Fonseca Sobrinho}

\section{Desenvolvimento de uma unidade de medição fasorial otimizada para sistemas de distribuição}

Tese de doutorado apresentada ao Programa de Engenharia Elétrica da Escola de Engenharia de São Carlos como parte dos requisitos para obtenção do título de Doutor em Ciências.

Área de concentração: Sistemas Dinâmicos

Orientador: Rogério Andrade Flauzino

São Carlos

2016 
AUTORIZO A REPRODUÇÃO TOTAL OU PARCIAL DESTE TRABALHO, POR QUALQUER MEIO CONVENCIONAL OU ELETRÔNICO, PARA FINS DE ESTUDO E PESQUISA, DESDE QUE CITADA A FONTE.

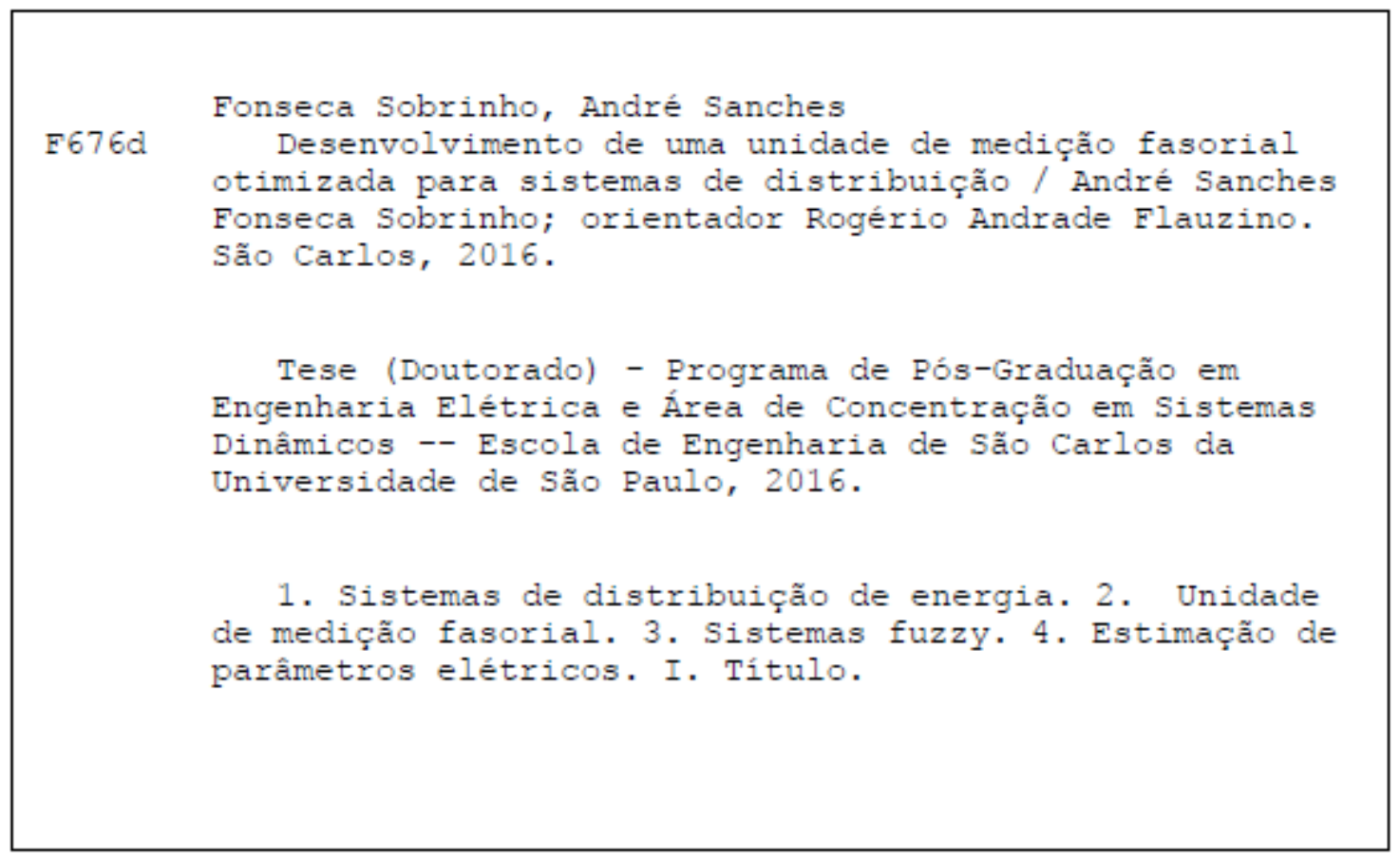


FOLHA DE JULGAMENTO

Candidato: Engenheiro ANDRÉ SANCHES FONSECA SOBRINHO.

Título da tese: "Desenvolvimento de uma unidade de medição fasorial otimizada para sistemas de distribuição".

Data da defesa: 11/03/2016

Comissão Julgadora:

Resultado:

Prof. Associado Rogério Andrade Flauzino (Orientador)

(Escola de Engenharia de São Carlos/EESC)

Prof. Titular Ruy Alberto Corrêa Altafim

(Escola de Engenharia de São Carlos/EESC)

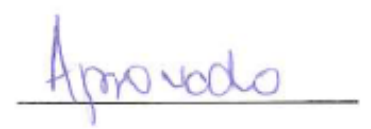

Prof. Dr. Sérgio Kurokawa

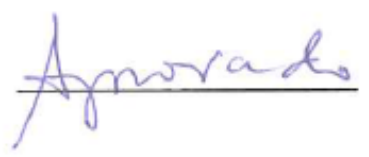

(Universidade Estadual Paulista "Júlio de Mesquita Filho"/UNESP - Ilha Solteira)

Prof. Dr. Luciano Vieira Lima

(Universidade Federal de Uberlândia/UFU)

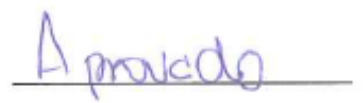

Prof. Dr. Claudionor Francisco do Nascimento

Aprov450

(Universidade Federal de São Carlos/UFSCar)

Coordenador do Programa de Pós-Graduação em Engenharia Elétrica:

Prof. Associado Luis Fernando Costa Alberto

Presidente da Comissão de Pós-Graduação:

Prof. Associado Paulo César Lima Segantine 

Dedico este trabalho às mulheres da minha família (minha mãe Rosana, minha avó Leonor, minha futura esposa Fabiane e minha tia Valéria) pelo carinho, presença e constante apoio durante a elaboração deste trabalho. 



\section{AGRADECIMENTOS}

Muitas pessoas e instituições contribuíram efetivamente para a realização deste trabalho. Gostaria de deixar registrada minha gratidão a todas elas e desde já me desculpo por alguma omissão:

Ao meu orientador Prof. Dr. Rogério Andrade Flauzino, por partilhar sua sabedoria e experiência em sistemas dinâmicos, pelas sugestões no decorrer do desenvolvimento deste trabalho e pela confiança depositada em mim.

Ao Prof. Dr. Alessandro Goedtel, valoroso colega de trabalho na UTFPR Campus Cornélio Procópio que desde o início se prontificou em me ajudar em meu curso de doutorado, tanto no primeiro contato com os docentes da Escola de Engenharia de São Carlos quanto no levantamento de fundos para a construção do primeiro protótipo do equipamento proposto nesta tese.

Aos colegas professores da UTFPR Msc. Wagner Fontes Godoy, Msc. Rodrigo Henrique Cunha Palácios e Msc. Leonardo Bruno Garcia Campanhol pelo apoio oferecido às mais diferentes dúvidas no decorrer do desenvolvimento deste trabalho.

À chefia do Departamento de Engenharia Elétrica da UTFPR Campus Cornélio Procópio, a qual ofereceu total apoio à realização deste trabalho.

Aos colegas professores do IFPR Msc. Edson Junior Acordi e Msc. Rodrigo Barriviera pelo companheirismo e amizade durante a realização das disciplinas do curso.

Aos meus amigos da Universidade Estadual de Londrina, Prof. Dr. Marcelo Tosin, Prof. Dr. Francisco Granziera Júnior e Eng. Daniel Batista Strufaldi, que além de me permitirem utilizar a estrutura do Laboratório de Instrumentação Eletrônica, compartilharam comigo conhecimentos acadêmicos e uma grande amizade.

À Identech, empresa onde trabalhei por quase dez anos e no qual adquiri imensa bagagem profissional como engenheiro de desenvolvimento, pelo apoio na aquisição de componentes.

À Fundação Araucária e CAPES, pela concessão de bolsa de estudos com o qual foi possível custear o material utilizado neste trabalho e as viagens realizadas a São Carlos.

Ao Programa de Pós-Graduação em Engenharia Elétrica da EESC, pela minha aceitação como pesquisador. 

“A educação torna fácil liderar um povo, mas difícil manobrá-lo; fácil governá-lo, mas impossível escravizá-lo". 



\section{RESUMO}

Sobrinho, A. S. F. Desenvolvimento de uma Unidade de Medição Fasorial Otimizada para Sistemas de Distribuição. 218 p. Tese de Doutorado - Escola de Engenharia de São Carlos, Universidade de São Paulo, São Carlos, 2016.

Os sistemas elétricos de distribuição estão evoluindo rapidamente devido à penetração de geração distribuída e ao crescimento na utilização de avançadas estruturas de medição e sistemas de gerenciamento de distribuição de energia elétrica. Esta evolução traz consigo novos desafios devido à intermitência da geração, a qual pode gerar impactos indesejáveis nos sistemas de distribuição, como a interação de diferentes harmônicos. As Unidades de Medição Fasorial $(P M U s)$ tem potencial para desempenhar um importante papel no monitoramento de sistemas elétricos de distribuição por meio dos fasores com medidas temporalmente sincronizadas de tensão e corrente em vários locais do sistema, oferecendo assim inúmeras possibilidades para estimar o estado de uma rede de distribuição. Porém, para serem utilizadas amplamente em redes de distribuição, é necessário que as $P M U s$ apresentem um menor custo e possuam algumas características funcionais exclusivas para o uso nestas redes. Assim, o objetivo desta tese consiste no desenvolvimento de uma unidade de medição fasorial de baixo custo com características originais para o uso no nível de distribuição de energia elétrica, tais como medição fasorial nas redes de média e baixa tensão utilizando a modelagem dos transformadores e a identificação e estimação dos parâmetros da causa de ocorrência de distúrbios elétricos. Para isso, foram construídos dois protótipos da unidade de medição fasorial proposta neste trabalho, visando verificar a sincronização na medição de fasores de tensão e corrente. Os protótipos também foram acoplados à rede com diferentes combinações de impedância e alimentaram variadas cargas, onde foi possível através das técnicas implementadas nos equipamentos identificar e estimar os parâmetros elétricos da origem (rede ou carga) da ocorrência de variações na tensão e potência fornecidas pela rede distribuição.

Palavras-chave: Sistemas de distribuição de energia. Unidade de medição fasorial. Sistemas Fuzzy. Estimação de parâmetros elétricos. 


\section{ABSTRACT}

Sobrinho, A. S. F. Developing of an Optimized Phasor Measurement Unit for Power Distribution Systems. Thesis (Doctorate Degree) - Escola de Engenharia de São Carlos, Universidade de São Paulo, São Carlos, 2016.

Power distribution systems are evolving at a high pace largely due to the proliferation of distributed energy resources and the growing utilization of advanced metering infrastructures and distribution management system. This evolution is also leading to new challenges due large penetration of intermittent distributed generation, which can lead to noticeable impacts on distribution feeders. Phasor Measurement Units (PMUs) have the potential to play an essential role in power distribution system monitoring. For providing synchronized measurements of voltage and current phasors at various system locations, PMUs offer numerous possibilities for ascertaining information relating to the state of the power distribution system. However, to be used widely in power distribution systems, it's necessary that PMUs get a low cost and have some exclusive features for these systems. Thus, the main objective of this thesis have consisted of developing a low cost Phasor Measurement Unit with original features proposed for distribution level, such as compatibility with low and medium voltage power networks using transformer modeling and also the identification and parameter estimation of the cause of electrical disturbances. So, they were built two prototypes of the Phasor Measurement Unit, in order to verify the synchronization in the measurement of voltage and current phasors. The prototypes were also coupled to the network with different combinations of impedance and they fed varying loads, where it was possible through the techniques implemented in the equipment identify and estimate electrical parameters of the cause (network or load) of variations in voltage and power supplied by the network distribution.

Keywords: Power distribution networks. Phasor measurement unit. Fuzzy systems. Estimation of electrical parameters. 


\section{LISTA DE FIGURAS}

Figura 2.1 Estrutura básica de uma PMU ............................................................... 10

Figura 2.2 Ilustração de um sistema de medição fasorial ............................................ 10

Figura 2.3 Sincronização para medição de fasores ........................................................... 11

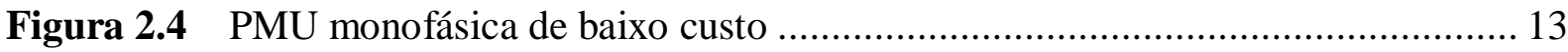

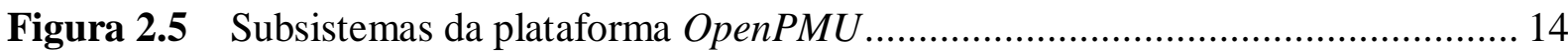

Figura 3.1 Sequenciamento das tarefas realizadas pelo sistema embarcado....................... 19

Figura 3.2 Visão superior do protótipo com a tampa aberta ......................................... 20

Figura 3.3 Visão frontal do protótipo..................................................................... 20

Figura 3.4 Equipamento instalado na rede de distribuição utilizando a mecânica plástica . 21

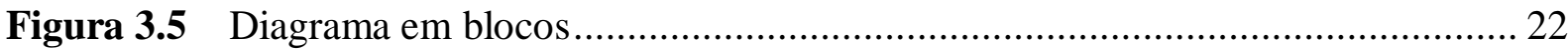

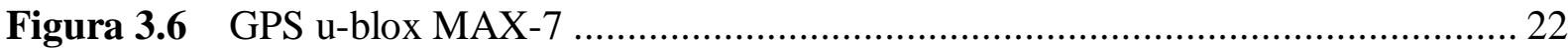

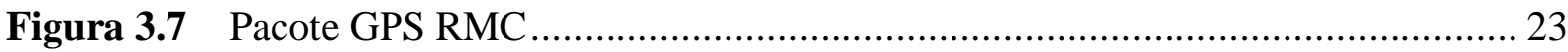

Figura 3.8 Esquemático da placa do módulo GPS....................................................... 23

Figura 3.9 Placa do módulo GPS ............................................................................. 24

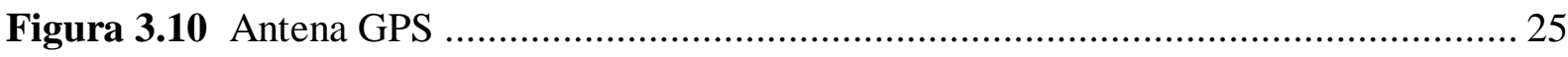

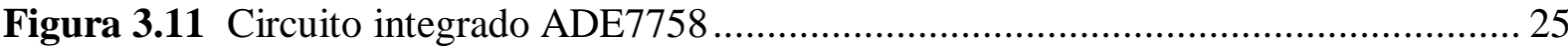

Figura 3.12 Primeira parte do esquemático da placa da interface de medição trifásica ........ 26

Figura 3.13 Transformador de corrente CT07-1000 ................................................... 27

Figura 3.14 Segunda parte do esquemático da placa da interface de medição trifásica ........ 28

Figura 3.15 Última parte do esquemático da placa da interface de medição trifásica.......... 29

Figura 3.16 Face superior da placa de interface de medição trifásica ................................ 30

Figura 3.17 Face inferior da placa de interface de medição trifásica ................................ 31

Figura 3.18 Placa de desenvolvimento Cerebot MX7CK ............................................. 32

Figura 3.19 Padrão da comunicação SPI do circuito ADE7758 ….................................... 32

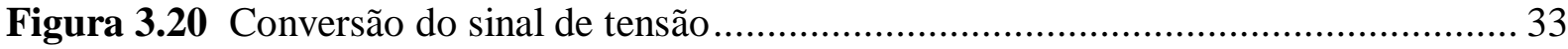

Figura 3.21 Conversão do sinal de corrente ...................................................................... 34

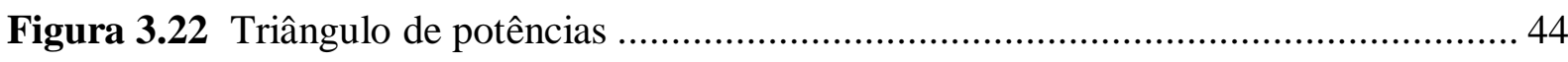

Figura 3.23 Temporização das atividades realizadas pelo microcontrolador ...................... 46

Figura 3.24 Protocolos disponíveis na Microchip TCP/IP Stack ..................................... 49

Figura 3.25 Circuito de um transformador real monofásico .......................................... 50 
Figura 3.26 Circuito equivalente de um transformador real monofásico com impedância referida ao primário

Figura 3.27 Circuito equivalente de um transformador real monofásico com impedância referida ao primário, desprezando-se o ramo de excitação.

Figura 3.28 Primeira simulação de um circuito com transformador real monofásico.

Figura 3.29 Redução do primeiro circuito simulado ao equivalente de um transformador real monofásico com impedância referida ao primário

Figura 3.30 Defasagem angular para o primeiro circuito simulado 55

Figura 3.31 Segunda simulação de um circuito com transformador real monofásico. 56

Figura 3.32 Redução do segundo circuito simulado ao equivalente de um transformador real monofásico com impedância referida ao primário 56

Figura 3.33 Defasagem angular para o segundo circuito simulado 58

Figura 4.1 Modelo RL para linha de distribuição 60

Figura 4.2 Modelo elétrico equivalente rede-carga para cada uma das fases 60

Figura 4.3 Exemplo de simulação do modelo elétrico equivalente rede-carga...... 61

Figura 4.4 Função de pertinência da variável de entrada "Variação da potência ativa"...... 65

Figura 4.5 Função de pertinência da variável de entrada "Variação da potência reativa"... 66

Figura 4.6 Função de pertinência da variável de entrada "Variação da tensão RMS" ........ 66

Figura 4.7 Função de pertinência da variável de saída "Origem do distúrbio".................. 67

Figura 4.8 Fluxograma do algoritmo de estimação dos parâmetros da carga e da rede. ..... 69

Figura 4.9 Modelo elétrico equivalente rede-carga para apenas uma fase........................ 70

Figura 5.1 Conexão Ethernet e transmissão das informações ........................................ 73

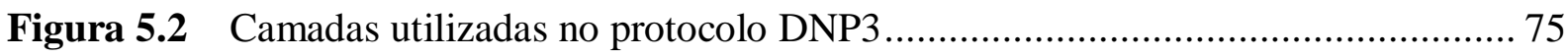

Figura 5.3 Fluxograma de ações durante requisição..................................................... 75

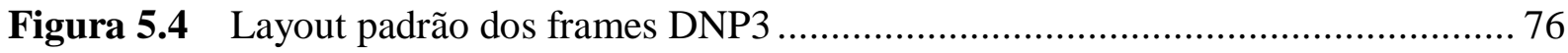

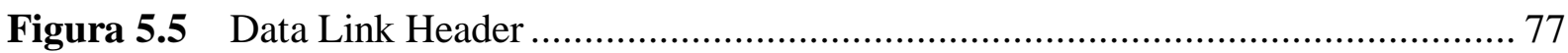

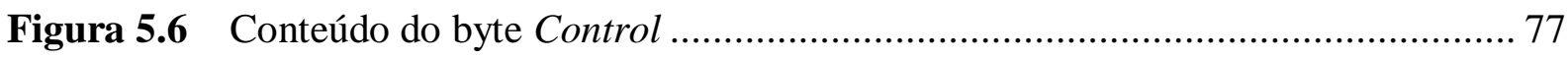

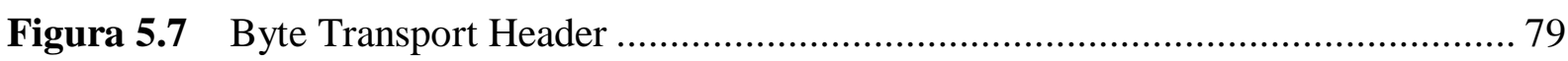

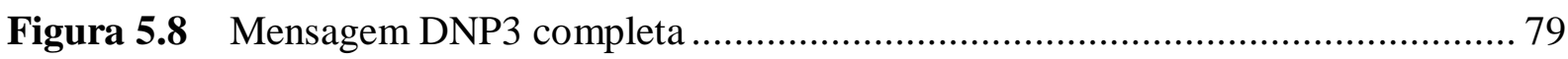

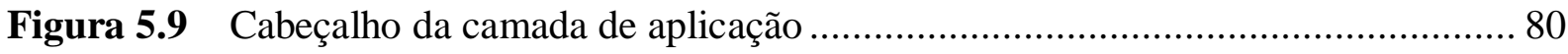

Figura 5.10 Composição do byte Application Control ......................................................... 80

Figura 5.11 Composição do byte Internal ................................................................. 81

Figura 5.12 Composição do byte Indication .............................................................. 82

Figura 5.13 Partes componentes do bloco ADSU ......................................................... 82

Figura 5.14 Composição do byte Qualifier .................................................................. 83 
Figura 5.15 Mensagem de requisição para a leitura da frequência da fase A 88

Figura 5.16 Mensagem de resposta para a leitura da frequência da fase A 88

Figura 5.17 Mensagem de requisição para a leitura das potências ativas nas fases B e C .... 89

Figura 5.18 Mensagem de resposta para a leitura das potências ativas nas fases B e C 89

Figura 5.19 Mensagem de requisição para a leitura das duas causas de distúrbio na fase A 90

Figura 5.20 Mensagem de resposta para a leitura das duas causas de distúrbio na fase A... 90

Figura 5.21 Mensagem de requisição para a leitura da resistência e reatância na fase A...... 91

Figura 5.22 Mensagem de resposta para a leitura da resistência e reatância na fase A........ 91

Figura 5.23 Mensagem de requisição para a leitura dos fasores de tensão na fase B para as duas amostras mais recentes

Figura 5.24 Mensagem de resposta para a leitura dos fasores de tensão na fase B para as duas amostras mais recentes

Figura 5.25 Mensagem de requisição para a leitura da frequência de amostragem ............. 93

Figura 5.26 Mensagem de resposta para a leitura da frequência de amostragem ................ 93

Figura 5.27 Mensagem de requisição para configurar a frequência de amostragem............. 94

Figura 5.28 Mensagem de resposta para configurar a frequência de amostragem............... 94

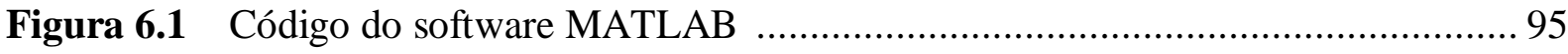

Figura 6.2 Convenção para representação dos fasores ................................................. 96

Figura 6.3 Forma de onda no canal A para tensão................................................... 97

Figura 6.4 Gerador de sinais Doble F6150............................................................... 98

Figura 6.5 Forma de onda no canal C para tensão...................................................... 98

Figura 6.6 Forma de onda no canal B para tensão.................................................... 99

Figura 6.7 Forma de onda no canal A para corrente de 90 A........................................ 100

Figura 6.8 Forma de onda no canal A para corrente de 50 A........................................ 101

Figura 6.9 Forma de onda no canal C para corrente de 12,5 A................................... 102

Figura 6.10 Forma de onda no canal A para corrente de um aquecedor........................... 102

Figura 6.11 Forma de onda no canal A para corrente de lâmpada fluorescente ................. 103

Figura 6.12 Forma de onda no canal B para corrente de uma geladeira ........................... 104

Figura 6.13 Forma de onda no canal B para corrente em um resistor de $90 \Omega$................ 105

Figura 6.14 Forma de onda no canal $\mathrm{C}$ para corrente em um resistor de $520 \Omega$.............. 105

Figura 6.15 Leitura de frequência de amostragem ....................................................... 107

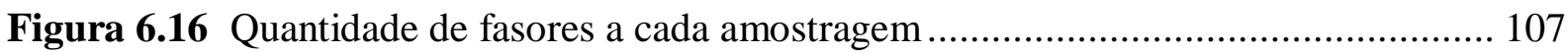

Figura 6.17 Conexão entre a PMU e rede elétrica monofásica para a realização de testes . 108

Figura 6.18 Leitura de quatro fasores de tensão no canal A .......................................... 108 
Figura 6.19 Leitura de quatro fasores de tensão no canal C ........................................ 109

Figura 6.20 Leitura de cinco fasores de corrente no canal B ......................................... 110

Figura 6.21 Escrita e leitura da quantidade de fasores por amostragem.......................... 111

Figura 6.22 Leitura de quatro fasores de corrente no canal B ...................................... 112

Figura 6.23 Escrita e leitura da frequência de amostragem ........................................ 113

Figura 6.24 Escrita e leitura da nova quantidade de fasores por amostragem .................. 113

Figura 6.25 Leitura de novos fasores de corrente no canal B ...................................... 114

Figura 6.26 Leitura das frequências para os três canais de tensão ................................... 115

Figura 6.27 Leitura das tensões RMS para os três canais e das correntes RMS para os canais

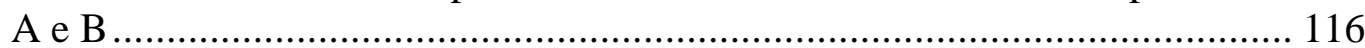

Figura 6.28 Leitura da corrente RMS para o canal C .................................................. 117

Figura 6.29 Leitura das potências ativas nos canais A, B e C e das potências aparentes nos canais A e B

Figura 6.30 Leitura da potência aparente no canal $\mathrm{C}$ e das potências reativas nos canais A, B e C

Figura 6.31 Leitura de fasores de tensão no canal B, limpeza dos buffers e nova leitura ... 119

Figura 6.32 Leitura de identificação da causa de distúrbios no canal C 120

Figura 6.33 Leitura de parâmetros do transformador

Figura 6.34 Leitura de tensão e corrente RMS no canal A refletidas nos terminais primários do transformador

Figura 6.35 Simulação com um circuito com os parâmetros iguais ao teste em bancada ... 123

Figura 6.36 Sincronismo entre duas PMUs na leitura de fasores de tensão no canal A...... 125

Figura 6.37 Sincronismo entre duas PMUs na leitura de fasores de tensão no canal C ...... 126

Figura 6.38 Sincronismo entre duas PMUs na leitura de dois fasores de tensão a cada amostragem no canal B

Figura 6.39 Sincronismo entre duas PMUs na leitura de três fasores de tensão a cada amostragem no canal B

Figura 6.40 Sincronismo entre duas PMUs na leitura de fasores de corrente no canal B ... 130

Figura 6.41 Sincronismo entre duas PMUs na leitura de três fasores de corrente no canal A utilizando frequências de amostragem iguais

Figura 6.42 Sincronismo entre duas PMUs na leitura de três fasores de corrente no canal A utilizando frequências de amostragem diferentes

Figura 6.43 Equipamentos e componentes utilizados nos testes ................................... 134

Figura 6.44 Topologia do circuito adotado para a realização dos testes........................... 135

Figura 6.45 Região fuzzy de saída para a Combinação 1 obtida em laboratório ................ 136

Figura 6.46 Região fuzzy de saída para a Combinação 2 obtida em laboratório ................ 137 
Figura 6.47 Região fuzzy de saída para a Combinação 3 obtida em laboratório 139

Figura 6.48 Região fuzzy de saída para a Combinação 3 obtida com a base de dados ....... 140

Figura 6.49 Região fuzzy de saída para a Combinação 4 obtida em laboratório ................ 141

Figura 6.50 Região fuzzy de saída para a Combinação 4 obtida com a base de dados ....... 142

Figura 6.51 Região fuzzy de saída para a Combinação 5 obtida em laboratório ................ 144

Figura 6.52 Região fuzzy de saída para a Combinação 5 obtida com a base de dados ....... 145

Figura 6.53 Região fuzzy de saída para a Combinação 6 obtida em laboratório ................ 146

Figura 6.54 Região fuzzy de saída para a Combinação 7 obtida em laboratório ................ 148

Figura 6.55 Região fuzzy de saída para a Combinação 8 obtida em laboratório ................ 149

Figura 6.56 Região fuzzy de saída para a Combinação 9 obtida em laboratório ................ 150

Figura 6.57 Região fuzzy de saída para a Combinação 10 obtida em laboratório .............. 152

Figura 6.58 Região fuzzy de saída para a Combinação 10 obtida com a base de dados ..... 153

Figura 6.59 Região fuzzy de saída para a Combinação 11 obtida em laboratório ............... 154

Figura 6.60 Região fuzzy de saída para a Combinação 12 obtida em laboratório ............... 155

Figura 6.61 Região fuzzy de saída para a Combinação 12 obtida com a base de dados ..... 157

Figura 6.62 Região fuzzy de saída para a Combinação 13 obtida em laboratório .............. 158

Figura 6.63 Região fuzzy de saída para a Combinação 13 obtida com a base de dados ..... 159

Figura 6.64 Região fuzzy de saída para a Combinação 14 obtida em laboratório .............. 160

Figura 6.65 Região fuzzy de saída para a Combinação 14 obtida com a base de dados ..... 162

Figura 6.66 Região fuzzy de saída para a Combinação 14 obtida em laboratório .............. 163

Figura 6.67 Região fuzzy de saída para a Combinação 14 obtida com a base de dados ..... 164

Figura 6.68 Primeira leitura de parâmetros finais da carga no canal A .............................. 166

Figura 6.69 Primeira simulação para obtenção dos parâmetros da carga no canal A.......... 166

Figura 6.70 Segunda leitura de parâmetros finais da carga no canal A............................. 167

Figura 6.71 Segunda simulação para obtenção dos parâmetros da carga no canal A.......... 168

Figura 6.72 Terceira leitura de parâmetros finais da carga no canal A ............................ 169

Figura 6.73 Terceira simulação para obtenção dos parâmetros da carga no canal A ........... 169

Figura 6.74 Quarta leitura de parâmetros finais da carga no canal A............................... 170

Figura 6.75 Quarta simulação para obtenção dos parâmetros da carga no canal A ............ 171

Figura 6.76 Simulação para obtenção dos parâmetros iniciais da carga no canal A ........... 172

Figura 6.77 Simulação para obtenção dos parâmetros finais da carga no canal A.............. 172

Figura 6.78 Leitura dos parâmetros da carga e da rede no canal A.................................. 173

Figura 6.79 Simulação para obtenção dos parâmetros iniciais da carga no canal B ........... 174

Figura 6.80 Simulação para obtenção dos parâmetros finais da carga no canal B .............. 175 
xxii

Figura 6.81 Leitura dos parâmetros da carga e da rede no canal B ............................... 175

Figura 6.82 Simulação para obtenção dos parâmetros finais da carga no canal C .............. 177

Figura 6.83 Leitura dos parâmetros da carga e da rede no canal C ................................. 178

Figura A.1 Funções de pertinência ........................................................................ 201

Figura A.2 Representação da variável linguística temperatura .................................... 204

Figura A.3 Mecanismo de inferência fuzzy ........................................................ 205

Figura A.4 Método do Centro de Área ..................................................................... 206

Figura A.5 Método das Médias dos Máximos................................................................ 206

Figura A.6 Método do Primeiro Máximo............................................................................. 207 


\section{LISTA DE TABELAS}

Tabela 3.1 Características elétricas e físicas............................................................ 21

Tabela 3.2 Relações de conversão utilizadas para o cálculo da tensão ............................. 35

Tabela 3.3 Offsets utilizados para compensação no cálculo da tensão ............................. 36

Tabela 3.4 Relações de conversão utilizadas para o cálculo da corrente ........................... 36

Tabela 3.5 Relações de conversão utilizadas para o cálculo da tensão RMS ..................... 39

Tabela 3.6 Offsets utilizados para compensação no cálculo da tensão RMS ..................... 40

Tabela 3.7 Relações de conversão utilizadas para o cálculo da corrente RMS .................. 40

Tabela 3.8 Offsets utilizados para compensação no cálculo da corrente RMS .................. 41

Tabela 3.9 Relações de conversão utilizadas para o cálculo da potência ativa .................. 43

Tabela 3.10 Relações de conversão utilizadas para o cálculo da potência aparente.............. 44

Tabela 3.11 Taxa de informações exigidas para um PMU ............................................... 47

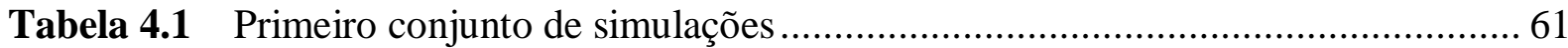

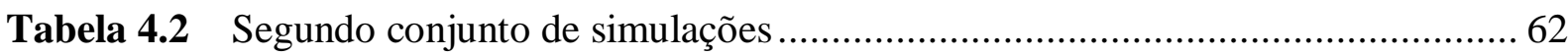

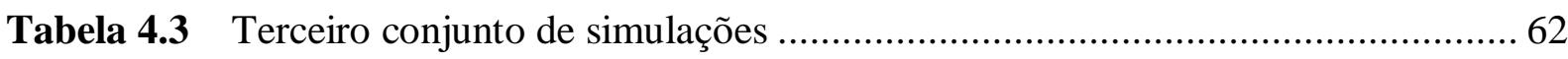

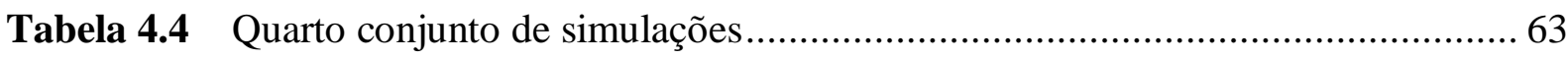

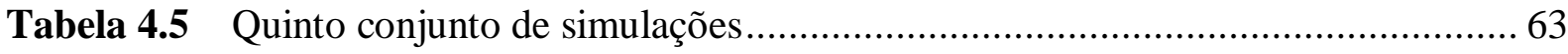

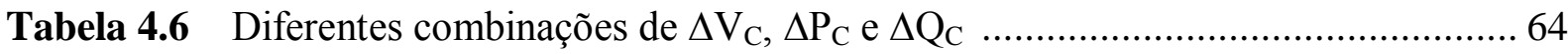

Tabela 4.7 Conjunto de regras para o sistema de inferência fuzzy ................................. 67

Tabela 5.1 Funções mais comuns para requisições......................................................... 78

Tabela 5.2 Funções mais comuns para respostas............................................................ 78

Tabela 5.3 Funções mais comuns para a camada de aplicação ....................................... 81

Tabela 5.4 Grupos e variações mais comuns para a camada de aplicação......................... 83

Tabela 5.5 Primeira parte: endereço de fasores, grandezas e parâmetros de configuração.. 86

Tabela 5.6 Segunda parte: endereço de fasores, grandezas e parâmetros de configuração.. 87

Tabela 6.1 Comparação dos cálculos fasoriais e erros calculados para o primeiro sinal..... 97

Tabela 6.2 Comparação dos cálculos fasoriais e erros calculados para o segundo sinal ..... 99

Tabela 6.3 Comparação dos cálculos fasoriais e erros calculados para o terceiro sinal ...... 99

Tabela 6.4 Comparação dos cálculos fasoriais e erros calculados para o quarto sinal ...... 100

Tabela 6.5 Comparação dos cálculos fasoriais e erros calculados para o quinto sinal ...... 101

Tabela 6.6 Comparação dos cálculos fasoriais e erros calculados para o sexto sinal........ 101

Tabela 6.7 Comparação dos cálculos fasoriais e erros calculados para o sétimo sinal...... 103 
Tabela 6.8 Comparação dos cálculos fasoriais e erros calculados para o oitavo sinal ...... 103

Tabela 6.9 Comparação dos cálculos fasoriais e erros calculados para o nono sinal ........ 104

Tabela 6.10 Comparação dos cálculos fasoriais e erros calculados para o décimo sinal..... 104

Tabela 6.11 Comparação dos cálculos fasoriais e erros calculados para o décimo primeiro

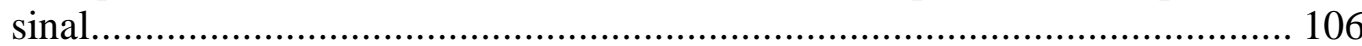

Tabela 6.12 Sincronimo entre duas PMUs para fasores de tensão no canal A.................... 126

Tabela 6.13 Sincronimo entre duas PMUs para fasores de tensão no canal C ................... 127

Tabela 6.14 Sincronimo entre duas PMUs no canal B (2 fasores de tensão por canal)....... 127

Tabela 6.15 Sincronimo entre duas PMUs no canal B (3 fasores de tensão por canal)....... 129

Tabela 6.16 Sincronimo entre duas PMUs para fasores de corrente no canal B ................. 131

Tabela 6.17 Sincronimo entre duas PMUs para fasores de corrente no canal A................ 131

Tabela 6.18 Sincronimo entre duas PMUs para fasores de corrente no canal A (frequências

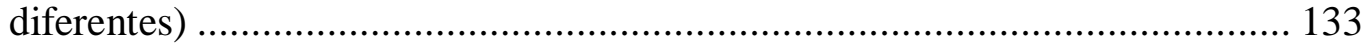

Tabela 6.19 Combinações utilizadas para explorar o conjunto de regras .......................... 134

Tabela 6.20 Valores dos parâmetros da rede para o canal A............................................ 173

Tabela 6.21 Valores dos parâmetros da rede para o canal B ............................................ 176

Tabela 6.22 Valores dos parâmetros da rede para o canal C ............................................. 179

Tabela 7.1 Medições provenientes de um transformador de distribuição........................ 183

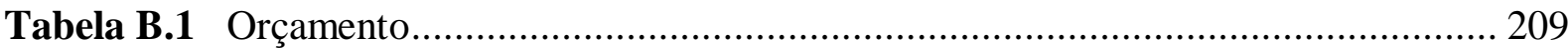




\section{LISTA DE SIGLAS}

ARP Address Resolution Protocol

ASCII American Standard Code for Information Interchange

ATP Alternative Transients Program

CPU Central Processing Unit

DFT Discrete Fourier Transformer

DHCP Dynamic Host Configuration Protocol

GPS Global Positioning System

HTTP Hypertext Transfer Protocol

IED Intelligent Electronic Device

IP Internet Protocol

MAC Media Access Control

NMEA National Marine Electronics Association

PDC Phasor Data Concentrator

PHY Physical Layer

PMU Phase Measurement Unit

PPS Pulse per second

PTP Precision Time Protocol

RMC Recommended Minimum Data for GPS

ROCOF Rate-of-Change of Frequency

RTU Remote Terminal Unit

SCADA Supervisory Control And Data Acquisition

SEE Sistemas de Energia Elétrica

SPI Serial Peripheral Interface

SPMS Synchronized Phasor Measurement Systems

TCP Transmission Control Protocol

TVE Total Vector Error

UDP User Datagram Protocol

UTC Universal Time Coordinated

XML eXtensible Markup Language 


\section{SUMÁRIO}

CAPÍTULO 1. INTRODUÇÃ̃ À TESE DE DOUTORADO ........................................... 1

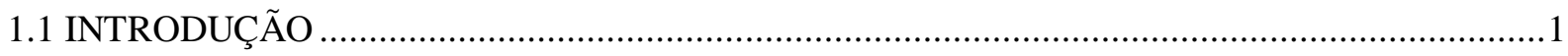

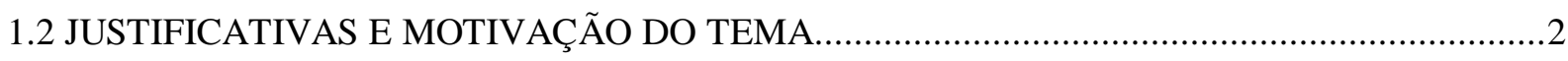

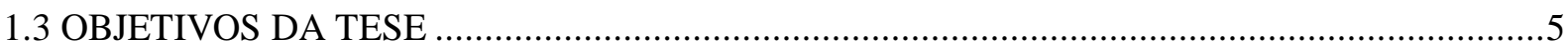

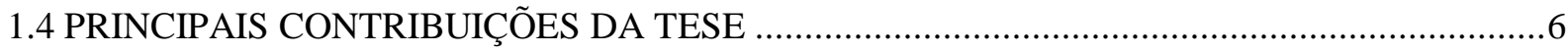

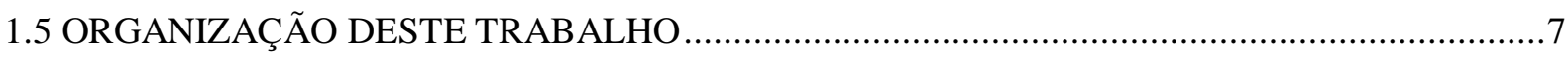

CAPÍTULO 2. A UNIDADE DE MEDIÇÃO FASORIAL SINCRONIZADA ................ 9

2.1 O FUNCIONAMENTO DE UMA UNIDADE DE MEDIÇÃO FASORIAL SINCRONIZADA ....9

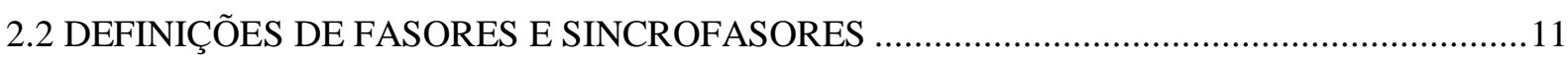

2.3 PANORAMA ATUAL DA UTILIZAÇÃO DE PMUS EM SISTEMAS DE DISTRIBUIÇÃO.....12

2.4 CONSIDERAÇÕES QUANTO À IMPORTÂNCIA DA UTILIZAÇÃO DE PMUS VOLTADAS PARA OS SISTEMAS DE DISTRIBUIÇÃO

CAPÍTULO 3. A UNIDADE DE MEDIÇÃO FASORIAL OTIMIZADA PARA SISTEMAS DE DISTRIBUIÇÃ̃O ..................................................................................... 17

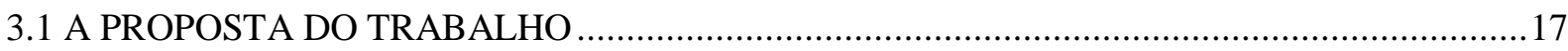

3.2 CARACTERÍSTICAS FUNCIONAIS DA UNIDADE DE MEDIÇÃO FASORIAL OTIMIZADA

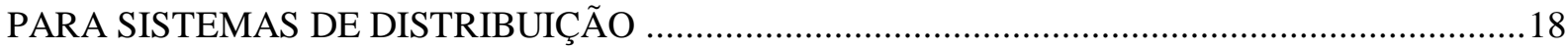

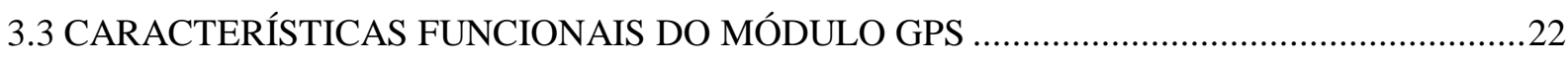

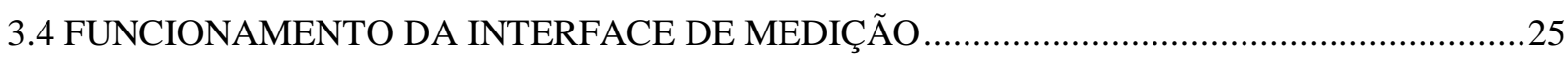

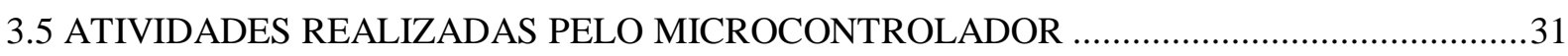

3.6 MODELAGEM ELÉTRICA DO TRANSFORMADOR DE DISTRIBUIÇÃO............................50

CAPÍTULO 4. IDENTIFICAÇÃO E ESTIMAÇÃO DOS PARÂMETROS ELÉTRICOS DAS CAUSAS DOS DISTÚRBIOS .......................................................... 59

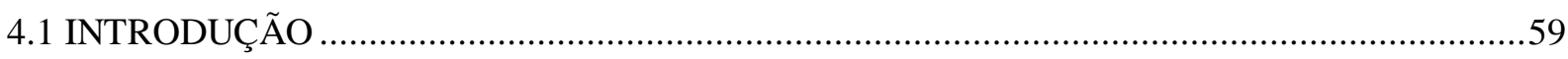

4.2 MODELAGEM DE UM SISTEMA ELÉTRICO EQUIVALENTE REDE-CARGA ...................59

4.3 CONJUNTO DE REGRAS PARA A DETERMINAÇÃO DE DISTÚRBIOS ............................60

4.4 SISTEMA FUZZY PARA IDENTIFICAÇÃO DAS CAUSAS DOS DISTÚRBIOS ...................64 
4.5 ESTIMAÇÃO NA UNIDADE DE MEDIÇÃO FASORIAL DOS PARÂMETROS ELÉTRICOS DAS CAUSAS DOS DISTÚRBIOS .68

CAPÍtUlO 5. TRANSMISSÃO DE DADOS POR MEIO DO PROTOCOLO DNP3 OTIMIZADO 73

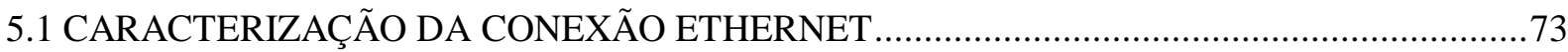

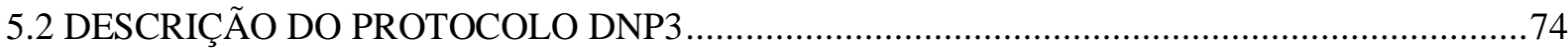

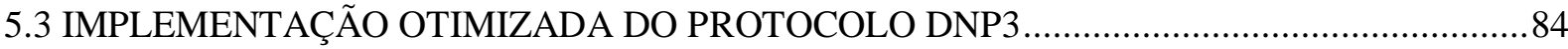

5.4 REQUISIÇÃO DE FASORES E OUTRAS GRANDEZAS ELÉTRICAS …..............................86

CAPÍTULO 6. RESULTADOS E DISCUSSÕES .........................................................95

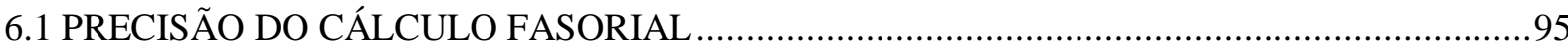

6.2 AQUISIÇÕES DE FASORES E OUTRAS GRANDEZAS ELÉTRICAS POR MEIO DO

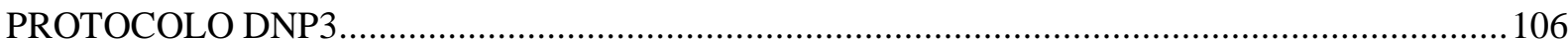

6.3 SINCRONISMO NO CÁLCULO FASORIAL ENTRE DIFERENTES PMUs ...........................124

6.4 DESEMPENHO DO SISTEMA DE IDENTIFICAÇÃO DA CAUSA DOS DISTÚRBIOS ........134

6.5 DESEMPENHO DO ALGORITMO DE ESTIMAÇÃO DE PARÂMETROS ELÉTRICOS ....... 165

CAPÍTULO 7. ESTIMAÇÃO REMOTA DE PARÂMETROS E MODELAGEM DE CARGAS

7.1 ESTIMAÇÃO REMOTA EM UM SERVIDOR DOS PARÂMETROS ELÉTRICOS DA CARGA E DA REDE

7.2 MODELAGEM MATEMÁTICA DA CARGA EM UM SERVIDOR REMOTO 183

CAPÍTULO 8. CONCLUSÕES E TRABALHOS FUTUROS 189

8.1 CONCLUSÕES 189

8.2 TRABALHOS FUTUROS 191

REFERÊNCIAS BIBLIOGRÁFICAS 193

ANEXO A. CONCEITOS RELACIONADOS À LÓGICA FUZZY

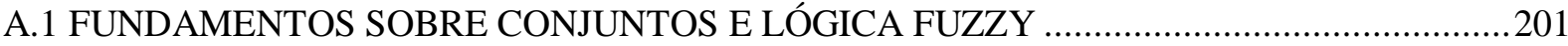

A.2 DEFINIÇÃO DE OPERAÇÕES E OPERADORES DA LÓGICA FUZZY .............................202

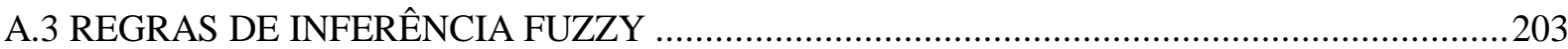




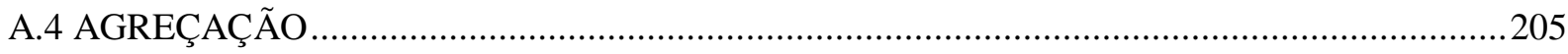

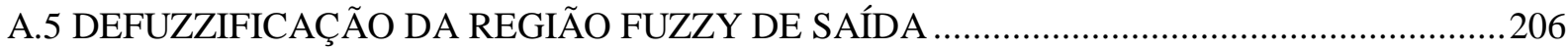

ANEXO B. CUSTO MATERIAL DO PROTÓTIPO ...................................................... 209 



\section{Capítulo 1}

\section{INTRODUÇÃO À TESE DE DOUTORADO}

\subsection{INTRODUÇÃO}

Os Sistemas de Energia Elétrica (SEE) estão sofrendo uma transformação de grandes proporções que consiste na modernização das tecnologias de geração, transmissão, distribuição e no uso final da energia elétrica. Essa nova concepção de SEE pode ser definida pelo nome genérico de Smart Grids (Redes Inteligentes), como vem sendo traduzido para a língua portuguesa (FALCÃO, 2010).

A expressão Smart Grids deve ser entendida como um conceito e não como uma tecnologia ou equipamento específico. Esse conceito, por sua vez, se baseia na utilização intensiva de tecnologias de automação, computação e comunicações para monitoramento e controle da rede elétrica, permitindo a implantação de estratégias de controle da rede de forma mais eficiente (FALCÃO, 2010; EL-HAWARY, 2014).

Uma das principais tecnologias disponíveis para a implantação do conceito Smart grids são as Unidades de Medição Fasorial Sincronizada (PMU - Phase Measurement Unit), as quais representam um avanço considerável na disponibilidade de informações para a determinação do estado operativo do sistema elétrico em grandes áreas geoelétricas (FALCÃO, 2009; GIANNAKIS et al., 2013).

Atualmente, as unidades de medição fasorial sincronizada são utilizadas principalmente junto aos sistemas de geração e transmissão de energia elétrica (ANDRADE et al., 2009). Os custos dessas unidades limitam o número de unidades instaladas, tornando necessária a escolha de localizações que maximizem o conteúdo da informação adquirida (MARINI, 2005).

Para a estimação de estados em sistemas de distribuição de energia elétrica raramente são utilizados $P M U s$ devido ao alto custo. Como exemplo, o custo da $P M U$ modelo $G E$ Multilin N60 é de US\$ 8.819,00 nos Estados Unidos (GE, 2015), sem levar em consideração custos de instalação. Para superar esta dificuldade são utilizados modelos matemáticos conjugados com algumas medições, tais como magnitude de corrente e tensão, junto com potências medidas nos transformadores para inferir o estado do sistema (FRAZÃO, 2012). 
Porém, a restrição quanto ao alto custo das $P M U s$ deve ser superada devido à necessidade de outras importantes análises providas pelo uso destes equipamentos em redes de distribuição além da estimação de estados, como o cálculo do fluxo de potência, as quais são detalhadas na Seção 1.2.

\subsection{JUSTIFICATIVAS E MOTIVAÇÃO DO TEMA}

O desenvolvimento de um protótipo funcional de unidade de medição fasorial, porém com diferenciais que promovam um baixo custo e possibilitam sua ampla utilização junto aos sistemas de distribuição de energia elétrica, possibilita o atendimento a importantes requisitos para a constituição de funcionalidades adicionais aos Smart Grids já existentes, como os citados a seguir.

\subsubsection{Estimação de estados e cálculo do fluxo de potência}

A estimação de estados visa determinar a condição operativa do sistema: normal (sem violação nas restrições operacionais dos níveis de tensão e frequência), emergencial (violação dessas restrições) e restaurativo (blackout parcial ou total). Normalmente, o conjunto a ser determinado são as tensões e correntes complexas, visto que com isso é possível determinar também os fluxos de potência ativo e reativo (FRAZÃO, 2012).

Se utilizadas em quantidade suficiente, as PMUs garantem a observação do sistema de distribuição na média tensão e a maximização da redundância. Com a $P M U$ a aquisição de medições realizadas no sistema elétrico pode ser obtida em intervalos de tempo inferiores a um segundo, sendo possível uma análise dinâmica do mesmo. Sem a $P M U$ é muito longo o tempo (podendo ser vários minutos) entre a primeira medição coletada e o momento que a estimativa do estado é fornecida pelo estimador o que não representa efetivamente o estado de operação corrente (FRAZÃO, 2012).

\subsubsection{Monitoramento dinâmico}

Embora condições transitórias não possam ser precisamente descritas por fasores computados pela $P M U$, a capacidade dos sincrofasores pode ser estendida para aplicações de monitoramento dinâmico, visando fornecer ferramentas para garantir a operação e estabilidade do sistema, principalmente com a crescente introdução de geração baseada em 
fontes alternativas renováveis (energia solar e eólica), o que promove um aumento no dinamismo dos sistemas de distribuição (WACHE et al., 2011).

Como exemplo, um processo de detecção de ilhamento não intencional pode ser analisado pela instalação de uma $P M U$ na subestação e outro na planta do sistema de geração distribuída. Estas PMUs comunicam via intranet com o servidor da concessionária e fornecem medidas para um simulador capaz de detectar condições de ilhamento por meio da diferença do ângulo da tensão (SANCHEZ-AYALA et al., 2013).

\subsubsection{Estimação harmônica}

A estimação de níveis harmônicos de tensão e corrente ocupa um importante papel em aplicações que necessitam de qualidade de energia elétrica, principalmente quando há o envolvimento de cargas sensíveis, como motores elétricos. Embora sistemas com geração distribuída e inversores devam atender aos limites de emissão de harmônicos estabelecidos por diferentes normas, os efeitos cumulativos e a interação de harmônicos injetados por um grande número de inversores podem causar impactos na rede de distribuição que necessitam ser identificados (SANCHEZ-AYALA et al., 2013).

Uma forma de se realizar a estimação dos componentes harmônicos presentes nos sinais de tensão e corrente, apresentada em AREFI et al. (2011), é usando um estimador de estado harmônico, o qual utiliza um algoritmo Particle Swarm Optimization (PSO) baseado em meta heurística, medições provenientes de uma $P M U$, parâmetros da geração distribuída e pseudo medições para estimar os fasores harmônicos por meio da minimização do erro entre as medidas da $P M U$ e os valores estimados.

Além do emprego de metas heurísticas para a realização de estimação harmônica, nos últimos anos, a técnica de processamento de sinais sofreu um grande avanço com o surgimento do Deep learning (LECUN et al., 2015). Com este novo método, o índice de acerto, não dependente de meta heurística e não caindo em máximos e mínimos locais, revolucionou os sistema de análise, principalmente de sinais digitalizados.

\subsubsection{Modelagem de cargas}

Ao longo do tempo vários estudos e pesquisas (AMARAL, 2004; GOMES, 2007) foram realizados com o propósito de aprimorar os modelos dos componentes do sistema (linhas de transmissão/distribuição, transformadores, geradores etc.), porém desde o início a carga 
apresentou-se como o componente de difícil modelagem. Apesar de se conhecer como cada elemento da carga se comporta individualmente, não se tem uma ideia precisa da sua composição final, devido à grande diversidade de equipamentos que a compõem de forma aleatória.

Observa-se que tarefas de análise pré e pós-operacionais tais como estudos de planejamento, análises de contingência, reconfigurações operativas de redes, análise de eventos e tantos outros que em determinado momento envolvam a avaliação do estado e tendências da rede, são claramente afetados pela questão da modelagem de suas cargas.

Assim, uma modelagem estática de carga mais realista impacta positivamente os resultados e as análises inerentes aos estudos de carregamento e estabilidade de tensão associados aos estudos de planejamento da expansão, reconfiguração de redes, contingências, diagnósticos e planejamentos operativos e tantos outros que envolvam programas de análise de redes elétricas, tornando-os igualmente mais realistas e confiáveis.

Duas abordagens têm sido usadas para a modelagem de carga. A primeira delas é baseada no conhecimento prévio dos componentes individuais da carga, sendo o modelo obtido por meio da combinação destes componentes.

A segunda abordagem não requer o conhecimento das características físicas da carga. Essa abordagem se baseia em medidas obtidas em baixa tensão da resposta da carga quando a mesma é submetida a variações (NEVES, 2008). As simples respostas do sistema de identificação das causas de ocorrência de distúrbios (variações de grandezas elétricas na rede de distribuição) e o fornecimento de medidas elétricas, funcionalidades presentes no equipamento proposto neste trabalho, permitem a um servidor remoto realizar a modelagem estática das cargas.

Ainda através da técnica de deep learning citada anteriormente e utilizando linguagens funcionais como Lisp, Scheeme, Haskell e Clean, pode-se utilizar funções como argumentos, permitindo uma modelagem dinâmica da carga, onde cada argumento é afetado pelo outro, obtendo-se, em uma única função, um simulador em tempo real.

\subsubsection{Identificação de perdas comerciais}

As perdas comerciais são relacionadas ao processo de comercialização da energia e envolvem erros de medição e leitura de consumo, erros no processo de faturamento e, principalmente, às fraudes e furtos de energia. 
Os tipos de fraudes mais comuns incluem uma vasta gama de adulterações na medição de consumo, como travamento do disco do medidor via agente externo, rompimento do lacre do medidor com adulteração de seu mecanismo ou da parte eletroeletrônica e diversos outros métodos, dificultando a sua detecção pela empresa distribuidora.

Os furtos de energia são normalmente ligações diretas à rede secundária ou ao ramal de serviço sem que haja qualquer medição (ABI-ACKEL e CAMPOS, 2013).

Desta forma, é possível realizar a identificação de perdas comerciais confrontando as medições de potência realizadas por uma $P M U$ em um determinado período com as leituras realizadas pelos leituristas das concessionárias em domicílios ligados a esta $P M U$.

Uma forma ainda melhor seria confrontar as medições realizadas pela $P M U$ com as realizadas por smart meters. Com um servidor rápido e com centenas de acessos persistentes (vários pontos de medição em tempo real), poder-se-ia fazer a detecção em tempo real, evitando a perda, corrigindo o erro e punindo o infrator.

\subsubsection{Identificação de perdas técnicas}

As perdas técnicas são inerentes ao transporte de energia na rede, relacionadas à transformação de energia elétrica em energia térmica nos condutores (perdas joule), perdas nos núcleos dos transformadores, perdas dielétricas, etc. (ANEEL, 2015).

Assim, é possível estimar parâmetros elétricos de trechos da rede de distribuição em média tensão, nos quais aparentam apresentar faltas, por meio das medidas fornecidas por diferentes $P M U s$ instaladas em pontos específicos. Outra alternativa, quando não se dispõe de várias $P M U$ s instaladas, é a utilização do sistema de identificação das causas de ocorrência de distúrbios elétricos em conjunto com as técnicas para a estimação dos parâmetros elétricos destas causas, sendo que estes estudos serão apresentados posteriormente no Capítulo 4.

\subsection{OBJETIVOS DA TESE}

Este trabalho tem por objetivo o desenvolvimento de um sistema eletrônico de baixo custo para medição fasorial em sistemas de distribuição de energia elétrica. O mesmo está alinhado com as necessidades reportadas neste capítulo de forma que sua motivação vem da oportunidade de dominar as tecnologias que contribuam efetivamente para desenvolver uma 
unidade de medição fasorial otimizada tanto no custo quanto nas características funcionais, visando sua ampla utilização.

Desta forma, os objetivos deste trabalho podem ser pontuados da seguinte maneira:

- Desenvolvimento de uma plataforma computacional de baixo custo que permita realizar os procedimentos funcionais típicos de uma $P M U$, tais como medição de tensão e corrente trifásica, cálculo fasorial sincronizado via satélite e posterior disponibilização segura de informações por meio da internet;

- Otimização da operação das $P M U s$ aplicadas em sistemas de transmissão, isto é, algumas funcionalidades não estão presentes ou suas frequências de operação são reduzidas (como a quantidade de fasores sincronizados), porém sem descaracterizar o propósito funcional do equipamento;

- Acréscimo no equipamento proposto de funcionalidades desejadas para sua utilização em sistemas de distribuição de energia, tais como sua compatibilidade com o protocolo DNP3 (GRIGOLETTO, 2012), a medição de grandezas elétrica tanto em sistemas de distribuição de baixa tensão quanto de média tensão e a identificação das causas de ocorrência de distúrbios elétricos, seguida da estimação de seus parâmetros elétricos.

Para que os objetivos pontuados nesta seção fossem atingidos, foi necessária a elaboração de desenvolvimentos dedicados aos propósitos citados. Desta forma, têm-se na Seção 1.4 as contribuições que foram alcançadas por meio deste trabalho e, de forma que se apresente a estrutura adequada para delineamento do tema aqui abordado, reporta-se na Seção 1.5 como a organização em capítulos fora feita.

\subsection{PRINCIPAIS CONTRIBUIÇÕES DA TESE}

Quando da revisão da literatura acadêmica acerca do tema abordado nesta tese de doutorado, verificam-se pontos comuns às abordagens existentes. O principal destes pontos é a arquitetura do equipamento proposto, baseado no sincronismo das medições dos fasores de tensão e corrente por meio do sinal proveniente de um módulo GPS, cujo custo juntamente com o uso de uma antena externa é muito competitivo e inferior à U\$24,00 (detalhes no Anexo 2), e a posterior disponibilidade destas medições para comunicação Ethernet.

Porém, visando alcançar os objetivos citados na Seção 1.3, foram desenvolvidas nesta tese contribuições inovadoras que podem ser pontuadas da seguinte forma: 
- Implementação de um hardware de baixo custo para medição trifásica com solução mecânica apropriada para instalação junto aos terminais de baixa tensão de transformadores instalados em redes de distribuição. O cálculo fasorial de tensão e corrente para cada uma das fases e a aquisição de outras grandezas é realizado de forma sequencial, havendo a identificação temporal do momento de aquisição para cada dado (mais detalhes no Capítulo 6).

- Desenvolvimento de uma modelagem de transformadores no firmware (programação) do equipamento, visando refletir na média tensão grandezas medidas na baixa tensão;

- Elaboração de um sistema inteligente baseado em inferência fuzzy para a identificação das causas de variações nas medições realizadas;

- Desenvolvimento de técnicas para estimação dos parâmetros elétricos das causas (rede de distribuição ou carga) da ocorrência dos distúrbios, levando-se em consideração a identificação destas causas e as medições realizadas pela $P M U$;

- Desenvolvimento de uma versão otimizada do protocolo DNP3 (protocolo industrial para comunicação entre dispositivos), compatível com os sistemas supervisórios disponíveis no mercado.

As contribuições aqui citadas agregam valor a este trabalho quando o mesmo é comparado a outras soluções encontradas na literatura, posteriormente detalhadas na Seção 2.3, principalmente em relação ao projeto de baixo-custo proposto e as técnicas utilizadas para a identificação e a estimação dos parâmetros elétricos das causas dos distúrbios elétricos.

\subsection{ORGANIZAÇÃO DA TESE DE DOUTORADO}

Este trabalho está organizado em sete capítulos de maneira que o tema abordado seja coerentemente explorado. Assim, após esse primeiro capítulo introdutório, foi desenvolvido o Capítulo 2, no qual é destacado o funcionamento típico de uma unidade de medição fasorial sincronizada. Ainda neste capítulo serão destacadas, às recentes iniciativas internacionais de utilização de unidades de medição fasorial sincronizadas em sistemas de distribuição de energia elétrica, com foco nas vantagens obtidas e dificuldades encontradas nessa operação.

No Capítulo 3 são apresentadas as características funcionais e construtivas do equipamento proposto neste trabalho, demonstrando as técnicas utilizadas para alcançar os objetivos citados na Seção 1.3. Neste capítulo, cada bloco funcional é detalhado quanto ao seu próprio funcionamento e quanto a sua interface com os demais blocos que compõe o equipamento como um todo. 
O Capítulo 4 explora de forma detalhada o desenvolvimento do sistema baseado em inferência fuzzy para a identificação das causas de variações nas medições realizadas. Também são apresentadas neste capítulo as técnicas para estimação dos parâmetros elétricos das causas (rede de distribuição ou carga) de variações nas medições realizadas.

No Capítulo 5 é destacada a implementação otimizada do protocolo $D N P 3$, visando atender as características funcionais do equipamento proposto e impactar da menor forma possível o processamento das demais tarefas a serem realizadas pelo mesmo.

No Capítulo 6 são apresentados resultados relacionados ao funcionamento do equipamento, com foco quanto à precisão dos cálculos fasoriais dos sinais de tensão e corrente, a identificação e estimação dos parâmetros elétricos da causa de distúrbios e a disponibilização das informações para um sistema supervisório utilizando o protocolo DNP3.

Por fim, no Capítulo 7 são apresentadas as discussões decorrentes do trabalho desenvolvido, bem como se pontuará as conclusões gerais do mesmo. 


\section{CAPítulo 2}

\section{Principais ASPECTOS REFERENTES Às UNIDAdeS DE MEDIÇÃo FASORIAL SINCRONIZADA}

\subsection{PRINCÍPIOS DE FUNCIONAMENTO DE UMA UNIDADE DE MEDIÇÃO FASORIAL SINCRONIZADA}

A $P M U$ é um equipamento de medição fasorial de tensão e de corrente, que utiliza sistemas de processamento digital e sinais de sincronização via satélite (GPS - Global Positioning System). A referência temporal de amostragem é dada por meio do receptor de sinais GPS que recebe os sinais do tipo pulsos por segundo (PPS), o qual, em conjunto com um oscilador auxiliar, fornece os instantes de amostragem (DECKER et al., 2006).

A Figura 2.1 ilustra a estrutura simplificada de uma $P M U$, que consiste basicamente de um sistema de aquisição de dados composto por filtros anti-aliasing, circuito oscilador, um módulo de conversão analógica/digital e de um microprocessador que realiza o processamento matemático dos dados. Cada $P M U$ deve estar acoplada a um equipamento receptor de sinal de GPS.

As PMUs disponíveis atualmente têm a capacidade de medir fasores de tensão, corrente e potência, além da frequência e variação da frequência no tempo. Os dados medidos são exteriorizados em grandezas de fase ou de sequência positiva, em forma polar ou retangular (EHRENSPERGER, 2004).

$\mathrm{Na}$ maioria dos sistemas, as medições fasoriais são enviadas a um Concentrador de Dados (PDC - Phasor Data Concentrator), a uma taxa de 30 ou 60 fasores por segundo, embora existam instalações em desenvolvimento operando a taxa de 120 fasores por segundo. O $P D C$, por sua vez, tem a finalidade de armazenar os fasores enviados pelas $P M U s$, verificar eventuais erros de transmissão, além de organizar e disponibilizar os dados para outras aplicações (SANTOS e AGOSTINI, 2011). 


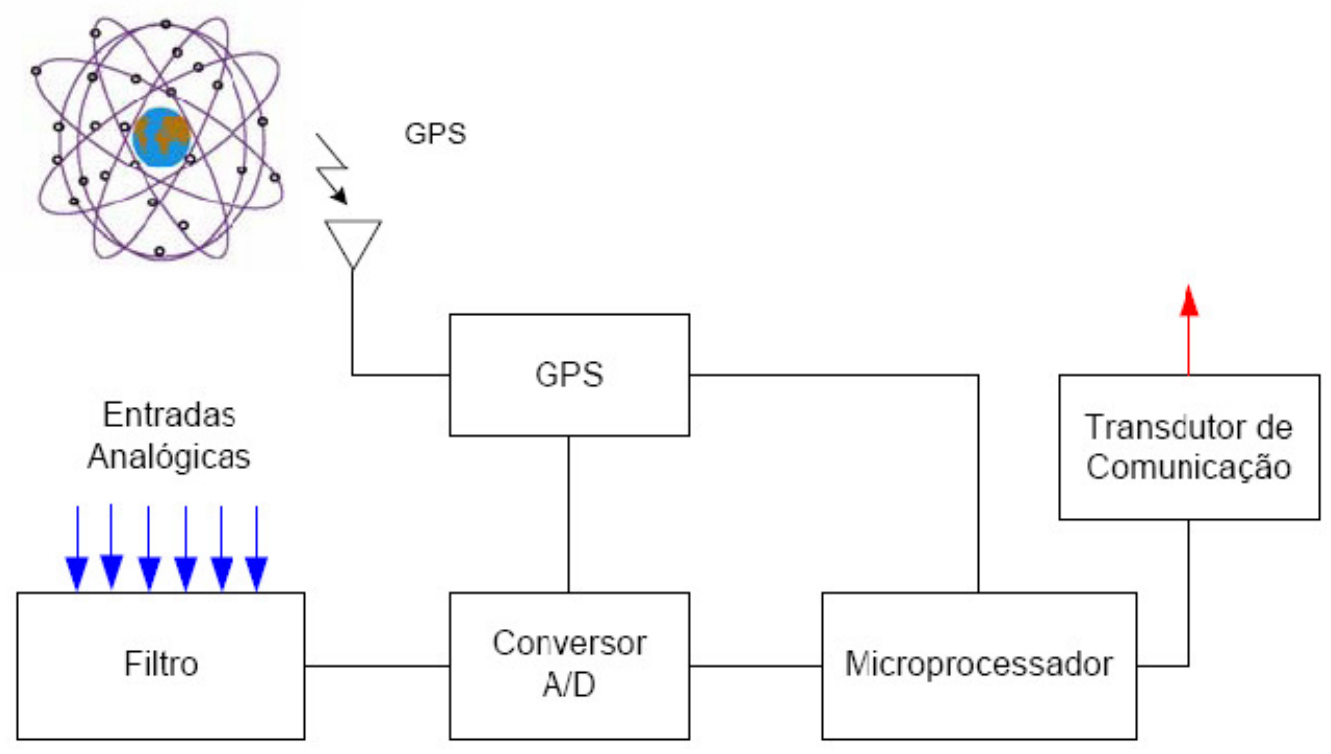

Figura 2.1 - Estrutura básica de uma PMU (EHRENSPERGER, 2004).

A utilização conjunta das $P M U s$ e do $P D C$ compõe o Sistema de Medição Fasorial Sincronizada (SPMS - Synchronized Phasor Measurement Systems), ilustrado na Figura 2.2.

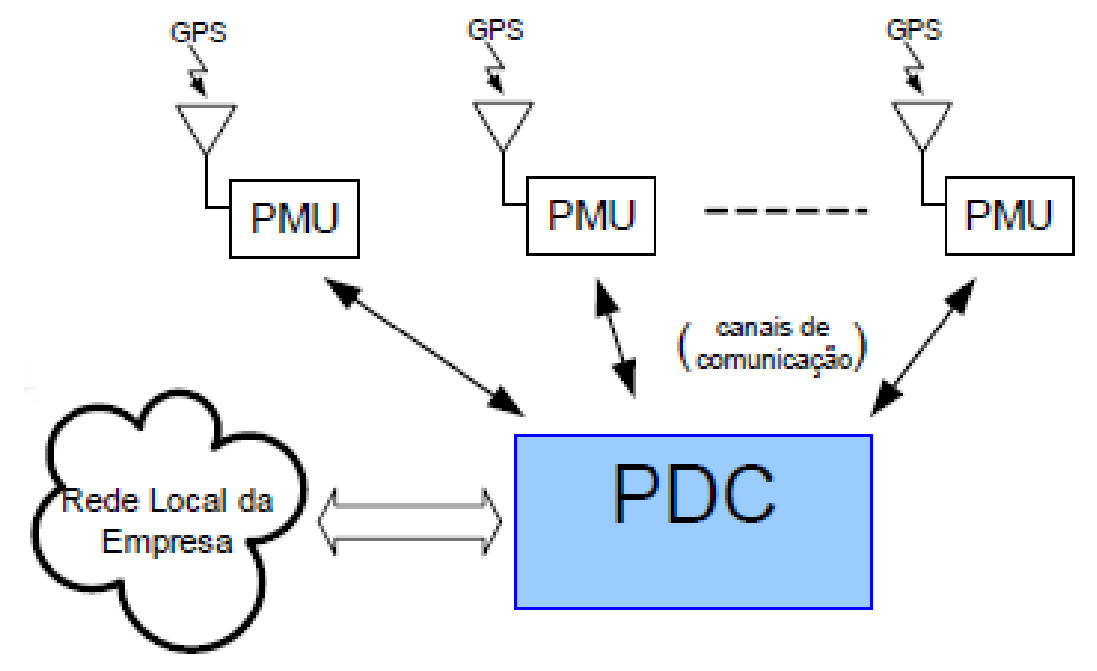

Figura 2.2 - llustração de um Sistema de Medição Fasorial (SANTOS e AGOSTINI, 2011).

Atualmente, as principais pesquisas sobre SPMS têm sido explorar as potenciais aplicações da medição sincronizada de fasores, visando à segurança operacional e à otimização no uso de recursos energéticos e estruturais dos sistemas elétricos (XIE et al., 2006). 


\subsection{DEFINIÇÕES DE FASORES E SINCROFASORES}

O fasor é uma ferramenta matemática utilizada para analisar os circuitos elétricos de corrente alternada em regime permanente e para representar a forma de onda de um sinal senoidal de tensão ou de corrente na frequência fundamental de um sistema de potência. São compostos por uma amplitude, representada em valor eficaz, e um ângulo. Por meio da identidade de Euler, expressa na Equação (2.1), obtém-se a relação entre as formas trigonométricas e complexas, ou polares e retangulares, dos fasores (ANDRADE, 2008):

$$
e^{j \phi}=\cos (\phi)+j \operatorname{sen}(\phi)
$$

O Sincrofasor é um fasor medido com relação a uma referência de tempo absoluta, possibilitando determinar a relação de fase absoluta entre outras quantidades de fase em diversas localidades de um sistema elétrico, como mostrado na Figura 2.3, onde em um mesmo instante são calculadas as medições fasoriais em quatro em posições geográficas distantes. Devido a esta simultaneidade das medições fasoriais, é possível que sejam tiradas "fotografias" do estado do sistema elétrico (EHRENSPERGER, 2004).

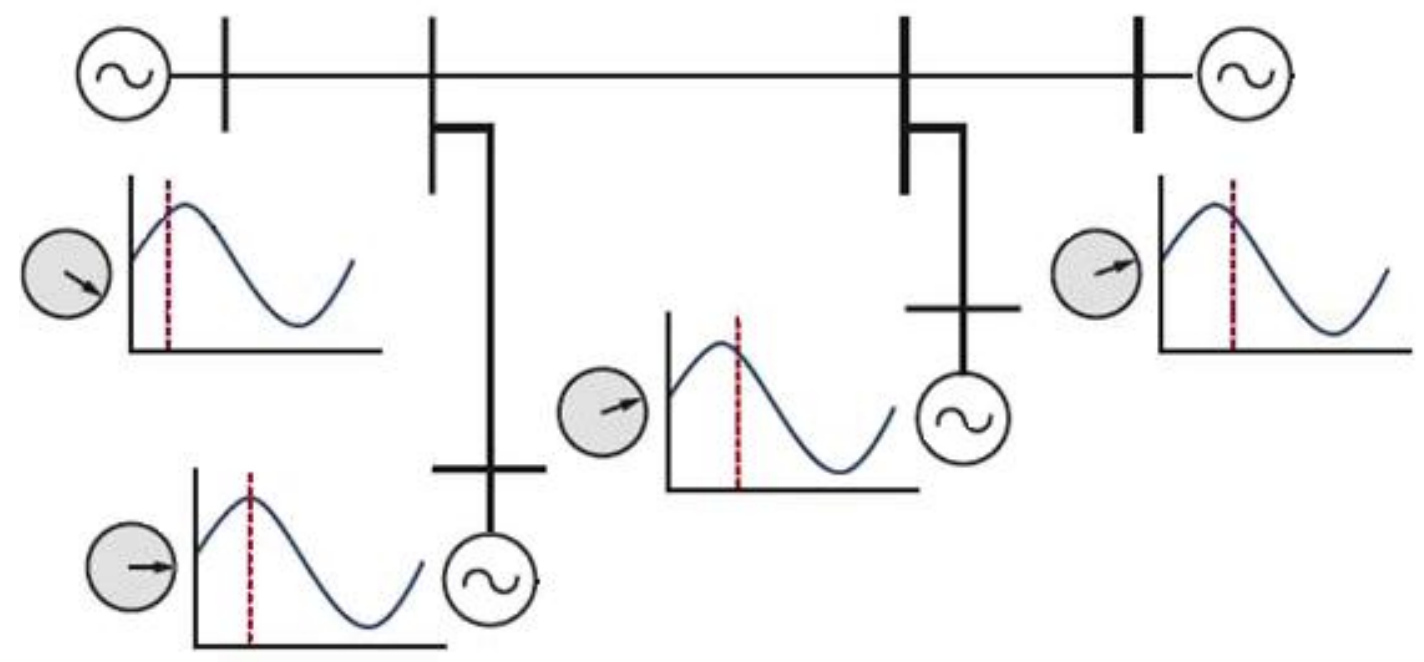

Figura 2.3 - Sincronização para medição de fasores (EHRENSPERGER, 2004).

Para uma medição de sincrofasores confiável, a precisão temporal deve necessariamente atender alguns pré-requisitos. Para sistemas de frequência fundamental, estima-se que erros temporais de ordem de $1 \mu$ s produzam erros angulares de aproximadamente $0,02^{\circ}$, enquanto erros temporais de ordem de $1 \mathrm{~ms}$ poderiam gerar erros superiores a $20^{\circ}$ (IEEE, 2005). No 
caso de sincrofasores calculados para frequência harmônicas, o impacto de erros temporais é ainda maior no processo de estimação dos ângulos de fase dos fasores.

A medição dos sincrofasores permite, segundo Wilson (2007), que o estado do Sistema Elétrico de Potência (SEP) seja estimado de forma mais exata, rápida e confiável. Uma consequência direta desta facilidade é a possibilidade de se aferir a dinâmica do sistema elétrico. Esse requisito, de acordo com Andrade (2008), torna-se de grande importância em sistemas de distribuição de energia elétrica com grande presença de geração distribuída na forma de mini e micro geração (ANEEL, 2012).

\subsection{PANORAMA ATUAL DA UTILIZAÇÃO DE PMUS EM SISTEMAS DE DISTRIBUIÇÃO}

No mundo existem iniciativas recentes quanto à utilização de PMUs nas redes de distribuição de energia elétrica para realização de atividades tais como detecção de sistemas ilhados, prevenção de colapsos de tensão e um melhor entendimento da resposta dinâmica da geração distribuída (HATAWAY;FLERCHINGER;MOXLEY, 2012).

Para a estimação de estados com sistemas compostos por geradores ilhados, Li e Yunus (2007) cita a pouca quantidade e o alto custo dos equipamentos destinados a esse propósito. Em Ding e Booth (2011) e em Borghetti et al. (2011) é compartilhada a ideia na qual as informações disponibilizadas por $P M U s$ instaladas na rede de distribuição facilitam as operações de manobra de sistemas ilhados por permitirem o desenvolvimento de um sistema de gerenciamento e controle mais aperfeiçoado.

O projeto com duração de três anos nomeado "Micro Syncrofasors for Distribution Systems" (VON MEIER et al., 2014), iniciado em 2013 pela Universidade da California em conjunto com o Power Standards Lab (PSL) e o Lawrence Berkeley National Lab (LBNL) visa a construção de uma unidade de medição fasorial otimizada para redes de distribuição, a qual possibilita além da medição de sincrofasores, a análise local da qualidade de energia. Os autores deste projeto destacam que além da necessidade de redução do custo das $P M U \mathrm{~s}$, a utilização em redes de distribuição apresenta outros desafios como a realização de medições com grande presença de ruídos e a diferença da medição do ângulo de fase da tensão entre diferentes locais da rede de distribuição, o qual apresenta magnitudes duas ordens menor quando comparado às redes de transmissão. 
No Brasil destaca-se o projeto MedFasee desenvolvido pela Universidade Federal de Santa Catarina (AGOSTINI, 2007; DECKER et al., 2010). Esse sistema reportado na literatura tem a finalidade de observar como ocorre a defasagem angular e, principalmente, a frequência entre os diferentes subsistemas (sul, sudeste e centro-oeste, norte e nordeste).

Apesar das inúmeras vantagens em se utilizar $P M U$ s em redes de distribuição, o custo alto dos equipamentos encontrados no mercado limita a disseminação em larga escala desses equipamentos em redes de distribuição (ABBASY e ISMAIL, 2009). Assim, algumas iniciativas recentes visando à concepção de $P M U$ s com menor custo estão sendo criadas.

$\mathrm{O}$ artigo intitulado "Low-Cost Microcontroller-Based Phasor Measurement Units Improve Smart Grid Reliability" cita que as PMUs disponíveis no mercado e utilizadas principalmente pelos sistemas de transmissão apresentam custo elevado devido à grande quantidade de memória para armazenar os dados calculados e de arquiteturas computacionais baseadas em grandes CPUs projetadas tipicamente para computadores industriais. Porém, o lançamento de microcontroladores de 32-bits tem permitido o projeto de PMUs mais compactas e baratas (PUBLITEK EUROPEAN EDITORS, 2014).

A tese intitulada "Concept for Next Generation Phasor Measurement: A Low-Cost, Self-Contained, and Wireless Design" (MILLER, 2010) propõe um conceito de PMU monofásico com tamanho reduzido, para a instalação ao redor de um condutor e com custo dos componentes próximo a US\$200,00, a qual realiza a medição de tensão e corrente por meio dos campos elétricos e magnéticos sem a necessidade de utilização de transformadores de corrente. A Figura 2.4 mostra detalhes do equipamento citado.

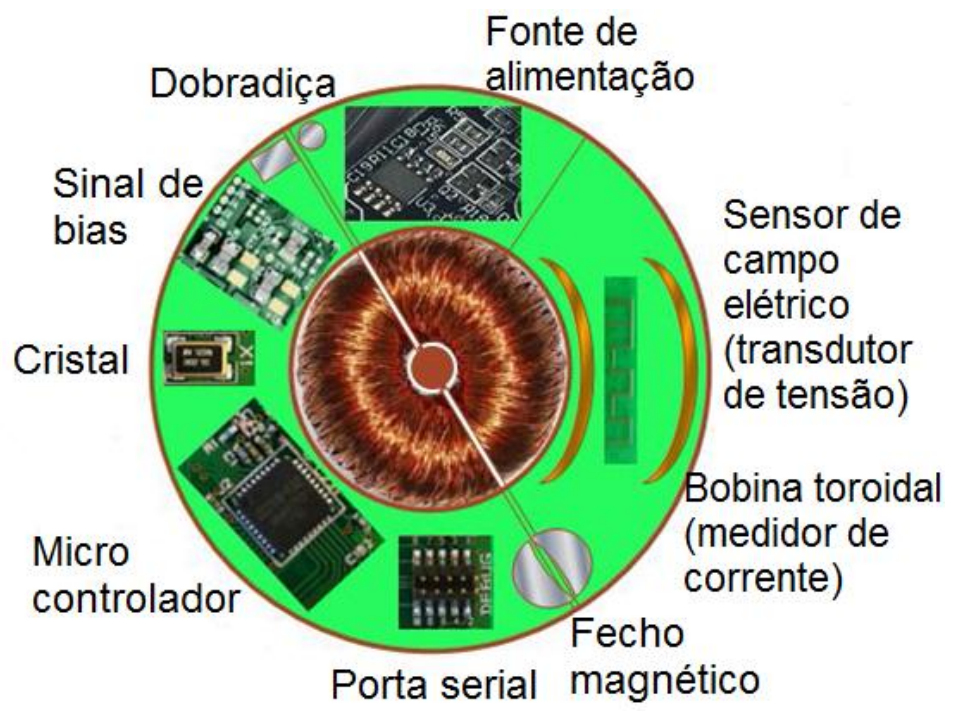

Figura 2.4 - PMU monofásica de baixo custo (adaptado de MILLER, 2010). 
O equipamento também possui sincronização de tempo real por meio do protocolo PTP (Precision Time Protocol) utilizando a comunicação internet sem fio, devendo assim ser instalado próximo de um ponto Wi-Fi.

Já em Laverty et al. (2013), visando a redução de custos é proposta uma plataforma tecnológica denominada "OpenPMU", a qual é modularizada em três subsistemas: medição, estimação de fase e telecomunicações, como mostrado na Figura 2.5.

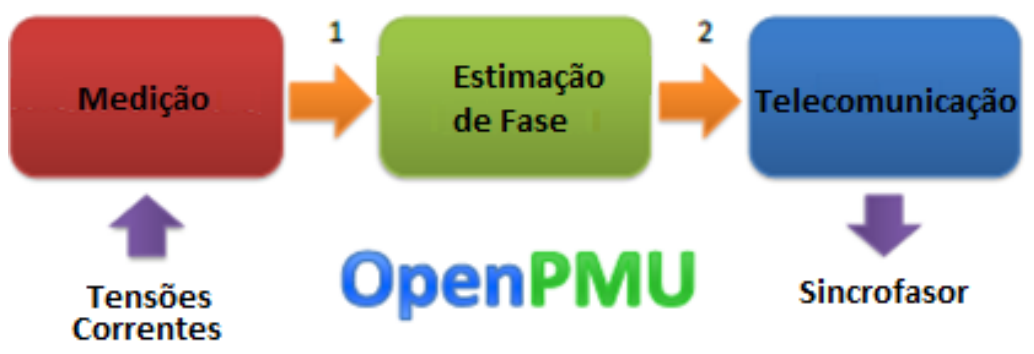

Figura 2.5 - Subsistemas da plataforma OpenPMU (adaptado de LAVERTY et al., 2013).

De acordo com os autores, a interface entre cada subsistema é aberta, permitindo a rápida integração de novas tecnologias em um sistema já existente. A primeira versão do hardware do OpenPMU utiliza a placa de aquisição do fabricante National Instruments no subsistema de medição para a realização das medições, sendo os dados obtidos transmitidos no formato XML (eXtensible Markup Language) via protocolo UDP (User Datagram Protocol) para o subsistema de estimação de fase baseado em um computador pessoal operando a plataforma Labview da National Instruments que realiza a estimação de fase. Posteriormente, os autores sugerem que os dados calculados pelo subsistema de estimação de fase sejam enviados para o subsistema de telecomunicações também utilizando o protocolo $U D P$.

Em Casali (2013) tem-se um estudo de caso onde foram instaladas PMUs de baixo custo em pontos nevrálgicos (com históricos de faltas) de redes de distribuição de média e baixa tensão na Suíça, o que permitiu ao operador uma estimação de estados dinâmica no sistema de distribuição especialmente na presença do aumento de produção de energia descentralizada.

\subsection{CONSIDERAÇÕES QUANTO À IMPORTÂNCIA DA UTILIZAÇÃO DE PMUS VOLTADAS PARA OS SISTEMAS DE DISTRIBUIÇÃO}

A análise apresentada neste capítulo deixa clara a importância crescente a nível mundial da utilização de $P M U s$ em sistemas de distribuição, principalmente quanto à estimação de estados com sistemas geradores ilhados. 
Porém, um grande empecilho para a ampla utilização das PMUs em sistemas de distribuição continua sendo o alto custo apresentado pelos equipamentos já disponíveis no mercado, como citado na Seção 1.1.

Desta forma, o alto custo dos equipamentos comerciais com características funcionais voltadas aos sistemas de transmissão juntamente com a incipiente oferta de soluções mais adequadas nos aspectos financeiro e técnico, cria um ambiente propício para a realização de pesquisas e desenvolvimento de $P M U s$ para uso em redes de distribuição de energia. 


\section{Capítulo 3}

\section{DESENVOLVIMENTOS REFERENTES À UNIDADE DE Medição Fasorial Otimizada Para Sistemas de DISTRIBUIÇÃo}

\subsection{A PROPOSTA DO TRABALHO}

Para que a Unidade de Medição Fasorial Otimizada proposta neste trabalho seja utilizada em conjunto com os sistemas de distribuição de energia elétrica, a mesma tem como objetivo coletar e processar as grandezas elétricas nas redes de distribuição em Média Tensão (MT) e Baixa Tensão (BT), nas tensões eficazes de conexão respectivamente em 13,8 kV e $127 \mathrm{~V}$. Para que o equipamento proposto seja otimizado quanto ao custo é necessário que as grandezas elétricas sejam medidas sempre nos terminais de baixa tensão do transformador de distribuição, o que impactará em um menor custo quanto à transdução dessas grandezas sem perda das características funcionais esperadas para o equipamento.

Assim, quando é necessária a aquisição das grandezas na média tensão, a modelagem discreta do transformador presente no firmware da Unidade de Medição Fasorial Otimizada faz com que as grandezas elétricas medidas nos terminais de baixa tensão do transformador possam ser refletidas na média tensão.

A modelagem de transformadores utilizando softwares como o ATP (Alternative Transients Program) em plataformas de processamento elevado é amplamente difundida (NASCIMENTO et al., 2009). Assim, o desafio presente neste trabalho, explorado com mais detalhes na Seção 3.6, ficou caracterizado pela realização da modelagem do transformador sob condições estacionárias em um sistema embarcado de baixo custo, com as tensões e correntes variando senoidalmente.

Ainda visando à redução do custo da Unidade de Medição Fasorial Otimizada e permitir sua utilização nos sistemas de energia elétrica, a quantidade máxima de sincrofasores processados pelo mesmo em um segundo é igual a 30. Esta taxa é inferior a de alguns equipamentos encontrados no mercado que podem processar até 120 sincrofasores por segundo como comentado na Seção 2.1. Porém, como citado com detalhes na Subseção 3.5.5, 
a taxa utilizada no equipamento proposto não descaracteriza o propósito funcional do mesmo, estando adequada à quantidade mínima de sincrofasores esperada para uma $P M U$.

O cálculo do parâmetro ROCOF (Rate -of-Change of Frequency), presente em algumas $P M U s$ e utilizado para verificar mudanças na inércia de sistema elétricos, não é realizado pela Unidade de Medição Fasorial Otimizada pois necessita de um maior poder de processamento. Além disso, devido à falta de uma padronização mais adequada para $P M U s$, a medição deste parâmetro é mais propícia através da utilização de relés G81G (EURAMET, 2015).

O formato das mensagens de comunicação, detalhado no Capítulo 5, também é personalizado para as funcionalidades exclusivas presentes no equipamento proposto, tais como o sistema de identificação da causa de distúrbios (mostrado em detalhes no Capítulo 4), o qual por meio da análise da variação de parâmetros como potência e tensão busca-se identificar a causa (rede de distribuição ou carga) de distúrbios nas medições realizadas. Após a identificação da causa destes distúrbios é realizada a estimação dos parâmetros da mesma.

Além da verificação por meio de revisão bibliográfica de outras iniciativas internacionais que visam à concepção de $P M U$ s para utilização em sistemas de distribuição, o grau de inovação deste trabalho é ratificado por meio de consulta prévia realizada à base de patente do Instituto Nacional de Propriedade Industrial (2015) e da plataforma LATIPAT (2015) com dados em espanhol e português, no qual se utilizando as palavras-chave "PMU", "Sincrofasor" e "Sistemas de Distribuição", individualmente e de forma combinada, não foi encontrado nenhum projeto com as mesmas características da unidade de medição fasorial sincronizada. O mesmo ocorreu ao se utilizar as palavras-chave "PMU", "synchrophasor" e "low cost" em consulta às bases de patente do The United States Patent and Trademark Office (2015) e do European Patent Office (2015).

\subsection{CARACTERÍSTICAS FUNCIONAIS DA UNIDADE DE MEDIÇÃO FASORIAL OTIMIZADA PARA SISTEMAS DE DISTRIBUIÇÃO}

O sistema embarcado que caracteriza a Unidade de Medição Fasorial Otimizada para Sistemas de Distribuição, é responsável pela execução das seguintes tarefas:

- coleta da data e hora em tempo real por meio da interface com o módulo GPS e temporização das atividades por meio dos pulsos gerados por este módulo;

- coleta das amostras de tensão e corrente nos terminais de baixa tensão do transformador de distribuição por meio da interface de medição trifásica; 
- cálculo dos sincrofasores de tensão e corrente para a frequência fundamental utilizando a Transformada Discreta de Fourier, além do cálculo da frequência, tensão RMS, corrente RMS e potências ativa, reativa e aparente para cada fase;

- reflexão dos fasores na média tensão quando solicitado, por meio da modelagem elétrica do transformador;

- utilização de um sistema fuzzy para identificar a causa (rede de distribuição ou carga) de distúrbios nas medições realizadas. Após a identificação da causa destes distúrbios é realizada a estimação dos parâmetros elétricos da rede e da carga.

- disponibilidade dos sincrofasores e outras informações para as concessionárias por meio da interface de comunição Ethernet e protocolo DNP3.

A Figura 3.1 mostra um diagrama com o sequenciamento destas tarefas. Na Seção 3.3 é destacado o funcionamento do módulo GPS, enquanto nas Seções 3.5 e 3.6 são detalhados o papel do microcontrolador na temporização das atividades e a reflexão dos fasores na média tensão. No Capítulo 4 são abordadas a identificação da causa de distúrbios e a estimação dos parâmetros elétricos e no Capítulo 5 é detalhado o protocolo DNP3 utilizado para a solicitação de envio dos sincrofasores e outras informações.

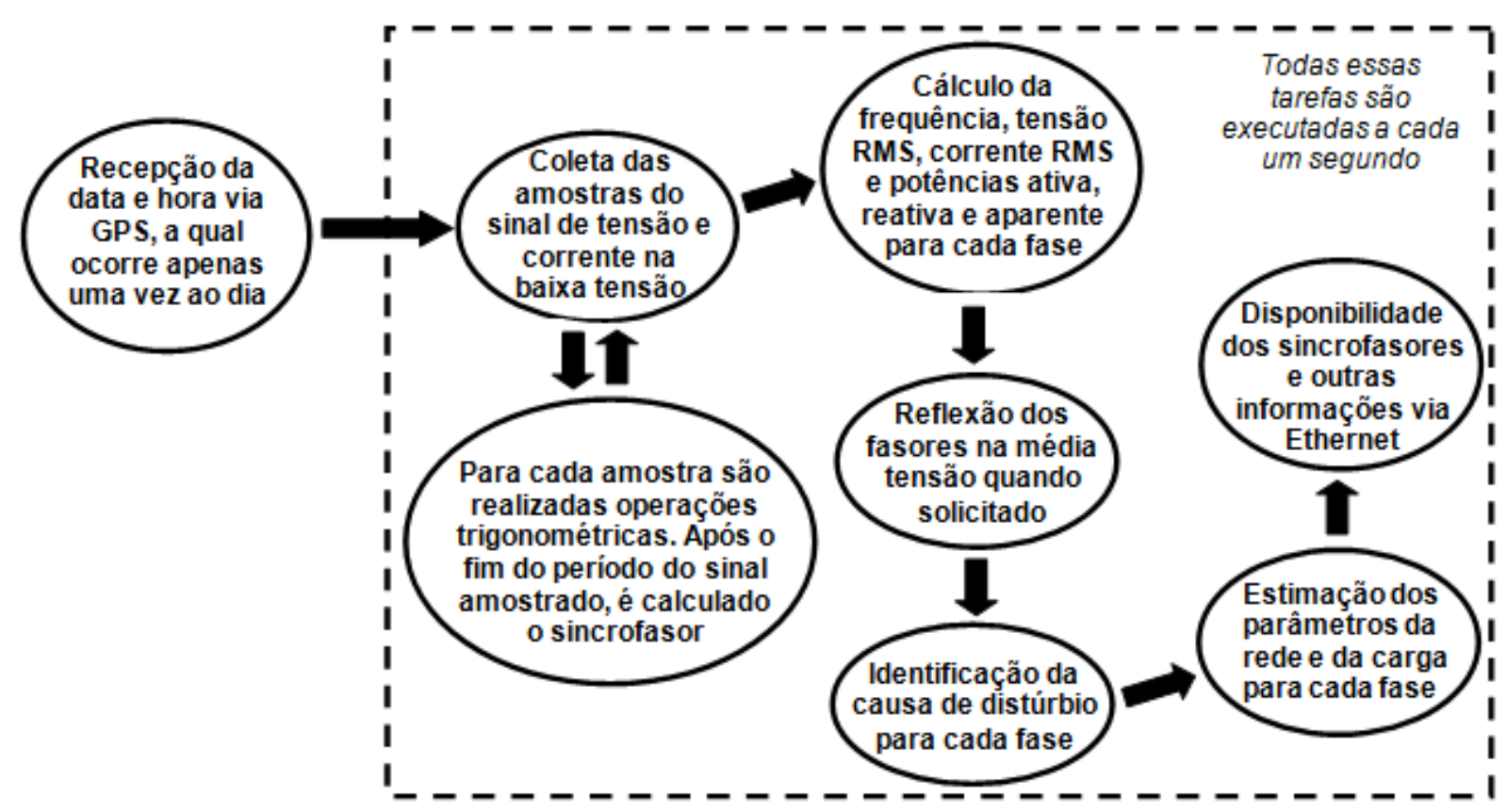

Figura 3.1 - Sequenciamento das tarefas realizadas pelo sistema embarcado.

A Figura 3.2 mostra uma visão superior do protótipo da Unidade de Medição Fasorial Otimizada desenvolvido nesta tese, onde é possível identificar as placas de circuito impresso e suas ligações internas. Essas placas serão exploradas em detalhes ainda neste capítulo. 


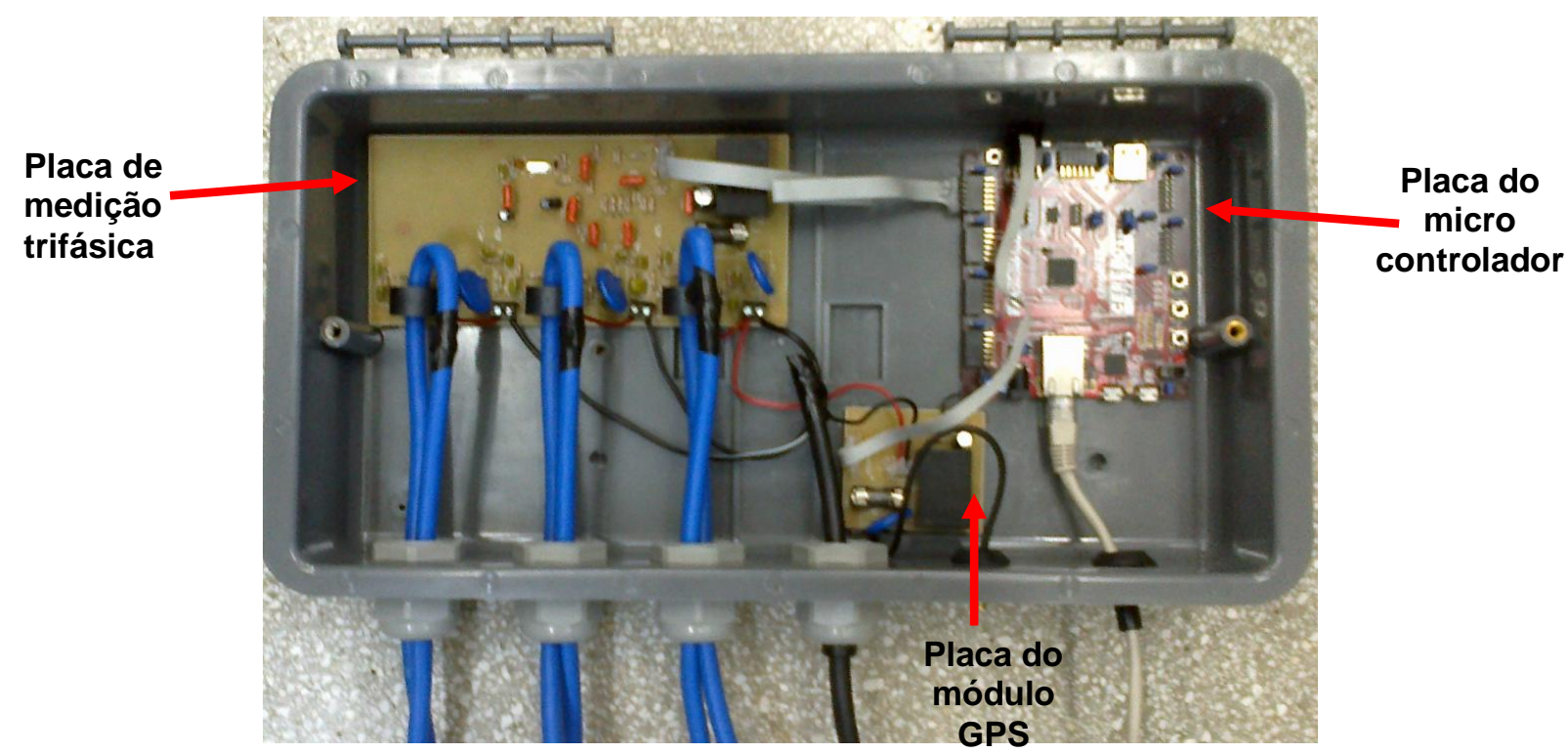

Figura 3.2 - Visão superior do protótipo com a tampa aberta.

A Figura 3.3 mostra uma visão frontal do protótipo da Unidade de Medição Fasorial Otimizada, onde é possível verificar com mais detalhes as entradas e saídas das três fases de tensão, a entrada do fio neutro, o conector para antena GPS e o cabo de conexão Ethernet. Em todos os cabos foram instalados prensa-cabos modelo 0704 da fabricante Strahl (STRAHL, 2014), os quais evitam que uma eventual tração mecânica sobre estes cabos cause danos aos componentes do protótipo.

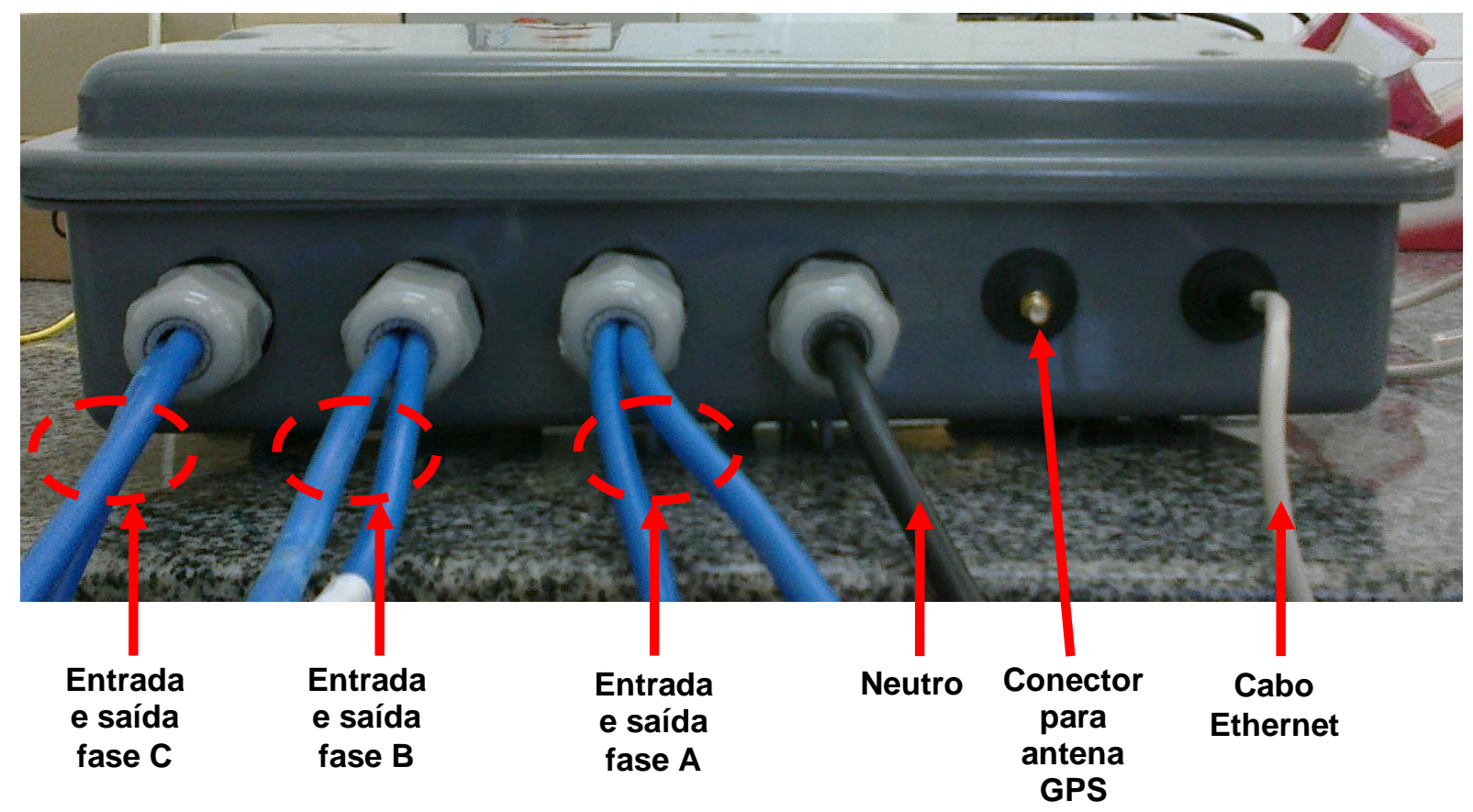

Figura 3.3 - Visão frontal do protótipo. 
A mecânica plástica escolhida para este protótipo, modelo 3068 da fabricante Strahl (STRAHL, 2014), foi utilizada em outro projeto no qual um equipamento também foi instalado na rede de distribuição em baixa tensão na cidade de Fortaleza (Figura 3.4) e o mesmo apresentava entradas e saídas de fases de tensão. Na ocasião, esta mecânica plástica apresentou a performance esperada sob ensaios climáticos, de névoa salina e de penetração prejudicial de água realizados em laboratórios certificadores (LIMA et al., 2012).

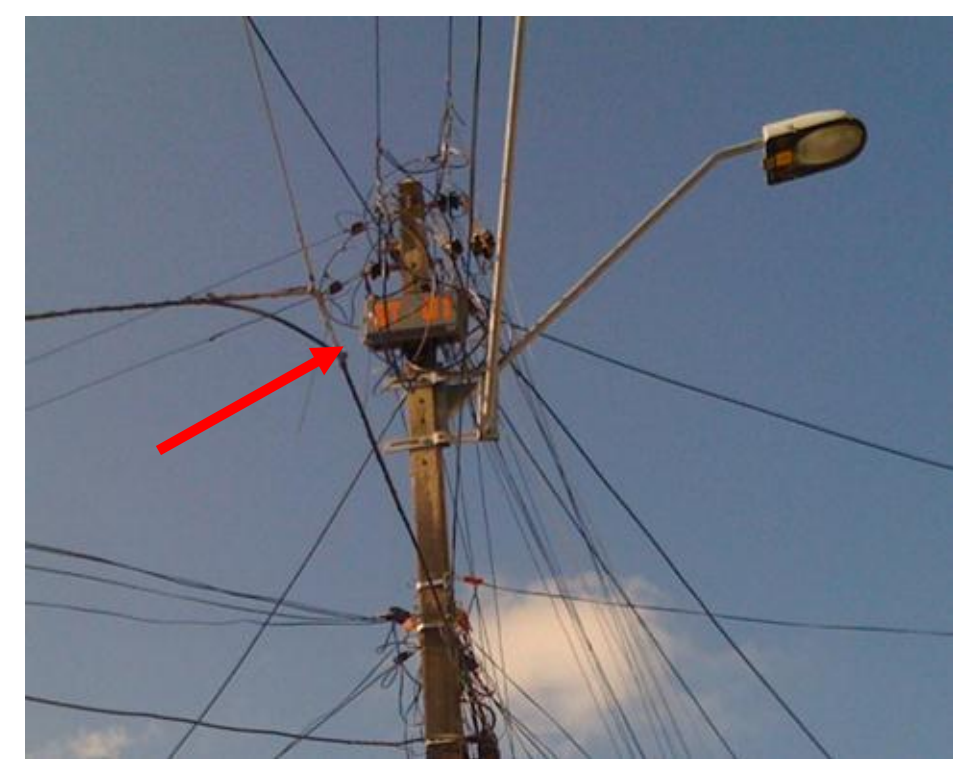

Figura 3.4 - Equipamento instalado na rede de distribuição utilizando a mecânica plástica modelo 3068 (LIMA et al., 2012).

A Tabela 3.1 resume as características elétricas e físicas da Unidade de Medição Fasorial Otimizada para Sistemas de Distribuição.

Tabela 3.1 - Características elétricas e físicas.

\begin{tabular}{|l|c|}
\hline \multicolumn{1}{|c|}{ Parâmetro } & Valor \\
\hline Corrente máxima (valor RMS) para cada fase & $141,42 \mathrm{~A}$ \\
\hline Tensão máxima (valor RMS) para cada fase & $275 \mathrm{~V}$ \\
\hline Consumo do equipamento (alimentado através da fase A) & $3,8 \mathrm{VA}$ \\
\hline Temperatura de operação & $-40{ }^{\circ} \mathrm{C}$ a $+85^{\circ} \mathrm{C}$ \\
\hline Graus de proteção (IP) do invólucro mecânico & 55 (contra poeira e jatos d'água) \\
\hline Dimensões do invólucro mecânico & $412 \mathrm{~mm}$ X $230 \mathrm{~mm} \mathrm{X} 100 \mathrm{~mm}$ \\
\hline
\end{tabular}

O diagrama em blocos a seguir (Figura 3.5) ilustra os componentes da Unidade de Medição Fasorial Otimizada para Sistemas de Distribuição: 


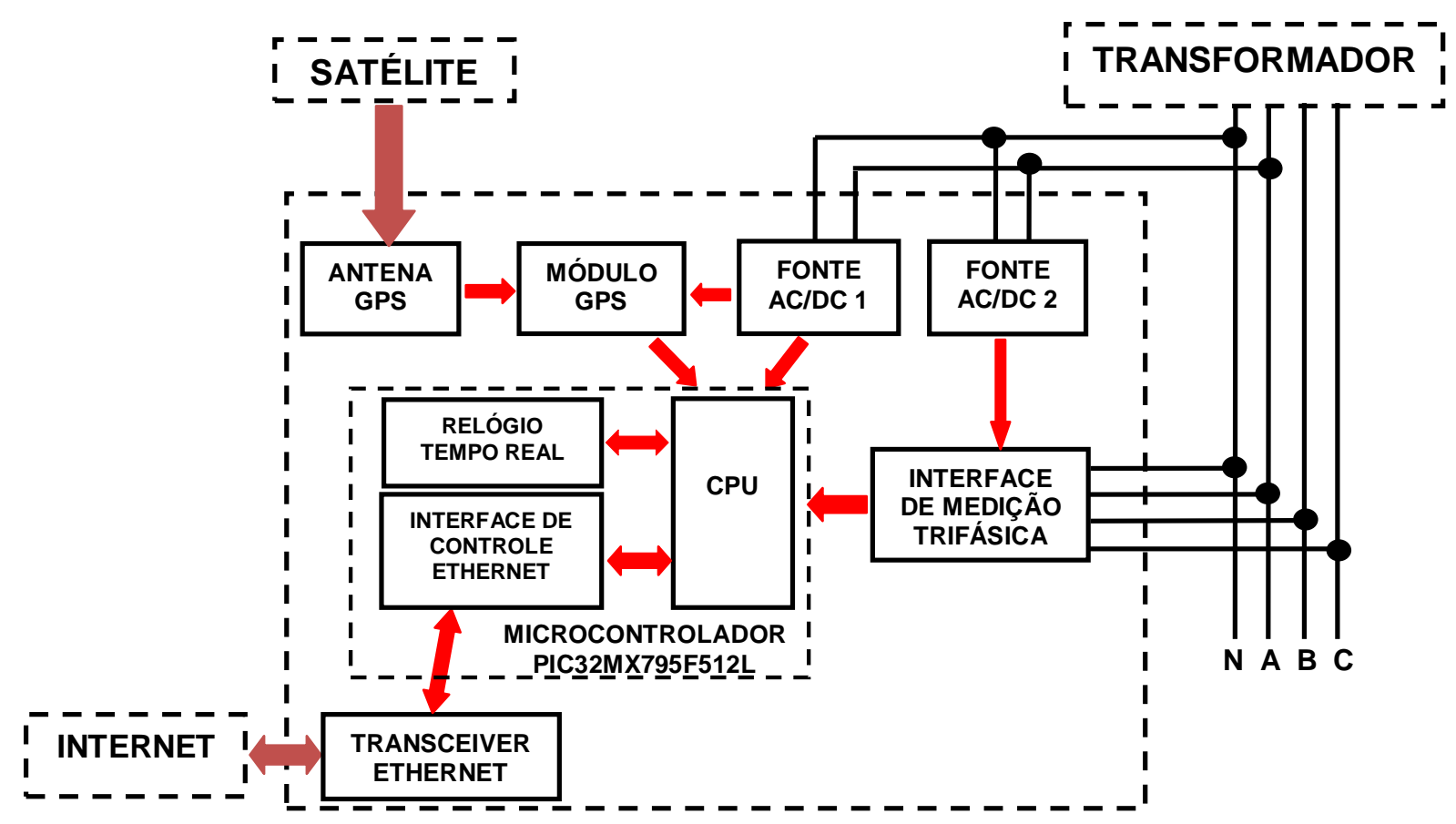

Figura 3.5 - Diagrama em blocos.

A seguir é mostrado o desenvolvimento da Unidade de Medição Fasorial Otimizada com foco em seus blocos funcionais. A escolha dos componentes que compõe os blocos funcionais foi baseada na funcionalidade esperada e no baixo custo a ser alcançado para este equipamento, o qual será mostrado em detalhes no Capítulo 7.

\subsection{CARACTERÍSTICAS FUNCIONAIS DO MÓDULO GPS}

O módulo GPS U-blox MAX-7, mostrado na Figura 3.6 e utilizado na Unidade de Medição Fasorial Otimizada opera com a tensão de 3,3 V e em uma faixa de temperatura entre $-40{ }^{\circ} \mathrm{C}$ e $85^{\circ} \mathrm{C}$, apresentando desta forma a robustez funcional necessária para que o equipamento possa ser exposto a diferentes condições ambientais.

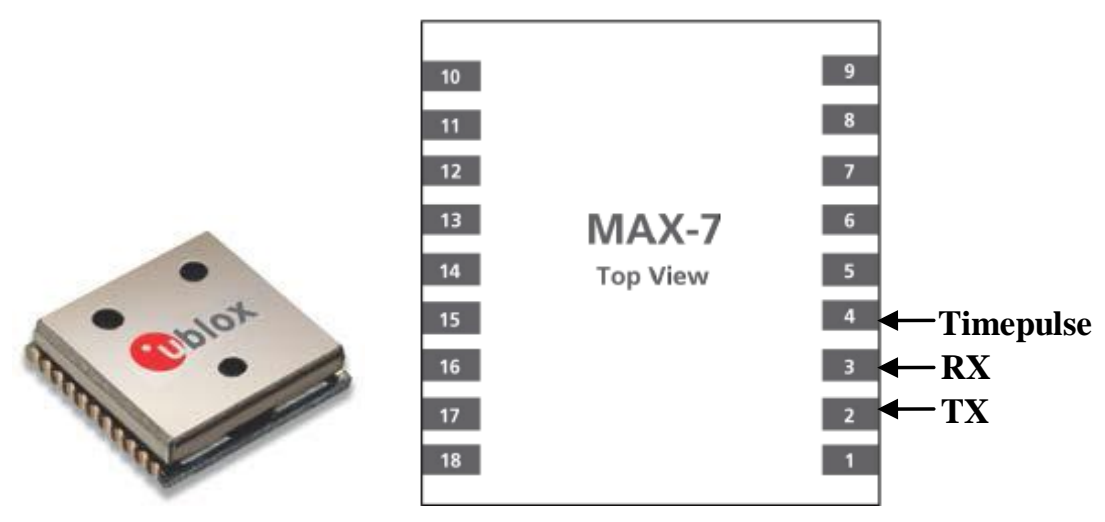

Figura 3.6 - GPS u-blox MAX-7 (U-BLOX AG, 2013a). 
Este módulo gera um pulso de tensão sincronizado via satélite com o fuso horário de referência UTC (Universal Time Coordinated). Este pulso é gerado a cada mudança de segundo e possui duração de 100ms (U-BLOX AG, 2013a).

No momento em que o pulso é gerado, o módulo GPS disponibiliza por meio da comunicação serial assíncrona o pacote de dados RMC (Recommended Minimum Data for GPS) do protocolo NMEA (National Marine Electronics Association), onde estão presentes a data e hora sincronizadas com o UTC (Figura 3.7), além do caractere validador.

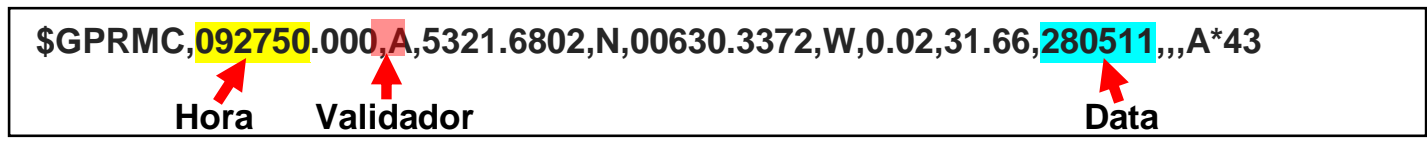

Figura 3.7 - Pacote GPS RMC (adaptado de U-BLOX, 2013b).

Para se obter os dados relativos à data e hora é necessária a recepção de um total de 59 caracteres, onde cada caractere padrão ASCII equivale a um byte, sendo esses dados válidos somente quando o caractere validador do pacote $R M C$ é igual a "A" (U-BLOX AG, 2013b).

A Figura 3.8 mostra o esquemático da placa confeccionada utilizando os softwares ISIS e ARES (PROTEUS Design Suite, 2011) necessário para o funcionamento do módulo GPS (identificado por U2), o qual é alimentado pela tensão de saída 3.3 V do regulador MIC37100, identificado por $\mathrm{U} 3$.

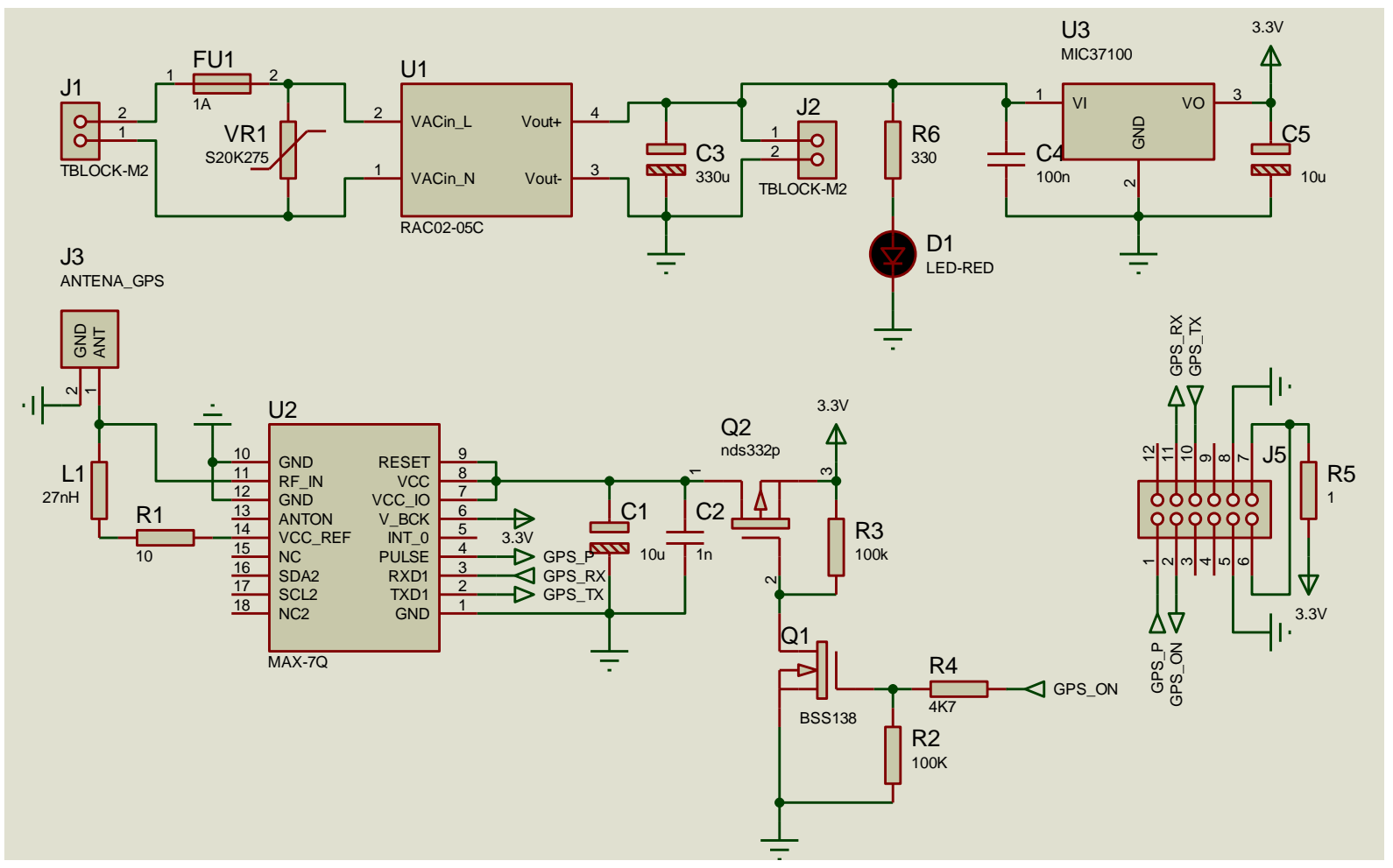

Figura 3.8 - Esquemático da placa do módulo GPS. 
Por sua vez, o regulador MIC37100 é alimentado por uma fonte chaveada AC/DC (identificado por U1), a qual também é responsável pela alimentação da placa do microcontrolador (mostrada em mais detalhes na Seção 3.5) através da interface elétrica identificada em J2. Esta fonte, modelo RAC02-05SC da fabricante RECOM, fornece tensão igual a $5 \mathrm{~V}$ e corrente até $400 \mathrm{~mA}$, além de outras características desejáveis ao projeto como baixo valor de ripple igual a $100 \mathrm{mV}$ e temperatura de operação entre $-40{ }^{\circ} \mathrm{C}$ e $85{ }^{\circ} \mathrm{C}$ (RECOM, 2014).

Junto a esta fonte está instalado um circuito de proteção formado por um fusível de 1A (identificado por FU1) e um varistor modelo S20K275E3K1 (identificado por VR2) da fabricante EPCOS, a qual apresenta regime de tensão CA de 275 V e corrente de sobretensão de pico igual $12 \mathrm{kA}$ (EPCOS, 2011). Este varistor também foi utilizado no projeto citado anteriormente na Seção 3.2, no qual um equipamento foi instalado na rede de distribuição em baixa tensão e apresentou ótimo desempenho em ensaios de metrologia e de tensão suportável sob impulso atmosférico realizados em um laboratório certificado (LIMA et al., 2012).

Também são identificadas na Figura 3.8 a interface com a antena GPS (J3) e a interface de comunicação com a placa do microcontrolador, identificada por J5. A Figura 3.9 mostra a placa do módulo GPS confeccionada e que está sendo utilizada no protótipo da Unidade de Medição Fasorial Otimizada.

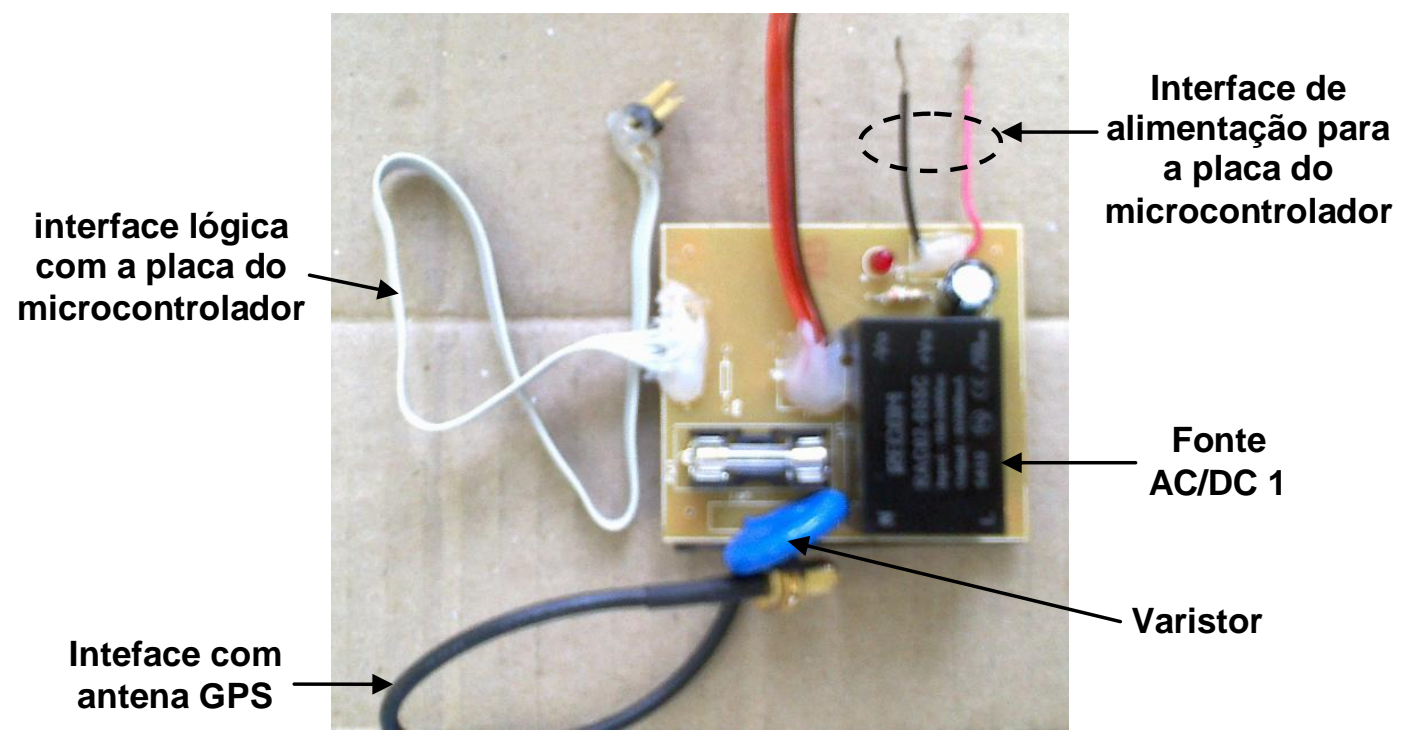

Figura 3.9 - Placa do módulo GPS.

A antena utilizada no projeto (Figura 3.10), modelo RANG001312G do fabricante Richardson RFPD, possui frequência de 1575,42 MHz e ganho de 27 dB (RICHARDSON RFPD, 2011). 


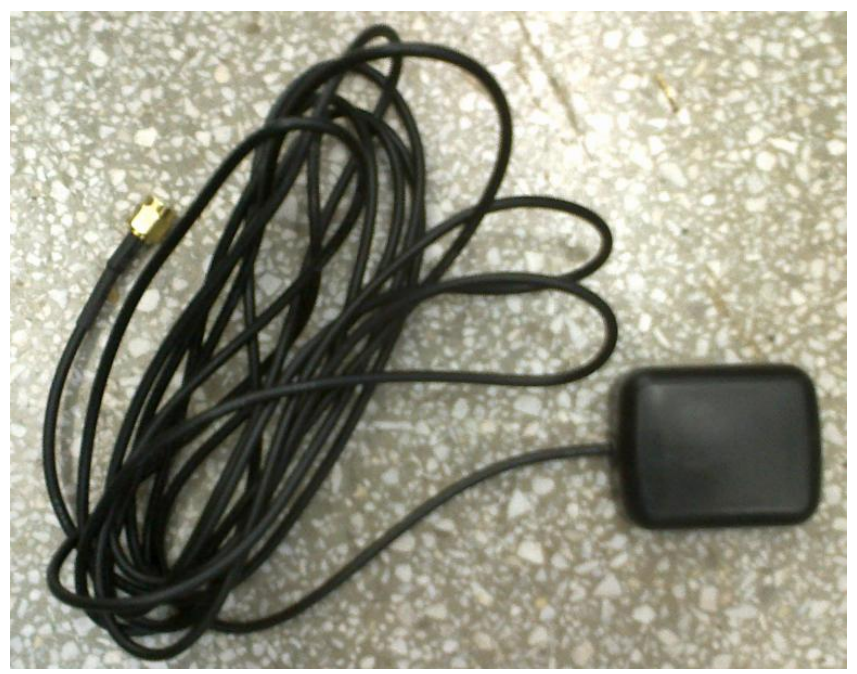

Figura 3.10 - Antena GPS.

\subsection{FUNCIONAMENTO DA INTERFACE DE MEDIÇÃO}

O circuito integrado ADE7758 (Figura 3.11) fabricado pela empresa Analog Devices realiza a conversão analógico-digital dos sinais presentes nos três canais de tensão (VAP, VBP e $V C P)$ e nos três canais diferenciais de corrente (IAP/IAN, IBP/IBN e ICP/ICN), além de oferecer outras funcionalidades que serão apresentadas posteriormente. Este circuito integrado precisa ser alimentado com uma tensão igual a $5 \mathrm{~V}$ e suprido por um corrente máxima igual a $21 \mathrm{~mA}$.

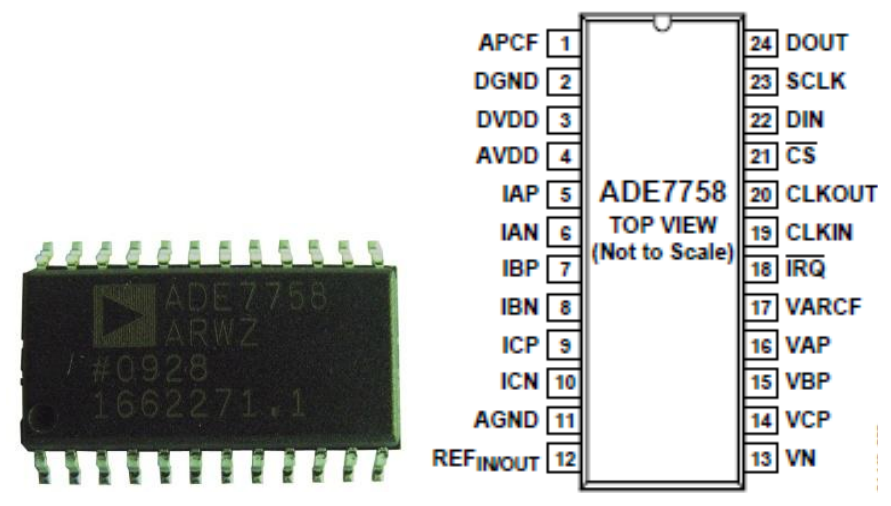

Figura 3.11 - Circuito intregrado ADE7758 (ANALOG DEVICES, 2011).

O circuito ADE7758 já possui um conversor A/D para cada um dos canais de tensão e corrente, o que elimina (praticamente) a necessidade de circuitos Sample and Hold. No caso dos três canais de tensão, os sinais são atenuados por meio de divisores resistivos para explorar a faixa de operação dos conversores A/D presentes no ADE7758, a qual é compreendida entre $500 \mathrm{mV}$ e $500 \mathrm{mV}$ (ANALOG DEVICES, 2011). 
A Figura 3.12 mostra a primeira parte do esquemático da placa da interface de medição trifásica, confeccionada utilizando os softwares ISIS e ARES (PROTEUS Design Suite, 2011), onde estão destacados os circuitos que realizam a interface entre os sinais de tensão e o neutro oriundos do transformador e os canais de tensão do circuito integrado ADE7758.

As três fases de tensão são conectadas à placa através dos conectores J1, J7 e J8. Na entrada de cada fase de tensão foi incluído o varistor modelo S20K275E3K1, cujas características de proteção foram discutidas anteriormente na Seção 3.1.

Como citado anteriormente, a tensão de cada fase é atenuada por meio dos divisores resistivos formados por R23/R24, R25/R26 e R27/R28. Junto à saída destes divisores foram adicionados capacitores que funcionam em conjunto com os resistores como filtros antialiasing (ANALOG DEVICES, 2003).
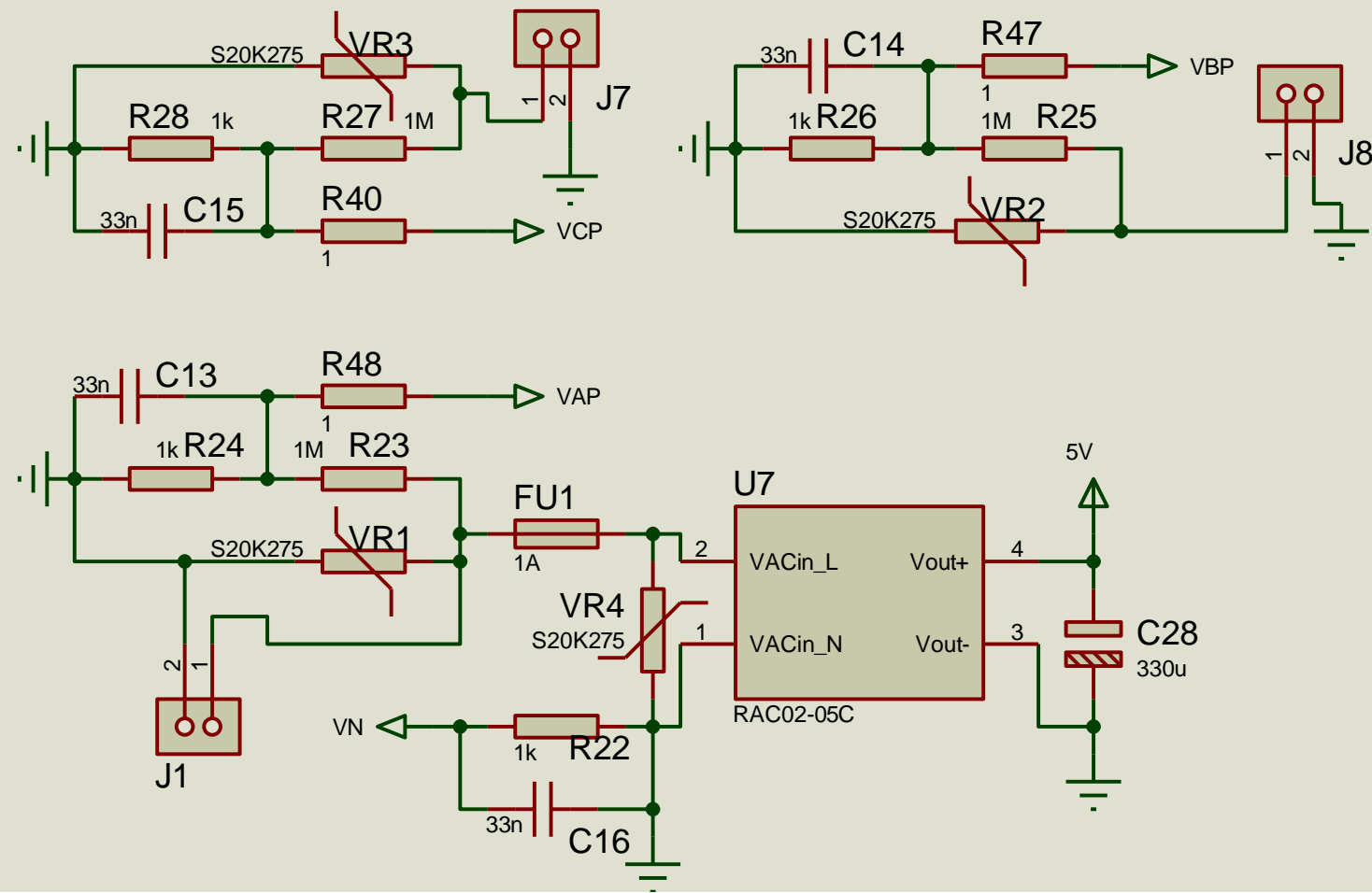

Figura 3.12 - Primeira parte do esquemático da placa de interface de medição trifásica.

Os divisores resistivos possuem a seguinte relação de atenuação expressa por meio da Equação (3.1).

$$
V_{N}=\frac{1 k \Omega}{1 k \Omega+1 M \Omega} V_{I N}=9,99 \cdot 10^{-4} V_{I N}
$$

onde $V_{N}$ é a tensão apresentada em um dos canais de tensão do circuito integrado ADE7758 e $V_{I N}$ é a tensão de uma das fases oriundas do transformador. 
Assim, estará presente a tensão de $500 \mathrm{mV}$ na entrada do conversor $\mathrm{A} / \mathrm{D}$ quando a tensão de entrada do divisor resistivo for igual 500,5 V (Equação 3.2).

$$
V_{I N}=\frac{1 M \Omega+1 K \Omega}{1 K \Omega} .500 m V=500,5 \mathrm{~V}
$$

Esta relação de atenuação permite que mesmo tensões monofásicas com valor RMS igual a $220 \mathrm{~V}$ sejam amostradas garantindo toda a excursão do sinal.

Ainda é possível verificar na Figura 3.12 que o acoplamento entre o neutro da rede e o canal $V N$ do ADE7758 ocorre por meio do filtro anti-aliasing formado pelo resistor R22 e capacitor C16.

Também está presente nesta figura uma fonte AC/DC modelo RAC02-05SC juntamente com seu circuito de proteção, cujas características funcionais estão descritas na Seção 3.2. O objetivo desta fonte é alimentar individualmente o circuito integrado ADE7758, já que o funcionamento correto do mesmo exige que o sinal Ground DC fornecido pela fonte AC/DC seja acoplado diretamente ao sinal "Neutro" da rede elétrica (ANALOG DEVICES, 2003). Assim, as placas do módulo GPS e do microcontrolador são alimentadas por outra fonte, já que o acoplamento entre o sinal Ground DC presente nestas placas e o sinal neutro na rede poderia gerar danos a estas placas.

Para os três canais de corrente, os sinais passam por transformadores de corrente modelo CT07-1000 do fabricante Ice Componentes (Figura 3.13), os quais possuem uma relação de transformação $(N)$ igual a 1000:1, resposta em frequência entre $40 \mathrm{~Hz}$ e $200 \mathrm{kHz}$ e suportam uma corrente máxima de pico (IMAX) de 200 A (ICE COMPONENTS, 2011).

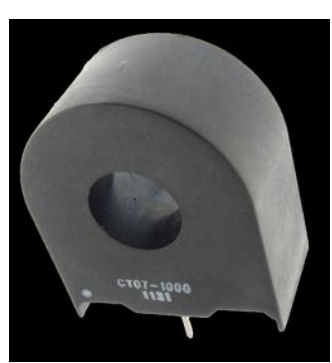

Figura 3.13 - Transformador de Corrente CT07-1000 (ICE COMPONENTS, 2011).

A corrente transformada é espelhada em forma de tensão para os conversores analógicodigital por meio dos resistores $R_{B}$, sendo que a faixa de operação para estes conversores também devem estar compreendidas entre $-500 \mathrm{mV}$ e $500 \mathrm{mV}\left(V_{M A X}\right)$. Assim, o valor do 
resistor necessário para explorar toda a resolução do conversor analógico-digital $\left(R_{B}\right)$ é encontrado por meio da Equação (3.3).

$$
R_{B}=\frac{V_{M A X}}{\frac{I_{M A X}}{N}}=\frac{500 m V}{\frac{200 A}{1000}}=2,50 \Omega
$$

Comercialmente está disponível o valor de 2,49 $\Omega$. Assim, utilizando este valor para o resistor $R_{B}$, a tensão gerada na entrada do conversor analógico para a corrente de pico de 200 A é encontrada na Equação (3.4).

$$
V=R_{B} \frac{I_{M A X}}{N}=2,49 \frac{200}{1000}=498 \mathrm{mV}
$$

A Figura 3.14 mostra a segunda parte do esquemático da placa de interface de medição trifásica, onde estão destacados os canais de corrente.

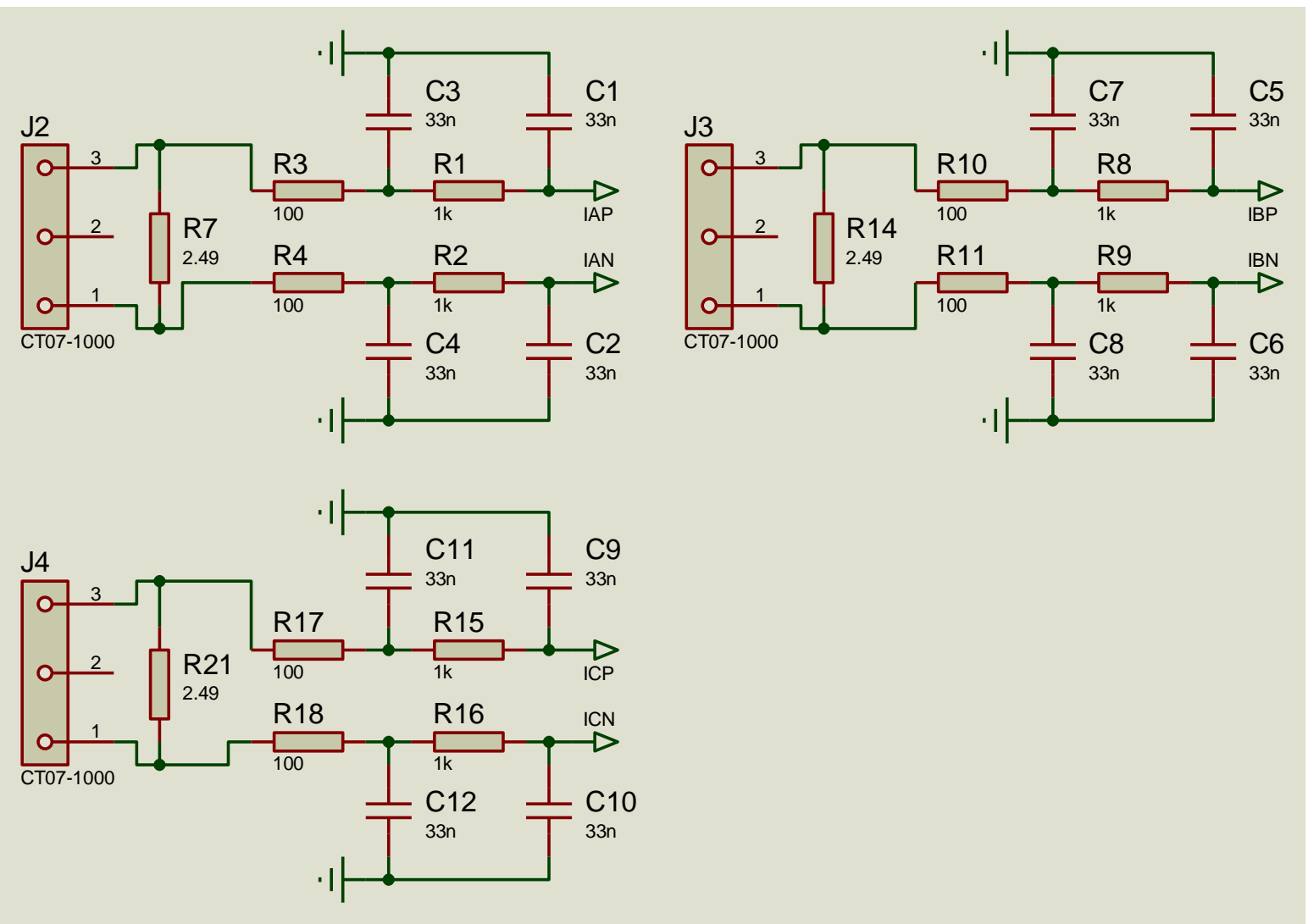

Figura 3.14 - Segunda parte do esquemático da placa de interface de medição trifásica.

Os transformadores de corrente para as fases A, B e C são identificados respectivamente por J2, J3 e J4. Já os resistores $R_{B}$ são identificados por R7, R14 e R21. 
Os conjuntos RC formados por R3/C3, R4/C4, R10/C7, R11/C8, R17/C11 e R18/C12 são utilizados para prover compensação de fase quando um transformador de corrente está sendo utilizado com o ADE7758. Já os conjuntos RC formados por R1/C1, R2/C2, R8/C5, R9/C6, R15/C09 e R16/C10 são filtros anti-aliasing necessários ao correto funcionamento do circuito integrado ADE7758 (ANALOG DEVICES, 2003).

A interface de comunicação utilizada entre o microcontrolador e o circuito integrado ADE7758 é a SPI (Serial Peripheral Interface). Assim, além da placa de medição trifásica possuir sua própria fonte AC/DC, a comunicação SPI entre esta placa e a placa do microcontrolador foi eletricamente desacoplada por meio de acopladores óticos, visando evitar danos aos componentes da placa do microcontrolador cujo sinal Ground DC também é oriundo da conexão Ethernet e da porta $U S B$ de um microcomputador, a qual é utilizada para realizar a programação do microcontrolador.

A Figura 3.15 mostra a última parte do esquemático da interface de medição trifásica.

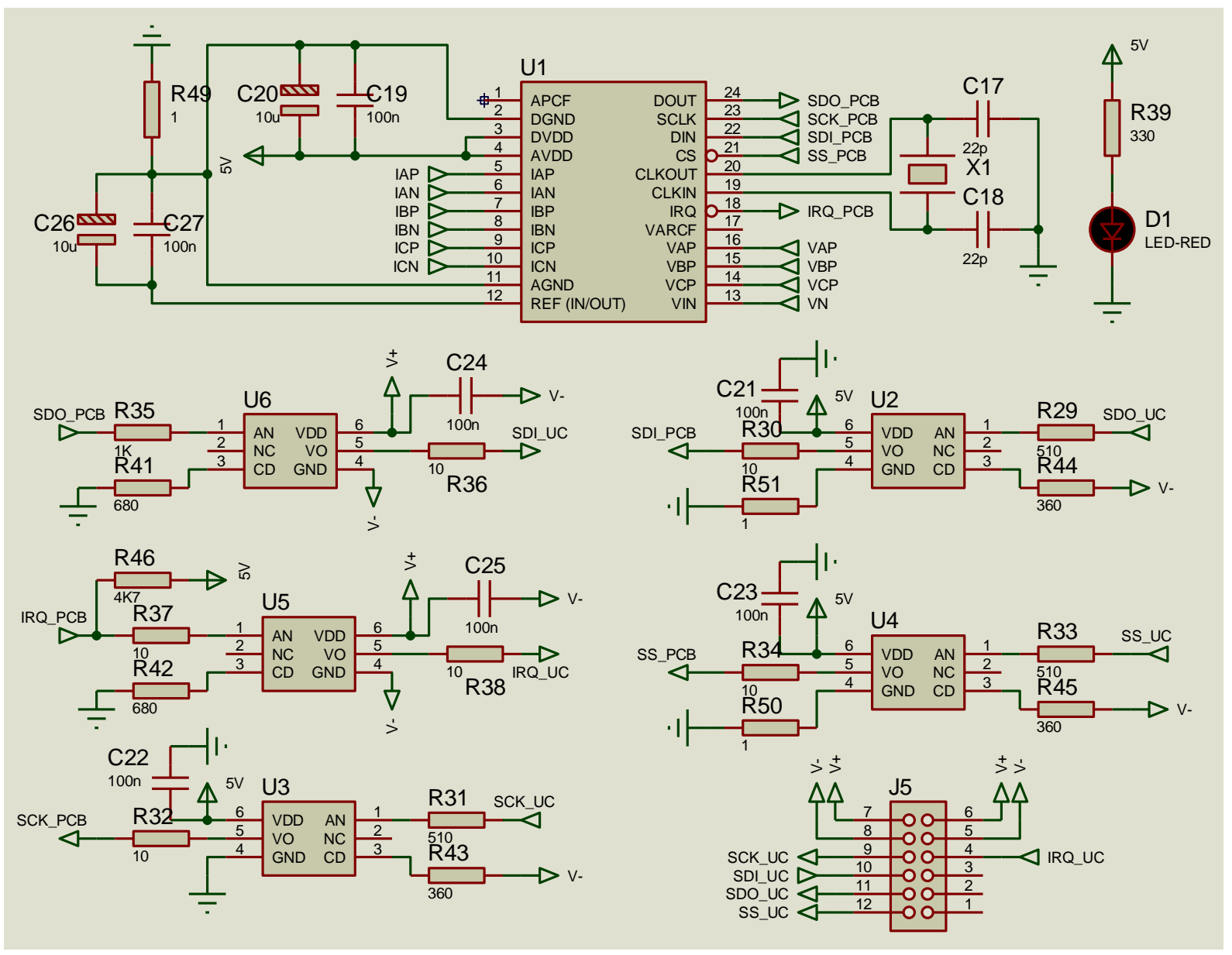

Figura 3.15 - Última parte do esquemático da placa de interface de medição trifásica. 
Na Figura 3.15, é possível identificar o circuito integrado ADE7758 (U1), a interface de comunicação SPI com a placa do microcontrolador (J5) e os acopladores ópticos modelo ACPL-M61L do fabricante Avago Technologies (U2 a U6), os quais garantem velocidade mínima de chaveamento de 10 Mbps e consumo de corrente máximo igual a 1,6 mA (AVAGO TECHNOLOGIES, 2013).

As características desses acopladores ópticos viabilizam sua utilização nos quatro sinais (MOSI, MISO, CLK e CS) que compõe a comunicação SPI, além de um quinto acoplador óptico utilizado junto ao sinal de interrupção que indica uma nova amostra, gerado pelo pino $I R Q$ do circuito ADE7758 e que será discutido posteriormente na Seção 3.5.

A Figura 3.16 mostra a face superior da placa da interface de medição trifásica confeccionada e que está sendo utilizada no protótipo da Unidade de Medição Fasorial Otimizada.

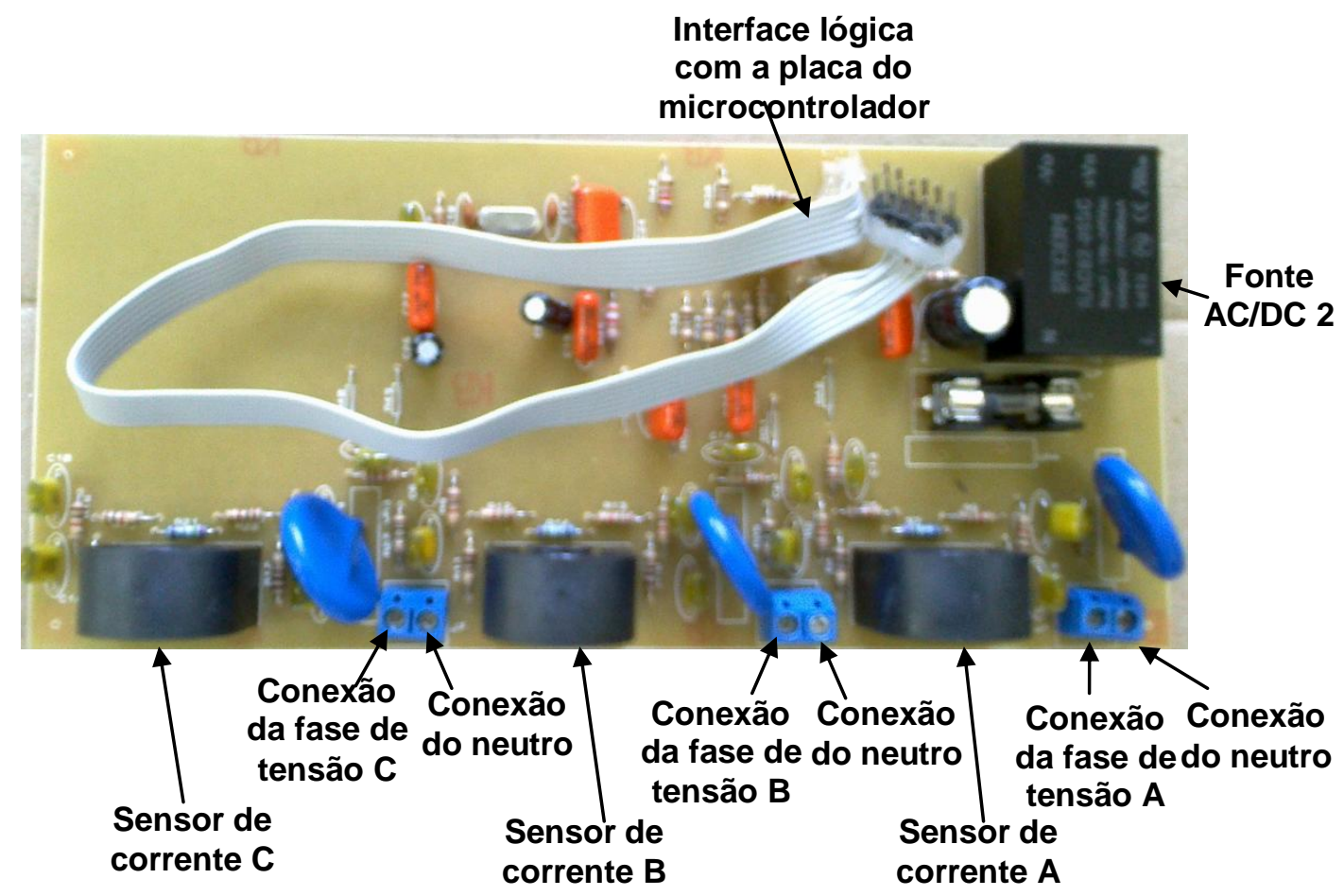

Figura 3.16 - Face superior da placa de interface de medição trifásica.

É importante destacar na Figura 3.16 as três conexões do neutro, as quais estão presentes próximos à entrada de cada fase e a cada varistor. O objetivo é evitar a circulação de uma alta corrente na placa caso algum dos varistores precise ser acionado, evitando assim danos à placa.

A Figura 3.17 mostra a face inferior da placa da interface de medição trifásica. 


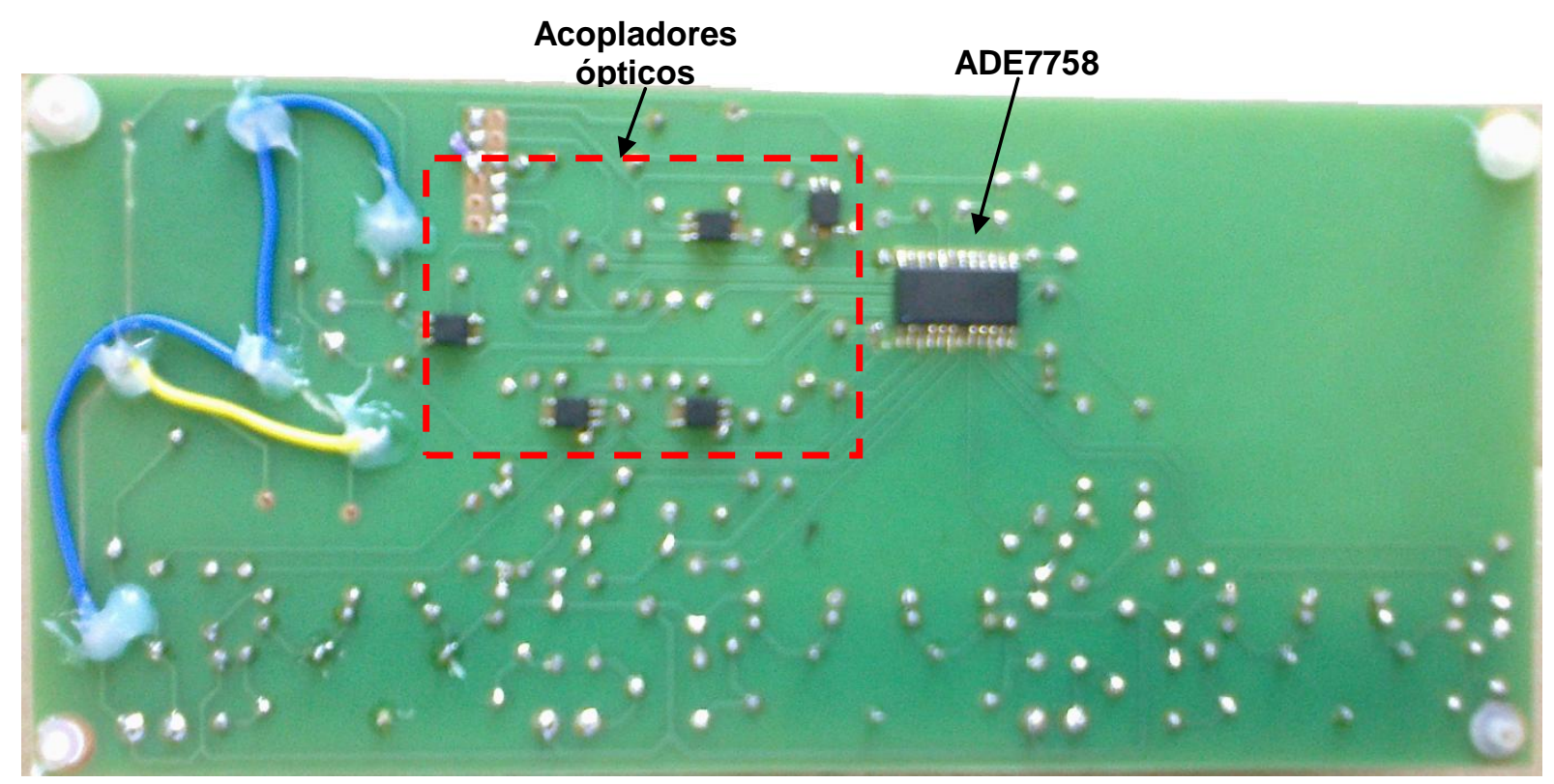

Figura 3.17 - Face inferior da placa de interface de medição trifásica.

\subsection{ATIVIDADES REALIZADAS PELO MICROCONTROLADOR}

\subsubsection{Características gerais}

O microcontrolador modelo PIC32MX795F512L fabricado pela empresa Microchip Technology Incorporated possui uma unidade de processamento de 32 bits operando com frequência de $80 \mathrm{MHz}$. Apresenta também $512 \mathrm{kB}$ de memória Flash, 128 kB de memória RAM, 52 pinos de I/O, tensão de operação entre 2,3 V e 3,6 V, e temperatura de operação entre $-40^{\circ} \mathrm{C}$ e $105^{\circ} \mathrm{C}$, mostrando-se assim uma opção robusta para utilização neste projeto. Este microcontrolador ainda possui interface para controle de acesso ethernet (MAC) de 10/100 Mbps, módulo de calendário e relógio em tempo real, timers, interfaces de comunicação serial síncronas e assíncronas, além de outros periféricos (MICROCHIP TECHNOLOGY INCORPORATED, 2013a).

Neste projeto, o microcontrolador PIC32MX795F512L foi utilizado por meio da placa de desenvolvimento Cerebot MX7CK fabricado pela empresa Digilent Incorporated (Figura 3.18). Esta placa, alimentada com $5 \mathrm{~V}$ proveniente da placa do módulo GPS, inclui programador e debugger compatíveis com o ambiente de programação MPLAB IDE (MPLAB, 2010) conector e tranceiver ethernet, conectores USB, leds, cosciladores, botões, barramentos externos para conexão e outros periféricos (DILIGENT INCORPORATED, 2013). Além disso, este microcontrolador está sendo programado em linguagem $\mathrm{C}$ utilizando o compilador MPLAB C Compiler for PIC32 MCUs (MPLAB, 2011). 


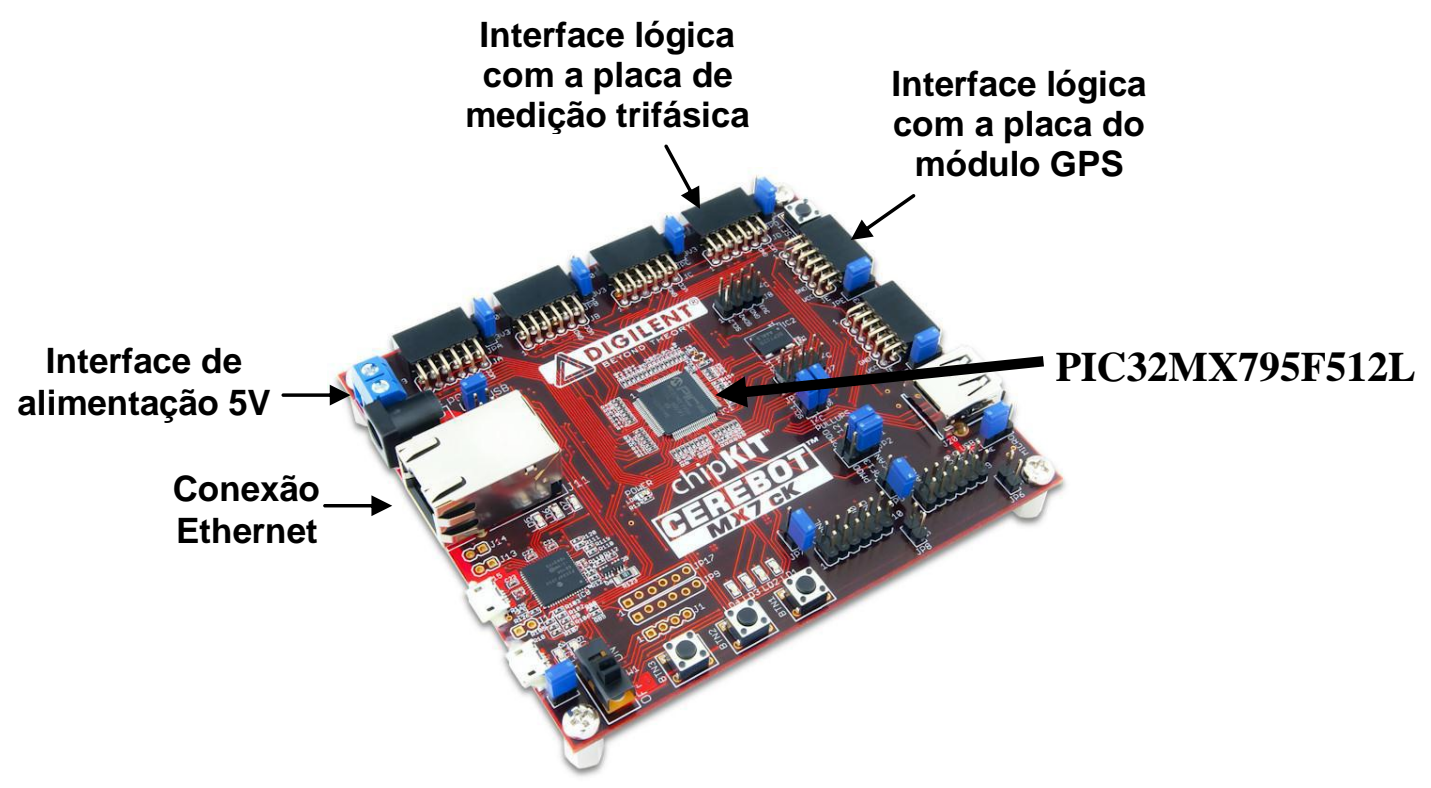

Figura 3.18 - Placa de desenvolvimento Cerebot MX7CK.

\subsubsection{Inteface com o circuito integrado ADE7758}

A interface de comunicação utilizada com o circuito integrado ADE7758 é a SPI canal 1, uma das quatro interfaces SPI disponíveis no microcontrolador PIC32MX795F512L (MICROCHIP TECHNOLOGY INCORPORATED, 2011). A mesma foi configurada no microcontrolador como mestre, no padrão de 8 bits, frequência de operação igual a 1,25 MHz e com o sinal de clock no formato mostrado na Figura 3.19, o qual é exigido para o correto funcionamento junto ao circuito ADE7758 (ANALOG DEVICES, 2011).

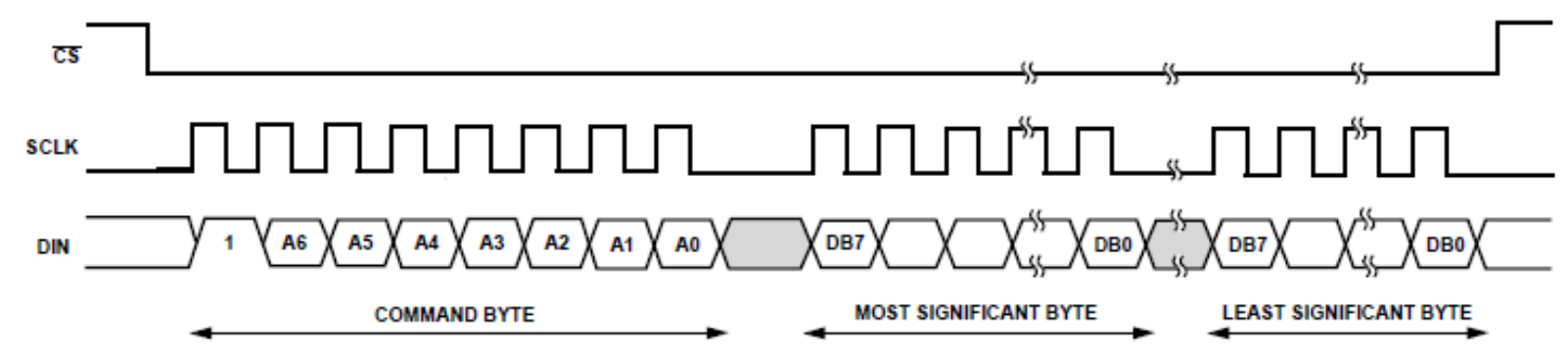

Figura 3.19 - Padrão da comunicação SPI do circuito ADE7758.

\subsubsection{Realização do cálculo fasorial}

Como mostrado na Figura 3.1 (Seção 3.2), para cada amostra que compreende o período do sinal na baixa tensão são realizadas operações trigonométricas, visando posteriormente ao final do período do sinal o cálculo fasorial, como detalhado a seguir. 
A seleção do canal de tensão ou corrente que será amostrado é realizada por meio da programação do registrador WAVEFORM do circuito integrado ADE7758, cujo byte de comando é 0x15. Após a seleção de um dos canais, o ADE7758 começa a disponibilizar as amostras com uma das seguintes frequências: 3250, 6510, 13020 ou 26040 amostras por segundo. Para o presente sistema foi utilizada a frequência de 3250 amostras por segundo, cuja motivação será explicada adiante nesta seção.

Quando uma amostra está disponível o ADE7758 gera um pulso de tensão (com borda de subida) por meio do seu pino $I R Q$. O microcontrolador fica sempre aguardando de forma bloqueante este pulso em seu pino RD12, e após o mesmo ser detectado é realizada a leitura do valor da amostra por meio da leitura do registrador WFORM (byte de comando 0x12). Após a leitura é enviado por meio do registrador RSTATUS (byte de comando 0x1A) a instrução que reseta o indicador de amostra recebida, fazendo assim com que o pino IRQ do circuito integrado ADE7758 retorne ao nível lógico zero, permitindo assim identificar novamente se uma nova amostra está disponível.

Após receber a amostra, a mesma é normalizada, isto é, o valor da conversão A/D é relacionado a um valor de tensão e corrente.

Os sinais de tensão são convertidos pelo circuito integrado ADE7758 em uma nova faixa variando entre $+10056(0 \times 2768)$ e -10056(0xD8B8) para a frequência de $60 \mathrm{~Hz}$ e entre +10135(0x2797) e -10135(0xD869) para a frequência de $50 \mathrm{~Hz}$, como mostrado na Figura 3.20 (ANALOG DEVICES, 2011). As diferenças dos valores das faixas para cada uma das frequências ocorrem devido à atuação de filtros passa-baixa com apenas um polo e frequência de corte de $260 \mathrm{~Hz}$, os quais estão implementados no circuito ADE7758 na saída do conversor A/D de cada canal de tensão.

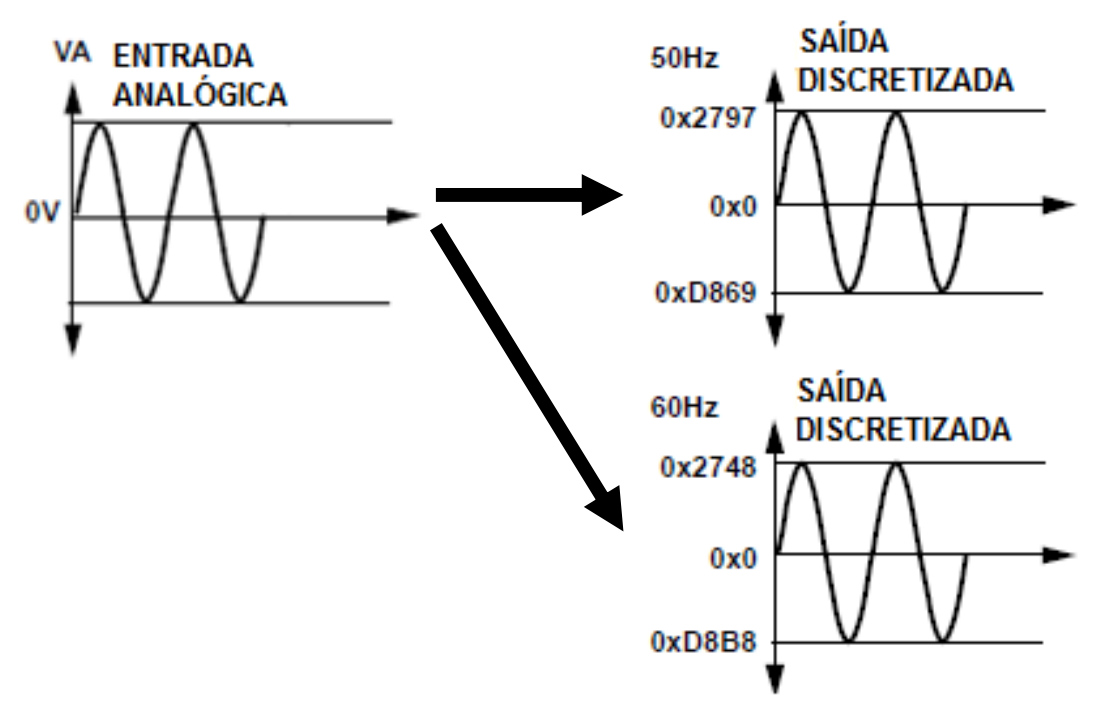

Figura 3.20 - Conversão do sinal de tensão (Adaptado de ANALOG DEVICES, 2011). 
Para os canais de corrente a faixa de saída dos conversores A/D do circuito integrado ADE7758 varia entre +2642412(0x2851EC) e -2642412(0xD7AE14), como mostrado na Figura 3.21 (ANALOG DEVICES, 2011).
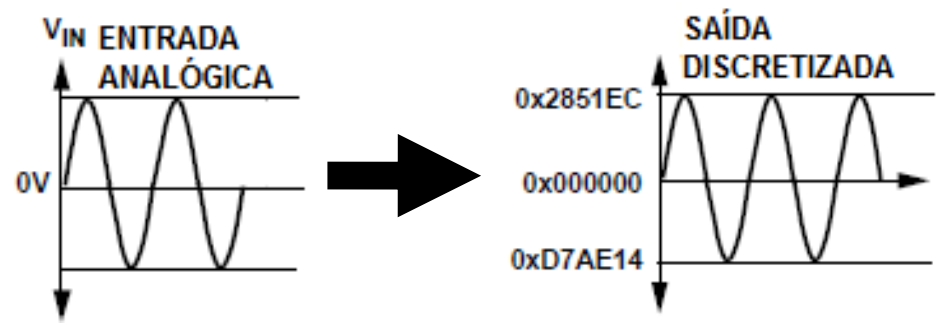

Figura 3.21 - Conversão do sinal de corrente (Adaptado de ANALOG DEVICES, 2011).

A primeira etapa da normalização é determinar se o valor convertido é positivo ou negativo, já que o circuito integrado ADE7758 utiliza a representação binária de complemento de dois para essa determinação. Desta forma, se o bit mais significativo (MSB) da amostra é '0', o valor é positivo, se for ' 1 ', o valor é negativo. A Expressão numérica (3.5) exemplifica o valor para uma amostra de tensão recebida, a qual é representada por 16 bits:

$$
\text { 0xF5E8 = 0b1111010111101000 }
$$

Como o bit MSB, destacado em vermelho, é igual a '1', o valor é negativo. Neste caso a amostra deverá sofrer a seguinte conversão para poder ter seu valor negativo representado, como mostrado na Expressão numérica (3.6).

$$
\begin{aligned}
& -32768+(\text { valor da amostra \& 0x7FFF })= \\
& -32768+(0 x F 5 E 8 \& 0 \times 7 F F F)= \\
& -32768+0 \times 75 E 8=-32768+30184=-2584
\end{aligned}
$$

onde caractere '\&' representa o operador lógico bit a bit AND. A Expressão numérica (3.7) mostra a verificação do valor para uma amostra de corrente recebida, a qual é representada por 24 bits:

$$
\text { 0xE9B356 = 0b101010011011001101010110 }
$$

Como o bit MSB, destacado em vermelho, é igual a '1', o valor é negativo, sendo que a amostra sofrerá a conversão mostrada na Expressão (3.8). 


$$
\begin{aligned}
& -8388608+(\text { valor da amostra \& 0x7FFFFF })= \\
& -8388608+(\text { 0xE9B356 \& 0x7FFFFF })= \\
& -8388608+\text { 0x69B356 }=-8388608+6927190=-1461418
\end{aligned}
$$

Após a verificação da polaridade da amostra e sua conversão em caso de valor negativo, é preciso relacionar o valor da amostra com um valor de tensão e corrente.

Como mostrado anteriormente por meio da Equação (3.2) na Seção 3.4, a tensão de pico de $+500,5 \mathrm{~V}$ na entrada dos resistores resistivos equivale a $+500 \mathrm{mV}$ na entrada do conversor A/D do circuito ADE7758, valor este que após a conversão é igual a +10056 para um sinal senoidal com frequência de $60 \mathrm{~Hz}$ e +10135 para um sinal com frequência de $50 \mathrm{~Hz}$ (Figura 3.19). Como 500,5 V equivale a 10056 unidades de amostragem para um sinal com frequência de $60 \mathrm{~Hz}$, chega-se a relação onde $1 \mathrm{mV}$ é igual a 0,02009 unidades de amostragem. Para a frequência de $50 \mathrm{~Hz}$, a relação é de $1 \mathrm{mV}$ para 0,02025 unidades de amostragem.

Assim, cada amostra recebida é dividida por 0,02009 ou 0,02025 para obter o seu valor em milivolts. Para o exemplo citado anteriormente na Expressão numérica (3.6), o valor em milivolts desta amostra oriunda de um sinal senoidal com frequência de $60 \mathrm{~Hz}$ é obtido por meio da Expressão numérica (3.9).

$$
\frac{-2584}{0,02009}=-128621 \mathrm{mV}=-128,621 \mathrm{~V}
$$

É importante ressaltar que devido às imprecisões existentes em resistores com valores elevados, presentes nos divisores resistivos, é necessário realizar uma calibração individualizada por canal para encontrar o valor correto para conversão do valor da amostra em milivolts (Tabela 3.2), a qual ocorre utilizando uma forma de onda com tensão estável e previamente conhecida. Além disso, as características estruturais da placa de circuito impresso que abriga o circuito ADE7758 podem gerar offsets nos sinais convertidos, os quais são compensados no próprio firmware do protótipo antes dos valores das amostras serem convertidos em milivolts (Tabela 3.3).

Tabela 3.2 - Relações de conversão utilizadas para o cálculo da tensão.

\begin{tabular}{|c|c|c|c|c|c|c|}
\hline \multirow{2}{*}{ Protótipo } & \multicolumn{4}{|c|}{$\begin{array}{c}\text { Relações de conversão (unidades/mV) } \\
\text { para a frequência } 60 \mathrm{~Hz}\end{array}$} & \multicolumn{3}{c|}{$\begin{array}{c}\text { Relações de conversão (unidades/mV) } \\
\text { para a frequência } 50 \mathrm{~Hz}\end{array}$} \\
\cline { 2 - 7 } & Fase A & Fase B & Fase C & Fase A & Fase B & Fase C \\
\hline 1 & 0,0213 & 0,0209 & 0,0208 & 0,0215 & 0,0211 & 0,0210 \\
\hline 2 & 0,0209 & 0,0214 & 0,0209 & 0,0211 & 0,0215 & 0,0211 \\
\hline
\end{tabular}


Tabela 3.3 - Offsets utilizados para compensação no cálculo da tensão.

\begin{tabular}{|c|c|c|c|}
\hline \multirow{2}{*}{ Protótipo } & \multicolumn{3}{|c|}{ Offsets } \\
\cline { 2 - 4 } & Fase A & Fase B & Fase C \\
\hline 1 & -656 & -656 & -679 \\
\hline 2 & 825 & 706 & 774 \\
\hline
\end{tabular}

Como citado na Seção 3.4 por meio da Expressão numérica 3.4, o valor de $498 \mathrm{mV}$ na entrada do conversor A/D equivale a uma corrente de pico 200 A. Desta forma, usando uma simples regra de três chega-se a conclusão que $500 \mathrm{mV}$ equivalem a uma corrente de 200,803 A. A Figura 3.20 mostra que $500 \mathrm{mV}$ equivalem a 2642412 unidades de amostragem. Assim, 1 mA equivale a 13,16 unidades de conversão, como mostrado na Expressão numérica (3.10).

$$
\frac{2642412 \text { unidades }}{200803 m A}=13,16 \text { unidades } / m A
$$

Os resistores $R_{B}$ utilizados na conversão da corrente na entrada dos conversores $\mathrm{A} / \mathrm{D}$ também podem apresentar variações em sua precisão, sendo necessário assim realizar novamente uma calibração individualizada por canal (Tabela 3.4) com uma carga que apresente uma corrente estável e previamente conhecida para encontrar o valor correto para conversão do valor da amostra em miliamperes. Porém não ocorre a presença de offsets para os canais de corrente devido à ação de um filtro passa-alta presente nestes canais.

Tabela 3.4 - Relações de conversão utilizadas para o cálculo da corrente.

\begin{tabular}{|c|c|c|c|}
\hline \multirow{2}{*}{ Protótipo } & \multicolumn{3}{|c|}{ Relações de conversão (unidades/mA) } \\
\cline { 2 - 4 } & Fase A & Fase B & Fase C \\
\hline 1 & 14,1306 & 13,8719 & 13,9434 \\
\hline 2 & 13,9674 & 13,7565 & 13,8513 \\
\hline
\end{tabular}

Para cada amostra normalizada são calculadas as Equações (3.11) e (3.12) mostradas a seguir, que posteriormente serão utilizadas para calcular a DFT (Transformada Discreta de Fourier) do sinal para a frequência fundamental (AGOSTINI, 2006):

$$
\begin{aligned}
& X r=X r+\left(X_{k} \cos \left(k \frac{2 \pi}{N}\right)\right) \\
& X i=X i+\left(X_{k} \operatorname{sen}\left(k \frac{2 \pi}{N}\right)\right)
\end{aligned}
$$

onde $X_{k}$ é o valor da amostra, $k$ é o número da amostra, $N$ é a quantidade total de amostras que compreende o período de um sinal, $X r$ é o somatório de amostras multiplicadas por cosseno e $X i$ é o somatório de amostras multiplicadas por seno. 
É realizada a leitura de uma quantidade de amostras que equivalem à duração de um período de um sinal. Como as frequências da rede elétrica são padronizadas em $50 \mathrm{~Hz}$ e $60 \mathrm{~Hz}$, os períodos dos sinais de tensão e corrente são respectivamente $20 \mathrm{~ms}$ e 16,67 ms. Como a frequência de amostragem selecionada é de 3250 amostras por segundo, são necessárias respectivamente 65 e 54 amostras para compreender o período dos sinais. É importante ressaltar que essa quantidade de amostras é selecionada automaticamente pela Unidade de Medição Fasorial Otimizada após medir a frequência dos canais de tensão. Qualquer frequência de amostragem superior a 720 amostras por segundo pode ser utilizada para calcular a DFT do sinal para a frequência fundamental (AGOSTINI, 2006).

A DFT foi escolhida para a realização do cálculo fasorial devido sua menor necessidade de processamento quando comparado a outros algoritmos baseados em aproximação sensitiva.

Foi verificado, com a inserção de marcadores no firmware do equipamento e o auxílio de um osciloscópio, que as Equações (3.11) e (3.12) citadas anteriormente consomem cerca de $200 \mu$ s de tempo de processamento do microcontrolador funcionando com uma frequência de operação de $80 \mathrm{MHz}$. Assim, a escolha da frequência de amostragem de 3250 amostras por segundo gera um espaço de tempo entre amostras igual a $1 / 3250 \approx 308 \mu \mathrm{s}$, o que permite ao microcontrolador fazer a leitura do valor de uma amostra e em seguida já calcular as operações matemáticas citadas anteriormente para esta amostra, antes de realizar a leitura do valor da próxima amostra.

Se fosse selecionada uma frequência de amostragem maior, como exemplo a de 6510 amostras por segundo, não seria possível o microcontrolador realizar as operações matemáticas citadas anteriormente entre as amostras.

Após a aquisição do total de amostras que compreendem o período do sinal tanto de tensão ou de corrente, são realizadas as operações abaixo para calcular o módulo e o ângulo de fase do sinal para a frequência fundamental (AGOSTINI, 2006):

$$
\begin{gathered}
X=\sqrt{\left(\frac{\sqrt{2}}{N} X r\right)^{2}+\left(\frac{\sqrt{2}}{N} X i\right)^{2}} \\
\phi=-\arctan \left(\frac{X i}{X r}\right)
\end{gathered}
$$

As Equações (3.13) e (3.14) juntas consomem cerca de $150 \mu$ s de tempo de processamento do microcontrolador. É importante ressaltar também que quando ocorre no circuito integrado ADE7758 a seleção do canal de tensão ou corrente no qual o sinal será amostrado, as primeiras quatro amostras são desprezadas devido à instabilidade do canal após 
o chaveamento. Desta forma, o cálculo fasorial do sinal presente em cada canal possui a duração de tempo calculada por meio da Equação (3.15), onde foi considerado o número de amostras relacionado à frequência de $50 \mathrm{~Hz}$.

$$
\begin{aligned}
& T=\left(\mathrm{N}^{\mathrm{o}} \text { de amostras do período } / \text { freq. de amostragem }\right)+\text { cálculo do módulo e ângulo } \\
& T=((4 \text { amostras desprezadas }+65 \text { amostras }) / 3250)+150 \mu \mathrm{s} \\
& T=21230 \mu \mathrm{s}+150 \mu \mathrm{s}=21380 \mu \mathrm{s} \approx 21,4 \mathrm{~ms}
\end{aligned}
$$

Para a frequência de $60 \mathrm{~Hz}$, a duração de tempo do cálculo fasorial é próxima de $18 \mathrm{~ms}$.

\subsubsection{Cálculo da frequência, da tensão e corrente RMS e das potências}

Além do cálculo dos fasores, também são calculadas na baixa tensão as frequências das fases, tensões e correntes RMS e as potências ativas, reativas e aparentes para cada fase, sendo que essas grandezas serão posteriormente utilizadas pela Unidade de Medição Fasorial Otimizada em um sistema fuzzy para identificar e estimar os parâmetros elétricos da causa (rede de distribuição ou carga) de distúrbios nas medições realizadas.

O cálculo das frequências deve ser realizado de forma sequencial, onde primeiramente por meio do registrador $M M O D E$ (byte de comando 0x14) é selecionada a fase para a qual será calculada a frequência e posteriormente deve-se aguardar ao menos quatro períodos deste sinal para se obter um valor atualizado (ANALOG DEVICES, 2011). Assim, para o caso de uma fase com frequência de $50 \mathrm{~Hz}$, é necessário aguardar pelo menos $80 \mathrm{~ms}$ para se realizar a leitura. Para o caso de uma frequência de $60 \mathrm{~Hz}$ são necessários 66,67 ms.

Desta forma, após a fase ser selecionada para o cálculo da frequência, são aguardadas quatro interrupções geradas pelo periférico TIMER2 (mais detalhes no item 3.5.5), sendo que a soma destas interrupções totaliza $88 \mathrm{~ms}$ e garante a consistência do valor medido. Este valor é posteriormente disponibilizado no registrador $F R E Q$ (byte de comando 0x10), o qual é igual a 960 para uma frequência de $60 \mathrm{~Hz}$ e 800 para uma frequência de $50 \mathrm{~Hz}$ (ANALOG DEVICES, 2011). Após a medição da frequência para uma das fases, todo o processo é repetido novamente para as outras duas fases.

Os valores de tensão RMS para a frequência fundamental para cada fase são disponibilizados individualmente nos registradores $A V R M S$ (byte de comando 0x0D), BVRMS (byte de comando 0x0E) e CVRMS (byte de comando 0x0F). Porém, para que seja computado um valor de tensão RMS estável é recomendado realizar a leitura de cada um destes 
registradores de forma sincronizada com o término do ciclo de onda (valor de tensão igual a 0 V) de cada uma das fases, o qual é possível por meio do monitoramento da interrupção gerada pelo pino $I R Q$, programado para esta finalidade por meio do registrador MASK (byte de comando 0x18).

A faixa de valores obtidos por meio dos registradores AVRMS, BVRMS e CVRMS varia entre 0 e o valor máximo 1639101 unidades (ANALOG DEVICES, 2011), sendo que este último corresponde ao valor RMS para uma forma de onda senoidal com tensão de pico igual a 500,5 V(comentado anteriormente na Seção 3.4) e frequência de $60 \mathrm{~Hz}$. Nas mesmas condições, mas para a frequência de $50 \mathrm{~Hz}$, o valor máximo é igual a 1651972 unidades.

Assim, $1 \mathrm{mV}_{\mathrm{RMS}}$ equivale a 4,631 unidades de conversão para um sinal senoidal com frequência de $60 \mathrm{~Hz}$, como mostrado na Expressão numérica (3.16).

$$
\frac{1639101 \text { unidades }}{\frac{500500 m V}{\sqrt{2}}}=\frac{1639101 \text { unidades }}{353907 m V_{R M S}}=4,631 \text { unidades } / \mathrm{m} V_{R M S}
$$

Como citado na Subseção 3.5.3, é importante ressaltar que devido às imprecisões existentes em resistores com valores elevados, presentes nos divisores resistivos, é necessário realizar uma calibração individualizada por canal com o auxílio de um multímetro para encontrar o valor correto para conversão do valor da amostra em mV $\mathrm{RMS}_{\mathrm{RMS}}$ (Tabela 3.5).

Tabela 3.5 - Relações de conversão utilizadas para o cálculo da tensão RMS.

\begin{tabular}{|c|c|c|c|c|c|c|}
\hline \multirow[t]{2}{*}{ Protótipo } & \multicolumn{3}{|c|}{$\begin{array}{c}\text { Relações de conversão } \\
\text { (unidades } / \mathrm{mV}_{\mathrm{RMS}} \text { ) para } 60 \mathrm{~Hz}\end{array}$} & \multicolumn{3}{|c|}{$\begin{array}{c}\text { Relações de conversão } \\
\text { (unidades } / \mathrm{mV}_{\mathrm{RMS}} \text { ) para } 50 \mathrm{~Hz}\end{array}$} \\
\hline & Fase A & Fase B & Fase C & Fase A & Fase B & Fase C \\
\hline 1 & 4,6869 & 4,6506 & 4,6139 & 4,7244 & 4,6878 & 4,6508 \\
\hline 2 & 4,6278 & 4,7515 & 4,6527 & 4,6648 & 4,7895 & 4,6899 \\
\hline
\end{tabular}

Pode ocorrer a presença de offsets no cálculo da tensão RMS, devido a ruídos na entrada do ADE7758 e offsets presentes nas amostras utilizadas para realizar o cálculo RMS. Os offsets na tensão RMS em cada fase podem ser compensados por meio dos registradores AVRMSOS (byte de comando 0x33), BVRMSOS (byte de comando 0x34) e CVRMSOS (byte de comando 0x35), onde o valor a ser carregado nestes registradores pode ser obtido por meio da Equação (3.17) (ANALOG DEVICES, 2011).

$$
V R M S=V R M S_{0}+(V R M S O S \cdot 64)
$$

onde $V R M S$ é o valor esperado e $V R M S_{0}$ é o valor medido. 
Para a compensação dos offsets, os registradores AVRMSOS, BVRMSOS e CVRMSOS foram carregados com os valores presentes na Tabela 3.6. Os offsets presentes na tensão RMS impactam também o cálculo da potência aparente, sendo importante desta forma a compensação destes offsets.

Tabela 3.6 - Offsets utilizados para compensação no cálculo da tensão RMS.

\begin{tabular}{|c|c|c|c|}
\hline \multirow{2}{*}{ Protótipo } & \multicolumn{3}{|c|}{ Offsets } \\
\cline { 2 - 4 } & Fase A & Fase B & Fase C \\
\hline 1 & -534 & -482 & -508 \\
\hline 2 & -580 & -485 & -528 \\
\hline
\end{tabular}

De forma semelhante à obtenção das tensões RMS, os valores da corrente RMS para a frequência fundamental para cada fase são disponibilizados individualmente nos registradores AIRMS (byte de comando 0x0A), BIRMS (byte de comando 0x0B) e CIRMS (byte de comando 0x0C), sendo novamente necessário realizar a leitura de cada um destes registradores de forma sincronizada com o término do ciclo de onda de cada uma das fases.

A faixa de valores obtidos por meio dos registradores AIRMS, BIRMS e CIRMS varia entre 0 e o valor máximo 1914753 unidades (ANALOG DEVICES, 2011), sendo que este último corresponde ao valor RMS para uma forma de onda senoidal com corrente de pico igual a 200,803 A (comentado anteriormente na Subseção 3.5.3). Desta forma, $1 \mathrm{~mA}_{\mathrm{RMS}}$ equivale a 13,485 unidades de conversão, como mostrado na Expressão numérica (3.18).

$$
\frac{1914753 \text { unidades }}{\frac{200803 m A}{\sqrt{2}}}=\frac{1914753 \text { unidades }}{141989 m A_{R M S}}=13,485 \text { unidades } / m A_{R M S}
$$

Como citado na Subseção 3.5.3, é importante ressaltar que os resistores $R B$ utilizados na conversão da corrente na entrada dos conversores A/D também podem apresentar variações em sua precisão sendo necessário assim realizar uma calibração individualizada por canal, com o auxílio de instrumentação adequada, para encontrar o valor correto para conversão do

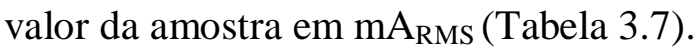

Tabela 3.7 - Relações de conversão utilizadas para o cálculo da corrente RMS.

\begin{tabular}{|c|c|c|c|}
\hline \multirow{2}{*}{ Protótipo } & \multicolumn{4}{|c|}{ Relações de conversão (unidades/mA) } \\
\cline { 2 - 4 } & Fase A & Fase B & Fase C \\
\hline 1 & 14,1306 & 13,8719 & 13,9434 \\
\hline 2 & 13,9674 & 13,7565 & 13,8513 \\
\hline
\end{tabular}

Também pode ocorrer a presença de offsets no cálculo da corrente RMS, devido a ruídos na entrada do ADE7758 que são integrados no componente DC da corrente durante o 
processo do cálculo RMS (ANALOG DEVICES, 2011). Os offsets na corrente RMS podem ser compensados por meio dos registradores AIRMSOS (byte de comando 0x36), BIRMSOS (byte de comando 0x37) e CIRMSOS (byte de comando 0x38), onde o valor a ser carregado nestes registradores pode ser obtido por meio da Equação (3.19) (ANALOG DEVICES, 2011).

$$
I R M S=\sqrt{\operatorname{IRMS}_{0}^{2}+(\operatorname{IRMSOS} \cdot 16384)}
$$

onde IRMS é o valor esperado e $I R M S_{0}$ é o valor medido.

Para a compensação dos offsets foram carregados respectivamente nos registradores AIRMSOS, BIRMSOS e CIRMSOS os valores apresentados na Tabela 3.8. Da mesma forma que os offsets presentes na tensão RMS, os offsets presentes na corrente RMS impactam o cálculo da potência aparente, sendo importante desta forma a compensação destes offsets.

Tabela 3.8 - Offsets utilizados para compensação no cálculo da corrente RMS.

\begin{tabular}{|c|c|c|c|}
\hline \multirow{2}{*}{ Protótipo } & \multicolumn{3}{|c|}{ Offsets } \\
\cline { 2 - 4 } & Fase A & Fase B & Fase C \\
\hline 1 & -79 & -127 & -159 \\
\hline 2 & -82 & -120 & -156 \\
\hline
\end{tabular}

A potência ativa para a frequência fundamental em cada fase é obtida pelo circuito integrado ADE7758 por meio da média da potência instantânea $p(t)$, o qual por sua vez é o resultado da multiplicação dos sinais de tensão e a corrente, como mostrado na Equação (3.20) (ANALOG DEVICES, 2011).

$$
p(t)=v(t) i(t)
$$

A medida potência instantânea $(p(t))$, equivalente à potência ativa, é igual ao produto entre a tensão $(v(t))$ e corrente $\operatorname{RMS}(i(t))$ e extraída por meio de um filtro passa-baixa presente no ADE7758. Os valores das potências ativas em cada fase são acumulados nos registradores AWATTHR (byte de comando 0x01), BWATTHR (byte de comando 0x02) e CWATTHR (byte de comando 0x03).

O acúmulo da potência ativa nestes registradores pode chegar ao valor máximo de 32767 unidades. Esse valor máximo acumulado é atingido em 680 ms quando está sendo calculada a potência para sinais senoidais de tensão com amplitude de 500,5 V e de corrente com amplitude de 200,083 A. 
Se for programado o valor 2047 em um dos registradores de ganho de potência ( $A W G$, $B W G$ ou $C W G$ ), o valor máximo acumulado de 32767 unidades será atingido em 340 ms para a fase respectiva ao registrador programado. Já se for programado o valor 2048, o valor máximo acumulado levará 1020 ms para ser atingido (ANALOG DEVICES, 2011).

Entre os dois módulos de acúmulo de potência ativa existentes no ADE7758, contagem de tempo ou quantidade de meio-ciclos de onda, foi utilizado este último já que o período em que ocorre o acúmulo de potência ativa para todas as fases é sincronizado com a duração de uma quantidade fixa de meio-ciclo de onda para uma determinada fase. Do outro modo, é necessário gerenciar no firmware o tempo decorrido entre o início e o fim do acúmulo da potência ativa, o que é mais suscetível à ocorrência de erros.

A quantidade de meio-ciclos de onda a serem considerados para o acúmulo da potência ativa, a qual deve ser carregada no registrador LINECYC (byte de comando 0x1C), deve ser pequena para que não sejam computadas grandes variações na potência. Por outro lado, uma pequena quantidade de meio-ciclos de onda irá acumular poucas unidades de potência ativa, o que impacta diretamente na resolução dos valores convertidos posteriormente em watts, cuja relação pode ser obtida por meio da Expressão numérica (3.21).

$$
\frac{\text { unidades_de_potência_ativa }}{W}=\text { unidades } / W
$$

Os exemplos a seguir auxiliam no entendimento da Expessão 3.21. No primeiro exemplo, para a medição da potência ativa na fase A, a qual está ligada em uma carga puramente resistiva, foram medidos $\mathrm{V}_{\mathrm{RMS}}=127,2 \mathrm{~V}$ e $\mathrm{I}_{\mathrm{RMS}}=1,198 \mathrm{~A}$. Considerando o registrador $A W G$ com valor igual a 2047, foram acumulados 39 unidades de potência ativa considerando 15 meio-ciclos de onda. Assim, por meio da Expressão numérica (3.21) é obtida a seguinte relação de conversão:

$$
\frac{39}{127,2 \cdot 1,198}=0,2559 \text { unidades } / W
$$

Isso significa que uma unidade de potência ativa equivale 3,9073 W, resolução esta que pode comprometer uma análise posterior para pequenas variações de potências, as quais serão utilizadas no sistema fuzzy para identificar a causa de distúrbios.

No próximo exemplo, permanecendo os mesmos valores para $\mathrm{V}_{\mathrm{RMS}}$, $\mathrm{I}_{\mathrm{RMS}}$ e AWG, foram acumuladas 152 unidades de potência ativa para uma quantidade de meio-ciclos elevada para 59. Utilizando a Expressão numérica (3.21) é obtida a relação de conversão: 


$$
\frac{152}{127,2 \cdot 1,198}=0,9974 \text { unidades } / W
$$

Com o aumento do número de meio-ciclos para o acúmulo de unidade de potência ativa houve diretamente uma melhora na resolução das medidas, onde para o caso ilustrado neste exemplo uma unidade de potência equivale a 1,0025 W.

Esta quantidade de 59 meio-ciclos de onda, cuja duração de processamento é igual a 492 ms, foi escolhida para Unidade de Medição Fasorial Otimizada já que garante a resolução necessária para as análises realizadas pelo sistema fuzzy sem comprometer seu desempenho, como será apresentado posteriormente no Capítulo 4.

Novamente, como citado anteriormente nesta seção, devido a variações presentes nos resistores $R B$ utilizados nos canais de corrente e nos resistores que formam os divisores resistivos utilizados nos canais de tensão, é necessário assim realizar uma calibração individualizada, com o auxílio de multímetros e uma carga puramente resistiva, para encontrar o valor correto para conversão do valor da amostra em Watts (Tabela 3.9).

Tabela 3.9 - Relações de conversão utilizadas para o cálculo da potência ativa.

\begin{tabular}{|c|c|c|c|}
\hline \multirow{2}{*}{ Protótipo } & \multicolumn{4}{|c|}{ Relações de conversão (unidades/W) } \\
\cline { 2 - 4 } & Fase A & Fase B & Fase C \\
\hline 1 & 1,0171 & 1,0011 & 0,9943 \\
\hline 2 & 0,9920 & 1,0068 & 0,9927 \\
\hline
\end{tabular}

Também no cálculo da potência ativa pode existir um offset devido a características construtivas presentes na placa de circuito impresso que abriga o circuito integrado ADE7758. A compensação do offset nos canais A, B e C pode ser realizada respectivamente por meio dos registradores AWATTOS(byte de comando 0x39), BWATTOS(byte de comando 0x3A) e CWATTOS(byte de comando 0x3B), os quais podem ter valores entre 2047 e -2047.

A compensação do offset permite que a quantidade de unidades de potência ativa seja mantida em zero quando nenhuma potência é consumida. Utilizando este método, os valores carregados nos registradores AWATTOS, BWATTOS e CWATTOS são iguais a zero.

A potência aparente $(S)$ para a frequência fundamental em cada fase é obtida pelo circuito integrado ADE7758 por meio do produto dos valores de tensão e corrente RMS calculados pelo próprio circuito, como mostrado na Equação (3.24) (ANALOG DEVICES, 2011).

$$
S=V_{R M S} I_{R M S}
$$


Os valores das potências aparentes em cada fase são acumulados nos registradores $A V A H R$ (byte de comando 0x07), BVAHR (byte de comando 0x08) e CVAHR (byte de comando 0x09). Os registradores de ganho para potência reativa $A V A G$ (byte de comando 0x30), BVAG (byte de comando 0x31) e CVAG (byte de comando 0x32) possuem características idênticas aos seus equivalentes para a potência ativa, tão bem quanto os métodos para o acúmulo de potência (contagem de tempo ou quantidade de meio-ciclo).

Desta forma, considerando os registradores $A V A G, B V A G$ e $C V A G$ configurados com valor igual a 2047 e a quantidade de meio-ciclos de onda igual a 59, a qual foi definida anteriormente para o cálculo da potência ativa, foram obtidas para as fases A, B e C as relações de conversão apresentadas na Tabela 3.10. Novamente foram levadas em consideração as variações presentes nos resistores $R B$ utilizados nos canais de corrente e nos resistores que formam os divisores resistivos utilizados nos canais de tensão.

Tabela 3.10 - Relações de conversão utilizadas para o cálculo da potência aparente.

\begin{tabular}{|c|c|c|c|}
\hline \multirow{2}{*}{ Protótipo } & \multicolumn{3}{|c|}{ Relações de conversão (unidades/VA) } \\
\cline { 2 - 4 } & Fase A & Fase B & Fase C \\
\hline 1 & 0,9740 & 09616 & 0,9542 \\
\hline 2 & 0,9561 & 0,9731 & 0,9575 \\
\hline
\end{tabular}

A compensação de offsets na medição da potência aparente em cada fase deve ser realizada por meio da compensação de offsets para a tensão e corrente RMS, as quais foram mostradas anteriormente nesta seção.

Para o cálculo da potência reativa para a frequência fundamental em cada fase foi utilizado o método vetorial baseado no triângulo de potências (Figura 3.22), onde a potência aparente $(S)$ é definida como a amplitude do vetor soma das potências ativa $(P)$ e reativa $(Q)$.

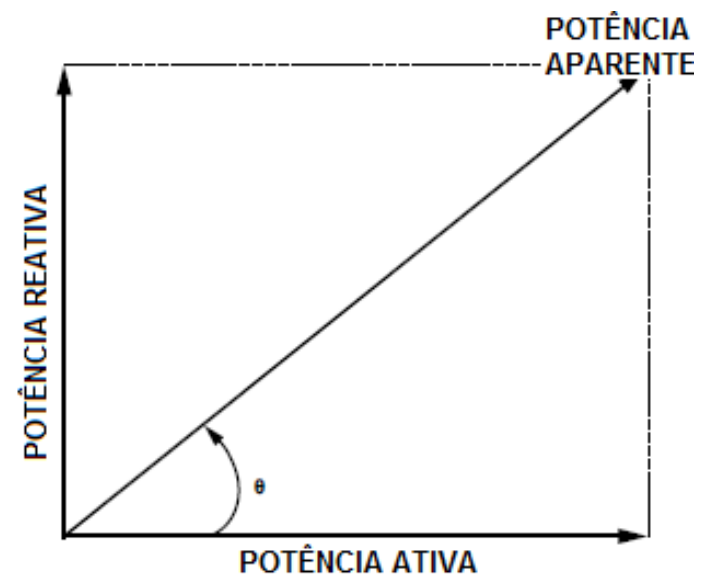

Figura 3.22 - Triângulo de potências (adaptado de ANALOG DEVICES, 2011). 
Assim, por meio da Equação (3.25) o módulo da potência reativa pode ser calculado para cada fase.

$$
Q=\sqrt{S^{2}-P^{2}}
$$

O bit mais significativo (byte 15) presente nos registradores AVARHR (byte de comando 0x04), BVARHR (byte de comando 0x05) e CVARHR (byte de comando 0x06) sinaliza a potência reativa para cada fase, sendo ' 1 ' para negativa e ' 0 ' para positiva.

\subsubsection{Inteface com o módulo GPS e temporização das atividades}

Como citado na Seção 3.3, o módulo GPS gera um pulso de tensão sincronizado via satélite com o fuso horário de referência UTC. No momento em que este pulso ocorre no pino RE08 do microcontrolador PIC32MX795F512L é gerada uma interrupção externa, que no caso deste projeto é a interrupção externa INT1 (MICROCHIP TECHNOLOGY INCORPORATED, 2012a). Dentro deste vetor de interrupção externa, o microcontrolador utiliza para este projeto o canal de comunicação serial assíncrono UART1 configurado em 57000 bps e no padrão 8 bits com um stop bit (MICROCHIP TECHNOLOGY INCORPORATED, 2012b), visando obter o pacote de dados $R M C$ que é sempre disponibilizado pelo módulo GPS logo após a geração do pulso de tensão sincronizado.

É importante ressaltar que a aquisição do pacote $R M C$ pelo microcontrolador ocorre somente quando a Unidade de Medição Fasorial Otimizada é energizada ou quando essa tarefa é eventualmente solicitada para atualizar o relógio em tempo real do sistema (isto será comentado em detalhes na Subseção 3.5.6). Esta metodologia foi adotada para evitar a perda na sincronização da medição e cálculo dos fasores com o pulso gerado pelo módulo GPS, já que para receber utilizando uma taxa de comunicação de 57600 bps os 59 caracteres presentes no pacote $R M C$, sendo que cada caractere (oito bits) também é acompanhado de um start bit e de um stop bit, seria gasto um tempo total igual a 590/57600 =20,24 ms.

Com exceção às situações comentadas anteriormente, o equipamento proposto neste trabalho realiza imediatamente após a detecção do pulso gerado pelo módulo GPS, em seu vetor de interrupção externa, o reinício do circuito integrado ADE7758 e a coleta da data e hora fornecidas pelo relógio em tempo real.

O reinício do circuito integrado ADE7758 logo após o pulso gerado pelo módulo GPS garante que o processo de amostragem para o cálculo dos fasores de tensão e corrente ocorra 
de forma sincronizada em diferentes unidades de medição fasorial, fator esse que garantirá o atendimento a importantes requisitos, tais como a estimação linear de estados e o gerenciamento de perdas.

O cálculo fasorial dos canais de tensão, dos canais de corrente e o cálculo das demais grandezas elétricas ocorre sequencialmente em períodos de tempo de $22 \mathrm{~ms}$ utilizando para isto o periférico TIMER2 do microcontrolador (MICROCHIP TECHNOLOGY INCORPORATED, 2010a). Desta forma, a cada $22 \mathrm{~ms}$ após a detecção do pulso gerado pelo módulo GPS o periférico TIMER2 gera uma interrupção externa onde as tarefas posteriores ao reinício do circuito integrado ADE7758 e a coleta de data e hora são executadas uma de cada vez, como mostrado na Figura 3.23.

A temporização das atividades em padrões fixos de tempo, com exceção da atividade “Conexão Ethernet e transmissão de dados solicitados" que será discutida na Subseção 3.5.7, visa garantir que as medições e cálculos ocorram nos mesmos instantes de tempo em diferentes Unidades de Medição Fasorial Otimizada.

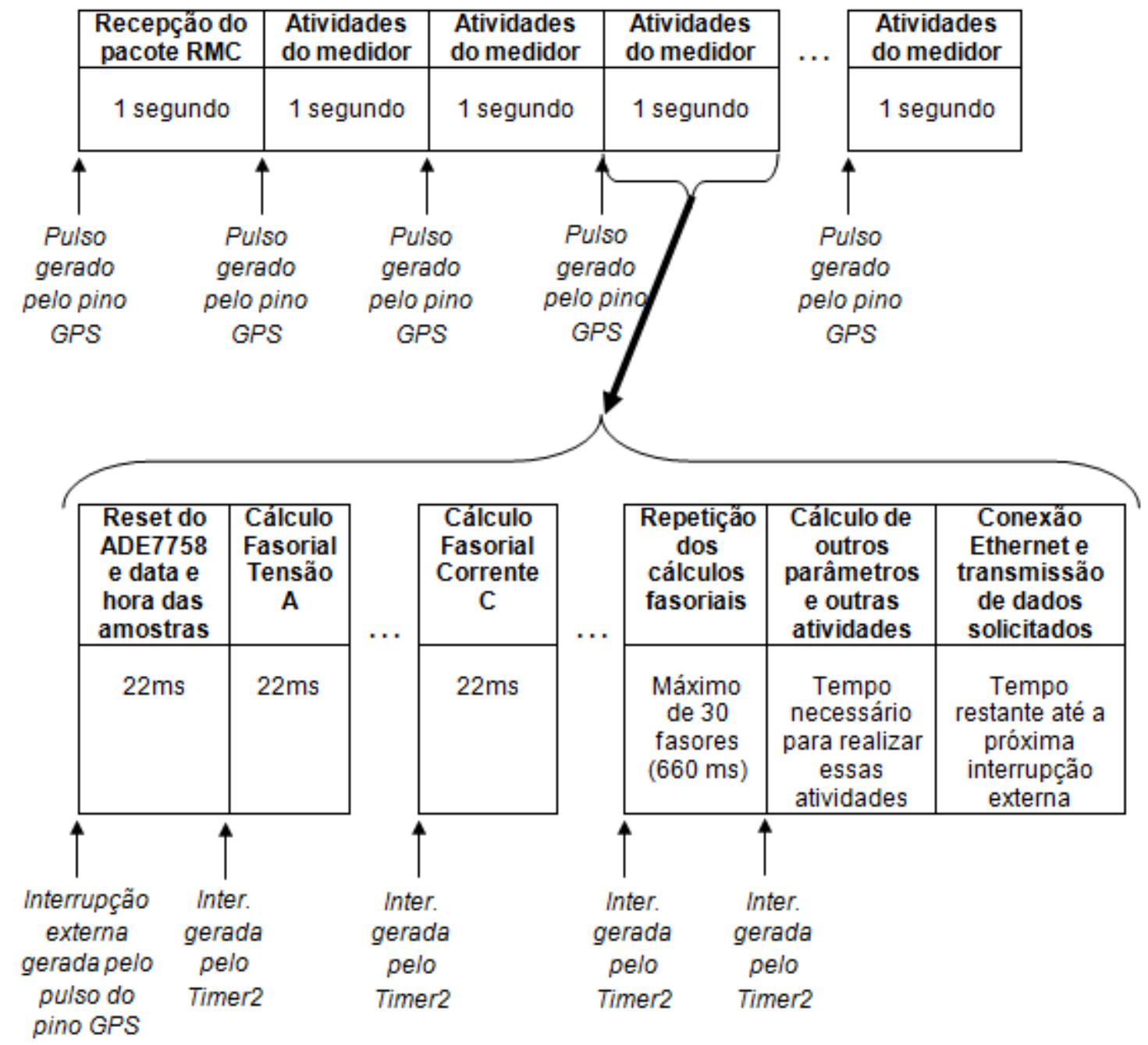

Figura 3.23 - Temporização das atividades realizadas pelo mirocontrolador. 
O período de tempo escolhido de $22 \mathrm{~ms}$ foi baseado no tempo de processamento necessário para o cálculo fasorial dos canais para a frequência de $50 \mathrm{~Hz}$, próximo a 21,4 ms, acrescido de uma margem de segurança de 600 us. O cálculo de no máximo de 30 sincrofasores visa garantir a integridade operacional das outras atividades a serem realizadas em um tempo restante de $340 \mathrm{~ms}$, tais como o cálculo das outras grandezas (frequência, tensão e corrente RMS e potências), o funcionamento do sistema fuzzy para identificar a causa de distúrbios nas medições realizadas e a posterior estimação dos parâmetros elétricos desta causa, a reflexão das medições realizadas para a média tensão quando necessário e transmissão de informações por meio da conexão Ethernet.

É importante destacar que entre sincrofasores para a mesma grandeza e fase, como exemplo, os sincrofasores de tensão para a fase A, decorre um espaço temporal igual a $132 \mathrm{~ms}$.

A disponibilidade máxima de 30 sincrofasores por segundo pela Unidade de Medição Fasorial, parâmetro configurável (Quantidade de fasores a cada amostragem) citado na Tabela 5.5 do Capítulo 5, está enquadrada entre as taxas que devem ser utilizados por PMUs de acordo com a norma estabelecido em IEEE (2005), como mostrado na Tabela 3.11.

Tabela 3.11 - Taxas de informações exigidas para um PMU (adaptado de IEEE, 2005).

\begin{tabular}{|c|c|c|c|c|c|c|c|c|c|}
\hline \multirow{2}{*}{$\begin{array}{l}\text { Frequência do Sistema } \\
\text { Taxas de informação (Fs - fasores por } \\
\text { segundo) }\end{array}$} & \multicolumn{3}{|c|}{$50 \mathrm{~Hz}$} & \multicolumn{6}{|c|}{$60 \mathrm{~Hz}$} \\
\hline & 10 & 25 & 50 & 10 & 12 & 15 & 20 & 30 & 60 \\
\hline
\end{tabular}

\subsubsection{Relógio em tempo real}

O periférico relógio em tempo em real presente no microcontrolador PIC32MX795F512L é temporizado por um cristal exclusivo com frequência de $32768 \mathrm{~Hz}$ e disponibiliza para consulta um calendário completo com dia da semana, dia, mês, ano e um relógio com horas, minutos e segundos com erro aproximado de $\pm 0,66$ segundos por mês (MICROCHIP TECHNOLOGY INCORPORATED, 2010b).

Como citado anteriormente na Subseção 3.5.3, logo após o equipamento ser energizado e conseguir receber um pacote $R M C$ do módulo GPS, o relógio em tempo real é atualizado e a data e hora disponibilizado por este acompanha as informações relacionadas aos cálculos fasoriais e de outras grandezas que posteriormente são transmitidas via ethernet (mais detalhes na Subseção 3.5.7). Por causa do erro pré-existente, uma vez por dia, sempre à meia noite (horário este presente indicado pelo próprio relógio em tempo real), o mesmo é 
novamente atualizado por meio da aquisição do pacote $R M C$, visando garantir a integridade desta informação sem impactar de forma brusca o funcionamento da Unidade de Medição Sincronizada Otimizada para Sistemas de Distribuição.

Ainda para garantir que o erro não seja superior a $\pm 0,66$ segundos por mês, foi verificado utilizando-se um osciloscópio a variação da frequência do cristal em relação ao valor esperado $(32768 \mathrm{~Hz})$. Essa diferença foi convertida em um valor relacionado ao número de pulsos de clock errados por minuto, obtido por meio da Expressão matemática (3.26):

(Frequência ideal (32758) - Frequência medida) $\cdot 60=$ pulsoserrados por minuto (3.26)

Esse número de pulsos de clock errados por minuto deve ser armazenado no registrador RTCCON. Com isso, automaticamente a cada minuto o relógio em tempo real será compensado com este valor (MICROCHIP TECHNOLOGY INCORPORATED, 2010b).

\subsubsection{Interface de controle Ethernet}

O microcontrolador PIC32MX795F512L possui como periférico uma interface para Controle de Acesso Ethernet (MAC) de 10/100 Mbps. Utilizando-se o MAC juntamente com um transceiver $(P H Y)$, um transformador de acoplamento e um conector RJ45 pode-se estabelecer uma conexão física Ethernet (DILIGENT INCORPORATED, 2013). O kit de

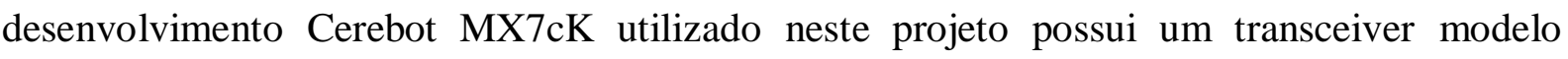
LAN8720 fabricado pela empresa SMSC Corporation (SMSC, 2012) e um conector RJ45 com transformador de acoplamento integrado.

$\mathrm{O}$ Endereço $M A C$, endereço físico único de um equipamento associado à interface de comunicação e usado para controle de acesso em redes de computadores (TORRES, 2009), é programado pela MICROCHIP para cada microcontrolador PIC32MX795F512L (MICROCHIP TECHNOLOGY INCORPORATED, 2013b).

Para se comunicar em uma rede Ethernet, o microcontrolador PIC32MX795F512L deve executar uma pilha de protocolos. Neste projeto está sendo utilizada a pilha TCP/IP disponibilizada gratuitamente pelo próprio fabricante Microchip e nomeada como "Microchip TCP/IP Stack" (MICROCHIP TECHNOLOGY INCORPORATED, 2008b). Esta pilha oferece interface lógica com o transceiver LAN8720 e uma infinidade de protocolos ilustrados na Figura 3.24 e relacionados a cada camada de uma comunicação Ethernet padrão. 
No Capítulo 5 são apresentados de forma detalhada a comunicação Ethernet, a utilização do protocolo DNP3 e o formato das mensagens de comunicação utilizados na Unidade de Medição Fasorial Otimizada.

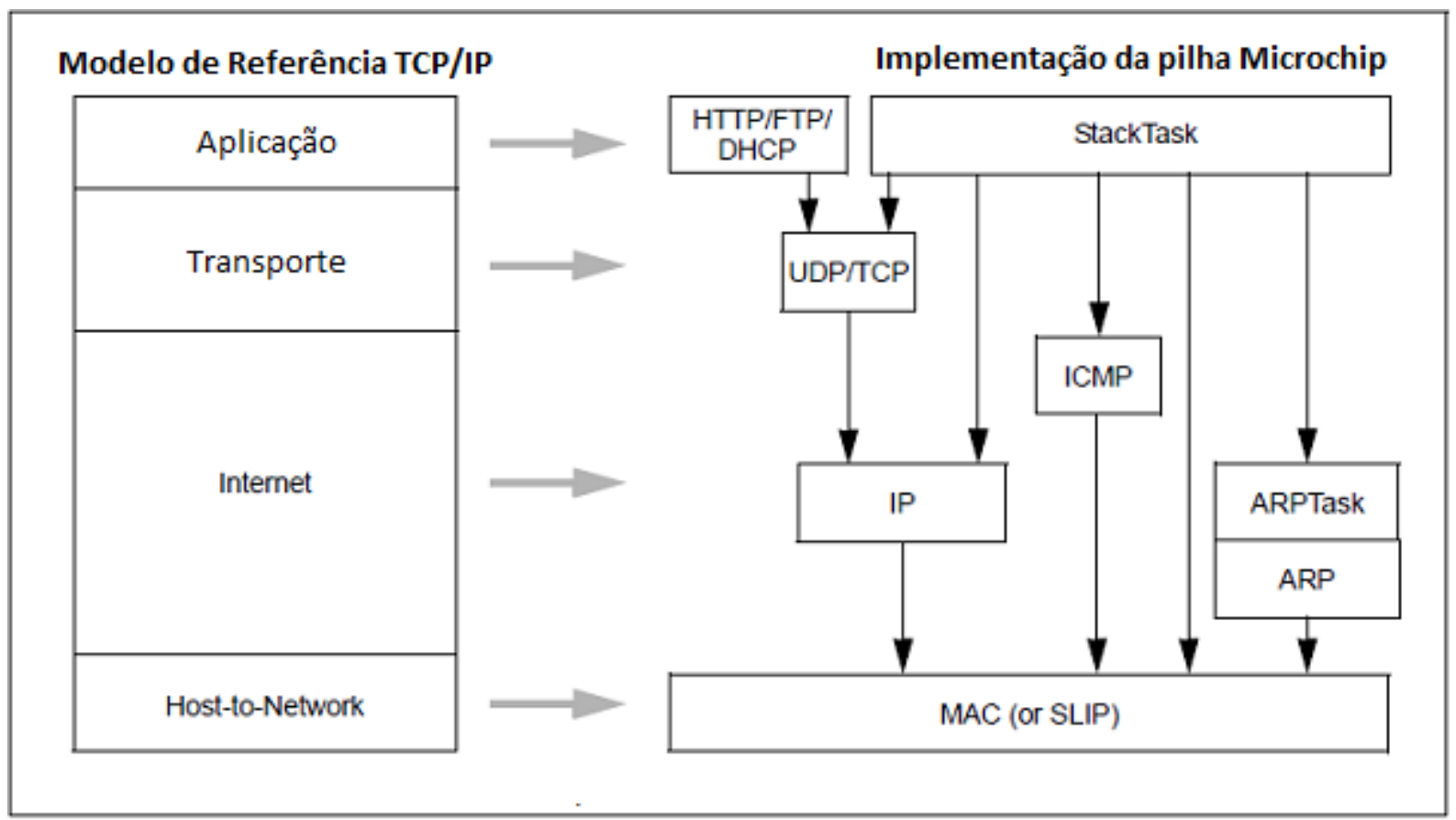

Figura 3.24 - Protocolos disponíveis na Microchip TCP/IP Stack(adaptado de MICROCHIP,2008). 


\subsection{MODELAGEM ELÉTRICA DO TRANSFORMADOR DE DISTRIBUIÇÃO}

Visando refletir nos terminais primários do transformador as correntes e tensões fasoriais calculadas pela $P M U$ nos terminais secundários (baixa tensão) do mesmo, optou-se em utilizar para cada fase o circuito equivalente de um transformador real com impedância referida ao primário.

A Figura 3.25 ilustra o esquema do transformador real monofásico com seus componentes (CAPARÓ, 2005).

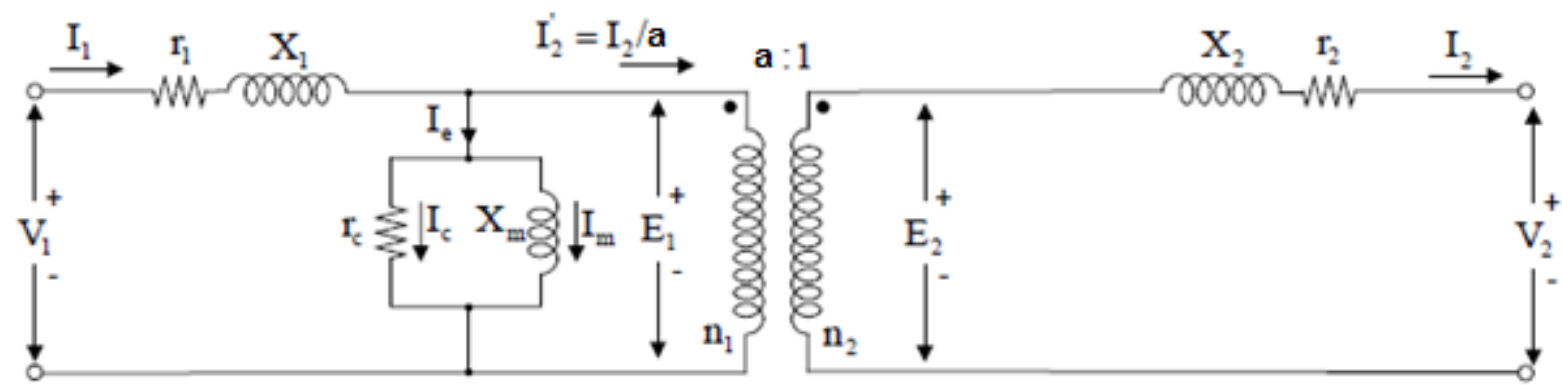

Figura 3.25 - Circuito de um transformador real monofásico.

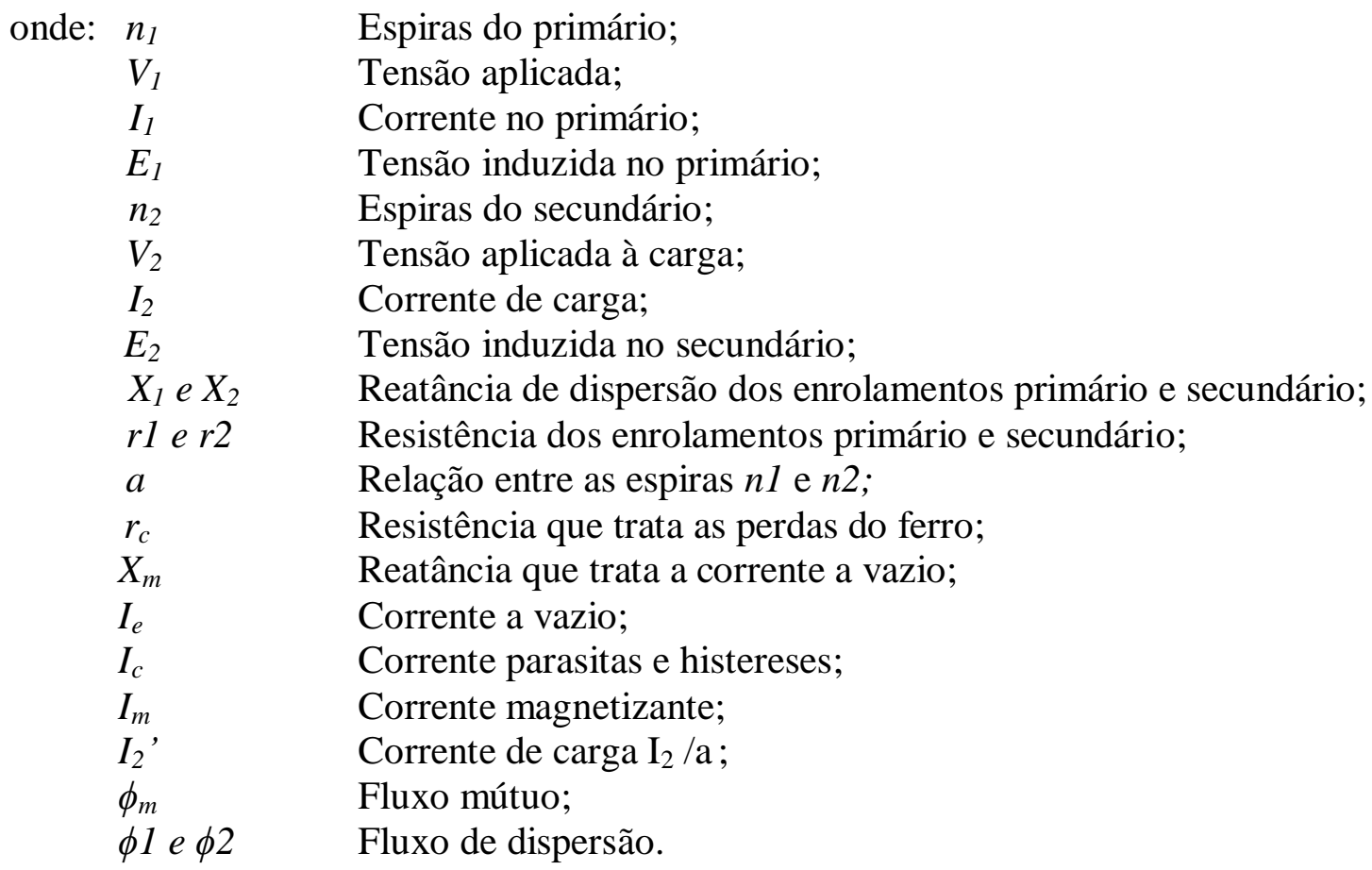

A Figura 3.26 ilustra o esquema do circuito transformador real com impedância referida ao primário e com uma carga ligada ao secundário (CAPARÓ, 2005). 


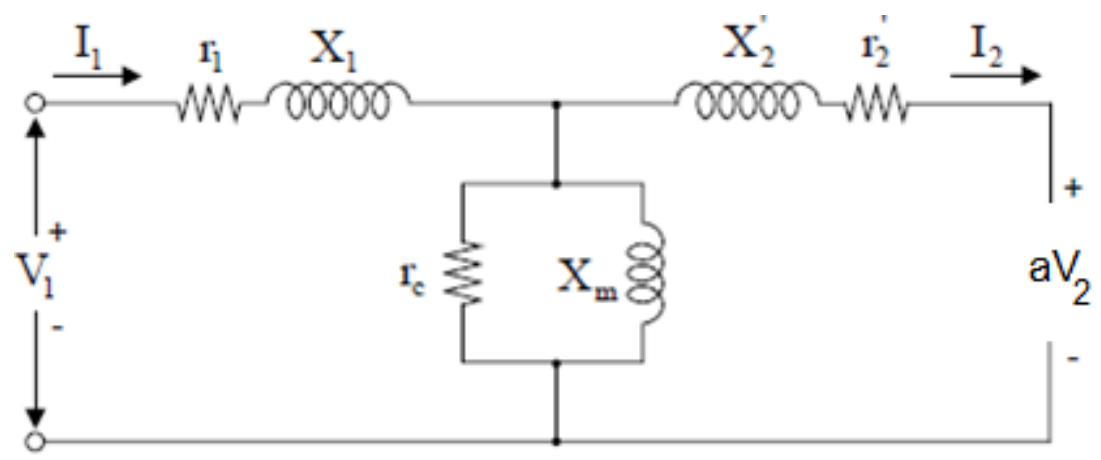

Figura 3.26 - Circuito equivalente de um transformador real monofásico com impedância referida ao primário.

Como a corrente de excitação $\mathrm{I}_{\mathrm{e}}$ é muito pequena se comparada com $\mathrm{I}_{1}$ (da ordem de $2 \%$ a 5\%) (GÖNEN, 1986), pode-se desprezar o ramo de excitação (magnetização e perdas no ferro). Desta forma, o circuito equivalente do transformador com impedância referida ao primário se reduz ao circuito mostrado na Figura 3.27 (CAPARÓ, 2005).

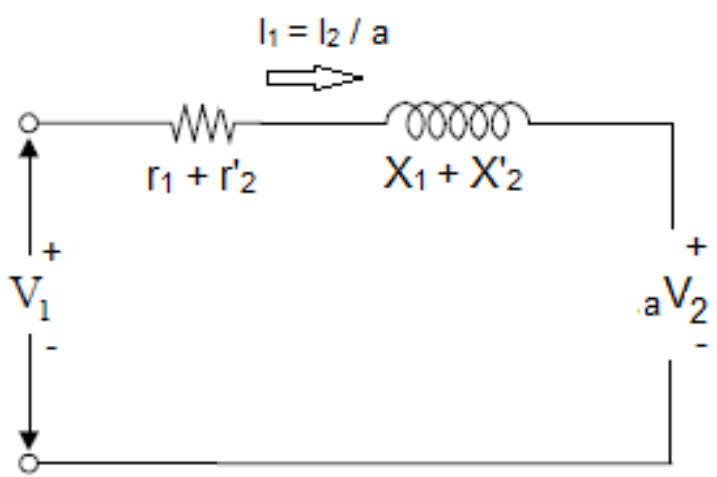

Figura 3.27 - Circuito equivalente de um transformador real monofásico com impedância referida ao primário, desprezando-se o ramo de excitação.

A relação (a) entre as espiras $n_{1}$ e $n_{2}$ é demonstrada por meio da Equação (3.27). As relações entre as correntes $I_{1}$ e $I_{2}$ e as tensões $V_{l}$ e $V_{2}$ são demonstradas por meio das Equações (3.28) e (3.29) respectivamente (CAPARÓ, 2005).

$$
\begin{gathered}
a=\frac{n_{1}}{n_{2}} \\
I_{1}=\frac{I_{2}}{a} \\
V_{2^{\prime}}=a V_{2}
\end{gathered}
$$

As tensões sobre os elementos do lado secundário, resistência $r_{2}$ e reatância $X_{2}$, são refletidos para o lado primário por meio das Equações (3.30) e (3.31) (CAPARÓ, 2005). 


$$
\begin{aligned}
& V_{r 2^{\prime}}=a r_{2} I_{2} \\
& V_{X 2^{\prime}}=a X_{2} I_{2}
\end{aligned}
$$

Substituindo a corrente $I_{2}$ nas expressões matemáticas (3.32) e (3.33) pela corrente $I_{1}$, chegam-se as Equações (3.32) e (3.33).

$$
\begin{gathered}
V_{r 2^{\prime}}=a^{2} r_{2} I_{1} \\
V_{X 2^{\prime}}=a^{2} X_{2} I_{1}
\end{gathered}
$$

Desta forma a resistência $r_{2}$, e a reatância $X_{2}$, mostradas na Figura 3.26, podem ser expressas por meio das Equações (3.34) e (3.35).

$$
\begin{gathered}
r_{2^{\prime}}=a^{2} r_{2} \\
X_{2^{\prime}}=a^{2} X_{2}
\end{gathered}
$$

A Figura 3.28 mostra um circuito baseado em um transformador real monofásico simulado com o software MULTISIM (2010), desprezando-se o ramo de excitação.

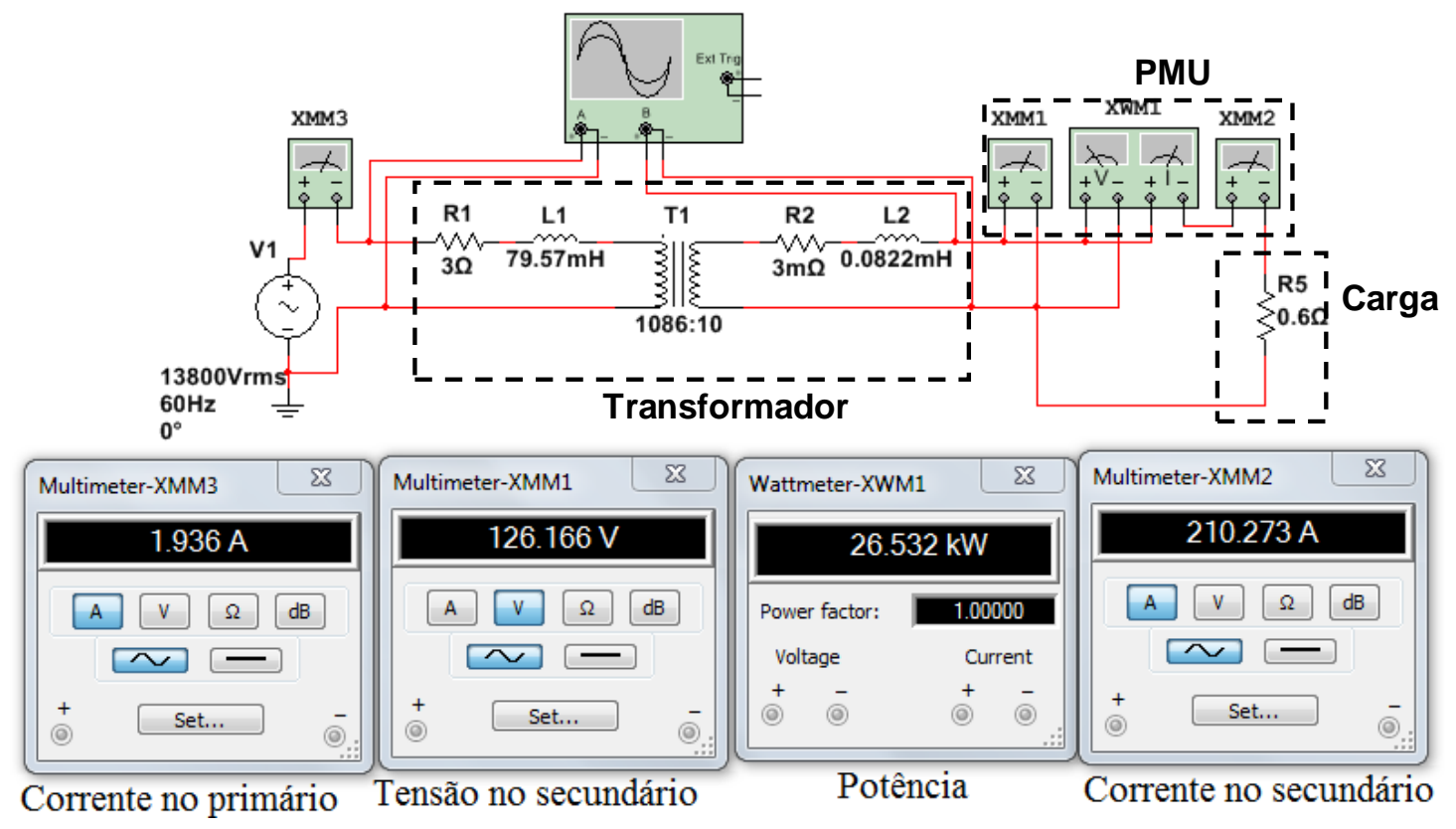

Figura 3.28 - Primeira simulação de um circuito com transformador real monofásico.

Na Figura 3.28 foram medidas a tensão RMS, a corrente RMS e as potências ativa, reativa e aparente nos terminais do enrolamento secundário do transformador, medições as quais são executadas pela Unidade de Mediação Fasorial Otimizada. Os valores desta 
simulação serão utilizados no decorrer desta subseção para exemplificar as operações matemáticas a serem realizadas pelo equipamento.

Para a Unidade de Mediação Fasorial espelhar os valores da tensão e corrente nos terminais do enrolamento primário do transformador, utiliza-se o circuito equivalente da Figura 3.27, onde os parâmetros $n_{1}, n_{2}, r_{1}, r_{2}, L_{1}$ e $L_{2}$ referentes ao transformador podem ser configurados a qualquer momento por meio do protocolo DNP3 (detalhes no Capítulo 5).

Quando solicitada a reflexão dos fasores de tensão e corrente nos terminais primários do transformador, são processadas oito etapas no firmware da $P M U$ para cada uma das fases de tensão. Na primeira etapa são calculados os parâmetros $X_{1}$ e $X_{2}$ através da Equação (3.36):

$$
X_{L}=2 \pi f L
$$

onde $f$ é a frequência da rede em $\mathrm{Hz}$ e $L$ o valor da indutância em $\mathrm{H}$.

Em seguida são calculados os parâmetros $a, r_{2}$, e $X_{2}$, do transformador por meio das Equações (3.27), (3.34) e (3.35):

$$
\begin{aligned}
& \text { - } X_{1}=2 \cdot \pi \cdot 60 \cdot 79,57 m=30 \Omega \\
& \text { - } X_{2}=2 \cdot \pi \cdot 60 \cdot 0,0822 m=31 \mathrm{~m} \Omega \\
& \text { - } a=\frac{n_{1}}{n_{2}}=\frac{1086}{10}=108,6 \\
& \text { - } r_{2^{\prime}}=a^{2} r_{2}=(108,6)^{2} 3 m=35382 \mathrm{~m} \Omega \\
& \text { - } X_{2^{\prime}}=a^{2} X_{2}=(108,6)^{2} 31 \mathrm{~m}=365613 \mathrm{~m} \Omega(969,82 \mathrm{mH})
\end{aligned}
$$

Assim, o circuito mostrado na Figura 3.28 é reduzido, para que possa ser processado pela $P M U$, ao equivalente de um transformador real monofásico com impedância referida ao primário, mostrado na Figura 3.29.

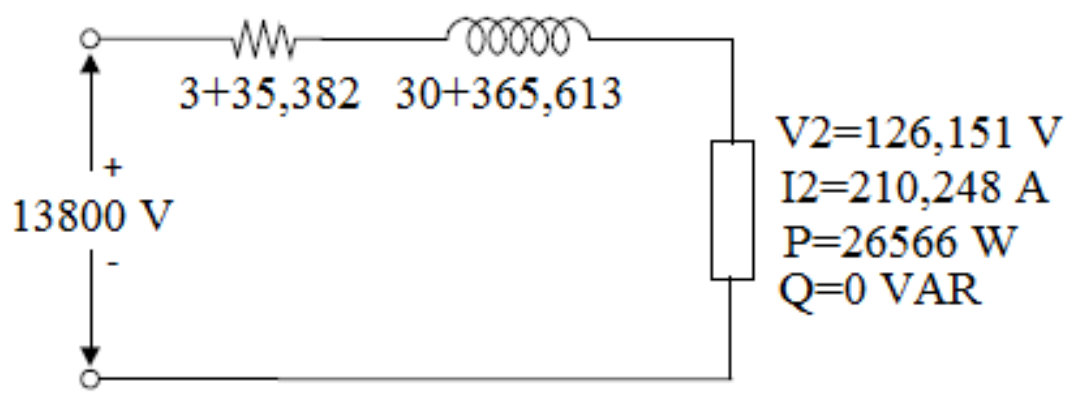

Figura 3.29 - Redução do primeiro circuito simulado ao equivalente de um transformador real monofásico com impedância referida ao primário. 
Na segunda etapa são calculados os parâmetros resistivo $\left(R_{C}\right)$ e reativo $\left(X_{C}\right)$ da carga por meio das Equações (3.37) e (3.38):

$$
\begin{array}{ll}
P=R_{C}\left(I_{2}\right)^{2} & 26566=R_{C}(210,25)^{2} \quad R_{C}=0,6 \Omega \\
Q=X_{C}\left(I_{2}\right)^{2} & 0=X_{C}(210,25)^{2} \quad X_{C}=0 \Omega
\end{array}
$$

$\mathrm{Na}$ terceira etapa são refletidos para o primário do transformador os parâmetros resistivo $\left(R_{C^{\prime}}\right)$ e reativo $\left(X_{C^{\prime}}\right)$ da carga, utilizando-se para isto as Equações (3.34) e (3.35):

$$
\begin{aligned}
& -R_{C^{\prime}}=a^{2} R_{C}=(108,6)^{2} 0,6=7076 \Omega \\
& \text { - } X_{C^{\prime}}=0 \Omega
\end{aligned}
$$

Na quarta etapa é calculado o ângulo de fase da impedância da carga $\left(\alpha_{C^{\prime}}\right)$ refletida para o primário, utilizando para isto a Equação (3.39), onde é calculada a impedância complexa da carga refletida para o primário $\left(\mathrm{Z}_{\mathrm{C}^{\prime}}\right)$, e a Equação (3.40):

$$
\begin{aligned}
& Z_{C^{\prime}}=\sqrt{R_{C^{\prime}}{ }^{2}+X_{C^{\prime}}{ }^{2}}=\sqrt{7076^{2}+0^{2}}=7076 \Omega \\
& \cos \alpha_{C^{\prime}}=\frac{R_{C^{\prime}}}{Z_{C^{\prime}}}=\frac{7076}{7076}=1 \quad \alpha_{C^{\prime}}=0^{\circ}=0 \mathrm{rad}
\end{aligned}
$$

Na quinta etapa é calculado o ângulo de fase da impedância do circuito como um todo $\left(\alpha_{T}\right)$, utilizando para isto a Equação (3.41), onde é calculada a impedância complexa do circuito como um todo $\left(\mathrm{Z}_{\mathrm{T}}\right)$, e a Equação (3.42):

$$
\begin{aligned}
& Z_{T}=\sqrt{\left(r_{1}+r_{2^{\prime}}+R_{C^{\prime}}\right)^{2}+\left(X_{1}+X_{2^{\prime}}+X_{C^{\prime}}\right)^{2}}=\sqrt{(3+35,38+7076)^{2}+(30+365,6)^{2}} \\
& Z_{T}=7125 \Omega \\
& \cos \alpha_{T}=\frac{r_{1}+r_{2^{\prime}}+R_{C^{\prime}}}{Z_{T}}=\frac{3+35,38+7076}{7125}=0,998 \quad \alpha_{T} \approx 3^{\circ}=0,05 \mathrm{rad}
\end{aligned}
$$

Na sexta etapa são refletidos temporariamente para o enrolamento primário os módulos da tensão e corrente RMS utilizando para isto as Equações (3.28) e (3.43):

$$
\text { - } I_{1}=\frac{I_{2}}{a}=\frac{210,248}{108,6}=1,94 A \quad \text { (valor equivalente a 100,2 \% ao da Figura 3.28) }
$$




$$
V_{1}=\frac{Z_{T}}{Z_{C^{\prime}}} V_{2} a=\frac{7125}{7076} \cdot 126,166 \cdot 108,6=13797 V \text { (valor próximo à Fig 3.28) }
$$

Também é calculado para o enrolamento primário a defasagem angular da tensão RMS $\left(\alpha_{V 1}\right)$ utilizando a Equação (3.44):

$$
\alpha_{V 1}=-\left(\alpha_{T}-\alpha_{C^{\prime}}\right)=-(0,05-0)=-0,05 \mathrm{rad}
$$

Como mostrado na Figura 3.30, a defasagem angular entre as tensões de $V_{l}$ (marcador vermelho) e $V_{2}$ (marcador azul) é igual $135,714 \mu$ s, o que representa que a tensão $V_{2}$ está atrasada 0,05 radianos em relação à tensão $V_{l}$ considerando uma frequência de $60 \mathrm{~Hz}$.

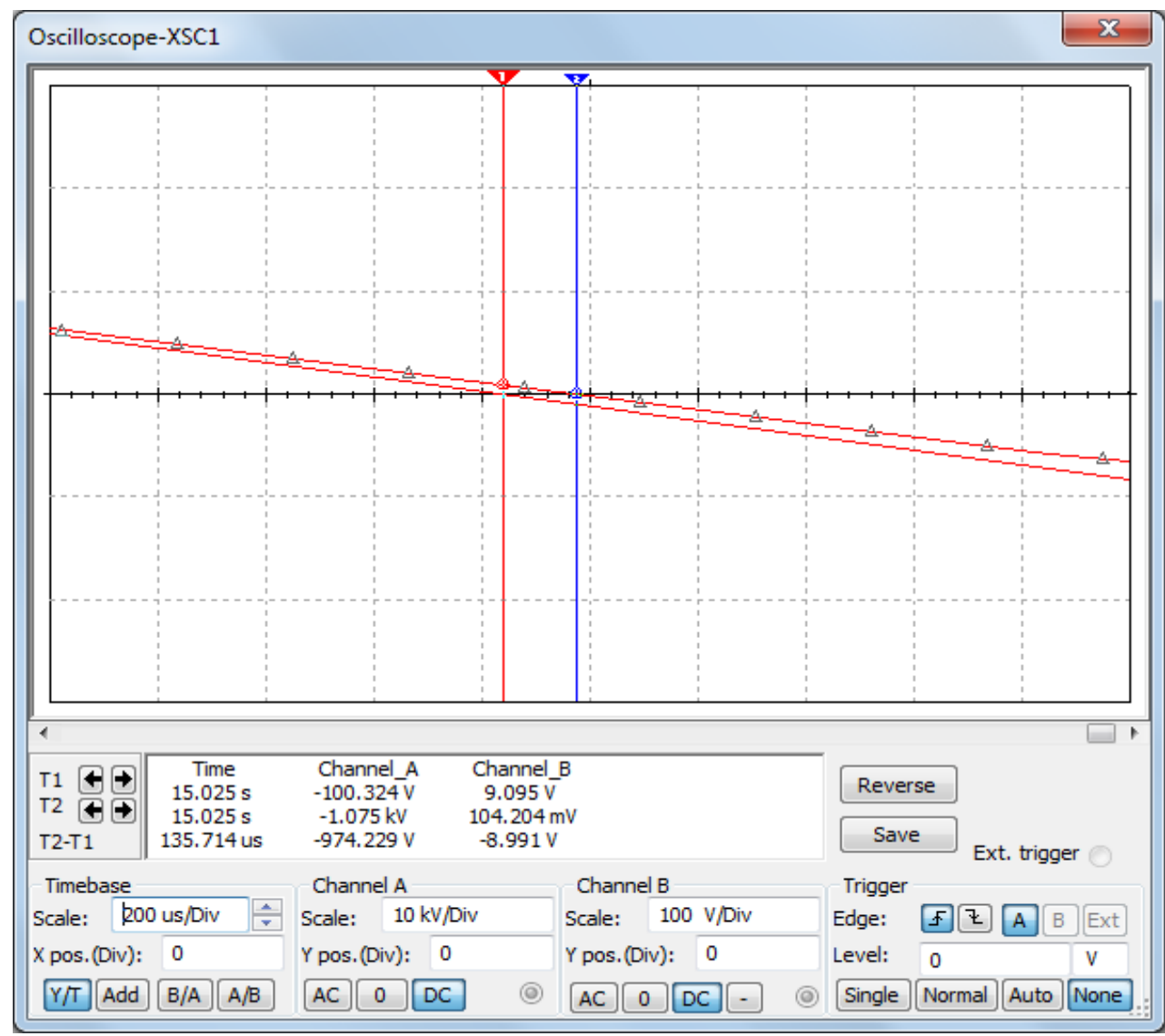

Figura 3.30 - Defasagem angular para o primeiro circuito simulado.

A sétima etapa consiste no cálculo de um índice que será utilizado para refletir de forma permanente os fasores de tensão para os terminais primários do transformador $\left(\alpha_{V}\right)$, utilizando para isso a Equação (3.45):

$$
a_{V}=V_{1} / V_{2}=13797 / 126,17=109,33
$$


A oitava e última etapa consiste no reflexo dos fasores de tensão e corrente nos terminais primários do transformador, por meio das Equações (3.46) e (3.47):

$$
\begin{gathered}
I_{F 1}=I_{F 2} / a \\
V_{F 1}=\left(V_{F 2} a_{V}\right) \angle\left(\alpha_{V 2}+\alpha_{V 1}\right)
\end{gathered}
$$

onde $I_{F 2}$ e $V_{F 2}$ são respectivamente os fasores de corrente e tensão medidos nos terminais de baixa tensão do transformador e $\alpha_{V 2}$ é o ângulo de fase do fasor $V_{F 2}$.

A Figura 3.31 exemplifica um segundo circuito baseado novamente em um transformador real monofásico, simulado com o software MULTISIM e no qual foi desprezado o ramo de excitação.
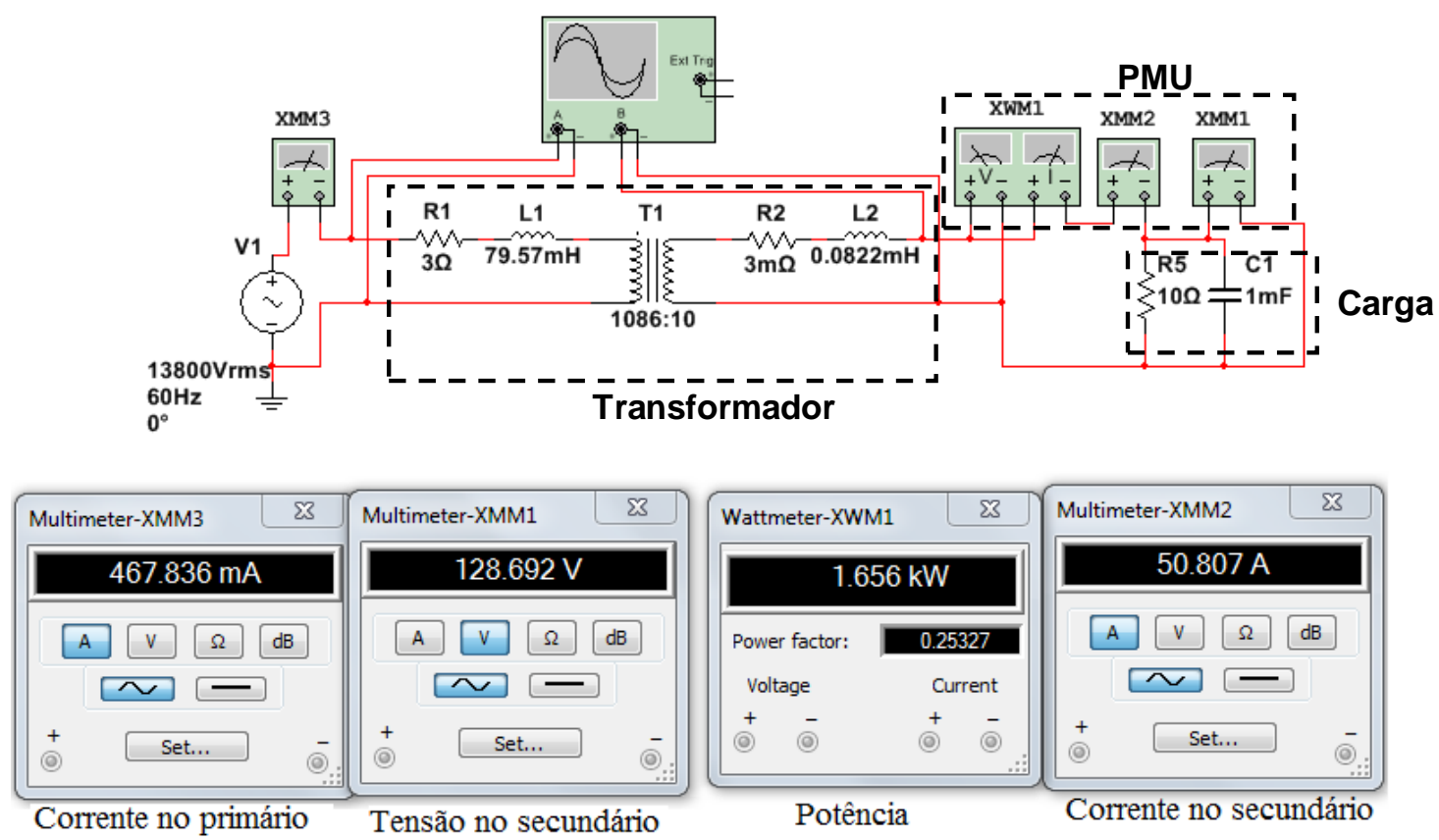

Figura 3.31 - Segunda simulação com um circuito com transformador real monofásico

O circuito mostrado na Figura 3.31 é reduzido ao circuito da Figura 3.32, para que o mesmo possa ser processado pela $P M U$.

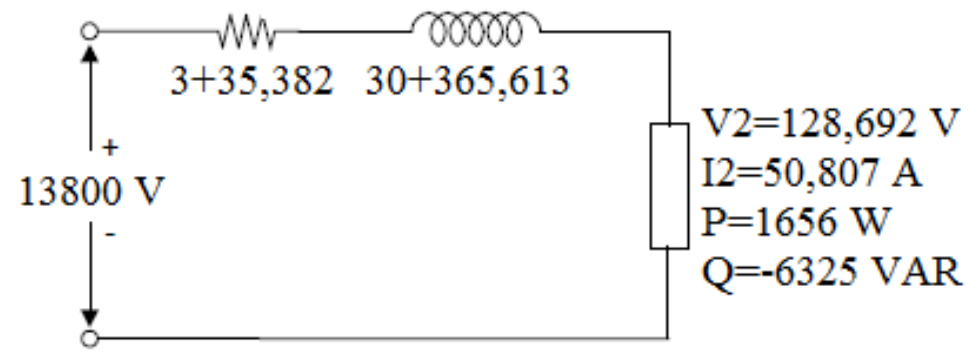

Figura 3.32 - Redução do segundo circuito simulado ao equivalente de um transformador real monofásico com impedância referida ao primário. 
Como mostrado anteriormente na primeira simulação, as mesmas etapas são novamente realizadas. Os valores dos parâmetros resistivo e reativo da carga espelhados para o primário do transformador são:

$$
\begin{aligned}
& -P=R_{C}\left(I_{2}\right)^{2} \quad 1656=R_{C}(50,807)^{2} \quad R_{C}=0,641 \Omega \\
& -Q=X_{C}\left(I_{2}\right)^{2} \quad-6325=X_{C}(50,807)^{2} \quad X_{C}=-2,45 \Omega \\
& \text { - } R_{C^{\prime}}=a^{2} R_{C}=(108,6)^{2} \cdot 0,641=7560 \Omega \\
& -X_{C^{\prime}}=a^{2} X_{C}=(108,6)^{2} \cdot(-2,45)=-28895 \Omega
\end{aligned}
$$

Em seguida são calculados os ângulos de fase das impedâncias da carga e do circuito como um todo:

$$
\begin{aligned}
& -Z_{C^{\prime}}=\sqrt{R_{C^{\prime}}{ }^{2}+X_{C^{\prime}}{ }^{2}}=\sqrt{7560^{2}+(-28895)^{2}}=29868 \Omega \\
& -\cos \alpha_{C^{\prime}}=\frac{R_{C^{\prime}}}{Z_{C^{\prime}}}=\frac{7560}{29868}=0,253 \quad \alpha_{C^{\prime}}=75,3^{\circ}=1,314 \mathrm{rad} \\
& -Z_{T}=\sqrt{\left(R_{C^{\prime}}+r_{1}+r_{2^{\prime}}\right)^{2}+\left(X_{1}+X_{2^{\prime}}+X_{C^{\prime \prime}}\right)^{2}}= \\
& Z_{T}=\sqrt{(3+35,38+7560)^{2}+(30+365,6-28895)^{2}}=29495 \Omega \\
& -\cos \alpha_{T}=\frac{R_{C^{\prime}}+r_{1}+r_{2^{\prime}}}{Z_{T}}=\frac{3+35,38+7560}{29495}=0,257 \quad \alpha_{T} \approx 75,2^{\circ}=1,311 \mathrm{rad}
\end{aligned}
$$

Abaixo são refletidos para o enrolamento primário o módulo e a defasagem angular da tensão RMS e a corrente RMS:

$$
\begin{aligned}
& -I_{1}=\frac{I_{2}}{a}=\frac{50,807}{108,6}=467,83 \mathrm{~mA} \quad(\text { Igual ao da Figura 3.31) } \\
& -V_{1}=\frac{Z_{T}}{Z_{C^{\prime}}} V_{2} a=\frac{29495}{29868} \cdot 128,692 \cdot 108,6=13801 \mathrm{~V} \quad(\text { valor próximo à Fig 3.31) } \\
& -\alpha_{V 1}=-\left(\alpha_{T}-\alpha_{C^{\prime}}\right)=-(1,311-1,314)=0,003 \mathrm{rad}
\end{aligned}
$$

Como mostrado na Figura 3.33, a defasagem angular entre as tensões de $V_{1}$ e $V_{2}$ é próximo a $0 \mu \mathrm{s}$ (0 radianos). 


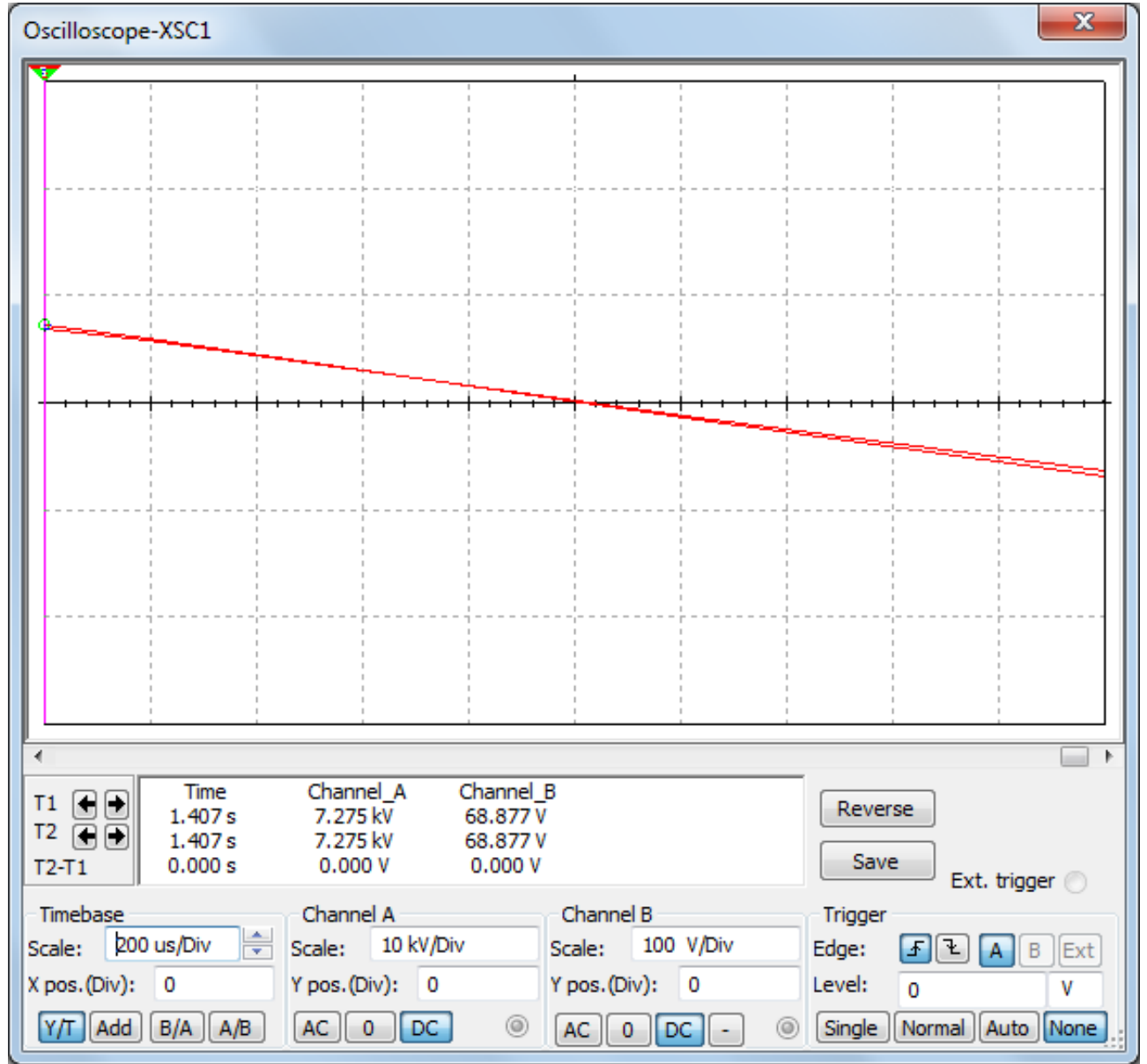

Figura 3.33 - Defasagem angular para o segundo circuito simulado.

O índice utilizado para refletir os fasores de tensão para os terminais primários do transformador é igual a:

$-a_{V}=V_{1} / V_{2}=13797 / 126,17=109,33$

É importante ressaltar que utilização da modelagem do transformador visa exclusivamente à reflexão das correntes e tensões fasoriais calculadas pela $P M U$, quando a mesma é solicitada pelo servidor. As demais grandezas elétricas calculadas pela $P M U$ como a tensão e corrente RMS possuem seus valores mantidos em baixa tensão para serem utilizados na posterior identificação e estimação dos parâmetros elétricos da causa de distúrbios.

No Capítulo 5 é mostrada a forma de configuração dos parâmetros do transformador no firmware da $P M U$, utilizando-se o protocolo $D N P 3$. No Capítulo 6 é demonstrada a aquisição de fasores de tensão e corrente refletidos nos terminais primários de um transformador. 


\section{CaPítulo 4}

\section{IdENTIFICAÇÃo E EstimaÇão dOS PARÂMetros Elétricos das CAUSAS dos Distúrbios Elétricos}

\subsection{INTRODUÇÃO}

O sistema de identificação de distúrbios proposto neste trabalho, a partir das variações da tensão RMS e das potências ativa e reativa medidas pela Unidade de Medição Fasorial Otimizada em cada uma das três fases, visa verificar se houve mudanças nos parâmetros elétricos da carga ou da rede de distribuição de energia.

Com este sistema é possível auxiliar a realização da modelagem remota de cargas e a estimação de parâmetros elétricos da rede, permitindo assim verificar eventuais perdas. Neste capítulo também são apresentadas duas técnicas para estimar os parâmetros elétricos da rede e da carga.

\subsection{MODELAGEM DE UM SISTEMA ELÉTRICO EQUIVALENTE REDE-CARGA}

As linhas de distribuição de energia elétrica, também chamados de alimentadores, são os elementos encarregados da ligação entre as cargas e as fontes de energia, neste caso, as subestações. Estas linhas são compostas de elementos condutores de eletricidade que podem ser do tipo aéreo ou subterrâneo, tendo cada um suas características particulares (PAZ, 2010).

A modelagem das linhas é um aspecto muito importante na representação dos sistemas elétricos e dos fenômenos que neles são produzidos. Segundo Kersting (2002), o principal modelo elétrico para as linhas aéreas de distribuição em média tensão, ou ainda, linhas de transmissão de comprimento inferior a $80 \mathrm{~km}$ é o modelo RL, mostrado na Figura 4.1, o qual é composto por uma resistência e uma indutância série.

A modelagem estática da carga, independente da sua composição por parâmetros resistivos, capacitivos e indutivos, também pode ser definida por uma impedância complexa $R \pm j X$ (IEEE, 1993). 


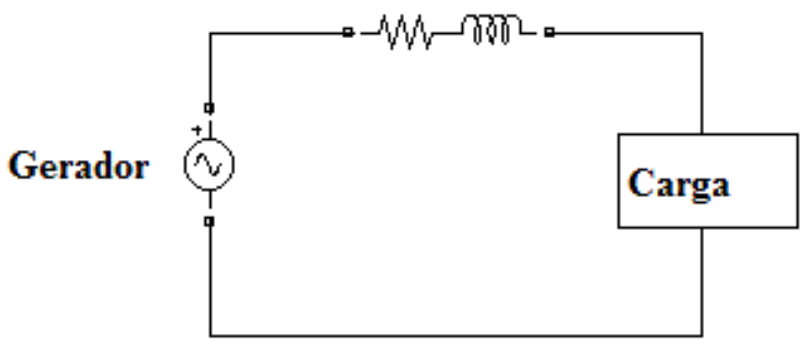

Figura 4.1 - Modelo RL para linha de distribuição (adaptado de PAZ, 2010).

Desta forma, chega-se a um modelo elétrico equivalente rede-carga trifásico (Figura 4.2), onde também estão inseridos o transformador de distribuição trifásico e a Unidade de Medição Fasorial Otimizada, instalada nos terminais secundários do transformador e responsável pela medição da tensão RMS $\left(V_{C}\right)$, potência ativa $\left(P_{C}\right)$ e reativa $\left(Q_{C}\right)$ da carga para cada uma das fases.

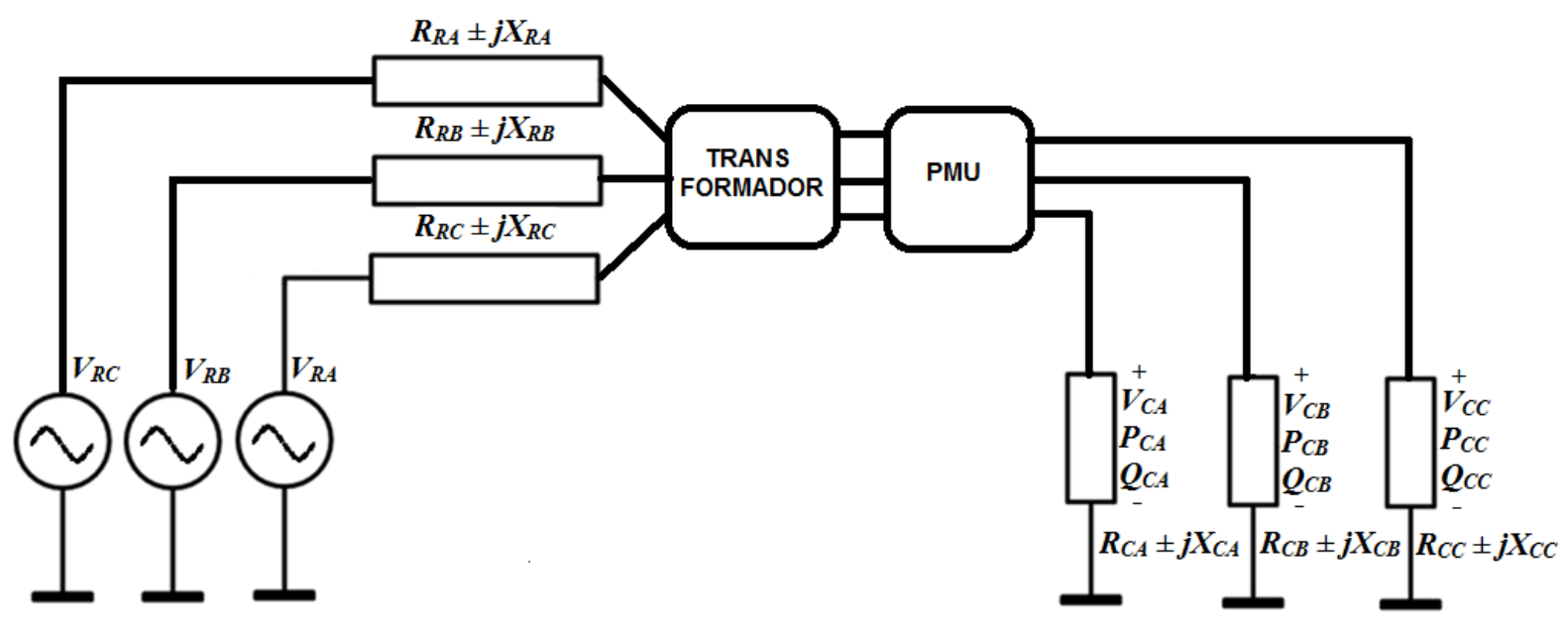

Figura 4.2 - Modelo elétrico equivalente rede-carga para cada uma das fases.

Este modelo é composto pelas resistências $\left(R_{C}\right)$ e reatâncias $\left(X_{C}\right)$ de cada uma das cargas, pelas fontes equivalentes da rede de distribuição trifásica de energia $\left(V_{R}\right)$ e seus componentes resistivos $\left(R_{R}\right)$ e reativos $\left(X_{R}\right)$.

\subsection{CONJUNTO DE REGRAS PARA DETERMINAÇÃO DO DISTÚRBIO}

Por meio de uma série de simulações computacionais sobre o modelo equivalente redecarga para apenas uma fase, as quais são descritas a seguir e onde foi utilizado o software MULTISIM, houve a variação dos parâmetros resistência $\left(R_{C}\right)$ e a reatância $\left(X_{C}\right)$ da carga, da fonte equivalente da rede de distribuição $\left(V_{R}\right)$ e de seus componentes resistivo $\left(R_{R}\right)$ e reativo 
$\left(X_{R}\right)$. Com a variação destes parâmetros ocorreu também a variação da tensão RMS e das potências ativa e reativa medidas sobre a carga, os quais são mostrados pelo software. A Figura 4.3 mostra um exemplo de simulação.

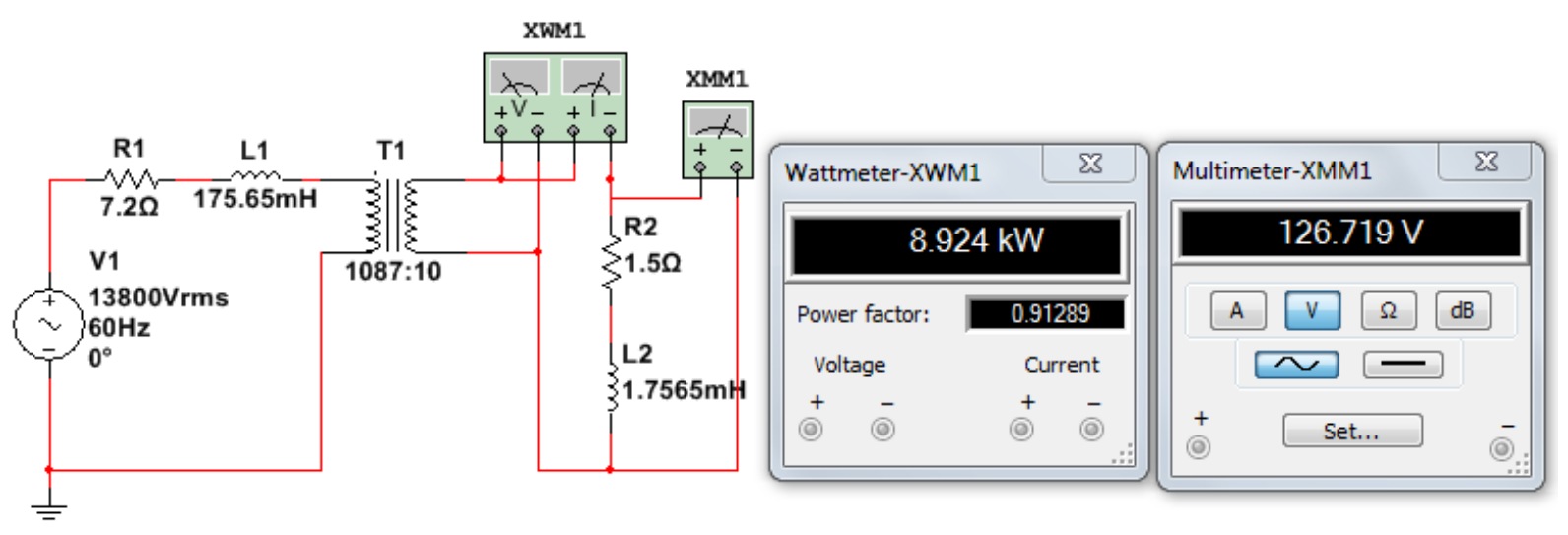

Figura 4.3 - Exemplo de simulação do modelo elétrico equivalente rede-carga.

Tabela 4.1 - Primeiro conjunto de simulações.

\begin{tabular}{|c|c|c|c|c|c|c|c|c|}
\hline Iteração & $\mathbf{R}_{\mathbf{C}}(\mathbf{\Omega})$ & $\mathbf{X}_{\mathbf{C}}(\mathbf{\Omega})$ & $\mathbf{V}_{\mathbf{R M S}}(\mathbf{V})$ & $\mathbf{P}(\mathbf{W})$ & $\mathbf{Q}(\mathbf{V A R})$ & $\Delta \mathbf{V}_{\text {RMs }}$ & $\Delta \mathbf{P}$ & $\Delta \mathbf{Q}$ \\
\hline 1 & 1 & 0,662 & 126,56 & 11048 & 7411 & & & \\
\hline 2 & 0,45 & 0,662 & 126,15 & 10984 & 16375 & Neg & Neg & Pos \\
\hline 3 & 1 & 0,662 & 126,56 & 11048 & 7411 & Pos & Pos & Neg \\
\hline 4 & 0,44 & 0,662 & 126,13 & 10885 & 16597 & Neg & Neg & Pos \\
\hline 5 & 0,35 & 0,792 & 126,17 & 7278 & 16675 & Pos & Neg & Pos \\
\hline 6 & 0,44 & 0,662 & 126,13 & 10885 & 16597 & Neg & Pos & Neg \\
\hline 7 & 0,6 & 0 & 126,80 & 26806 & 0 & Pos & Pos & Neg \\
\hline 8 & 1,4 & 0 & 126,88 & 11502 & 0 & Pos & Neg & Nula \\
\hline 9 & 10 & 0 & 126,94 & 1612 & 0 & Pos & Neg & Nula \\
\hline 10 & 1,4 & 0 & 126,88 & 11502 & 0 & Neg & Pos & Nula \\
\hline 11 & 0,6 & 0 & 126,80 & 26806 & 0 & Neg & Pos & Nula \\
\hline 12 & 0,57 & 0 & 126,82 & 28213 & 0 & Pos & Pos & Nula \\
\hline 13 & 0,6 & 0 & 126,80 & 26806 & 0 & Neg & Neg & Nula \\
\hline 14 & 0,6 & $-2,65$ & 127,19 & 1345 & 5871 & Pos & Neg & Pos \\
\hline 15 & 0,6 & 0 & 126,80 & 26806 & 0 & Neg & Pos & Neg \\
\hline 16 & 10 & 0 & 126,94 & 1612 & 0 & Pos & Neg & Nula \\
\hline 17 & 0,74 & $-2,65$ & 127,19 & 1612 & 5721 & Pos & Nula & Pos \\
\hline 18 & 10 & 0 & 126,94 & 1612 & 0 & Neg & Nula & Neg \\
\hline 19 & 0,45 & 0,662 & 126,15 & 10984 & 16375 & Neg & Pos & Pos \\
\hline 20 & 0,68 & 0,716 & 126,36 & 10984 & 11717 & Pos & Nula & Neg \\
\hline 21 & 0,45 & 0,662 & 126,15 & 10984 & 16375 & Neg & Nula & Pos \\
\hline
\end{tabular}

No primeiro conjunto de simulações mostrado na Tabela 4.1, onde foram variados os parâmetros elétricos da carga, levou-se em conta uma rede de distribuição de grande comprimento $(80 \mathrm{~km})$ para os quais os parâmetros $R_{R}$ e $X_{R}$ são iguais a 7,2 $\Omega$ e 66,22 $\Omega$ 
$(175,65 \mathrm{mH})$ respectivamente. Também foi considerada a fonte equivalente $\left(V_{R}\right)$ com tensão RMS igual a $13800 \mathrm{~V}$ e frequência de $60 \mathrm{~Hz}$.

É possível observar nesta tabela, e nas demais apresentadas nesta seção, a presença das colunas $\Delta V_{R M S}, \Delta P$ e $\Delta Q$, as quais representam a variação das grandezas medidas entre simulação atual e a anterior. As variações são classificadas como positivas, negativas ou nulas.

Em um segundo conjunto de simulações (Tabela 4.2) onde novamente foram variados os parâmetros elétricos da carga, levou-se em conta uma rede de distribuição de curto comprimento (inferiores a $1 \mathrm{Km}$ ), onde os parâmetros $R_{R}$ e $X_{R}$ são considerados nulos. Para estas simulações foi considerada uma fonte equivalente $\left(V_{R}\right)$ com tensão RMS de $13257 \mathrm{~V}$ e frequência de $60 \mathrm{~Hz}$.

Tabela 4.2 - Segundo conjunto de simulações.

\begin{tabular}{|c|c|c|c|c|c|c|c|c|}
\hline Interação & $\mathbf{R}_{\mathbf{C}}(\mathbf{\Omega})$ & $\mathbf{X}_{\mathbf{C}}(\boldsymbol{\Omega})$ & $\mathbf{V}_{\text {RMS }}(\mathbf{V})$ & $\mathbf{P}(\mathbf{W})$ & $\mathbf{Q}(\mathbf{V} \mathbf{R})$ & $\Delta \mathbf{V}_{\text {RMs }}$ & $\Delta \mathbf{P}$ & $\Delta \mathbf{Q}$ \\
\hline 1 & 300 & $-176,84$ & 122 & 36,80 & 21,73 & & & \\
\hline 2 & 150 & $-176,84$ & 122 & 41,528 & 48,94 & Nula & Pos & Pos \\
\hline 3 & 300 & $-176,84$ & 122 & 36,80 & 21,73 & Nula & Neg & Neg \\
\hline 4 & 300 & 0 & 122 & 49,62 & 0 & Nula & Pos & Neg \\
\hline 5 & 150 & 0 & 122 & 99,216 & 0 & Nula & Pos & Nula \\
\hline 6 & 300 & 0 & 122 & 49,62 & 0 & Nula & Neg & Nula \\
\hline 7 & 300 & $-176,84$ & 122 & 36,80 & 21,73 & Nula & Neg & Pos \\
\hline 8 & 82,17 & 55,74 & 122 & 124,12 & 84,05 & Nula & Pos & Pos \\
\hline 9 & 42,34 & 57,29 & 122 & 124,12 & 168,07 & Nula & Nula & Pos \\
\hline 10 & 82,17 & 55,74 & 122 & 124,12 & 84,05 & Nula & Nula & Neg \\
\hline
\end{tabular}

Já nas simulações presentes na Tabela 4.3 foram variados os parâmetros elétricos da carga para uma rede de distribuição de comprimento igual a $5 \mathrm{~km}$, onde os parâmetros $R_{R}$ e $X_{R}$ são iguais a $0,93 \Omega$ e $8,11 \Omega(21,5 \mathrm{mH})$ respectivamente. Para estas simulações foi considerada uma fonte equivalente $\left(V_{R}\right)$ com tensão RMS de $13800 \mathrm{~V}$ e frequência de $60 \mathrm{~Hz}$.

Tabela 4.3 - Terceiro conjunto de simulações.

\begin{tabular}{|c|c|c|c|c|c|c|c|c|}
\hline Interação & $\mathbf{R}_{\mathbf{C}}(\mathbf{\Omega})$ & $\mathbf{X}_{\mathbf{C}}(\mathbf{\Omega})$ & $\mathbf{V}_{\text {RMS }}(\mathbf{V})$ & $\mathbf{P}(\mathbf{W})$ & $\mathbf{Q}(\mathbf{V A R})$ & $\Delta \mathbf{V}_{\text {RMS }}$ & $\Delta \mathbf{P}$ & $\Delta \mathbf{Q}$ \\
\hline 1 & 0,1 & 0,377 & 126,72 & 10311 & 39362 & & & \\
\hline 2 & 0,1 & 1,885 & 126,88 & 688 & 10562 & Pos & Neg & Neg \\
\hline 3 & 0,1 & 0,377 & 126,72 & 10311 & 39362 & Neg & Pos & Pos \\
\hline 4 & 0 & 1,885 & 126,90 & 0 & 8518 & Pos & Neg & Neg \\
\hline 5 & 0,06 & 0 & 78,81 & 103511 & 0 & Neg & Pos & Neg \\
\hline 6 & 0,08 & 0 & 90,99 & 103510 & 0 & Pos & Nula & Nula \\
\hline 7 & 0,06 & 0 & 78,81 & 103511 & 0 & Neg & Nula & Nula \\
\hline
\end{tabular}

A Tabela 4.4 apresenta um conjunto de simulações onde há variações na tensão da fonte equivalente $\left(V_{R}\right)$ para duas diferentes reatâncias da carga $\left(X_{C}\right)$. Levou-se em conta também 
para estas simulações a resistência da carga $\left(R_{C}\right)$ com valor igual a $2 \Omega$, uma rede de distribuição com frequência de operação igual a $60 \mathrm{~Hz}$ e parâmetros $R_{R}$ e $X_{R}$ iguais a 7,2 $\Omega$ e $66,22 \Omega(175,65 \mathrm{mH})$ respectivamente.

Tabela 4.4 - Quarto conjunto de simulações.

\begin{tabular}{|c|c|c|c|c|c|c|c|c|}
\hline Interação & $\mathbf{V}_{\mathbf{R}}(\mathbf{V})$ & $\mathbf{X}_{\mathbf{C}}(\mathbf{\Omega})$ & $\mathbf{V}_{\mathbf{R M S}}(\mathbf{V})$ & $\mathbf{P}(\mathbf{W})$ & $\mathbf{Q}(\mathbf{V A R})$ & $\Delta \mathbf{V}_{\mathbf{R M S}}$ & $\Delta \mathbf{P}$ & $\Delta \mathbf{Q}$ \\
\hline 1 & 13800 & 0 & 126,91 & 8054 & 0 & & & \\
\hline 2 & 14000 & 0 & 128,75 & 8289 & 0 & Pos & Pos & Nula \\
\hline 3 & 13800 & 0 & 126,91 & 8054 & 0 & Neg & Neg & Nula \\
\hline 4 & 13800 & 0,754 & 126,79 & 7017 & 2679 & Neg & Neg & Pos \\
\hline 5 & 13500 & 0,754 & 124,03 & 6715 & 2564 & Neg & Neg & Neg \\
\hline 6 & 13800 & 0,754 & 126,79 & 7017 & 2679 & Pos & Pos & Pos \\
\hline
\end{tabular}

Finalmente nas simulações presentes na Tabela 4.5 foram variados os parâmetros elétricos da rede de distribuição $\left(R_{R}\right.$ e $\left.X_{R}\right)$ para dois diferentes valores da reatância da carga $\left(X_{C}\right)$. Para estas simulações foi considerada uma fonte equivalente $\left(V_{R}\right)$ com tensão RMS igual a $13800 \mathrm{~V}$ e frequência de $60 \mathrm{~Hz}$. A resistência da carga $\left(R_{C}\right)$ é igual a $0,7 \Omega$.

Tabela 4.5 - Quinto conjunto de simulações.

\begin{tabular}{|c|c|c|c|c|c|c|c|c|c|}
\hline Int & $\mathbf{R}_{\mathbf{R}}(\boldsymbol{\Omega})$ & $\mathbf{X}_{\mathbf{R}}(\boldsymbol{\Omega})$ & $\mathbf{X}_{\mathbf{C}}(\mathbf{\Omega})$ & $\mathbf{V}_{\mathbf{R M S}}(\mathbf{V})$ & $\mathbf{P}(\mathbf{W})$ & $\mathbf{Q}(\mathbf{V A R})$ & $\Delta \mathbf{V}_{\mathbf{R M}}$ & $\Delta \mathbf{P}$ & $\Delta \mathbf{Q}$ \\
\hline 1 & 7,2 & 66,22 & 0 & 126,83 & 22984 & 0 & & & \\
\hline 2 & 1,44 & 13,24 & 0 & 126,93 & 23017 & 0 & Pos & Pos & Nula \\
\hline 3 & 7,2 & 66,22 & 0 & 126,83 & 22984 & 0 & Neg & Neg & Nula \\
\hline 4 & 7,2 & 66,22 & 0,377 & 126,42 & 17592 & 9605 & Neg & Neg & Pos \\
\hline 5 & 1,44 & 13,24 & 0,377 & 126,83 & 17710 & 9669 & Pos & Pos & Pos \\
\hline 6 & 7,2 & 66,22 & 0,377 & 126,42 & 17592 & 9605 & Neg & Neg & Neg \\
\hline
\end{tabular}

Com as simulações mostradas anteriormente, foram exploradas todas as combinações de variações no tempo da tensão RMS $\left(\Delta V_{C}\right)$, da potência ativa $\left(\Delta P_{C}\right)$ e da potência reativa $\left(\Delta Q_{C}\right)$ e a causa destas combinações (Carga, Rede ou Indeterminado), como mostrado na Tabela 4.6.

Como exemplo do uso do conjunto de regras, caso sejam verificadas variações positivas da tensão RMS $\left(\Delta V_{C}>0\right)$, da potência ativa $\left(\Delta P_{C}>0\right)$ e da potência reativa $\left(\Delta Q_{C}<0\right)$, isso significa que as origens dessas variações são mudanças nos parâmetros da rede de distribuição.

Ainda é possível verificar na Tabela 4.6 que o conjunto de regras identifica como "Indeterminado" a causa dos distúrbios elétricos quando não há variações na tensão RMS $\left(\Delta V_{C}=0\right)$, potência ativa $\left(\Delta P_{C}=0\right)$ e potência reativa $\left(\Delta Q_{C}=0\right)$, já que não houve modificações nos parâmetros elétricos da carga ou da rede de distribuição. Esta identificação se repete para as combinações $\left(\Delta V_{C}>0 / \Delta P_{C}>0 / \Delta Q_{C}=0\right)$ e $\left(\Delta V_{C}<0 / \Delta P_{C}<0 / \Delta Q_{C}=0\right)$, onde foi impossível 
determinar se as mudanças nos parâmetros elétricos ocorreram na carga ou na rede de distribuição.

Tabela 4.6 - Diferentes combinações de $\Delta V_{C}, \Delta P_{C}$ e $\Delta Q_{C}$

\begin{tabular}{|c|c|c|c|}
\hline$\Delta P \quad \Delta V$ & POSITIVA & NULA & NEGATIVA \\
\hline \multirow{3}{*}{ POSITIVA } & $\Delta \mathrm{Q}>0$ - REDE & $\Delta Q>0$ - CARGA & $\Delta \mathrm{Q}>0-\mathrm{CARGA}$ \\
\hline & $\Delta \mathrm{Q}=0-\mathrm{IND}$ & $\Delta \mathrm{Q}=0-\mathrm{CARGA}$ & $\Delta \mathrm{Q}=0-\mathrm{CARGA}$ \\
\hline & $\Delta Q<0-C A R G A$ & $\Delta Q<0-C A R G A$ & $\Delta Q<0-C A R G A$ \\
\hline \multirow{3}{*}{ NULA } & $\Delta \mathrm{Q}>0$ - CARGA & $\Delta \mathrm{Q}>0$ - CARGA & $\Delta \mathrm{Q}>0-\mathrm{CARGA}$ \\
\hline & $\Delta \mathrm{Q}=0$ - CARGA & $\Delta \mathrm{Q}=0-\mathrm{IND}$ & $\Delta \mathrm{Q}=0-\mathrm{CARGA}$ \\
\hline & $\Delta \mathrm{Q}<0-$ CARGA & $\Delta Q<0-C A R G A$ & $\Delta Q<0-C A R G A$ \\
\hline \multirow{3}{*}{ NEGATIVA } & $\Delta \mathrm{Q}>0$ - CARGA & $\Delta Q>0-C A R G A$ & $\Delta Q>0-C A R G A$ \\
\hline & $\Delta \mathrm{Q}=0$ - CARGA & $\Delta \mathrm{Q}=0-\mathrm{CARGA}$ & $\Delta \mathrm{Q}=0-\mathrm{IND}$ \\
\hline & $\Delta \mathrm{Q}<0-$ CARGA & $\Delta \mathrm{Q}<0$ - CARGA & $\Delta \mathrm{Q}<0-\mathrm{REDE}$ \\
\hline
\end{tabular}

\subsection{SISTEMA FUZZY PARA IDENTIFICAÇÃO DAS CAUSAS DOS DISTÚRBIOS}

As medições da tensão RMS e das potências ativa e reativa, realizadas pela Unidade de Medição Fasorial Otimizada, podem apresentar variações em seus valores, devido principalmente à resolução utilizada pelo equipamento na medição destas grandezas e eventuais variações nas características funcionais dos componentes eletrônicos que fazem parte dos circuitos condicionadores de tensão e corrente.

Desta forma, foi observado nos testes realizados em laboratório que as potências ativa e reativa e a tensão RMS podem apresentar variações de aproximadamente $\pm 2 \mathrm{~W}, \pm 2$ VAR e $\pm 250 \mathrm{mV}$ em suas medições, mesmo sem variações nos parâmetros da carga ou da rede. Essas variações podem afetar a identificação da causa de distúrbios nas medições, baseada no conjunto de regras demonstrado na seção anterior.

Assim foi implementado no firmware da Unidade de Medição Fasorial Otimizada um sistema de inferência fuzzy com o objetivo de auxiliar no processo de identificação da causa de distúrbios nas medições, já que as variáveis de entrada deste processo (tensão RMS, potência ativa e potência reativa) podem apresentar variações eventuais em seus valores geradas pela própria PMU.

O fato das variáveis de entrada do sistema estarem imersas em ambientes de incerteza e imprecisão (quanto às medições realizadas pelo equipamento proposto) e a pré-existência de um conjunto de regras (geradas através de simulações em uma das fases do modelo equivalente rede-carga) para a classificação da causa do distúrbio determinaram a escolha 
neste trabalho do sistema de inferência fuzzy frente a outros sistemas inteligentes como redes neurais artificiais (ROSS, 2004). No Anexo A são apresentados os conceitos básicos relacionados à lógica fuzzy.

As respectivas funções de pertinência das variáveis linguísticas do sistema fuzzy proposto neste trabalho podem ser vistas nas Figuras 4.4 a 4.7. O comportamento das funções de pertinência das variáveis de entrada foi baseado nas eventuais variações citadas anteriormente.

Para todas as variáveis do sistema foram utilizadas as funções de pertinência trapezoidal no início e no fim dos universos de discurso, já que os elementos pertencentes a essas extremidades devem possuir grau de pertinência igual a 1 para atender às características do sistema. No restante do universo de discurso foram utilizadas funções de pertinência triangulares visando à facilidade de interseção entre os termos das variáveis.

Foram utilizados 200 pontos para a discretização das variáveis linguísticas e obtenção da região fuzzy de saída, quantidade suficiente para a definição dos graus de pertinência dos termos e viável para implementação na Unidade de Medição Fasorial Otimizada.

O universo de discurso da variável de entrada "Variação da potência ativa" (Figura 4.4) possui variação entre $-20000 \mathrm{~W}$ e $+20000 \mathrm{~W}$, a qual compreende o produto entre a faixa de tensão RMS monofásica e a corrente RMS máxima que o equipamento pode medir, acrescida de uma margem de segurança de $\pm 2000 \mathrm{~W}$. Os termos componentes desta variável são: "Variação Negativa" (-20000 W/0 W), "Variação Nula" (-4 W/+4 W) e "Variação Positiva" $(0 \mathrm{~W} /+20000 \mathrm{~W})$. O termo "Variação Nula" foi ajustado de forma que na ocorrência das variações intrínsecas do equipamento, nos valores de $2 \mathrm{~W}$ e $-2 \mathrm{~W}$ na medição da potência ativa, o grau de pertinência $(\mu P)$ seja igual 0,5 . Com isso o sistema fuzzy pode inferir de forma mais assertiva, como mostrado no item 6.4.1 apresentado no Capítulo 6.

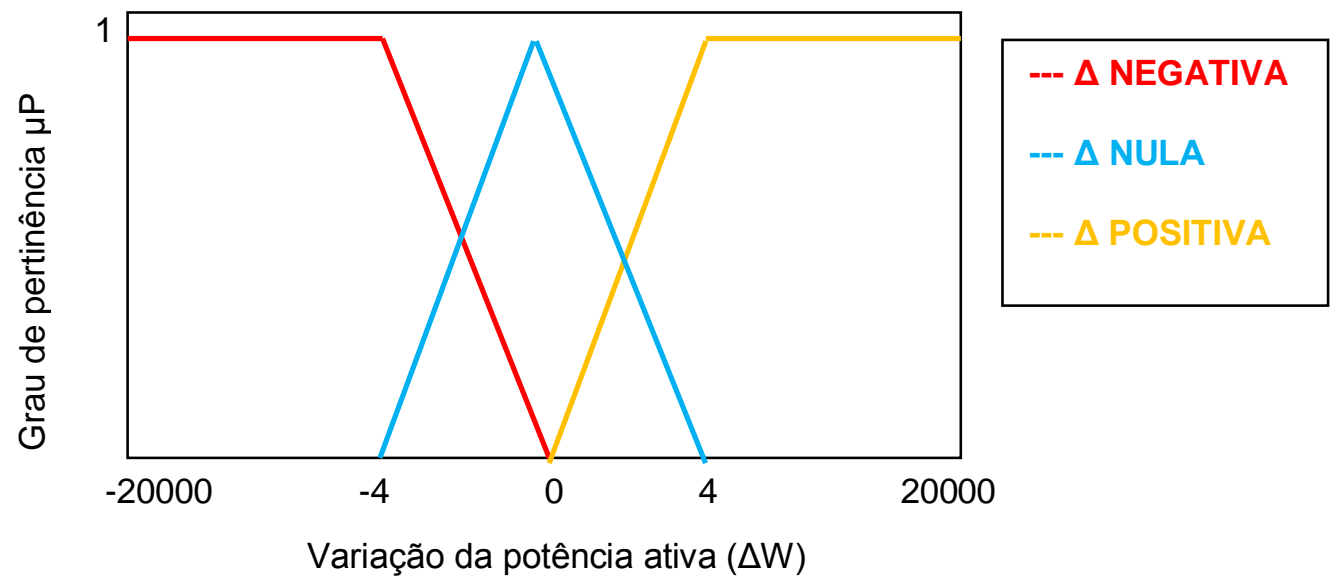

Figura 4.4 - Função de pertinência da variável de entrada "Variação da potência ativa". 
O universo de discurso da variável de entrada "Variação da potência reativa" (Figura 4.5) assemelha-se ao da variável "Variação da potência ativa", porém possui variação entre 20000 var e +20000 var visando um cenário onde a carga seja totalmente reativa.

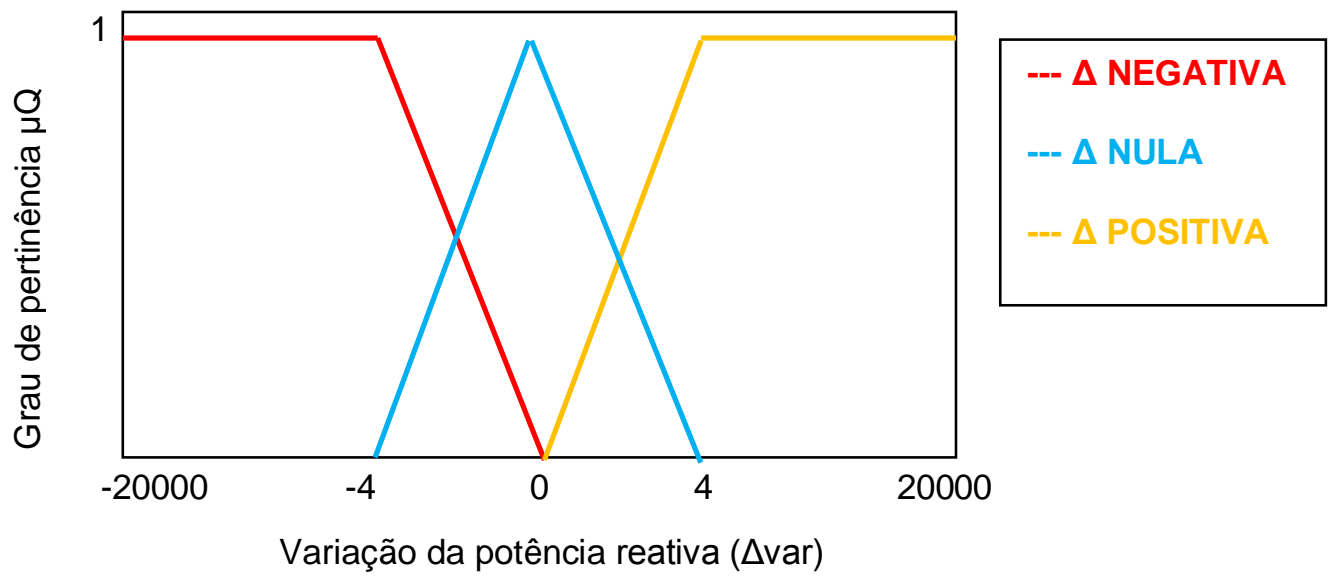

Figura 4.5 - Função de pertinência da variável de entrada "Variação da potência reativa".

Os termos componentes desta variável são: "Variação Negativa" (-20000 var/0 var), "Variação Nula" (-4 var/+4 var) e "Variação Positiva" (+0 var/+20000 var). O termo "Variação Nula" também foi ajustado de forma que na ocorrência das variações intrínsecas do equipamento, nos valores de 2 var e -2 var na medição da potência reativa, o grau de pertinência $(\mu Q)$ seja igual 0,5 . O Teste 6.4.1, apresentado no Capítulo 6, mostra a efetividade deste ajuste.

Por meio da Figura 4.6, observa-se que o universo de discurso da variável de entrada "Variação da tensão RMS" possui variação entre -137 V e 137 V, a qual compreende a faixa de tensão RMS monofásica acrescida de uma margem de segurança de $\pm 10 \mathrm{~V}$.

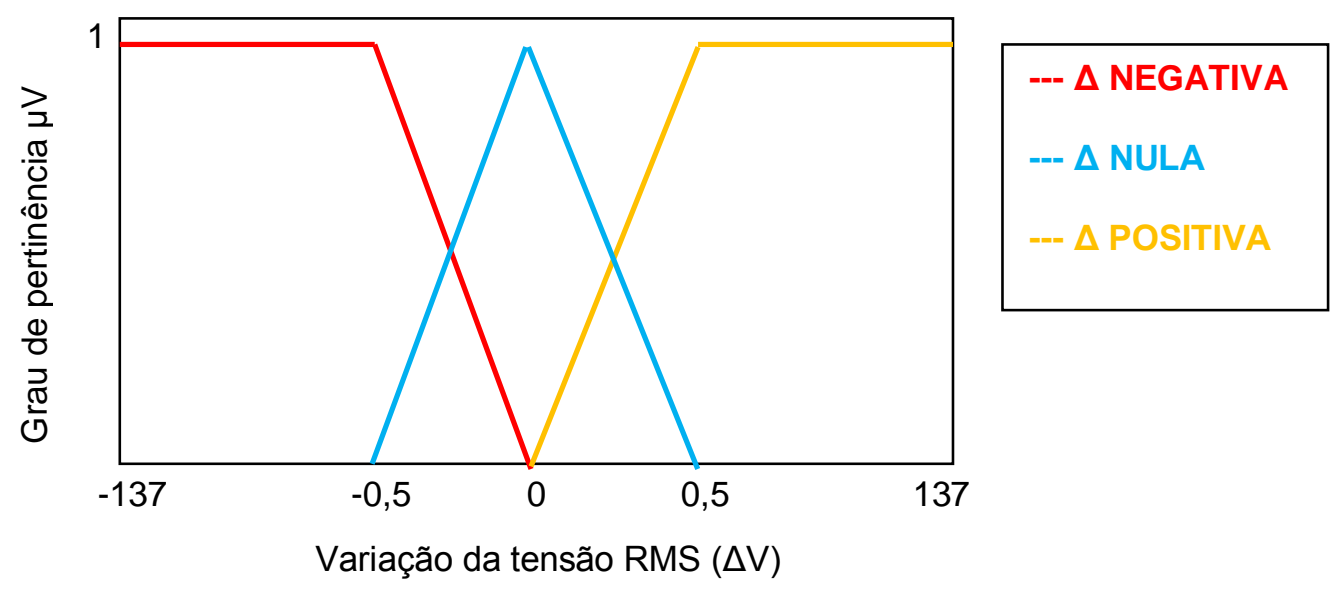

Figura 4.6 - Função de pertinência da variável de entrada "Variação da tensão RMS". 
Os termos componentes desta variável são: "Variação Negativa" (-137 V/0 V), "Variação Nula" (-0,5 V/+0,5 V) e "Variação Positiva" (0 V/+137 V). O termo "Variação Nula", de forma semelhante ao que ocorreu nas variáveis linguísticas "Variação da potência ativa" e "Variação da potência reativa", também foi ajustado para que na ocorrência de variações iguais a $+250 \mathrm{mV}$ ou $-250 \mathrm{mV}$ o grau de pertinência $(\mu V)$ seja igual 0,5.

A Figura 4.7 mostra o universo de discurso normalizado para os consequentes das regras, representando as três possíveis classes (CARGA, INDETERMINADO e REDE) esperadas como saída para o sistema. No ajuste dos termos para esta variável buscou-se obter intervalos para seleção de classe com tamanhos próximos, os quais se mostraram efetivos nos testes apresentados na Seção 4 do Capítulo 6.

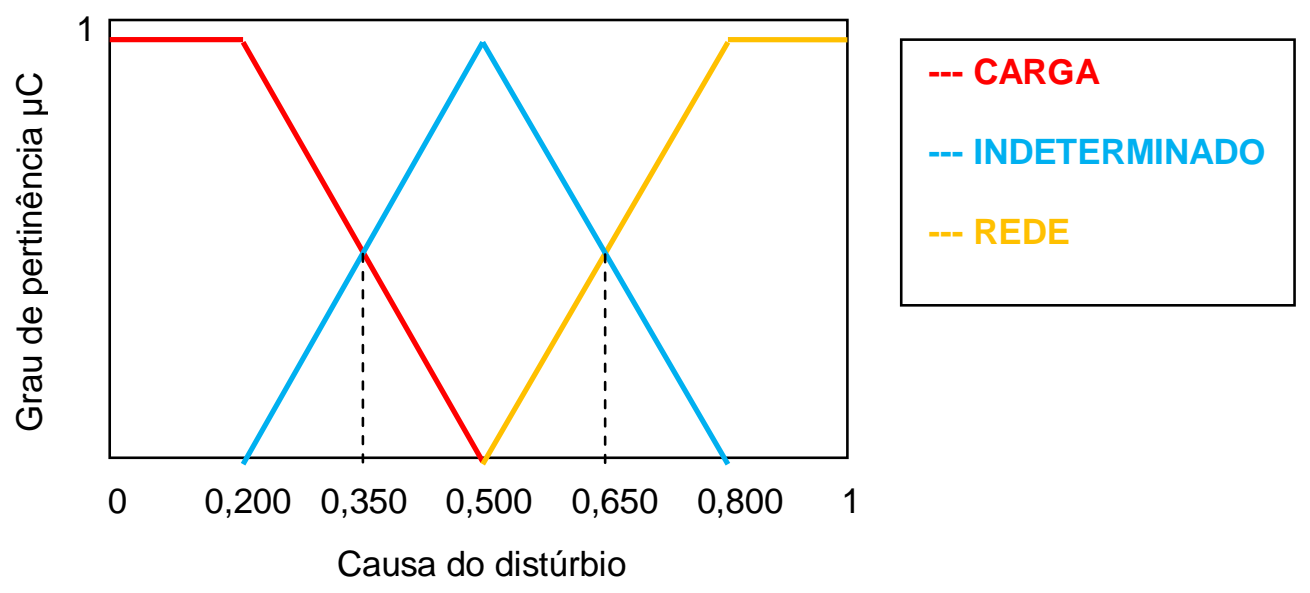

Figura 4.7 - Função de pertinência da variável de saída "Causa do distúrbio".

Visando explorar a tabela de regras mostrada na Tabela 4.7, a qual apresenta de forma otimizada as informações da Tabela 4.6, foi utilizado o conectivo "E" para a associação dos termos das variáveis de entrada e o operador de implicação Mamdani, pois os consequentes da tabela de regras são definidos por termos linguísticos (MENDEL, 2001; JASSBI et al., 2006).

Tabela 4.7 - Conjunto de regras para o sistema de inferência fuzzy

\begin{tabular}{|c|c|c|c|}
\hline$\Delta \mathbf{P} \quad \Delta \mathbf{V}$ & POSITIVA & NULA & NEGATIVA \\
\hline POSITIVA & $\begin{array}{c}\Delta \mathrm{Q}>0-\mathrm{REDE} \\
\Delta \mathrm{Q}=0-\mathrm{IND} \\
\Delta \mathrm{Q}<0-\mathrm{CARGA}\end{array}$ & CARGA & CARGA \\
\hline NULA & CARGA & $\begin{array}{c}\Delta \mathrm{Q}>0-\text { CARGA } \\
\Delta \mathrm{Q}=0-\mathrm{IND} \\
\Delta \mathrm{Q}<0-\mathrm{CARGA}\end{array}$ & CARGA \\
\hline NEGATIVA & CARGA & CARGA & $\begin{array}{c}\Delta Q>0-\text { CARGA } \\
\Delta Q=0-\text { IND } \\
\Delta Q<0-\text { REDE }\end{array}$ \\
\hline
\end{tabular}


Foi determinado para o sistema proposto que as funções de pertinência das três variáveis de entrada (Variação da tensão RMS, Variação da potência ativa e Variação da potência reativa) podem ativar até seis regras ao mesmo tempo sem gerar grande impacto no tempo de processamento. Assim para este projeto foi utilizado o operador de agregação "máximo", visando combinar as contribuições das regras ativadas.

Com a região fuzzy de saída, aplica-se o operador de defuzzificação $C D A$ a fim de obter um valor pontual pertencente ao universo de discurso da variável fuzzy de saída "Causa do distúrbio". Mesmo este operador requisitando uma maior complexidade computacional quando comparado a outros métodos (YEN e LANGARI, 1998), a utilização de 200 pontos na obtenção da região fuzzy de saída viabilizou a utilização deste operador no equipamento, o qual se mostrou eficiente por meio dos testes apresentados na Seção 4 do Capítulo 6.

A referida classe a ser fornecida como resposta será dada pelo termo que produzir o maior grau de ativação em relação ao valor defuzzificado. Assim, em relação à Figura 4.7, foram obtidos os seguintes intervalos para seleção de classe:

- Classe CARGA: entre 0 e 0,350;

- Classe INDETERMINADO: entre 0,350 e 0,650;

- Classe REDE: entre 0,650 e 1.

É importante ressaltar que o sistema de inferência fuzzy é processado para as três fases de tensão no firmware do microcontrolador de forma sequencial (primeiramente para a fase A, seguida da fase B e da fase C). O tempo de aquisição entre as amostras de tensão, potência ativa e reativa, utilizado para o cálculo das variações dessas grandezas, é um parâmetro configurável (Tempo para o cálculo das variações $\Delta V_{R M S}, \Delta P$ e $\Delta Q$ ), citado na Tabela 5.5 do Capítulo 5.

\subsection{ESTIMAÇÃO NA UNIDADE DE MEDIÇÃO FASORIAL DOS PARÂMETROS ELÉTRICOS DA CARGA E DA REDE}

Após a identificação da causa do distúrbio (carga ou rede) em cada uma das fases por meio do sistema de inferência fuzzy, a $P M U$ armazena este dado acompanhado dos valores atuais de tensão e corrente RMS, potência ativa e potência reativa em um buffer rotativo, onde podem ser armazenados até 16 conjuntos destes dados. A causa do distúrbio e os valores das 
grandezas armazenadas podem ser solicitados pelo servidor utilizando o protocolo DNP3, como detalhado posteriormente por meio da Tabela 5.6 (Capítulo 5) e ilustrado no Teste 6.2.17 (Capítulo 6).

Com a utilização da informação da causa do distúrbio e dos últimos valores para a tensão e corrente RMS, potência ativa e potência reativa, é possível com um servidor remoto estimar os parâmetros elétricos da carga e da rede com boa precisão e também modelar matematicamente as cargas, como mostrado em detalhes no Capítulo 7.

Nesta seção é apresentada uma técnica para a estimação dos parâmetros elétricos da carga e da rede, a qual foi implementada no firmware do microcontrolador do equipamento. Esta técnica não necessita de um grande nível de processamento, mas exige a adoção de certas condições iniciais as quais serão comentadas a seguir para que sejam obtidos resultados com boa precisão.

Imediatamente após a identificação da causa do distúrbio, o firmware do equipamento executa o algoritmo para cada uma das fases, cujo fluxograma é apresentado na Figura 4.8.

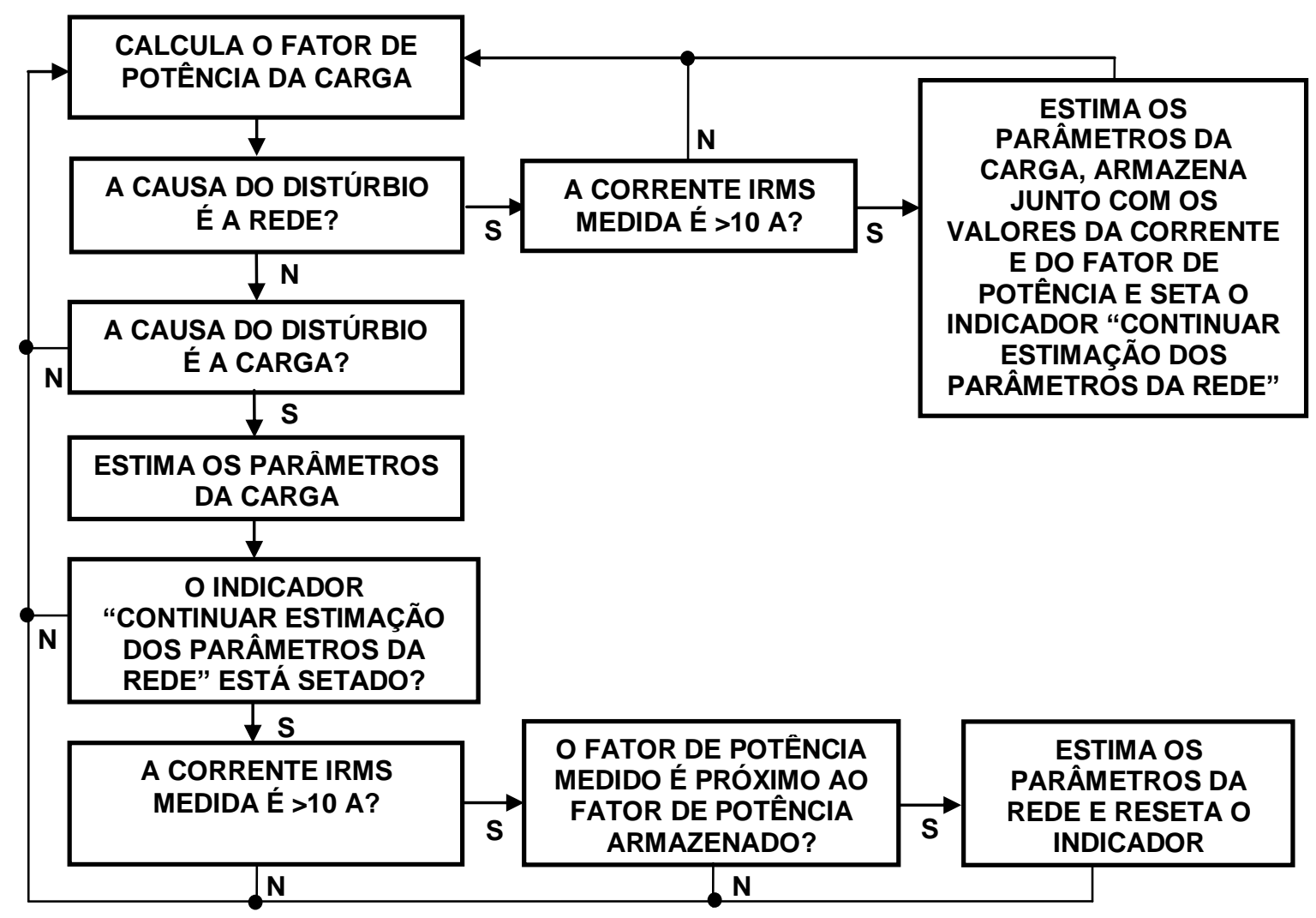

Figura 4.8 - Fluxograma do algoritmo de estimação dos parâmetros da carga e da rede

É possível verificar no algoritmo que o primeiro passo a ser executado é o cálculo do fator de potência, o qual é obtido por meio da Equação (4.1) (ALEXANDER et al., 2014) e 
onde são utilizadas as potência ativa e aparente medidas pela Unidade de Medição Fasorial Otimizada.

$$
F P=\frac{P_{C}}{S_{C}}
$$

onde $P_{C}$ e $S_{C}$ são respectivamente as potência ativa e aparente medidas na carga.

Em seguida, caso seja a rede a causa do distúrbio e a corrente RMS medida pelo equipamento superior a $10 \mathrm{~A}$, os valores do fator de potência e da corrente RMS são armazenados, o indicador "Continuar estimação dos parâmetros da rede" é setado e é realizada a estimação dos parâmetros resistivo $\left(R_{C}\right)$ e reativo $\left(X_{C}\right)$ da carga, utilizando as Equações (3.37) e (3.38).

Caso a carga seja a causa do distúrbio, a estimação dos parâmetros resistivo $\left(R_{C}\right)$ e reativo $\left(X_{C}\right)$ da carga é realizada imediatamente por meio das Equações (3.37) e (3.38). Em seguida é verificado se o indicador "Continuar estimação dos parâmetros da rede" está setado, se a corrente medida é superior a $10 \mathrm{~A}$ e se o valor do fator de potência medido para a carga varia até $\pm 0,1 \%$ quando comparado ao valor do fator de potência armazenado anteriormente.

Portanto, se as condições anteriores forem satisfeitas, o algoritmo realiza a estimação dos parâmetros elétricos da rede por meio de um sistema de equações (4.2) composto pelas informações levantadas anteriormente e utilizando o circuito da Figura 4.9, o qual por sua vez é baseado no circuito da Figura 4.2.

$$
\left\{\begin{array}{l}
V_{R^{\prime}}=\left(R_{R^{\prime}}+j X_{R^{\prime}}\right) I_{R M S 1}+\left(R_{C 1}+j X_{C 1}\right) I_{R M S 1} \\
V_{R^{\prime}}=\left(R_{R^{\prime}}+j X_{R^{\prime}}\right) I_{R M S 2}+\left(R_{C 2}+j X_{C 2}\right) I_{R M S 2}
\end{array}\right.
$$

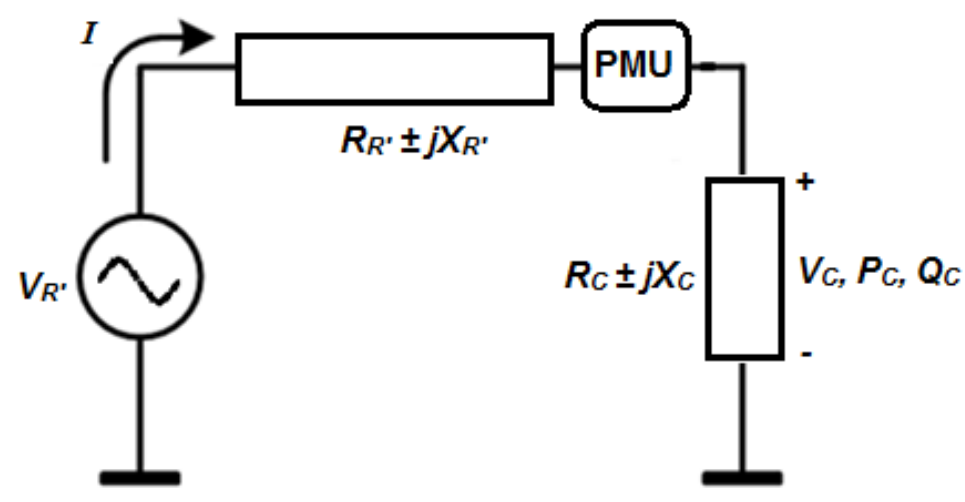

Figura 4.9 - Modelo elétrico equivalente rede-carga para apenas uma fase. 
Cada uma das equações que forma este sistema é composta pela tensão de rede refletida nos terminais secundários do transformador $\left(V_{R^{\prime}}\right)$, resultado da soma da tensão sobre a impedância complexa da rede $\left(R_{R}, \pm j X_{R}\right)$ refletida nos terminais do secundário do transformador com a tensão sobre a impedância complexa da carga $\left(R_{C} \pm j X_{C}\right)$.

A primeira equação considera a impedância complexa da carga que foi obtida pelo algoritmo após a identificação da rede como causa do distúrbio, juntamente com a corrente medida nesta ocasião. De forma análoga, a segunda equação considera a impedância complexa da carga e a corrente RMS que foram obtidas após a identificação da carga como causa do distúrbio.

A necessidade de que as correntes RMS sejam grandes, superiores a $10 \mathrm{~A}$, visa aumentar a precisão no levantamento dos parâmetros elétricos da rede, os quais apresentam valores muito pequenos por estarem refletidos nos terminais secundário do transformador durante o cálculo dos mesmos. Já em relação à necessidade de se utilizar cargas com fatores de potência muito próximos, isso permite que as partes real e imaginária das equações que utilizem estas cargas sejam igualadas, como mostrado nas Equações (4.3) e (4.4).

$$
\begin{gathered}
\left(R_{R^{\prime}}+R_{C 1}\right) I_{R M S 1}=\left(R_{R^{\prime}}+R_{C 2}\right) I_{R M S 2} \\
\left(X_{R^{\prime}}+X_{C 1}\right) I_{R M S 1}=\left(X_{R^{\prime}}+X_{C 2}\right) I_{R M S 2}
\end{gathered}
$$

O algoritmo calcula a resistência da rede refletida no secundário $\left(R_{R^{\prime}}\right)$ por meio da Equação (4.5), a qual foi obtida a partir da Equação (4.3).

$$
R_{R^{\prime}}=\frac{\left(R_{C 2} I_{R M S 2}-R_{C 1} I_{R M S 1}\right)}{\left(I_{R M S 1}-I_{R M S 2}\right)}
$$

Por sua vez, a reatância da rede refletida no secundário $\left(X_{R}\right)$ é calculada pelo algoritmo por meio da Equação (4.6), a qual foi obtida a partir da Equação (4.4).

$$
X_{R^{\prime}}=\frac{\left(X_{C 2} I_{R M S 2}-X_{C 1} I_{R M S 1}\right)}{\left(I_{R M S 1}-I_{R M S 2}\right)}
$$

Em seguida, o algoritmo substitui os parâmetros $R_{R}$, e $X_{R}$, em uma das equações que formam o sistema e calcula o módulo do parâmetro $V_{R}$, obtido por meio da Equação (4.7).

$$
V_{R^{\prime}}=\sqrt{\left(\left(R_{R^{\prime}}+R_{C 1}\right) I_{R M S 1}\right)^{2}+\left(\left(X_{R^{\prime}}+X_{C 1}\right) I_{R M S 1}\right)^{2}}
$$


Para que os parâmetros elétricos da rede sejam refletidos no lado primário do transformador, o algoritmo também utiliza as Equações (3.29), (3.34) e (3.35) exploradas na Subseção 4.5.1.

$\mathrm{Na}$ Seção 6.5 são apresentados diferentes testes visando à estimação dos parâmetros elétricos da carga e da rede. 


\section{CAPítulo 5}

\section{Transmissão de Dados Utilizando o Protocolo DNP3 OTIMIZADO}

\subsection{CARACTERIZAÇÃO DA CONEXÃO ETHERNET}

Visando otimizar a performance da Unidade de Medição Fasorial Otimizada sem abrir mão das funcionalidades essenciais que o caracterizam, estão sendo utilizados neste projeto os protocolos $M A C$, IP e TCP, sendo que na camada de aplicação está sendo utilizado o protocolo DNP3 de forma otimizada (detalhes na Seção 5.3). Assim, para que seja estabelecida a comunicação Ethernet o parâmetro "Porta" deve obrigatoriamente ser definido com o número 20000, referente ao protocolo DNP3 (TORRES, 2009).

A Unidade de Medição Fasorial Otimizada está configurada como um dispositivo "servidor", o qual possui um endereço IP fixo previamente definido e onde se conectam dispositivos "clientes" que requisitam dados relacionados aos fasores de tensão e correntes, outras grandezas elétricas e também outras informações. O diagrama em blocos da Figura 5.1 ilustra a operação da conexão Ethernet.

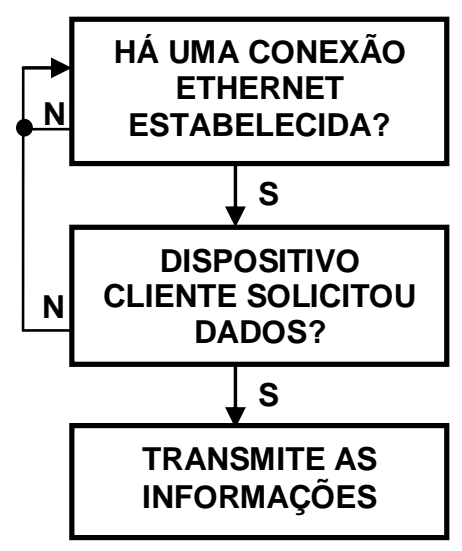

Figura 5.1 - Conexão Ethernet e transmissão das informações.

A Seção 5.2 mostra de forma sucinta as características do protocolo DNP3, informações estas necessárias para fomentar a Seção 5.3, onde é apresentado um modelo otimizado deste protocolo, o qual foi implementado na Unidade de Medição Fasorial Otimizada. 


\subsection{DESCRIÇÃO DO PROTOCOLO DNP3}

\subsubsection{Dados históricos}

O protocolo DNP3 (Distributed Network Protocol, versão 3.0) teve sua criação impulsionada pela demora da finalização do padrão IEC60870-5, já que o mercado ansiava por um padrão que focasse no quesito interoperabilidade de equipamentos de diferentes marcas utilizados nos sistemas SCADA.

Dessa forma, no início da década de noventa, a empresa Westronic utilizou os moldes inacabados do padrão IEC60870-5 para criar o protocolo DNP3 visando atender imediatamente os requisitos das plantas de energia e água do território norte-americano. Buscou-se a criação de um padrão que fosse imune às interferências eletromagnéticas (fortemente presentes nas áreas de aplicação) e que possibilitasse a transmissão de dados em meios físicos de baixa qualidade, tanto em comunicação seriais padrão $R S 232 / 485$ quanto Ethernet (CPFL ENERGIA, 2011).

O protocolo $D N P 3$ foi extensivamente utilizado em sistemas de aplicações de energia e água, sendo rara sua utilização em outros campos. Atualmente, o crescimento do número de novos sistemas com este protocolo sofreu redução devido à preferência ao padrão IEC61850, mais eficiente e de menor custo. Entretanto, o protocolo DNP3 ainda é bastante utilizado no campo de energia e distribuição, e, muitas vezes, opta-se por manter um protocolo já existente em uma planta do que implementar um novo protocolo (GRIGOLETTO, 2012).

O protocolo DNP3 é recomendado pelo IEEE e atualmente suas atualizações gerenciadas pelo DNP Group (www.dnp.org).

\subsubsection{Características Gerais}

O protocolo DNP3 pode ser dividido da maneira apresentada na Figura 5.2.

O processamento efetivo das mensagens ocorre na camada de aplicação. Muitas vezes, o tamanho da mensagem transmitida é superior ao tamanho máximo permitido na camada de Enlace, sendo assim necessária a fragmentação da mensagem, realizada pela camada de "Pseudo-Transporte", antes de repassá-la à camada de aplicação. 
MESTRE

\begin{tabular}{|c|}
\hline Camada de Aplicação \\
\hline $\begin{array}{c}\text { Camada de } \\
\text { pseudo-transporte }\end{array}$ \\
\hline Camada de enlace \\
\hline
\end{tabular}

ESCRAVO

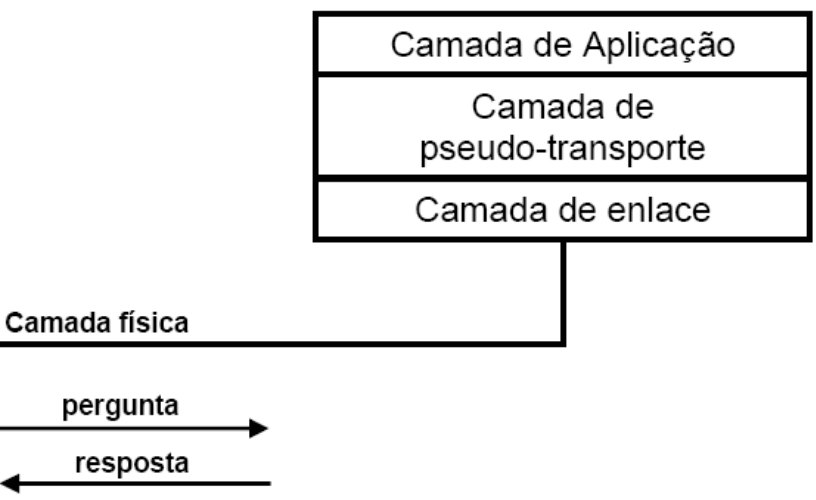

Figura 5.2 - Camadas utilizadas no DNP3 (CPFL ENERGIA, 2011).

A camada de Enlace tem a função de estabelecimento e controle do meio físico que conecta o dispositivo transmissor ao receptor, enquanto a camada Física é responsável, como o próprio nome diz, pela transmissão dos elementos básicos da mensagem, formada pelos bytes (GRIGOLETTO, 2012).

A Figura 5.3 apresenta um fluxograma genérico da sucessão de ações que podem ocorrer entre dois dispositivos que se comunicam utilizando o protocolo DNP3.

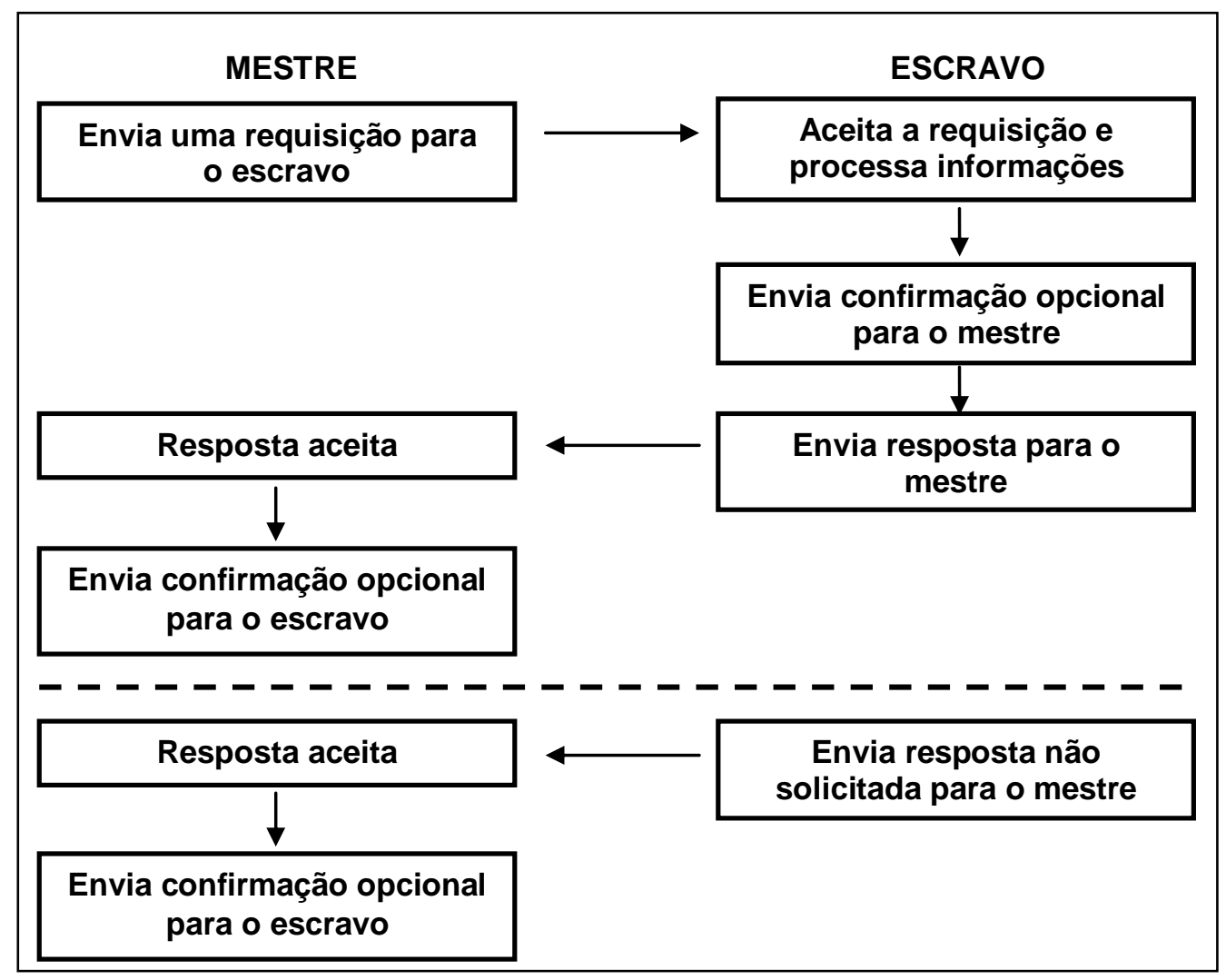

Figura 5.3 - Fluxograma de ações durante requisição (adaptado de VA TECH SAT, 2002). 
De acordo com a Figura 5.3, o dispositivo mestre manda uma mensagem de requisição a partir de sua camada de aplicação para o dispositivo escravo. Este, após interpretar a mensagem de requisição, responde ao dispositivo mestre com uma mensagem de resposta a partir de sua própria camada de aplicação.

É contemplada também no protocolo DNP3 uma modalidade na qual as mensagens de resposta chegam ao dispositivo mestre sem requisição. Em tais situações, o dispositivo mestre pode receber mensagens não solicitadas durante o processo de requisição de outra, mas o escravo só pode gerar uma mensagem espontânea quando tiver acabado de responder uma solicitação passada pelo dispositivo mestre.

Uma requisição partindo de um dispositivo mestre para um dispositivo escravo em particular só pode ser feita se todas as requisições anteriores tiverem sido finalizadas (resposta recebida, erro confirmado, por exemplo). Não é possível mandar uma requisição a um mesmo dispositivo escravo caso exista alguma comunicação pendente, ou seja, caso o dispositivo mestre esteja aguardando uma resposta (GRIGOLETTO, 2012).

\subsubsection{Formato das Mensagens}

As mensagens trocadas entre as camadas de Enlace são divididas em blocos de tamanho fixo, como mostrado na Figura 5.4.
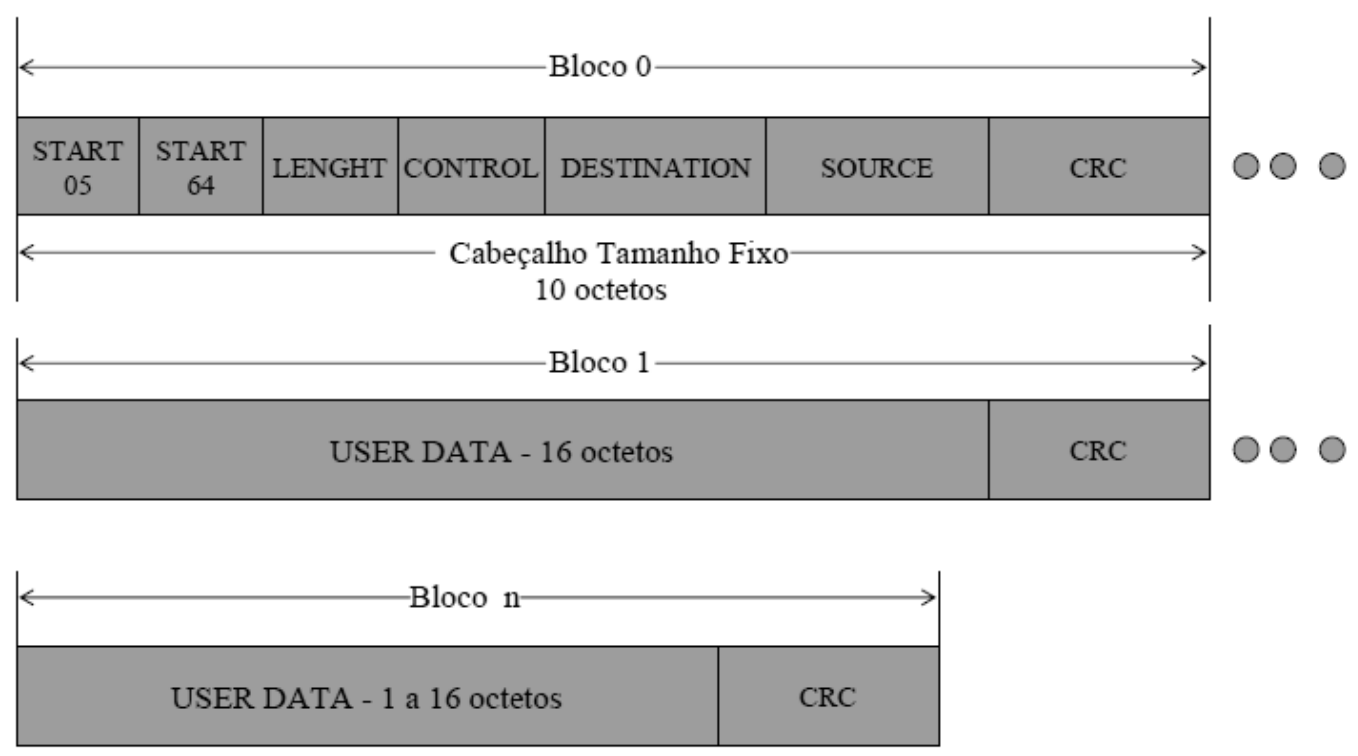

Figura 5.4 - Layout padrão dos frames DNP3 (OLIVEIRA, 2008).

As mensagens iniciam-se com o bloco 0 (Data Link Header - DLH) seguido de blocos de dados opcionais que sempre são acompanhados por dois octetos de checagem de erros 
(blocos $C R C$ ). O bloco Data Link Header, o qual corresponde à camada de enlace, possui um tamanho total de dez bytes, como mostrado na Figura 5.5.

\begin{tabular}{|c|c|c|c|c|c|}
\hline Start & Lenght & Control & Destination & Source & CRC \\
\hline 2 bytes & 1 byte & 1 byte & 2 bytes & 2 bytes & 2 bytes \\
\hline
\end{tabular}

Figura 5.5 - Data Link Header (adaptado de CPFL ENERGIA, 2011).

Os primeiros dois bytes sinalizam que a mensagem foi baseada no protocolo DNP3, e possuem valores fixos "0x05" e "0x64". O byte Lenght carrega a informação da quantidade de bytes (sempre 5 bytes), referentes aos bytes Control, Destination e Source. O byte Control possui uma codificação mostrada na Figura 5.6 e explorada em seguida.

\begin{tabular}{|c|c|c|c|c|}
\hline DIR & PRM & FCB & FCV & Function Code \\
\cline { 3 - 4 } & & RES & DFC & \\
\hline bit 7 & bit 6 & bit 5 & bit 4 & bits 3,2,1 e 0 \\
\hline
\end{tabular}

Figura 5.6 - Conteúdo do byte Control (adaptado de CPFL ENERGIA, 2011).

- DIR: Direção física de transmissão

1 - Dispositivo mestre para dispositivo escravo

0 - Dispositivo escravo para dispositivo mestre

- PRM: Mensagem primária

1 - Mensagem da estação primária (requisições)

0 - Mensagem da estação secundária (respostas)

- FCB: Frame Count Bit: Alterna entre 0 e 1 sempre que recebe a confirmação de envio da mensagem SEND-CONFIRM (Apenas quando $P R M=1$ )

- RES: Reservado (Apenas quando PRM=0)

- $F C V$ : Habilita a função do $F C B$ (Apenas quando $P R M=1$ )

1 - Habilita

0 - Desabilita

- DFC: Previne o enchimento do buffer no dispositivo escravo (Apenas quando $P R M=0$ )

1 - Mensagem SEND

0 - Mensagem REQUEST-RESPONSE

- FUNCTION CODE: Define a função da mensagem. A Tabela 5.1 mostra as funções mais comuns para requisições $(P R M=1)$ e a Tabela 5.2 para respostas $(P R M=0)$. 
Tabela 5.1 - Funções mais comuns para requisições (adaptado de OLIVEIRA, 2008).

\begin{tabular}{|c|c|c|c|c|}
\hline Função & Tipo do Quadro & Serviço & Formato & FCV \\
\hline 0 & Send/Confirm & Reset do enlace & Fixo & 0 \\
\hline 1 & Send/Confirm & $\begin{array}{c}\text { Reset do processo do } \\
\text { usuário }\end{array}$ & Fixo & 0 \\
\hline 2 & Send/Confirm & Função TEST & Fixo & 1 \\
\hline 3 & Send/Confirm & Dados do usuário & Variável & 1 \\
\hline 4 & Send/No Reply & Dados do usuário & Variável & 0 \\
\hline 9 & Request/Respond & Requisita estado enlace & Fixo & 0 \\
\hline
\end{tabular}

Tabela 5.2 - Funções mais comuns para respostas (adaptado de OLIVEIRA, 2008).

\begin{tabular}{|c|c|c|c|}
\hline Função & Tipo do Quadro & Serviço & Formato \\
\hline 0 & Confirm & ACK & Fixo \\
\hline 1 & Confirm & NACK & Fixo \\
\hline 11 & Respond & Estado do enlace & Fixo \\
\hline 14 & - & $\begin{array}{c}\text { Serviço de enlace } \\
\text { inoperante }\end{array}$ & Variável \\
\hline 15 & - & $\begin{array}{c}\text { Serviço não } \\
\text { implementado }\end{array}$ & Variável \\
\hline
\end{tabular}

Continuando a análise do bloco cabeçalho, seguem dois bytes contendo o endereço de destino da mensagem (primeiro o byte menos significativo, seguido do mais significativo) e, logo em seguida, os dois bytes referentes ao endereço de causa da mensagem (também na ordem LSB e MSB). Por último, seguem os dois bytes de checagem de erros (LSB do código cíclico seguido de seu MSB).

O endereçamento dos dispositivos pertencentes a uma rede DNP3 segue uma regra simples: dispositivos de controle são endereçados de 1 a 2000, enquanto dispositivos remotos (RTU's ou IED’s, por exemplo) são endereçados de 2001 a 65534. O último endereço 65535 (0xFFFF) é reservado para mensagens do tipo broadcast, ou seja, mensagens com este endereço de destino são entregues a todos os dispositivos da rede.

O tamanho máximo de uma mensagem é de 2048 bytes, mas sua transmissão pela camada de Enlace só pode se realizada se esta mensagem for separada em fragmentos de 249 bytes. A cada fragmento deste é adicionado um byte denominado Transport Header, cabeçalho de transporte, ou simplesmente $T H$, formando assim o bloco Transport Message (Mensagem de Transporte). Desta forma, esta mensagem de transporte pode ter, no máximo, 250 bytes.

O byte TH possui o papel de organizar a fragmentação da mensagem originária da camada de Aplicação. Este byte possui a composição mostrada na Figura 5.7, onde o primeiro 
bit FIN, quando setado, indica que o fragmento de mensagem é o último da mensagem original. Quando este bit é zero, indica que mais fragmentos ainda estão por vir.

O segundo bit FIR, quando setado, mostra que o fragmento que o segue é o primeiro fragmento da mensagem original. Os demais bits que compõe o byte $T H$ carregam o número da sequência dos fragmentos originários de uma mesma mensagem. Entre dois fragmentos contendo o bit $F I R=1$ e $F I N=1$, os bits da sequência devem ser consecutivos. A presença de códigos repetidos pertencentes à fragmentação de uma mesma mensagem significa que ocorreu uma retransmissão de informação (GRIGOLETTO, 2012).

\begin{tabular}{|c|c|c|}
\hline FIN & FIR & SEQUENCE \\
\hline 1 bit & 1 bit & 6 bits \\
\hline
\end{tabular}

Figura 5.7 - Byte Transport Header (adaptado de CPFL ENERGIA, 2011).

Em anexo a cada bloco Transport Message (TH e mais 249 bytes) há um bloco Data Link Header, mostrado anteriormente na Figura 5.5.

Também são inclusos os bytes de checagem de erros, os blocos $C R C$. Inicialmente, incluem-se dois bytes $C R C$ após o bloco de cabeçalho $D L H$, e a partir deste bloco, a cada 16 bytes vindos da camada de Pseudo-Transporte, incluem-se mais 2 bytes CRC até o último bloco que forma o fragmento da mensagem. Mesmo se este último bloco for menor que 16 bytes, fecha-se o mesmo com outros 2 bytes CRC (Figura 5.8).

\begin{tabular}{|c|c|c|c|c|c|c|c|c|}
\hline \multicolumn{7}{|c|}{ Data Link Header } & \multicolumn{6}{|c|}{ Transport Message } \\
\hline 8 bytes & CRC & 16 bytes & CRC & 16 bytes & CRC & $\cdots$ & $<=16$ bytes & CRC \\
\hline
\end{tabular}

Figura 5.8 - Mensagem DNP3 completa (adaptado de GRIGOLETTO, 2012).

Dentro do bloco Transport Message está encapsulada a camada de aplicação, cujo cabeçalho está presente após o byte Transport Header. Caso seja uma mensagem de requisição, o cabeçalho da camada de aplicação é formado por um byte denominado Application Control seguido de um byte denominado Function. Se for uma mensagem de resposta, além dos dois bytes citados anteriormente também são adicionados dois bytes denominados Internal e Indication, como mostrado na Figura 5.9. 


\section{REQUISIÇÃO}

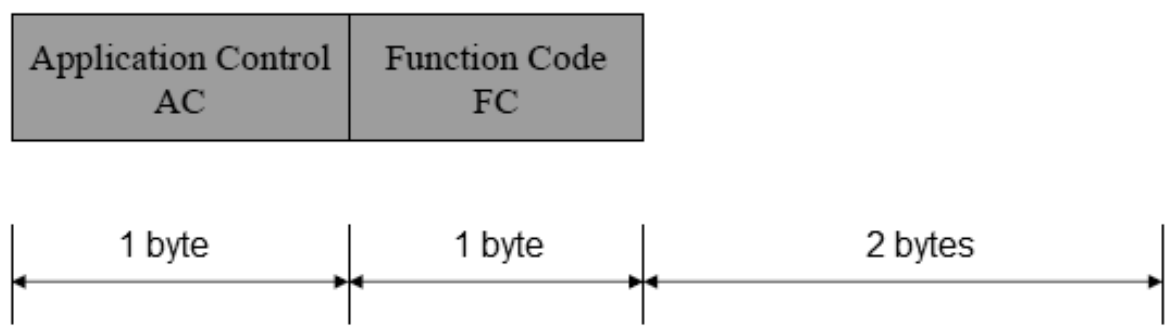

\section{RESPOSTA}

\begin{tabular}{|c|c|c|}
\hline $\begin{array}{c}\text { Application Control } \\
\text { AC }\end{array}$ & $\begin{array}{c}\text { Function Code } \\
\text { FC }\end{array}$ & Internal Indications \\
IIN \\
\hline
\end{tabular}

Figura 5.9 - Cabeçalho da camada de aplicação (adaptado de OLIVEIRA, 2008).

O byte Application Control (Figura 5.10) também possui dois bits denominados FIR e FIN que sinalizam se o fragmento que ele pertence é o primeiro ou o último fragmento da mensagem de aplicação. $\mathrm{O}$ bit $C O N$, quando setado, sinaliza que a aplicação que receber esta mensagem precisa devolver uma confirmação de envio para o transmissor. Já o bit $U N S$, quando setado, mostra que a mensagem a qual está inserido não foi solicitada por nenhuma aplicação, mas que sua geração foi espontânea. Os bits seguintes seguem o mesmo princípio dos bits do byte $T H$ : eles apresentam o número da sequência em que a mensagem de aplicação foi fragmentada, e entre duas mensagens que carregam bytes Application Control com bits FIR e FIN setados, estes bits de sequência devem ser consecutivos.

\begin{tabular}{|c|c|c|c|c|}
\hline FIR & FIN & COM & UNS & SEQUENCE \\
\hline 1 bit & 1 bit & 1 bit & 1 bit & 4 bits \\
\hline
\end{tabular}

Figura 5.10 - Composição do byte Application Control (adaptado de GRIGOLETTO, 2012).

O byte Function Code, como o próprio nome indica, mostra qual a função daquela mensagem de aplicação. Novamente, os códigos de função possuem significados diferentes caso o dispositivo seja primário ou secundário. Caso o dispositivo seja de controle, existem códigos para aplicações de transferência de dados, telecomandos, congelamento de acumuladores, controle de aplicação, configuração, sincronização de tempo, por exemplo. Caso o dispositivo seja remoto, podem-se encontrar funções de confirmação, resposta ou de mensagem não solicitada (GRIGOLETTO, 2012). A Tabela 5.3 mostra as funções mais comuns utilizadas na camada de aplicação. 
Tabela 5.3 - Funções mais comuns para a camada de aplicação (OLIVEIRA, 2008).

\begin{tabular}{|c|l|l|}
\hline Code & \multicolumn{1}{|c|}{ Function } & \multicolumn{1}{c|}{ Descrição } \\
\hline 0 & Confirm & $\begin{array}{l}\text { Confirmação do fragmento da mensagem, } \\
\text { utilizado tanto na pergunta quanto na resposta }\end{array}$ \\
\hline 1 & Read & $\begin{array}{l}\text { Pergunta de objeto especificado do escravo, } \\
\text { responde com o objeto que está disponível }\end{array}$ \\
\hline 2 & Write & $\begin{array}{l}\text { Escreve no escravo o objeto especificado, } \\
\text { responde com o estado da operação }\end{array}$ \\
\hline 129 & Response & $\begin{array}{l}\text { Resposta para uma mensagem requerida } \\
\text { Mensagens não solicitadas pelo mestre }\end{array}$ \\
\hline 130 & $\begin{array}{l}\text { Unsolicited } \\
\text { Message }\end{array}$ & Mensado \\
\hline
\end{tabular}

Os bytes Internal e Indication são obrigatórios ao final de todas as mensagens de resposta. O byte Internal (representado na Figura 5.11) é composto pelos seguintes bits: BRD, que é setado quando um comando é recebido por broadcast e zerado na próxima transmissão a ser realizada pelo dispositivo mestre; bits $C L 1, C L 2$ e $C L 3$, que quando setados (de forma exclusiva entre eles) mostram a qual tipo de classe pertencem os dados disponíveis - o dispositivo requisitante deverá adequar sua próxima mensagem de requisição para a classe correspondente; bit NTM, que quando setado indica a necessidade do dispositivo requisitante sincronizar o horário da mensagem (é zerado no momento de envio da informação de data/hora); bit $P M L$, setado quando uma ou mais saídas estão em modo local e não estão passíveis de controle via rede DNP3 (fator extremamente importante em sistemas de energia, que exige total controle local principalmente em situações de reparos); bit DVT, que indica situação anormal do dispositivo remoto; bit RST, setado quando o dispositivo remoto tiver sido reiniciado.

\begin{tabular}{|c|c|c|c|c|c|c|c|}
\hline RST & DVT & PML & NTM & CL3 & CL2 & CL1 & BRD \\
\hline 1 bit & 1 bit & 1 bit & 1 bit & 1 bit & 1 bit & 1 bit & 1 bit \\
\hline
\end{tabular}

Figura 5.11 - Composição do byte Internal (adaptado de GRIGOLETTO, 2012).

O byte Indication, representado na Figura 5.12, possui os seguintes bits: bit FNI, que quando setado, indica código de função não implementada no dispositivo remoto que a mensagem foi direcionada; bit $O U N$, em nível lógico "1" quando o objeto solicitado não existe no dispositivo ao qual a mensagem foi direcionada (situação bastante utilizada em casos de debugging); bit BOV, setado quando algum buffer possui seu limite máximo atingido; bit $O P E$, que indica que a requisição passada pelo dispositivo de controle já estava em execução antes do recebimento da mensagem; bit $C C R$, setado quando o objeto 
requisitado está corrompido, forçando o dispositivo mestre a atualizar este dado e a informar ao usuário sobre este fato (importante notar que, em muitos casos, objetos corrompidos podem reiniciar/desabilitar o dispositivo remoto, não sendo possível receber este "aviso prévio" de dado corrompido); bits NUS (seis e sete) não são utilizados (padrão igual à zero) (GRIGOLETTO, 2012).

\begin{tabular}{|c|c|c|c|c|c|c|c|}
\hline NUS & NUS & CCR & OPE & BOV & PIN & OUN & FNI \\
\hline 1 bit & 1 bit & 1 bit & 1 bit & 1 bit & 1 bit & 1 bit & 1 bit \\
\hline
\end{tabular}

Figura 5.12 - Composição do byte Indication (adaptado de GRIGOLETTO, 2012).

O cabeçalho da camada de aplicação é seguido do bloco denominado $A S D U$ (Application Service Data Unit). É neste bloco que toda a informação da aplicação de um dispositivo é passada para o outro dispositivo do link de comunicação. O bloco ASDU pode ser formado por vários blocos de informação, e cada um destes blocos é formado por um cabeçalho denominado DUI (Data Unit Identifier) seguido de um bloco de dados relacionados ao tipo de objeto especificado no cabeçalho. A Figura 5.13 mostra esquematicamente o bloco $A S D U$ e seus componentes.

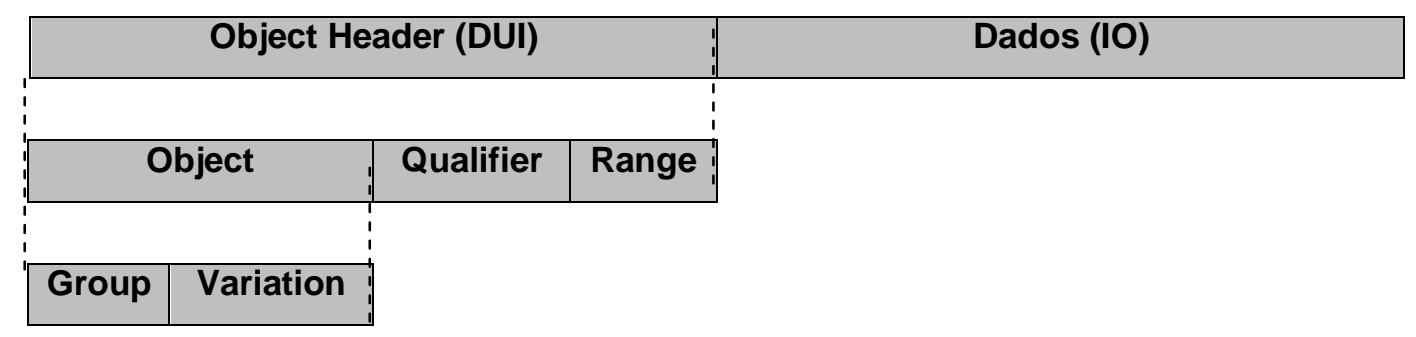

Figura 5.13 - Partes componentes do bloco ADSU (adaptado de GRIGOLETTO, 2012).

Analisando primeiramente o bloco cabeçalho de objeto DUI, verifica-se que este é composto por três outros blocos: Object, Qualifier e Range. O bloco Object, formado pelos bytes Group e Variation, carrega informações referentes ao grupo e à variação que pertence o dado daquela mensagem, sendo que esta combinação de informações define unicamente o objeto. A Tabela 5.4 mostra as combinações mais comuns de grupo e variação, trazendo também para cada combinação a função (Function) que pode ser utilizada (mostrado anteriormente na Tabela 5.3) e o qualificador (Qualifier), o qual será comentado a seguir. 
Tabela 5.4 - Grupos e variações mais comuns para a camada de aplicação (OLIVEIRA, 2008).

\begin{tabular}{|c|c|c|c|c|c|c|}
\hline \multicolumn{3}{|r|}{ Object } & \multicolumn{2}{|c|}{ Request } & \multicolumn{2}{|c|}{ Response } \\
\hline Group & Var & Description & $\begin{array}{l}\text { Func. } \\
\text { Codes } \\
\text { (dec) }\end{array}$ & $\begin{array}{l}\text { Qual } \\
\text { Codes } \\
\text { (hex) }\end{array}$ & $\begin{array}{l}\text { Func. } \\
\text { Codes } \\
\text { (dec) }\end{array}$ & $\begin{array}{l}\text { Qual } \\
\text { Codes } \\
\text { (hex) }\end{array}$ \\
\hline 1 & 0 & Binary Input - All Variations & 1 & 06 & 129,130 & $00,01,07$ \\
\hline 1 & 1 & Binary Input & 1 & 06 & 129,130 & $\begin{array}{l}00,01,07,1 \\
7,28\end{array}$ \\
\hline 1 & 2 & Binary Input with Status & 1 & 06 & 129,130 & $\begin{array}{l}00,01,07,1 \\
7,28\end{array}$ \\
\hline 2 & 1 & Binary Input Change without Time & & & 129,130 & $\begin{array}{l}00,01,07,1 \\
7,28\end{array}$ \\
\hline 2 & 2 & Binary Input Change with Time & & & 129,130 & $\begin{array}{l}00,01,07,1 \\
7,28\end{array}$ \\
\hline 2 & 3 & $\begin{array}{l}\text { Binary Input Change with Relative } \\
\text { Time }\end{array}$ & & & 129,130 & $\begin{array}{l}00,01,07,1 \\
7,28\end{array}$ \\
\hline 12 & 1 & Control Relay Output Block & $3,4,5$ & 17,28 & 129 & Echo \\
\hline 30 & 0 & Analog Input - All Variations & 1 & 06 & & \\
\hline 30 & 2 & 16-Bit Analog Input & 1 & 06 & 129,130 & $\begin{array}{l}00,01,07,1 \\
7,28\end{array}$ \\
\hline 30 & 4 & 16-Bit Analog Input without flag & 1 & 06 & 129,130 & $\begin{array}{l}00,01,07,1 \\
7,28\end{array}$ \\
\hline 32 & 2 & $\begin{array}{l}\text { 16-Bit Analog Change Event without } \\
\text { Time }\end{array}$ & & & 129,130 & $\begin{array}{l}00,01,07,1 \\
7,28\end{array}$ \\
\hline 41 & 2 & 16-Bit Analog Output Block & $3,4,5$ & 17,28 & 129 & Echo \\
\hline
\end{tabular}

O bloco Qualifier (Figura 5.14) contém informações de como interpretar a sequência de dados. Este byte possui também informação de como interpretar e especificar o byte seguinte, Range.

\begin{tabular}{|c|c|c|c|c|c|c|c|}
\hline Res & \multicolumn{3}{|c|}{ Index Size } & \multicolumn{4}{|c|}{ Qualifier Code } \\
\hline Bit 7 & Bit 6 & Bit 5 & Bit 4 & Bit 3 & Bit 2 & Bit 1 & Bit 0 \\
\hline & \multicolumn{3}{|c|}{$\begin{array}{l}0=\text { Sem índice armazenado } \\
1=1 \text { byte para } \circ \text { índice } \\
2=2 \text { bytes para } \circ \text { índice } \\
3=3 \text { bytes para } \circ \text { índice } \\
4=1 \text { byte para } \circ \text { objeto, sem índice } \\
5=2 \text { bytes para } \circ \text { objeto, sem } \\
\text { índice } \\
6=3 \text { bytes para o objeto, sem } \\
\text { índice }\end{array}$} & \multicolumn{4}{|c|}{$\begin{array}{l}0 \text { = índices de } 1 \text { byte indicando inicio e fim no } \\
\text { campo Range } \\
1 \text { = índices de } 2 \text { bytes indicando inicio e fim no } \\
\text { campo Range } \\
2 \text { = índices de } 4 \text { byte indicando inicio e fim no } \\
\text { campo Range } \\
3=\text { endereço absoluto de } 1 \text { byte no campo range } \\
4=\text { endereço absoluto de } 2 \text { bytes no campo range } \\
5=\text { endereço absoluto de } 4 \text { bytes no campo range } \\
6=\text { todos os objetos de um dado tipo (não há } \\
\text { Ranger ou índices) } \\
7 \text { = campo Range com } 1 \text { byte indicando o número } \\
\text { de índices e objetos } \\
8=\text { campo Range com } 2 \text { bytes indicando o número } \\
\text { de índices e objetos } \\
9=\text { campo Range com } 4 \text { bytes indicando o número } \\
\text { de índices e objetos }\end{array}$} \\
\hline
\end{tabular}

Figura 5.14 - Composição do byte Qualifier (adaptado de CPFL, 2011). 
O código de qualificação carregado nos quatro bits menos significativos do byte Qualifier mostra ao dispositivo receptor que tipo de informação está sendo recebida. Já os bits 4, 5 e 6 deste byte carregam informações de como interpretar o tamanho dos índices ou dos dados indexados no byte Range (GRIGOLETTO, 2012).

\subsection{IMPLEMENTAÇÃO OTIMIZADA DO PROTOCOLO DNP3}

A unidade de mediação fasorial otimizada para sistemas de distribuição funciona como um dispositivo DNP3 "Escravo", o qual responde às requisições solicitadas por um dispositivo DNP3 “Mestre” (sistema supervisor ou de controle).

O protocolo $D N P 3$ foi implementado de forma otimizada na Unidade de Mediação Fasorial, levando-se em consideração as características funcionais do equipamento, o que possibilitou assim um menor tempo de processamento nas tarefas relacionadas ao fluxo de mensagens. Porém, não foi deixado de atender a norma do protocolo DNP3, garantindo por meio de testes utilizando o software ASE2000 (1999) a compatibilidade com qualquer sistema supervisor ou de controle.

A seguir são apresentadas as principais otimizações implementadas.

\subsubsection{Envio de mensagens de resposta sem requisição}

O equipamento de medição fasorial não envia mensagens de resposta ao dispositivo mestre sem requisição, o que evita assim a necessidade de um gerenciamento mais robusto e eventuais perdas de mensagens enviadas.

\subsubsection{Funções relacionadas às requisições}

Somente requisições com as funções 0 (Reset do enlace), 1 (Reset do processo do usuário) e 4 (Dados do usuário) são processadas e geram resposta para o dispositivo "Master". Caso seja recebida uma requisição com uma função diferente destas citadas, o equipamento irá responder com a função 15 (Serviço não implementado). As requisições com as funções 0,1 e 4 cobrem todas as necessidades funcionais do equipamento, como será mostrado mais adiante na Seção 5.4. 


\subsubsection{Processamento de mensagens fragmentadas}

Uma outra otimização implementada no equipamento diz respeito ao não processamento de mensagens fragmentadas, tanto na camada de pseudo-transporte quanto na camada de aplicação, o que evita assim a necessidade de um gerenciamento mais robusto e eventuais perdas de mensagens recebidas.

Desta forma, serão respondidas com a função 1 (NACK) mensagens de requisição onde os bits FIR e FIN, presentes nos bytes Transport Message (TH) da camada de pseudotransporte e Application Control ( $A C$ ) da camada de aplicação, não estejam setados.

\subsubsection{Mensagem de confirmação de envio}

O equipamento não envia mensagem de confirmação de envio de resposta para o dispositivo mestre, que evita assim novamente a necessidade de um gerenciamento mais robusto. Desta forma, mensagens recebidas com o bit CON do byte Application Control (AC) setado são respondidas com a função $1(N A C K)$.

\subsubsection{Grupos, variações e qualificadores de objetos}

O único grupo de objetos da camada de aplicação, representado pelo byte Group e processado pelo equipamento é o do tipo 30 (Analog Input). Acompanhadas deste grupo só são processadas também mensagens com o byte Variation igual a 0 (All variations) ou 2 (16 bits). Para o byte Qualifier só são aceitos os códigos 0x00, 0x01 ou 0x28.

Estes grupos, variações e qualificadores cobrem todas as necessidades funcionais do equipamento, como será mostrado mais adiante na Seção 5.4.

Caso nas requisições estejam presentes outros grupos ou variações, estas serão respondidas com a função 1 (NACK).

Na Seção 5.4 são mostradas com mais detalhes as formas de requisição de leitura de fasores e de outras grandezas elétricas e de requisição de escrita de parâmetros de configuração, os quais estão presentes na Unidade de Medição Fasorial Otimizada. 


\subsection{REQUISIÇÃO DE FASORES E OUTRAS GRANDEZAS ELÉTRICAS}

\subsubsection{Endereços de fasores, demais grandezas elétricas e parâmetros de configuração}

Nas Tabelas 5.5 e 5.6 são mostrados os endereços dos fasores, das demais grandezas elétricas e de parâmetros que podem ser configurados no equipamento, indicando quais destes dados podem ser lidos e/ou escritos.

Tabela 5.5 - Primeira parte: endereço de fasores, grandezas e parâmetros de configuração.

\begin{tabular}{|c|c|c|}
\hline Endereço & Dado & Leitura/escrita \\
\hline $\begin{array}{l}0 \times 0000- \\
0 \times 0063\end{array}$ & $\begin{array}{l}\text { Fasor de tensão fase A (buffer rotativo de } 100 \text { fasores, sendo que } \\
\text { no endereço 0x0000 está o fasor mais recente e no endereço } \\
\text { 0x0063 o mais antigo) }\end{array}$ & Apenas leitura \\
\hline $\begin{array}{l}0 \times 0100- \\
0 \times 0163\end{array}$ & $\begin{array}{l}\text { Fasor de tensão fase } B \text { (buffer rotativo de } 100 \text { fasores, sendo que } \\
\text { no endereço 0x0100 está o fasor mais recente e no endereço } \\
\text { 0x0163 o mais antigo) }\end{array}$ & Apenas leitura \\
\hline $\begin{array}{l}0 \times 0200- \\
0 \times 0263\end{array}$ & $\begin{array}{l}\text { Fasor de tensão fase C (buffer rotativo de } 100 \text { fasores, sendo que } \\
\text { no endereço 0x0200 está o fasor mais recente e no endereço } \\
\text { 0x0263 o mais antigo) }\end{array}$ & Apenas leitura \\
\hline $\begin{array}{l}0 \times 0300- \\
0 \times 0363\end{array}$ & $\begin{array}{l}\text { Fasor de corrente fase } A \text { (buffer rotativo de } 100 \text { fasores, sendo que } \\
\text { no endereço 0x0300 está o fasor mais recente e no endereço } \\
\text { 0x0363 o mais antigo) }\end{array}$ & Apenas leitura \\
\hline $\begin{array}{l}0 \times 0400- \\
0 \times 0463\end{array}$ & $\begin{array}{l}\text { Fasor de corrente fase B (buffer rotativo de } 100 \text { fasores, sendo que } \\
\text { no endereço 0x0400 está o fasor mais recente e no endereço } \\
\text { 0x0463 o mais antigo) }\end{array}$ & Apenas leitura \\
\hline $\begin{array}{l}0 \times 0500- \\
0 \times 0563\end{array}$ & $\begin{array}{l}\text { Fasor de corrente fase } C \text { (buffer rotativo de } 100 \text { fasores, sendo que } \\
\text { no endereço 0x0500 está o fasor mais recente e no endereço } \\
\text { 0x0563 o mais antigo) }\end{array}$ & Apenas leitura \\
\hline $0 \times 0600$ & Frequência atual para a fase $A$ & Apenas leitura \\
\hline $0 \times 0601$ & Frequência atual para a fase $B$ & Apenas leitura \\
\hline $0 \times 0602$ & Frequência atual para a fase $C$ & Apenas leitura \\
\hline $0 \times 0603$ & Tensão RMS atual para a fase $A$ & Apenas leitura \\
\hline $0 \times 0604$ & Tensão RMS atual para a fase $B$ & Apenas leitura \\
\hline $0 \times 0605$ & Tensão RMS atual para a fase $\mathrm{C}$ & Apenas leitura \\
\hline $0 \times 0606$ & Corrente RMS atual para a fase $A$ & Apenas leitura \\
\hline $0 \times 0607$ & Corrente RMS atual para a fase $\mathrm{B}$ & Apenas leitura \\
\hline $0 \times 0608$ & Corrente RMS atual para a fase $\mathrm{C}$ & Apenas leitura \\
\hline $0 \times 0609$ & Potência ativa atual para a fase $\mathrm{A}$ & Apenas leitura \\
\hline $0 \times 060 \mathrm{~A}$ & Potência ativa atual para a fase $B$ & Apenas leitura \\
\hline $0 \times 060 \mathrm{~B}$ & Potência ativa atual para a fase $\mathrm{C}$ & Apenas leitura \\
\hline $0 \times 060 \mathrm{C}$ & Potência aparente atual para a fase $A$ & Apenas leitura \\
\hline $0 \times 060 \mathrm{D}$ & Potência aparente atual para a fase $B$ & Apenas leitura \\
\hline 0x060E & Potência aparente atual para a fase $\mathrm{C}$ & Apenas leitura \\
\hline $0 \times 060 \mathrm{~F}$ & Potência reativa atual para a fase $A$ & Apenas leitura \\
\hline $0 \times 0610$ & Potência reativa atual para a fase $B$ & Apenas leitura \\
\hline $0 \times 0611$ & Potência reativa atual para a fase $\mathrm{C}$ & Apenas leitura \\
\hline
\end{tabular}


Tabela 5.6 - Segunda parte: endereço de fasores, grandezas e parâmetros de configuração.

\begin{tabular}{|c|c|c|}
\hline Endereço & Dado & Leitura/escrita \\
\hline $\begin{array}{l}0 \times 0620- \\
0 \times 062 F\end{array}$ & $\begin{array}{l}\text { Indicador da causa do distúrbio na fase A e últimas medições } \\
\text { (buffer rotativo de } 16 \text { indicadores, sendo que no endereço 0x0620 } \\
\text { está o indicador mais recente e no endereço 0x062F o mais antigo) }\end{array}$ & Apenas leitura \\
\hline $\begin{array}{l}0 \times 0630- \\
0 \times 063 F\end{array}$ & $\begin{array}{l}\text { Indicador da causa do distúrbio na fase } \mathrm{B} \text { e últimas medições } \\
\text { (buffer rotativo de } 16 \text { indicadores, sendo que no endereço 0x0630 } \\
\text { está o indicador mais recente e no endereço 0x063F o mais antigo) }\end{array}$ & Apenas leitura \\
\hline $\begin{array}{l}0 \times 0640- \\
0 \times 064 \mathrm{~F}\end{array}$ & $\begin{array}{l}\text { Indicador da causa do distúrbio na fase } \mathrm{C} \text { e últimas medições } \\
\text { (buffer rotativo de } 16 \text { indicadores, sendo que no endereço 0x0640 } \\
\text { está o indicador mais recente e no endereço 0x064F o mais antigo) }\end{array}$ & Apenas leitura \\
\hline $0 \times 0650$ & Último valor da resistência da carga estimado para a fase $A$ & Apenas leitura \\
\hline $0 \times 0651$ & Último valor da reatância da carga estimado para a fase $\mathrm{A}$ & Apenas leitura \\
\hline $0 \times 0652$ & Último valor da resistência da rede estimado para a fase $A$ & Apenas leitura \\
\hline $0 \times 0653$ & Último valor da reatância da rede estimado para a fase $A$ & Apenas leitura \\
\hline $0 \times 0654$ & Último valor da tensão da rede estimado para a fase $\mathrm{A}$ & Apenas leitura \\
\hline $0 \times 0655$ & Último valor da resistência da carga estimado para a fase $B$ & Apenas leitura \\
\hline $0 \times 0656$ & Último valor da reatância da carga estimado para a fase B & Apenas leitura \\
\hline $0 \times 0657$ & Último valor da resistência da rede estimado para a fase B & Apenas leitura \\
\hline $0 \times 0658$ & Último valor da reatância da rede estimado para a fase B & Apenas leitura \\
\hline $0 \times 0659$ & Último valor da tensão da rede estimado para a fase B & Apenas leitura \\
\hline $0 \times 065 \mathrm{~A}$ & Último valor da resistência da carga estimado para a fase $\mathrm{C}$ & Apenas leitura \\
\hline 0x065B & Último valor da reatância da carga estimado para a fase C & Apenas leitura \\
\hline $0 \times 065 \mathrm{C}$ & Último valor da resistência da rede estimado para a fase C & Apenas leitura \\
\hline $0 \times 065 \mathrm{D}$ & Último valor da reatância da rede estimado para a fase C & Apenas leitura \\
\hline $0 \times 065 \mathrm{E}$ & Último valor da tensão da rede estimado para a fase $\mathrm{C}$ & Apenas leitura \\
\hline $0 \times 0700$ & Reset dos buffers fasoriais (1 para reset) & Apenas escrita \\
\hline $0 \times 0701$ & $\begin{array}{l}\text { Frequência de amostragem de fasores/grandezas (1 a } 65535 \\
\text { segundos) }\end{array}$ & Leitura/escrita \\
\hline $0 \times 0702$ & Quantidade de fasores a cada amostragem (1 a 5 unidades) & Leitura/escrita \\
\hline $0 \times 0703$ & $\begin{array}{l}\text { Frequência para a identificação da causa do distúrbio (multiplicador } \\
\text { do parâmetro "Frequência de amostragem"). Valor múltiplo de } 2 \text { até } \\
65534 \text {. O tempo para o cálculo das variações dos parâmetros é } \\
\text { metade da frequência para identificação. }\end{array}$ & Leitura/escrita \\
\hline $0 \times 0704$ & $\begin{array}{l}\text { Habilitar reflexo somente dos fasores de tensão e corrente para os } \\
\text { terminais do primário do transformador ( } 1 \text { para habilitar) }\end{array}$ & Leitura/escrita \\
\hline $0 \times 0705$ & Configurar o parâmetro $n 1$ do tranformador (1 a 65536) & Leitura/escrita \\
\hline $0 \times 0706$ & Configurar o parâmetro $n 2$ do tranformador (1 a 65536) & Leitura/escrita \\
\hline $0 \times 0707$ & Configurar o parâmetro $r 1$ do tranformador (1 a $65536 \mathrm{~m} \Omega$ ) & Leitura/escrita \\
\hline $0 \times 0708$ & Configurar o parâmetro $r 2$ do tranformador (1 a $65536 \mathrm{~m} \Omega$ ) & Leitura/escrita \\
\hline $0 \times 0709$ & Configurar o parâmetro $L 1$ do tranformador (1 a $65536 \mu \mathrm{H}$ ) & Leitura/escrita \\
\hline $0 \times 070 \mathrm{~A}$ & Configurar o parâmetro $L 2$ do tranformador (1 a $65536 \mu \mathrm{H}$ ) & Leitura/escrita \\
\hline
\end{tabular}




\subsubsection{Leitura de fasores, grandezas elétricas e parâmetros de configuração}

Para a realização da leitura destes dados é necessário primeiramente que o byte Function Code seja igual a 1(Read) e o byte Variations seja igual a 0 (All variations). Podem ser solicitados até cinco dados sequenciais de uma vez, por meio de um único endereço ou de uma faixa utilizando-se para isso o byte Qualifier com valor igual a 0x00, 0x01 ou 0x28.

Quando é recebida uma requisição solicitando a leitura de dados de grandezas elétricas, o equipamento envia uma resposta que sempre contém a data e hora da última aquisição realizada e a(s) grandeza(s) solicitada(s), sendo estes dados codificados em ASCII. As grandezas elétricas sempre seguem o formato \pm XXXXXX. Para as frequências o valor está em $\mathrm{mHz}$, para as tensões RMS em mV(baixa tensão)/V(média tensão), para as correntes RMS em mA, para as potências ativas em $\mathrm{W}$, reativas em VAR e aparentes em VA.

- Exemplo1: Leitura da frequência da fase A

Para este exemplo, as mensagens de requisição e resposta são mostradas respectivamente nas Figuras 5.15 e 5.16.

0564 0F C4 01000000 E2 C8 C0 C0 01 1E 002801000006 FC D8

Figura 5.15 - Mensagem de requisição para a leitura da frequência da fase $A$.

onde: 0xC4: Link Control

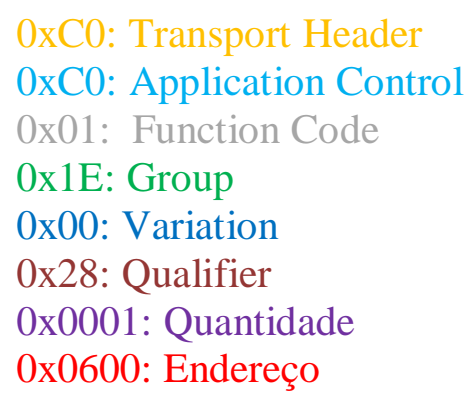

0564 2C 4400000100 FF B9 CO C0 810000 1E 0017 1E 0D 0A 3034 2F 3033 75 5A 2F 3135203131 3A 3035 3A 3032 0D 0A 2B 30 9D 623539393939 0D 0A A3 E1

Figura 5.16 - Mensagem de resposta para a leitura da frequência da fase A.

onde: 0x44: Link Control

OxC0: Transport Header

0xC0: Application Control

0x81: Function Code

0x1E: Group

0x00: Variation 
0x17: Qualifier

0x1E: Quantidade

Dados em ASCII: "04/03/15 11:05:02”

“+059999”

- Exemplo 2: Leitura das potências ativas nas fases B e C

A mensagem de requisição solicitando a leitura das potências ativas nas fases B e C é mostrada na Figura 5.17, enquanto a mensagem de resposta é mostrada na Figura 5.18.

0564 0F C4 01000000 E2 C8 C0 C0 01 1E 0001 0A 06 0B 06 F8 D7

Figura 5.17 - Mensagem de requisição para a leitura das potências ativas nas fases B e C.

onde: 0xC4: Link Control

OxC0: Transport Header

0xC0: Application Control

0x01: Function Code

0x1E: Group

0x00: Variation

0x01: Qualifier

0x060A: Endereço inicial

0x060B: Endereço final

0564354400000100 FF B9 C0 C0 810000 1E 001727 0D 0A 3034 2F 3033 75 5A 2F 3135203131 3A 3035 3A 3032 0D 0A 2B 30 9D 623030333337 0D 0A 2B 30 3030333334 0D 0A 4400

Figura 5.18 - Mensagem de resposta para a leitura das potências ativas nas fases B e C.

onde: 0x44: Link Control

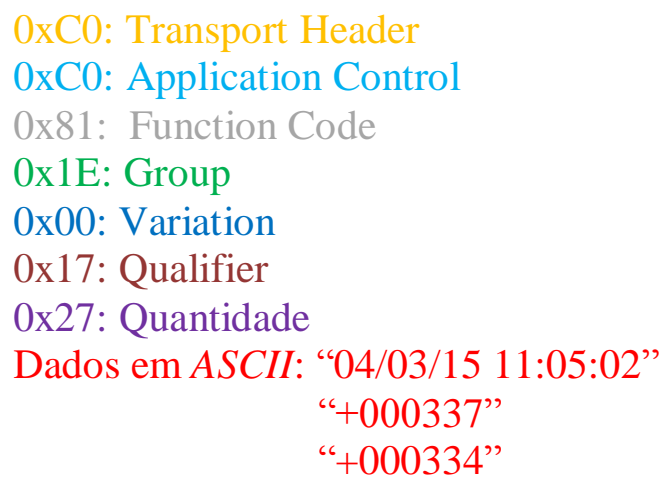

No caso de uma requisição solicitando a leitura dos indicadores de causas de distúrbios, o equipamento envia uma resposta que sempre contém no formato ASCII a data e hora da última aquisição realizada, a causa do distúrbio e as variações da tensão RMS, da corrente

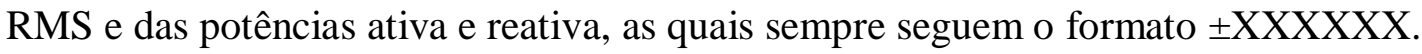


- Exemplo 3: Leitura das duas causas mais recentes de distúrbios na fase A

Para este exemplo a mensagem de requisição é mostrada na Figura 5.19.

0564 0F C4 01000000 E2 C8 C0 C0 01 1E 000120062106 F8 D7

Figura 5.19 - Mensagem de requisição para a leitura das duas causas de distúrbio na fase $\mathrm{A}$.

onde: 0xC4: Link Control

OxC0: Transport Header

0xC0: Application Control

0x01: Function Code

0x1E: Group

0x00: Variation

0x01: Qualifier

0x0620: Endereço inicial

0x0621: Endereço final

Já a mensagem de resposta é mostrada na Figura 5.20.

0564714400000100 FF B9 C0 C0 810000 1E 001763 0D 0A 3034 2F 303375 5A

2F 3135203131 3A 3035 3A 3032 0D 0A 49 4E ED 6444202020 2B 31323731

313220 2B 303031542330303020 2B 30303031323720 2B 30303033 A2 30

3030 0D 0A 49 4E 44202020 2B 31323730 B4 21313020 2B 30303131303120

2B 3030303182 7F 333920 2B 303030303030 0D 0A 4E AB

Figura 5.20 - Mensagem de resposta para a leitura das duas causas de distúrbio na fase A.

onde: 0x44: Link Control

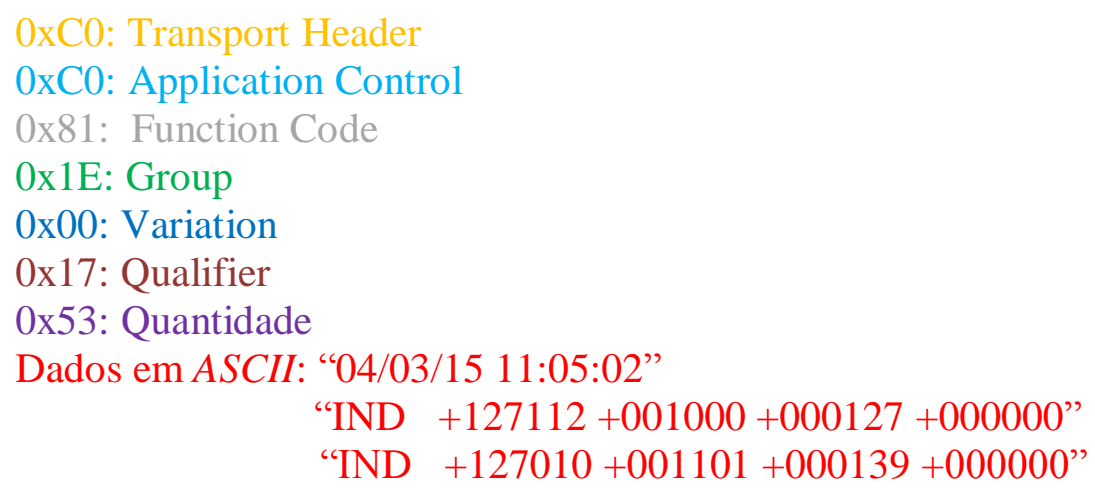

Para uma requisição solicitando a leitura dos parâmetros estimados para a carga e para a rede, a resposta enviada pelo equipamento é codificada em ASCII e apresentada no formato \pm XXXXXX. Os valores dos parâmetros de resistência e reatância da carga e da rede são apresentados em $\mathrm{m} \Omega$, enquanto o valor da tensão estimado para a rede é apresentado em $\mathrm{V}$. 
- Exemplo 4: Leitura da resistência e reatância da carga na fase A

Para este exemplo as mensagens de requisição e resposta são mostradas respectivamente nas Figuras 5.21 e 5.22.

0564 0F C4 01000000 E2 C8 C0 C0 01 1E 000150065106 A5 82

Figura 5.21 - Mensagem de requisição para a leitura da resistência e reatância na fase A.

onde: 0xC4: Link Control

OxC0: Transport Header

0xC0: Application Control

0x01: Function Code

0x1E: Group

0x00: Variation

0x01: Qualifier

0x0650: Endereço inicial

0x0651: Endereço final

0564224400000100 FF B9 C0 C0 810000 1E 001714 0D 0A 2B 3030303375

5A 3337 0D 0A 2B 303030333334 0D 0A 9D 62

Figura 5.22 - Mensagem de leitura para a leitura da resistência e reatância na fase A.

onde: 0x44: Link Control

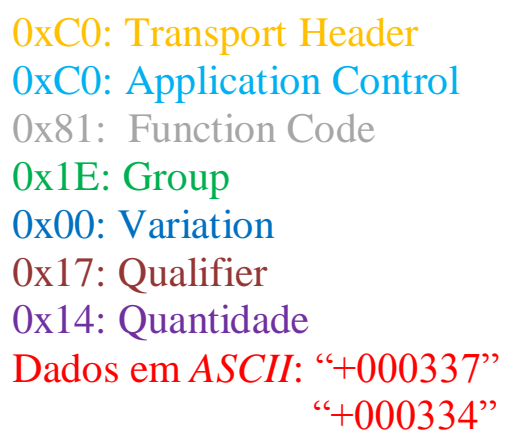

0xC0: Transport Header

0xC0: Application Control

0x81: Function Code

0x1E: Group

0x00: Variation

0x17: Qualifier

0x14: Quantidade

Dados em ASCII: “+000337"

“+000334”

Para uma requisição solicitando a leitura de dados de fasores, o equipamento envia uma resposta que sempre contém a data e hora da última aquisição realizada e o(s) fasores(s) solicitado(s), sendo estes dados também codificados em ASCII.

O módulo do fasor de tensão em mV(baixa tensão)/V(média tensão), ou de corrente em

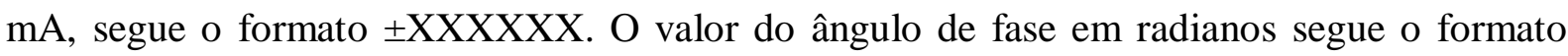
\pm X,XXX. 
- Exemplo 5: Leitura dos fasores de tensão na fase B para as duas amostras mais recentes

A mensagem de requisição solicitando a leitura dos fasores de tensão na fase B para as duas amostras mais recentes é mostrada na Figura 5.23, enquato a mensagem de resposta é mostrada na Figura 5.24.

0564 0F C4 01000000 E2 C8 C0 C0 01 1E 000100010101 F8 D7

Figura 5.23 - Mensagem de requisição para a leitura dos fasores de tensão na fase $B$ para as duas amostras mais recentes.

onde: 0xC4: Link Control

OxC0: Transport Header

0xC0: Application Control

0x01: Function Code

0x1E: Group

0x00: Variation

0x01: Qualifier

0x0100: Endereço inicial

0x0101: Endereço final

0564414400000100 FF B9 C0 C0 810000 1E 001733 0D 0A 3034 2F 303375 5A

2F 3135203131 3A 3035 3A 3032 0D 0A 2B 31 5D A7 3237333337 20 2B 31 2C

303037 0D 0A 2B 3139 D1 3237333234 20 2B 31 2C 333335 0D 0A A3 81

Figura 5.24 - Mensagem de resposta para a leitura dos fasores de tensão na fase B para as duas amostras mais recentes.

onde: 0x44: Link Control

OxC0: Transport Header

0xC0: Application Control

0x81: Function Code

0x1E: Group

0x00: Variation

0x17: Qualifier

0x25: Quantidade

Dados em ASCII: "04/03/15 11:05:02"

$$
\begin{aligned}
& \text { “+127337 +1,007" } \\
& "+127324+1,335 "
\end{aligned}
$$

Já para uma requisição solicitando a leitura de dados de parâmetros de configuração, o equipamento envia uma resposta cujo formato é personalizado e também codificado em ASCII. 
- Exemplo 6: Leitura da frequência de amostragem

Para este exemplo a mensagem de requisição é mostrada na Figura 5.25.

0564 0F C4 01000000 E2 C8 C0 C0 01 1E 002801000107 FC D8

Figura 5.25 - Mensagem de requisição para a leitura da frequência de amostragem.

onde: 0xC4: Link Control

OxC0: Transport Header

0xC0: Application Control

0x01: Function Code

0x1E: Group

0x00: Variation

0x28: Qualifier

0x0001: Quantidade

0x0701: Endereço

A mensagem de resposta é mostrada na Figura 5.26.

0564114400000100 E2 C8 C0 C0 810000 1E 001703 0D 0A 31 FC D8

Figura 5.26 - Mensagem de resposta para a leitura da frequência de amostragem.

onde: 0x44: Link Control

0xC0: Transport Header

0xC0: Application Control

0x81: Function Code

0x1E: Group

0x00: Variation

0x17: Qualifier

0x03: Quantidade

Dados em ASCII: "1"

\subsubsection{Escrita de parâmetros de configuração}

Para a escrita dos parâmetros de configuração, é necessário primeiramente que o byte Function Code seja igual a 2 (Write) e o byte Variations seja igual a 2 (Variation 16 bits). Pode ser escrito apenas um dado por requisição, com valor variando entre 1 e 65536, em um determinado endereço utilizando-se para isso o byte Qualifier com valor igual a 0x28.

- Exemplo 7: Configurar a frequência de amostragem com o valor 4

Para este exemplo as mensagens de requisição e resposta são mostradas respectivamente nas Figuras 5.27 e 5.28 . 
056412 C4 0100000076 D2 C0 C0 02 1E 022801000107000400 FC D8

Figura 5.27 - Mensagem de requisição para configurar a frequência de amostragem.

onde: 0xC4: Link Control

0xC0: Transport Header

0xC0: Application Control

0x02: Function Code

0x1E: Group

0x02: Variation

0x28: Qualifier

0x0001: Quantidade

0x0701: Endereço

0x0004: Dado

0564084400000100 0E 1E C0 C0 00 7D 3D

Figura 5.28 - Mensagem de resposta para configurar a frequência de amostragem.

onde: 0x44: Link Control

OxC0: Transport Header

0xC0: Application Control

0x00: Function Code

No Capítulo 6 - Resultados e Discussões são mostradas as interações entre a Unidade de Medição Fasorial Otimizada e o software HERCULES (2013), utilizado como dispositivo DNP3 "Mestre". 


\section{CAPítulo 6}

\section{RESUlTAdOS E DiscuSSÕES}

\subsection{PRECISÃO DO CÁLCULO FASORIAL}

Para os diferentes sinais amostrados apresentados a seguir são comparados o valor do módulo e do ângulo de fase na frequência fundamental destes sinais calculados tanto pela Unidade de Medição Fasorial Otimizada quanto pelo software MATLAB.

O objetivo dessa comparação é verificar o desempenho do cálculo fasorial realizado pelo microcontrolador PIC32MX795F512L, no qual foram utilizadas as funções matemáticas cosf, $\operatorname{sinf}$, sqrtf, powf e atan2f presentes na biblioteca math (MICROCHIP TECHNOLOGY INCORPORATED, 2008a).

No software MATLAB foi implementado o código apresentado na Figura 6.1 para o cálculo dos itens citados anteriormente, a partir do conjunto de amostras (arquivo .txt) obtido por meio do ambiente de desenvolvimento do microcontrolador:

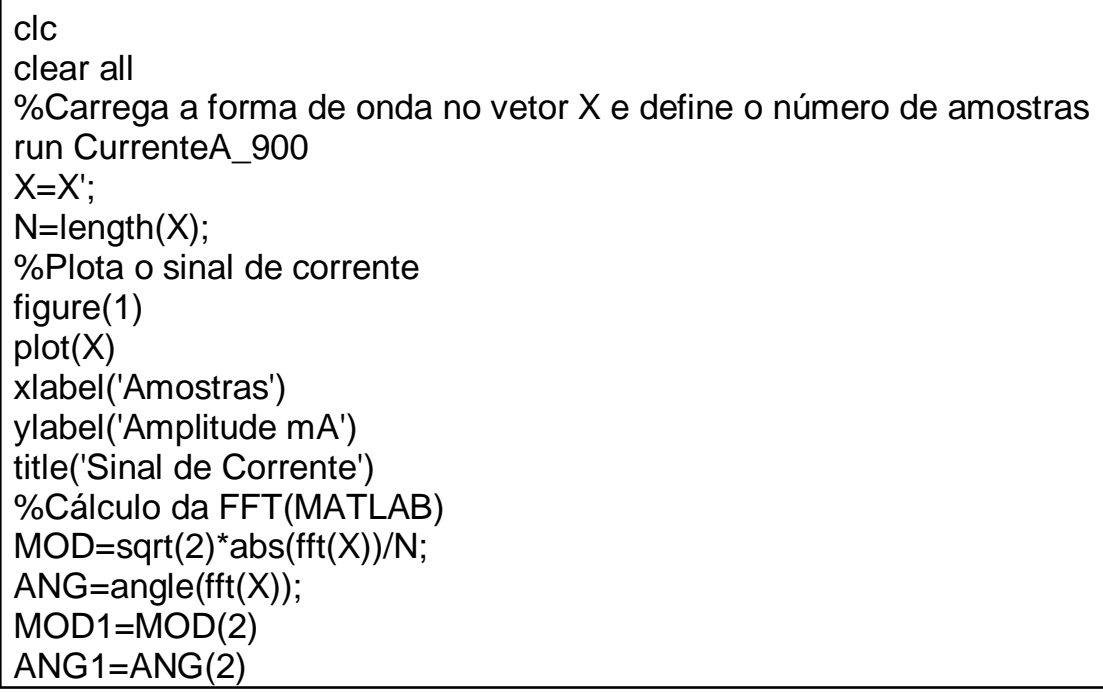

Figura 6.1 - Código no software MATLAB.

É importante ressaltar que o ângulo de fase é definido como $0^{\circ}$ (0 radianos) para o valor de pico positivo e $-90^{\circ}(-\pi / 2$ radianos) para o sinal ascendente com valor igual a $0 \mathrm{~V}$ (IEEE, 2005), como mostrado na Figura 6.2. 


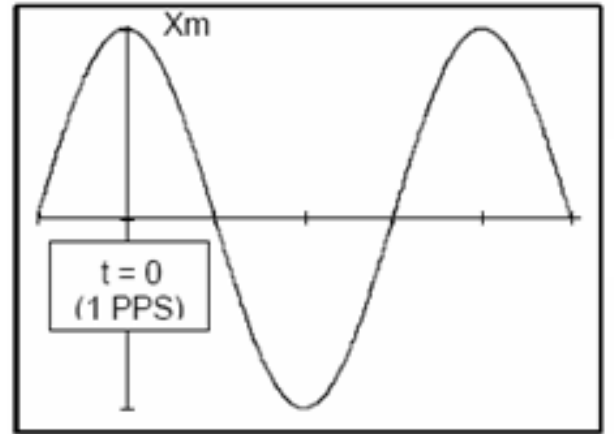

(0 graus)

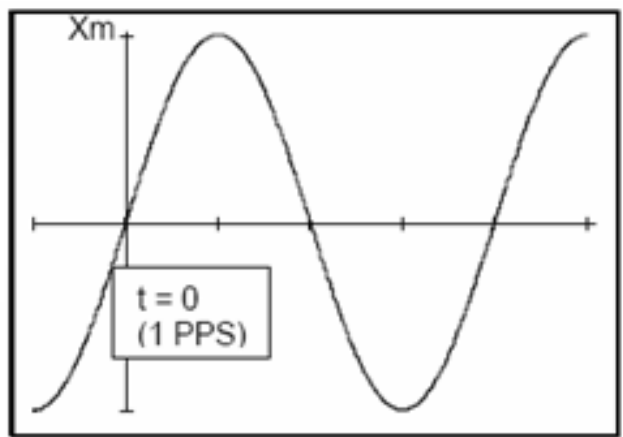

(-90 graus)

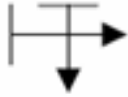

Figura 6.2 - Convenção para representação dos fasores (adaptado de IEEE, 2005).

Para a $P M U$ proposta neste trabalho atender à norma IEEE C37.118 (IEEE, 2005), o Erro Vetorial Total (Total Vector Error - TVE) apresentado na Equação (6.1) deve ser menor do que $1 \%$.

$$
T V E=100 \% \frac{\left|X_{M E A S}-X_{I D E A L}\right|}{\left|X_{\text {IDEAL }}\right|}
$$

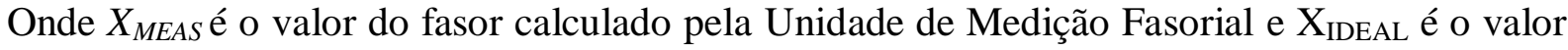
ideal esperado para o fasor, o qual neste teste é obtido por meio do software MATLAB.

Outros dois importantes parâmetros da norma IEEE C37.118 são o Erro de Magnitude do Módulo (EMM) e o Erro de Ângulo de Fase (EFA). O EMM deve ser inferior a $1 \%$ e pode ser encontrado por meio da Equação (6.2).

$$
E M M=100 \% \frac{\left|M M_{M E A S}-M M_{I D E A L}\right|}{\left|M M_{\text {IDEAL }}\right|}
$$

Onde $\mathrm{MM}_{\mathrm{MEAS}}$ é o valor da magnitude do módulo calculado pela e $M M_{I D E A L}$ é o valor ideal esperado para a magnitude fornecido pelo software MATLAB. O EAF deve ser menor que 0,01 rad e pode ser encontrado por meio da Equação (6.3).

$$
E A F=100 \% \frac{\left|A F_{\text {MEAS }}-A F_{\text {IDEAL }}\right|}{\left|A F_{\text {IDEAL }}\right|}
$$

Onde $A F_{M E A S}$ é o valor do ângulo de fase calculado pela Unidade de Medição Fasorial e $A F_{I D E A L}$ é o valor ideal esperado, o qual neste teste é obtido por meio do software MATLAB. 
A seguir são apresentados os cálculos fasoriais para diferentes cargas, realizados tanto pela Unidade de Medição Fasorial Otimizada quanto pelo MATLAB, os quais apresentam resultados quase idênticos que credenciam a continuidade na utilização do microcontrolador PIC32MX795F512L para essa tarefa. Também são apresentados os cálculos do Erro Vetorial Total, do Erro de Magnitude do Módulo e do Ângulo de Fase para cada simulação.

\subsubsection{Forma de onda no canal A para tensão com valor eficaz de 127,5 V}

- A Figura 6.3 mostra a forma de onda para este sinal e a Tabela 6.1 mostra a comparação dos cálculos fasoriais e os erros calculados.

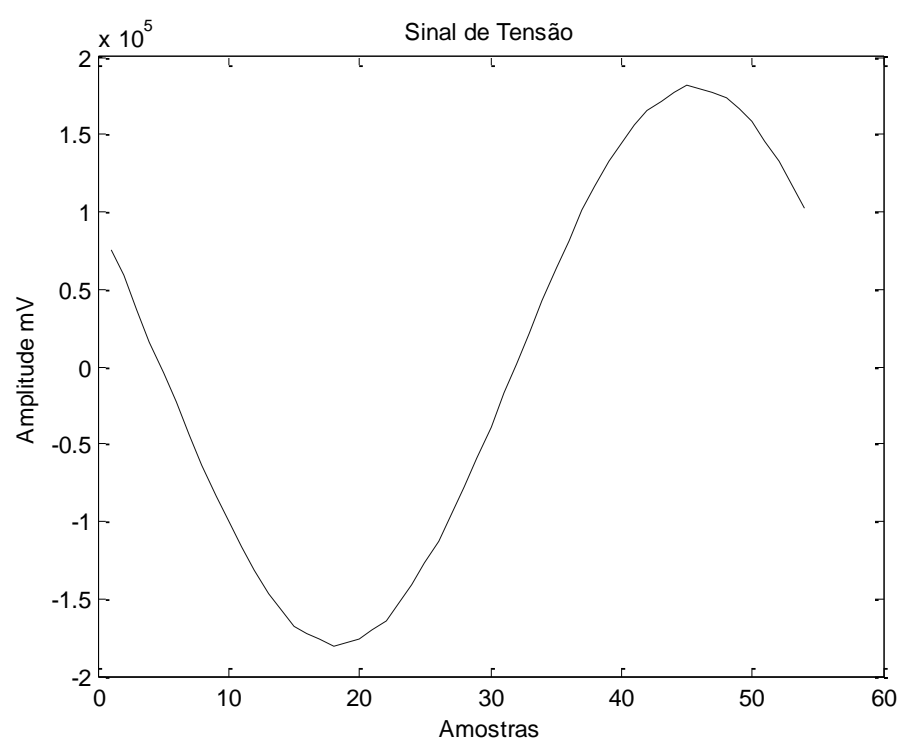

Figura 6.3 - Forma de onda no canal A para tensão.

Tabela 6.1 - Comparação dos cálculos fasoriais e erros calculados para o primeiro sinal.

\begin{tabular}{|c|c|c|c|c|c|c|}
\hline \multicolumn{2}{|c|}{$\begin{array}{c}\text { Valores calculados pela } \\
\text { Unidade de Medição } \\
\text { Fasorial Otimizada }\end{array}$} & \multicolumn{2}{|c|}{$\begin{array}{c}\text { Valores calculados pelo } \\
\text { MATLAB }\end{array}$} & \multirow{2}{*}{ TVE(\%) } & EMM(\%) & \multirow{2}{*}{ EAF(\%) } \\
\cline { 1 - 4 } Módulo (mV) Ángulo (rad) & Módulo (mV) & Ángulo (rad) & & & \\
\cline { 1 - 4 } 127291 & $+1,117$ & 127290 & $+1,117$ & 0,00079 & 0,00078 & 0 \\
\hline
\end{tabular}

Abaixo é demonstrada a forma como foram calculados o Erro Vetorial Total, o Erro de Magnitude do Módulo e o Erro de Ângulo de Fase, a qual foi adotada nos demais exemplos a serem explorados nesta seção:

$$
\begin{aligned}
& -X_{\text {MEAS }}=127291 \mathrm{mV} * \cos (1,117 \mathrm{rad})=55801,93 \mathrm{mV} \\
& -X_{I D E A L}=127290 \mathrm{mV} * \cos (1,117 \mathrm{rad})=55801,49 \mathrm{mV} \\
& \text { - } T V E=100 \% \frac{|55801,93 m V-55801,49 m V|}{|55801,49 m V|}=0,00079 \%
\end{aligned}
$$




$$
\begin{aligned}
& \cdot E M M=100 \% \frac{|127291 \mathrm{mV}-127290 \mathrm{mV}|}{|127290 \mathrm{mV}|}=0,00078 \% \\
& \cdot E A F=100 \% \frac{|1,117 \mathrm{rad}-1,117 \mathrm{rad}|}{|1,117 \mathrm{rad}|}=0 \%
\end{aligned}
$$

- Fonte do sinal: gerador de sinal Doble F6150 (Figura 6.4).

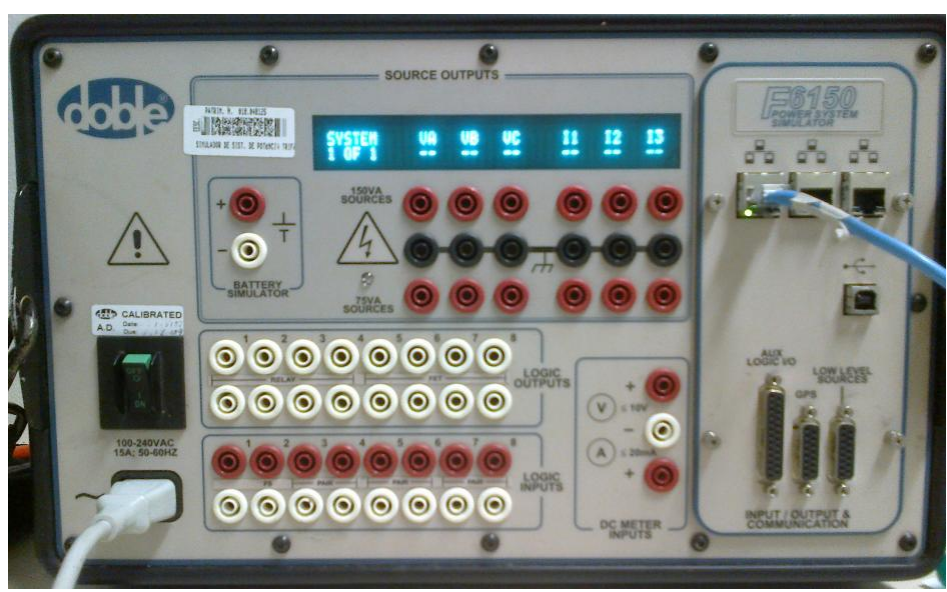

Figura 6.4 - Gerador de sinais Doble F6150.

- Análise: os valores do erro vetorial total, dos erros de magnitude do módulo e de ângulo de fase medidos para este sinal se enquadram perfeitamente na norma IEEE C37.118. O erro de ângulo de fase igual a $0 \%$ e a grande amplitude do sinal aquisitado contribuíram de forma significativa para o baixo erro vetorial total.

\subsubsection{Forma de onda no canal C para tensão com valor eficaz de $124 \mathrm{~V}$}

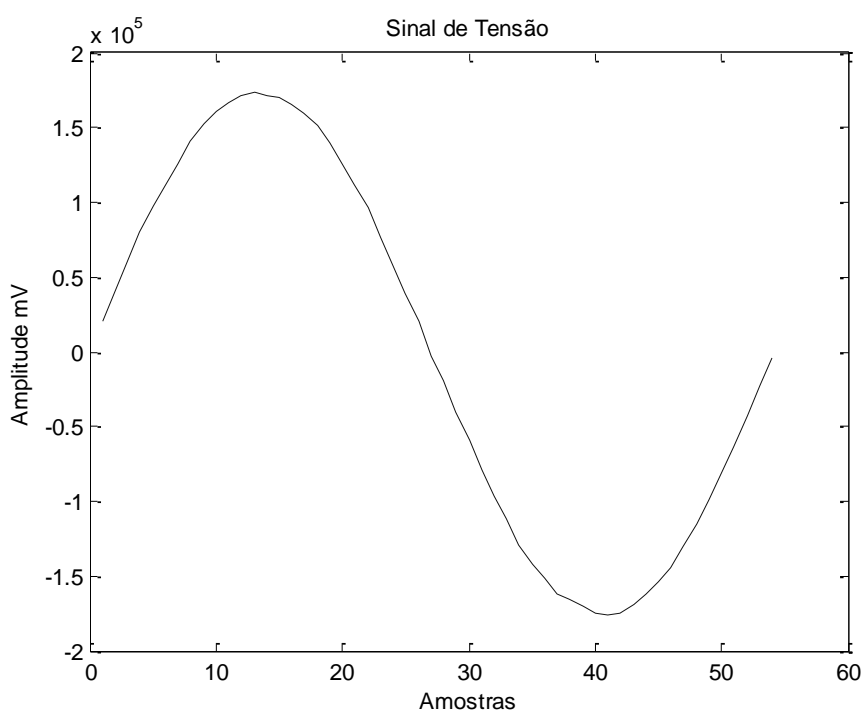

Figura 6.5 - Forma de onda no canal C para tensão. 
- A Figura 6.5 mostra a forma de onda para este sinal e a Tabela 6.2 mostra a comparação dos cálculos fasoriais e os erros calculados.

Tabela 6.2 - Comparação dos cálculos fasoriais e erros calculados para o segundo sinal.

\begin{tabular}{|c|c|c|c|c|c|c|}
\hline $\begin{array}{c}\text { Valores calculados pela } \\
\text { Unidade de Medição } \\
\text { Fasorial Otimizada }\end{array}$ & \multicolumn{2}{|c|}{$\begin{array}{c}\text { Valores calculados pelo } \\
\text { MATLAB }\end{array}$} & TVE(\%) & EMM(\%) & EAF(\%) \\
\cline { 1 - 4 } Módulo (mV) & Ângulo (rad) & Módulo (mV) & Ângulo (rad) & & & \\
\hline 123893 & $-1,456$ & 123890 & $-1,457$ & 0,877 & 0,0024 & 0,0686 \\
\hline
\end{tabular}

- Fonte de aquisição do sinal: gerador de sinal Doble F6150.

- Análise: os valores do erro vetorial total, dos erros de magnitude do módulo e de ângulo de fase medidos para este sinal se enquadram perfeitamente na norma IEEE C37.118. O ângulo de fase próximo $-\pi / 2$ rad impactou significativamente o cálculo do erro vetorial total, mesmo havendo uma pequena diferença de apenas 0,001 rad entre o valor calculado e o valor ideal.

\subsubsection{Forma de onda no canal B para tensão com valor eficaz de $130 \mathrm{~V}$}

- A Figura 6.6 mostra a forma de onda para este sinal e a Tabela 6.3 mostra a comparação dos cálculos fasoriais e os erros calculados.

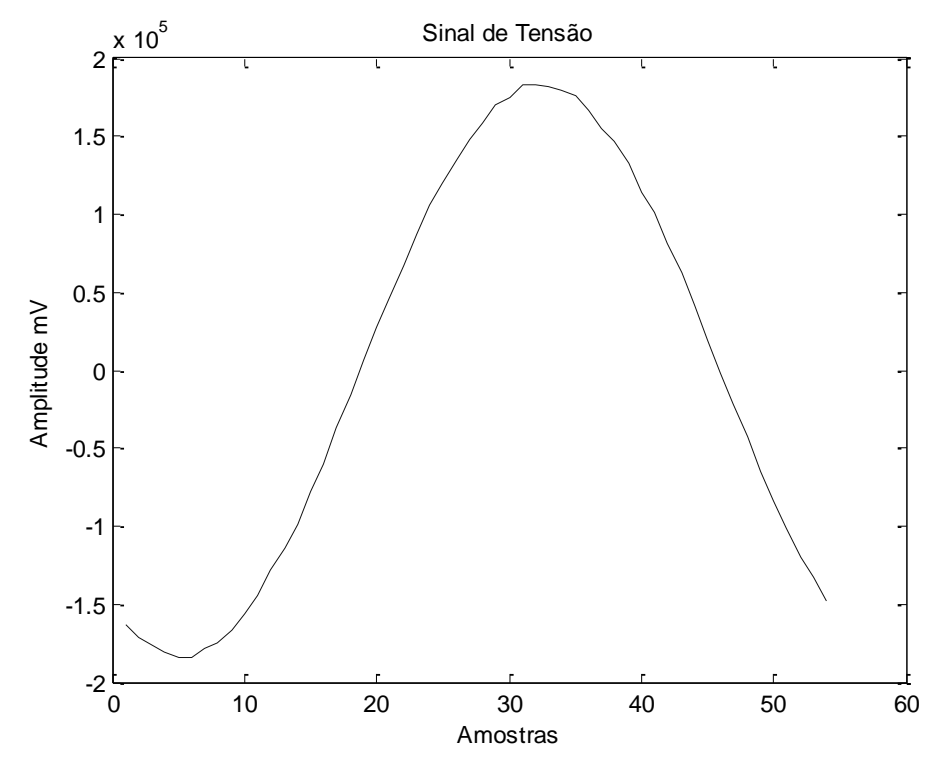

Figura 6.6 - Forma de onda no canal B para tensão.

Tabela 6.3 - Comparação dos cálculos fasoriais e erros calculados para o terceiro sinal.

\begin{tabular}{|c|c|c|c|c|c|c|}
\hline \multicolumn{2}{|c|}{$\begin{array}{c}\text { Valores calculados pela } \\
\text { Unidade de Medição } \\
\text { Fasorial Otimizada }\end{array}$} & \multicolumn{2}{|c|}{$\begin{array}{c}\text { Valores calculados pelo } \\
\text { MATLAB }\end{array}$} & TVE(\%) & EMM(\%) & EAF(\%) \\
\cline { 1 - 4 } Módulo (mV) & Ângulo (rad) & Módulo (mV) Ângulo (rad) & & & \\
\hline 129502 & $+2,634$ & 129500 & $+2,635$ & 0,054 & 0,0015 & 0,0379 \\
\hline
\end{tabular}


- Fonte de aquisição do sinal: gerador de sinal Doble F6150.

- Análise: os valores do erro vetorial total, dos erros de magnitude do módulo e de ângulo de fase medidos para este sinal se enquadram perfeitamente na norma IEEE C37.118. O erro de ângulo de fase igual a 0,0379\% e a grande amplitude do sinal aquisitado contribuíram de forma significativa para o baixo erro vetorial total.

\subsubsection{Forma de onda no canal A para corrente com valor eficaz de $90 \mathrm{~A}$}

- A Figura 6.7 mostra a forma de onda para este sinal e a Tabela 6.4 mostra a comparação dos cálculos fasoriais e os erros calculados.

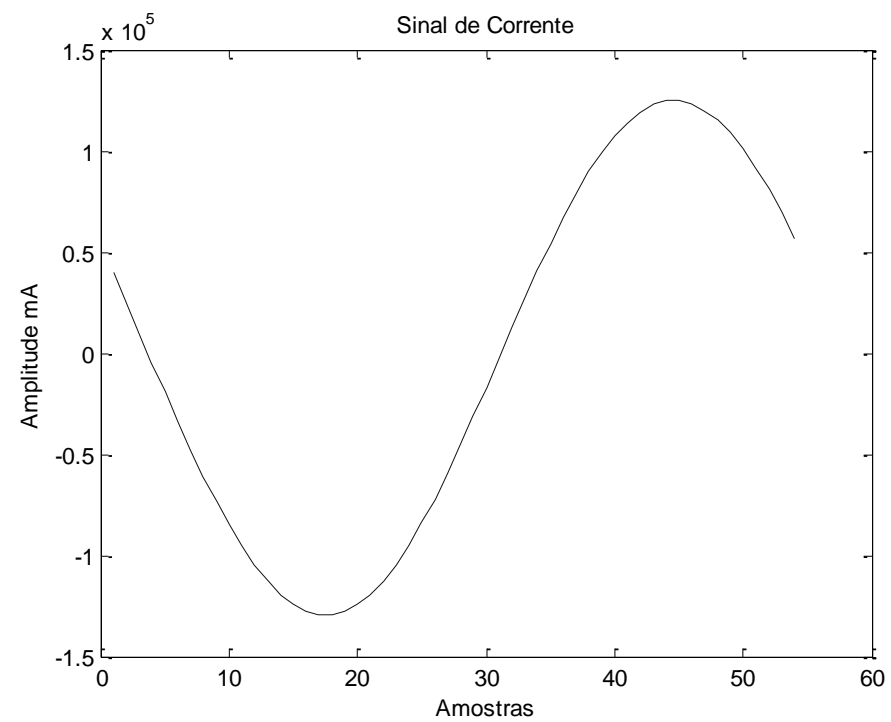

Figura 6.7 - Forma de onda no canal A para corrente de $90 \mathrm{~A}$.

Tabela 6.4 - Comparação dos cálculos fasoriais e erros calculados para o quarto sinal.

\begin{tabular}{|c|c|c|c|c|c|c|}
\hline \multicolumn{2}{|c|}{$\begin{array}{c}\text { Valores calculados pela } \\
\text { Unidade de Medição } \\
\text { Fasorial Otimizada }\end{array}$} & \multicolumn{2}{|c|}{$\begin{array}{r}\text { Valores calculados pelo } \\
\text { MATLAB }\end{array}$} & \multirow{2}{*}{ TVE(\%) } & EMM(\%) & \multirow{2}{*}{ EAF(\%) } \\
\cline { 1 - 4 } Módulo (mA) & Ángulo (rad) & Módulo (mA) & Ángulo (rad) & & & \\
\cline { 1 - 4 } 90190 & $+1,223$ & 90191 & $+1,223$ & 0,0011 & 0,0011 & 0 \\
\hline
\end{tabular}

- Fonte de aquisição do sinal: gerador de sinal Doble F6150.

- Análise: os valores do erro vetorial total, dos erros de magnitude do módulo e de ângulo de fase medidos para este sinal se enquadram perfeitamente na norma IEEE C37.118. O erro de ângulo de fase igual a $0 \%$ e a grande amplitude do sinal aquisitado contribuíram de forma significativa para o baixo erro vetorial total. 


\subsubsection{Forma de onda no canal A para corrente com valor eficaz de 50 A}

- A Figura 6.8 mostra a forma de onda para este sinal e a Tabela 6.5 mostra a comparação dos cálculos fasoriais e os erros calculados.

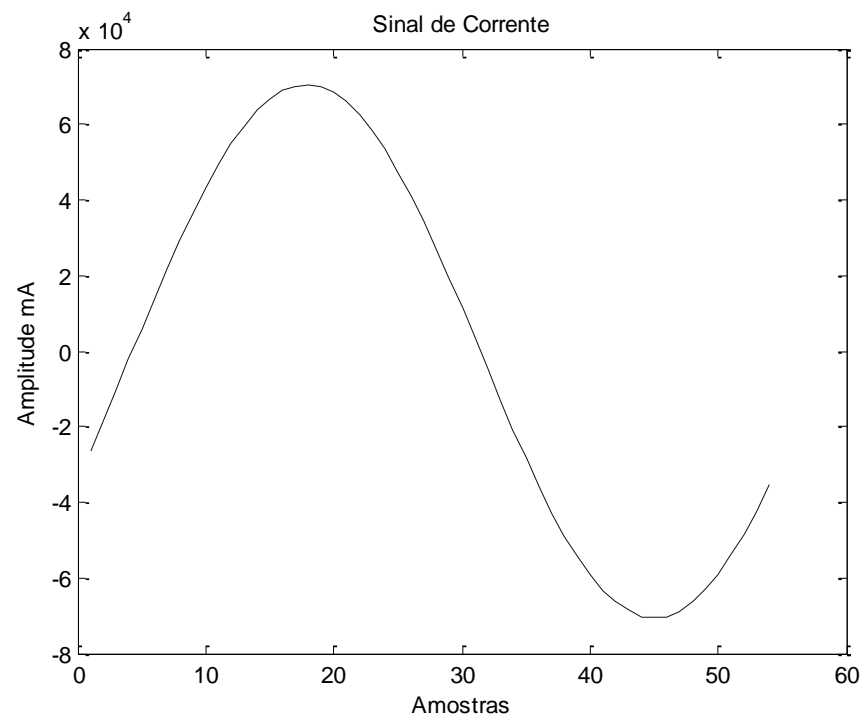

Figura 6.8 - Forma de onda no canal A para corrente de $50 \mathrm{~A}$.

Tabela 6.5 - Comparação dos cálculos fasoriais e erros calculados para o quinto sinal.

\begin{tabular}{|c|c|c|c|c|c|c|}
\hline \multicolumn{2}{|c|}{$\begin{array}{c}\text { Valores calculados pela } \\
\text { Unidade de Medição } \\
\text { Fasorial Otimizada }\end{array}$} & \multicolumn{2}{|c|}{$\begin{array}{c}\text { Valores calculados pelo } \\
\text { MATLAB }\end{array}$} & \multirow{2}{*}{ TVE(\%) } & EMM(\%) & \multirow{2}{*}{ EAF(\%) } \\
\cline { 1 - 4 } Módulo (mA) & Ángulo (rad) & Módulo (mA) & Ángulo (rad) & & & \\
\cline { 1 - 4 } 499971 & $-1,964$ & 49972 & $-1,964$ & 0,0021 & 0,002 & 0 \\
\hline
\end{tabular}

- Fonte de aquisição do sinal: gerador de sinal Doble F6150.

- Análise: os valores do erro vetorial total, dos erros de magnitude do módulo e de ângulo de fase medidos para este sinal se enquadram perfeitamente na norma IEEE C37.118. O erro de ângulo de fase igual a $0 \%$ e a grande amplitude do sinal aquisitado contribuíram de forma significativa para o baixo erro vetorial total.

\subsubsection{Forma de onda no canal $\mathrm{C}$ para corrente com valor eficaz de 12,5A}

- A Figura 6.9 mostra a forma de onda para este sinal e a Tabela 6.6 mostra a comparação dos cálculos fasoriais e os erros calculados.

Tabela 6.6 - Comparação dos cálculos fasoriais e erros calculados para o sexto sinal.

\begin{tabular}{|c|c|c|c|c|c|c|}
\hline \multicolumn{2}{|c|}{$\begin{array}{c}\text { Valores calculados pela } \\
\text { Unidade de Medição } \\
\text { Fasorial Otimizada }\end{array}$} & \multicolumn{2}{|c|}{$\begin{array}{r}\text { Valores calculados pelo } \\
\text { MATLAB }\end{array}$} & \multirow{2}{*}{ TVE(\%) } & \multirow{2}{*}{ EMM(\%) } & \multirow{2}{*}{ EAF(\%) } \\
\cline { 1 - 4 } Módulo (mA) & Ángulo (rad) & Módulo (mA) & Ángulo (rad) & & & \\
\cline { 1 - 4 } 12475 & $+0,756$ & 12477 & $+0,757$ & 0,0783 & 0,016 & 0,132 \\
\hline
\end{tabular}




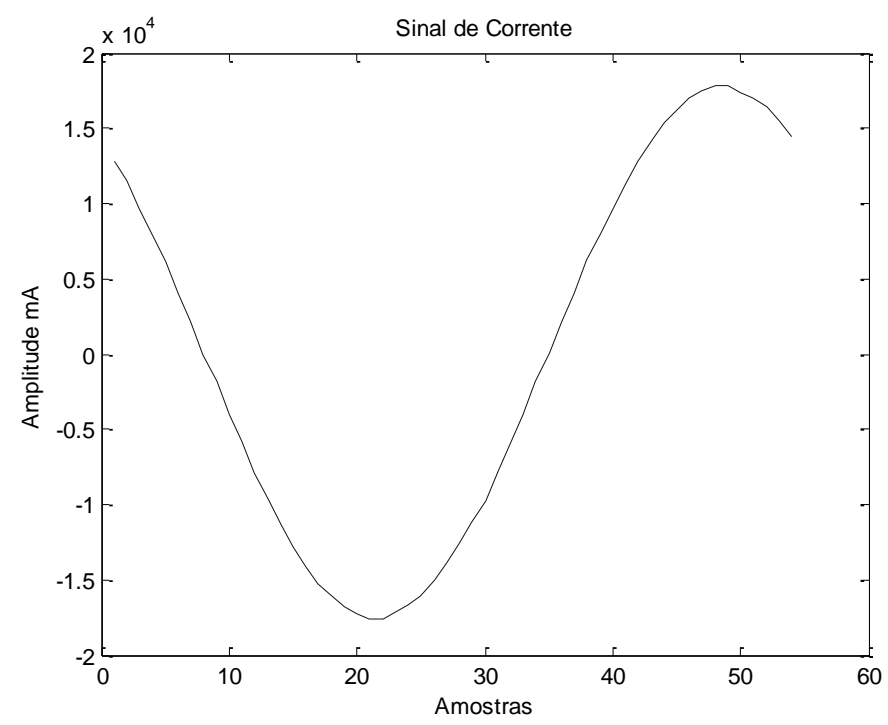

Figura 6.9 - Forma de onda no canal C para corrente com valor eficaz de 12,5 A.

- Fonte de aquisição do sinal: gerador de sinal Doble F6150.

- Análise: os valores do erro vetorial total, dos erros de magnitude do módulo e de ângulo de fase medidos para este sinal se enquadram perfeitamente na norma IEEE C37.118. O erro de ângulo de fase igual a $0,132 \%$ e a grande amplitude do sinal aquisitado contribuíram de forma significativa para o baixo erro vetorial total.

\subsubsection{Forma de onda no canal A para corrente de um aquecedor $1500 \mathrm{~W}$}

- A Figura 6.10 mostra a forma de onda para este sinal e a Tabela 6.7 mostra a comparação dos cálculos fasoriais e os erros calculados.

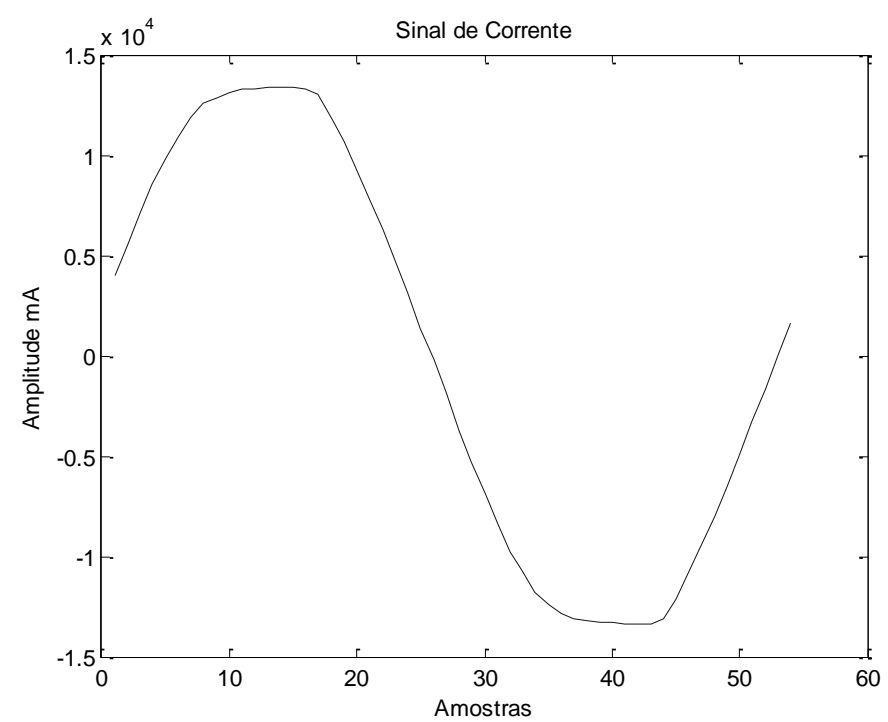

Figura 6.10 - Forma de onda no canal A para corrente de um aquecedor $1500 \mathrm{~W}$. 
Tabela 6.7 - Comparação dos cálculos fasoriais e erros calculados para o sétimo sinal.

\begin{tabular}{|c|c|c|c|c|c|c|}
\hline \multicolumn{2}{|c|}{$\begin{array}{c}\text { Valores calculados pela } \\
\text { Unidade de Medição } \\
\text { Fasorial Otimizada }\end{array}$} & \multicolumn{2}{|c|}{$\begin{array}{c}\text { Valores calculados pelo } \\
\text { MATLAB }\end{array}$} & \multirow{2}{*}{ TVE(\%) } & EMM(\%) & EAF(\%) \\
\cline { 1 - 4 } Módulo (mA) & Ângulo (rad) & Módulo (mA) & Ángulo (rad) & & & \\
\cline { 1 - 3 } & $-1,326$ & 10055 & $-1,326$ & 0,001 & 0,001 & 0 \\
\hline
\end{tabular}

- Fonte de tensão: rede elétrica monofásica sem a presença de harmônicos.

- Análise: os valores do erro vetorial total, dos erros de magnitude do módulo e de ângulo de fase medidos para este sinal se enquadram perfeitamente na norma IEEE C37.118. O erro de ângulo de fase igual a $0 \%$ e a grande amplitude do sinal aquisitado contribuíram de forma significativa para o baixo erro vetorial total.

\subsubsection{Forma de onda no canal A para corrente de uma lâmpada florescente}

- A Figura 6.11 mostra a forma de onda para este sinal e a Tabela 6.8 mostra a comparação dos cálculos fasoriais e os erros calculados.

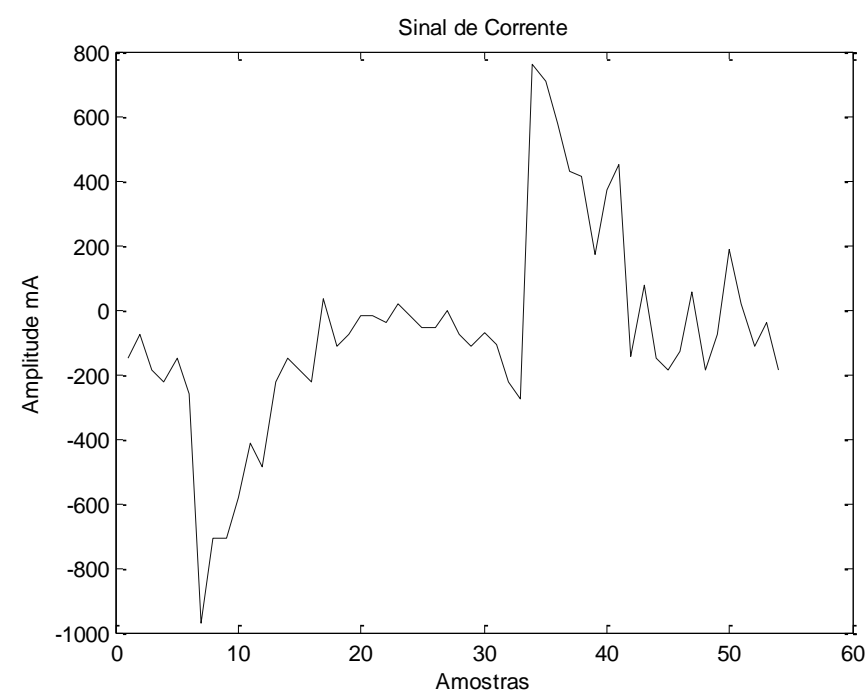

Figura 6.11 - Forma de onda no canal A para corrente de lâmpada fluorescente.

Tabela 6.8 - Comparação dos cálculos fasoriais e erros calculados para o oitavo sinal.

\begin{tabular}{|c|c|c|c|c|c|c|}
\hline \multicolumn{2}{|c|}{$\begin{array}{c}\text { Valores calculados pela } \\
\text { Unidade de Medição } \\
\text { Fasorial Otimizada }\end{array}$} & \multicolumn{2}{|c|}{$\begin{array}{r}\text { Valores calculados pelo } \\
\text { MATLAB }\end{array}$} & \multirow{2}{*}{ TVE(\%) } & EMM(\%) & \multirow{2}{*}{ EAF(\%) } \\
\cline { 1 - 4 } Módulo (mA) & Ángulo (rad) & Módulo (mA) & Ángulo (rad) & & & \\
\hline 211 & $+2,174$ & 212,76 & $+2,175$ & 0,97 & 0,83 & 0,05 \\
\hline
\end{tabular}

- Análise: os valores do erro vetorial total, dos erros de magnitude do módulo e de ângulo de fase medidos se enquadram na norma IEEE C37.118 mas possuem valores maiores quando comparados aos itens anteriores, já que o sinal amostrado possui uma menor excursão, evidenciando a menor precisão das funções matemáticas realizadas pelo microcontrolador. 


\subsubsection{Forma de onda no canal B para corrente de uma geladeira}

- A Figura 6.12 mostra a forma de onda para este sinal e a Tabela 6.9 mostra a comparação dos cálculos fasoriais e os erros calculados.

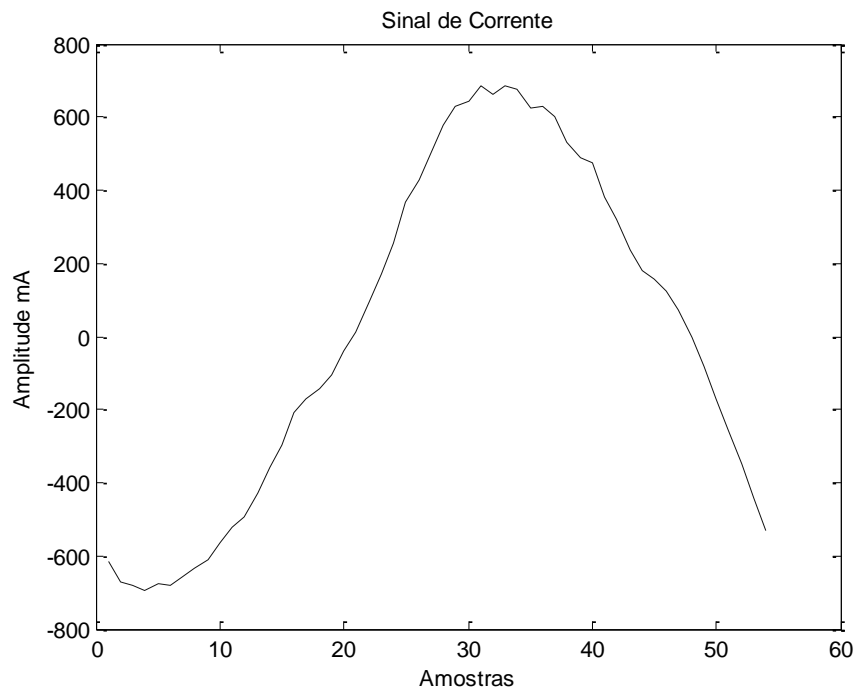

Figura 6.12 - Forma de onda no canal B para corrente de uma geladeira.

Tabela 6.9 - Comparação dos cálculos fasoriais e erros calculados para o nono sinal.

\begin{tabular}{|c|c|c|c|c|c|c|}
\hline \multicolumn{2}{|c|}{$\begin{array}{l}\text { Valores calculados pela } \\
\text { Unidade de Medição } \\
\text { Fasorial Otimizada }\end{array}$} & \multicolumn{2}{|c|}{$\begin{array}{c}\text { Valores calculados pelo } \\
\text { MATLAB }\end{array}$} & \multirow[t]{2}{*}{ TVE(\%) } & \multirow[t]{2}{*}{ EMM(\%) } & \multirow[t]{2}{*}{ EAF(\%) } \\
\hline Módulo (mA) & Ângulo (rad) & Módulo (mA) & Ângulo (rad) & & & \\
\hline 465 & $+2,516$ & 466,36 & $+2,516$ & 0,29 & 0,29 & 0 \\
\hline
\end{tabular}

- Análise: os valores do erro do cálculo vetorial, dos erros de magnitude do módulo e de ângulo de fase medidos para este sinal se enquadram perfeitamente na norma IEEE C37.118. De forma semelhante ao item 6.1.8, a pequena excursão deste sinal deixa em evidência a menor precisão das funções matemáticas utilizadas pelo microcontrolador do equipamento.

\subsubsection{Forma de onda no canal B para corrente em um resistor de $90 \Omega$}

- A Figura 6.13 mostra a forma de onda para este sinal e a Tabela 6.10 mostra a comparação dos cálculos fasoriais e os erros calculados.

Tabela 6.10 - Comparação dos cálculos fasoriais e erros calculados para o décimo sinal.

\begin{tabular}{|c|c|c|c|c|c|c|}
\hline \multicolumn{2}{|c|}{$\begin{array}{c}\text { Valores calculados pela } \\
\text { Unidade de Medição } \\
\text { Fasorial Otimizada }\end{array}$} & \multicolumn{2}{|c|}{$\begin{array}{c}\text { Valores calculados pelo } \\
\text { MATLAB }\end{array}$} & \multirow{2}{*}{ TVE(\%) } & EMM(\%) & EAF(\%) \\
\cline { 1 - 5 } Módulo (mA) & Ángulo (rad) & Módulo (mA) & Ángulo (rad) & & & 0,07 \\
\hline 1436 & $+1,512$ & 1437,2 & $+1,513$ & 1,64 & 0,08 & 0,07 \\
\hline
\end{tabular}




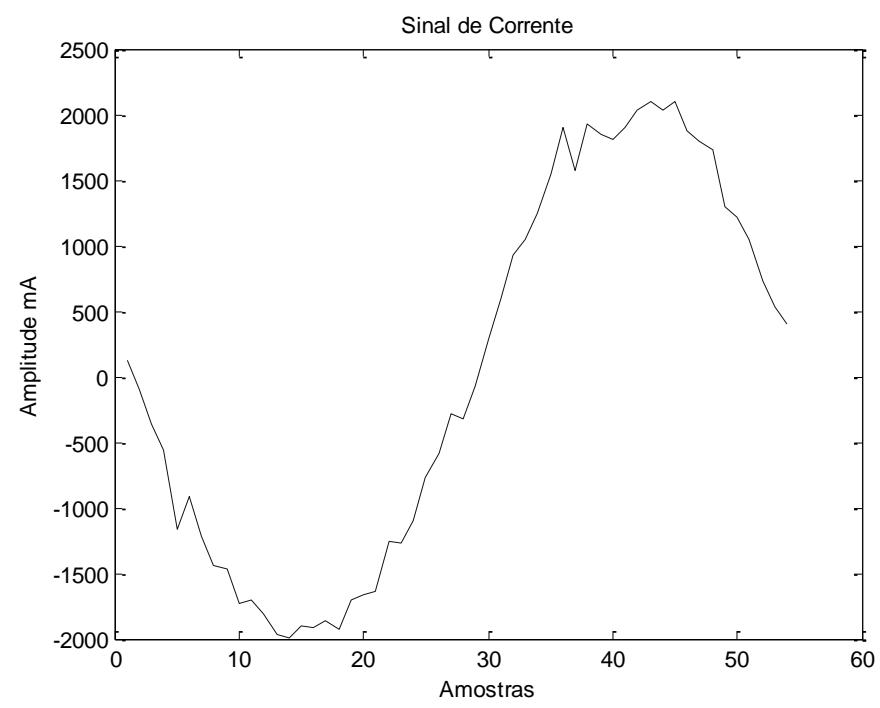

Figura 6.13 - Forma de onda no canal B para corrente em um resistor de $90 \Omega$.

- Fonte de tensão: rede elétrica monofásica

- Análise: apesar dos valores dos erros de magnitude do módulo e de ângulo de fase medidos para este sinal se enquadrarem perfeitamente na norma IEEE C37.118, é possível verificar que o erro vetorial total ficou acima do recomendado devido à pequena excursão do sinal combinado com um ângulo de fase próximo $\pi / 2 \mathrm{rad}$.

\subsubsection{Forma de onda no canal C para corrente em um resistor de $520 \Omega$}

- A Figura 6.14 mostra a forma de onda para este sinal e a Tabela 6.11 mostra a comparação dos cálculos fasoriais e os erros calculados.

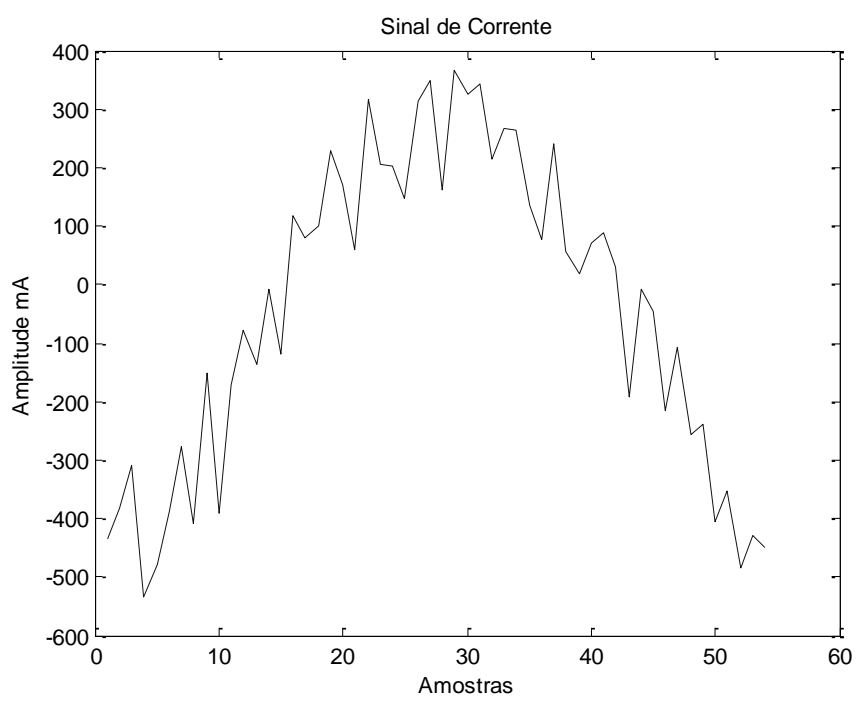

Figura 6.14 - Forma de onda no canal B para um sinal de corrente em um resistor de $520 \Omega$. 
Tabela 6.11 - Comparação dos cálculos fasoriais e erros calculados para o décimo primeiro sinal.

\begin{tabular}{|c|c|c|c|c|c|c|}
\hline \multicolumn{2}{|c|}{$\begin{array}{c}\text { Valores calculados pela } \\
\text { Unidade de Medição } \\
\text { Fasorial Otimizada }\end{array}$} & \multicolumn{2}{|c|}{$\begin{array}{c}\text { Valores calculados pelo } \\
\text { MATLAB }\end{array}$} & \multirow{2}{*}{ TVE(\%) } & \multirow{2}{*}{ EMM(\%) } & \multirow{2}{*}{ EAF(\%) } \\
\cline { 1 - 4 } Módulo (mA) & Ângulo (rad) & Módulo (mA) & Ángulo (rad) & & & \\
\cline { 1 - 3 } 251 & $+3,077$ & 252 & $+3,075$ & 0,397 & 0,40 & 0,03 \\
\hline
\end{tabular}

- Fonte de tensão: rede elétrica monofásica.

- Análise: os valores do erro do cálculo vetorial, dos erros de magnitude do módulo e de ângulo de fase medidos para este sinal se enquadram perfeitamente na norma IEEE C37.118. De forma semelhante ao item 6.1.8, a pequena excursão deste sinal, com baixa resolução deixa em evidência a menor precisão das funções matemáticas utilizadas pelo microcontrolador do equipamento.

\subsection{AQUISIÇÕES DE FASORES E OUTRAS GRANDEZAS ELÉTRICAS POR MEIO DO PROTOCOLO DNP3}

Os testes mostrados a seguir exploram a leitura de fasores e de diversos parâmetros elétricos, além da configuração de alguns destes parâmetros. Para a comunicação entre o dispositivo mestre (mensagem de requsição DNP3) e o dispositivo escravo (mensagem de resposta DNP3) foi utilizado o software HERCULES (2013), o qual consiste em um servidor TCP/IP e apresenta de forma organizada para a visualização, no formato ASCII, dos dados da mensagem de resposta enviada pela $P M U$ proposta neste trabalho.

\subsection{1 - Leitura da frequência de amostragem}

\section{- Características gerais do teste}

- Mensagem de requisição DNP3 (formato hexadecimal): 0564 0F C4 01000000 E2 C8 C0 C0 01 1E 002801000107 FC D8. Na Figura 6.15 esta mensagem é mostrada no formato ASCII, na cor rosa;

- Endereço da requisição: 0x0701;

- Dado da mensagem de resposta (formato ASCII): 1 (amostragem a cada um segundo, Figura $6.15)$. 


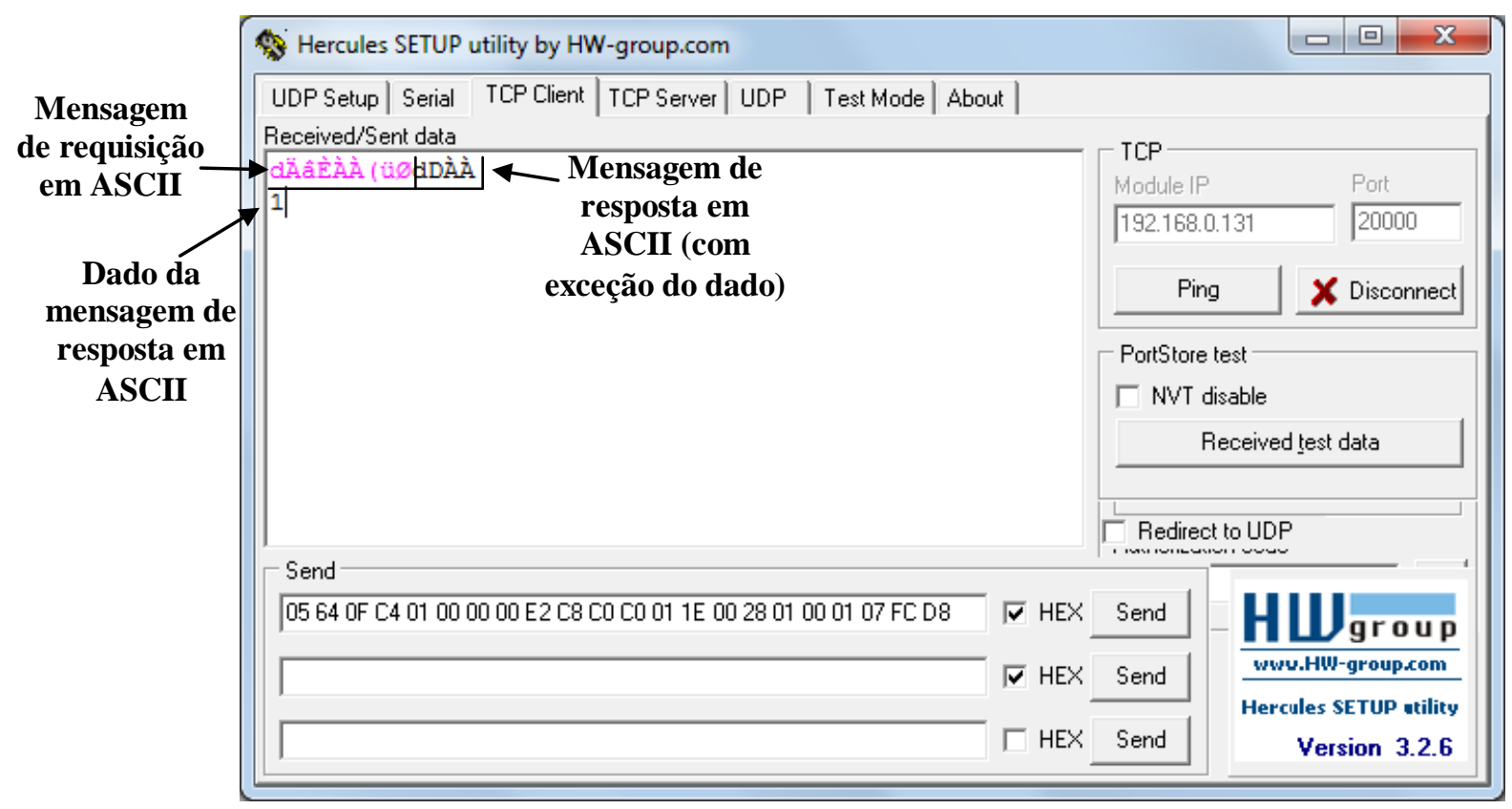

Figura 6.15 - Leitura da frequência de amostragem.

\subsection{2 - Leitura da quantidade de fasores por canal a cada amostragem}

\section{- Características gerais do teste}

- Mensagem de requisição DNP3 (formato hexadecimal): 0564 0F C4 01000000 E2 C8 C0 C0 01 1E 002801000207 FC D8;

- Endereço da requisição: 0x0702;

- Dado da mensagem de resposta (formato ASCII): 1 (um fasor por amostragem, Figura 6.16).

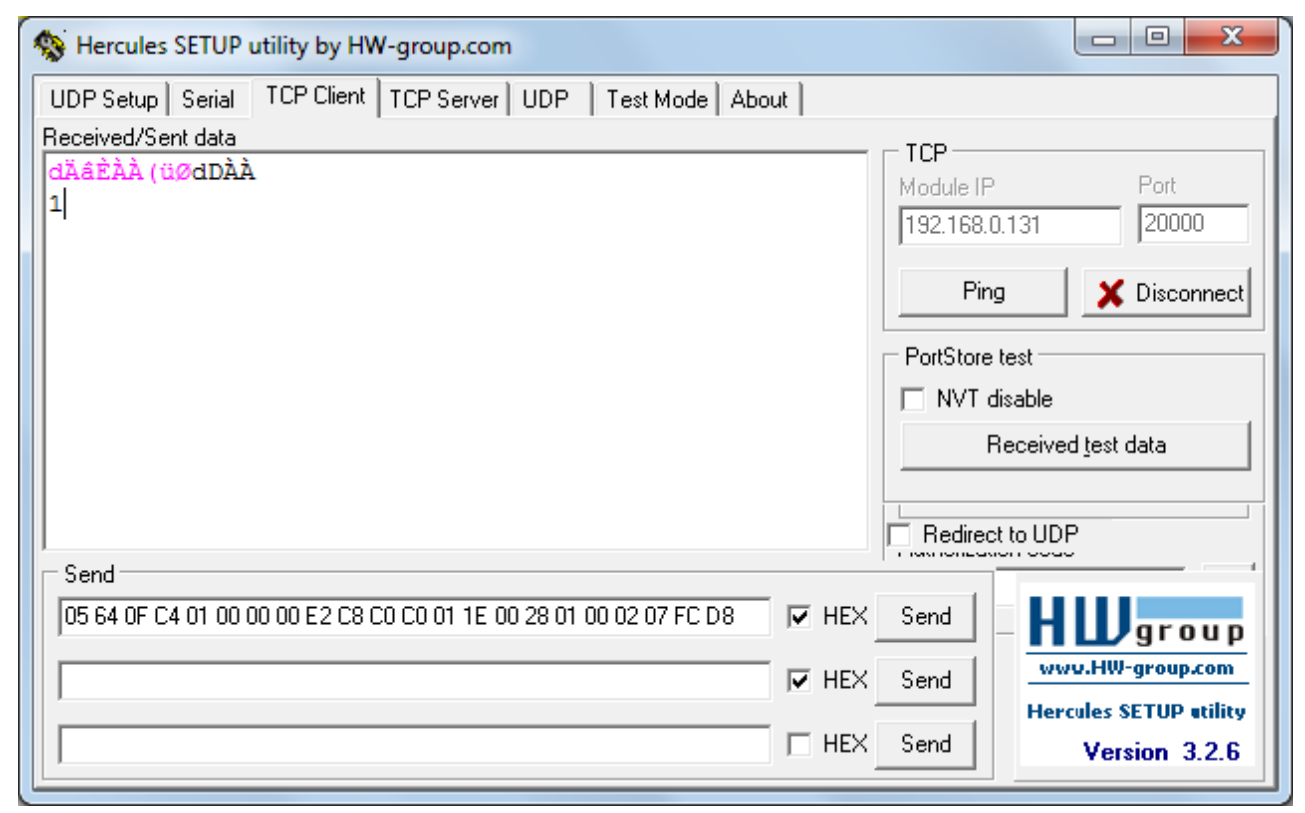

Figura 6.16 - Quantidade de fasores a cada amostragem. 


\subsection{3 - Leitura de fasores de tensão no canal A}

- Características gerais do teste

- Fonte de tensão: rede elétrica monofásica (Figura 6.17)

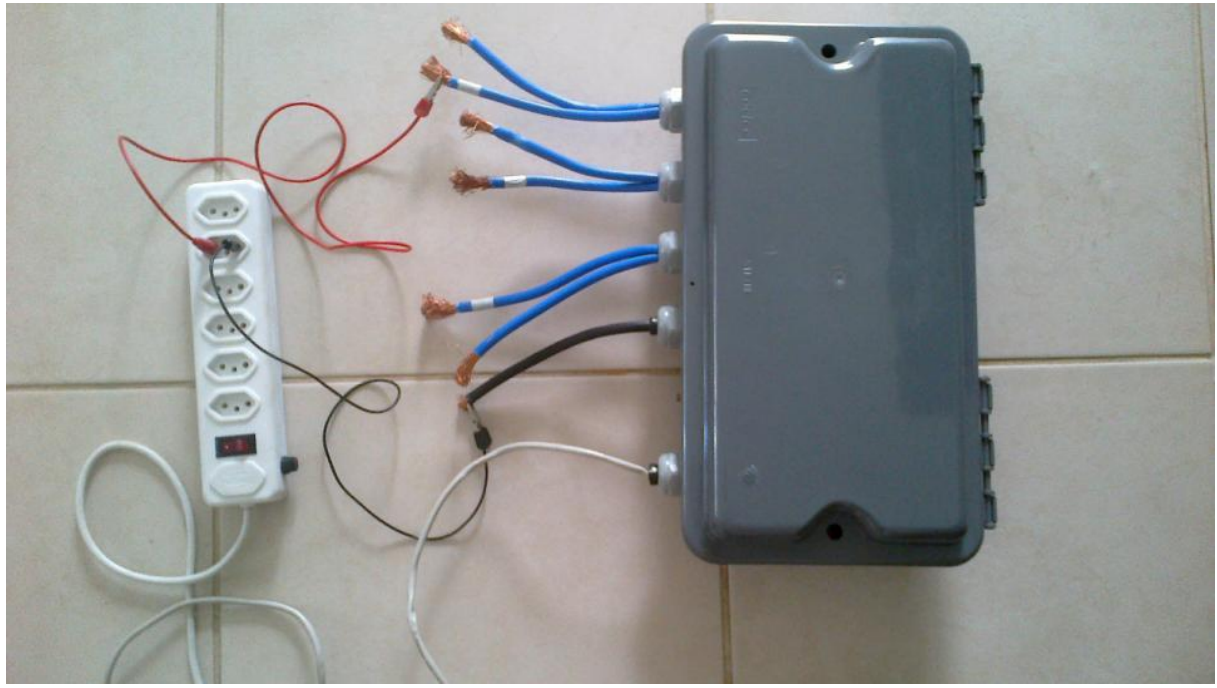

Figura 6.17 - Conexão entre a PMU a rede elétrica monofásica para realização de testes.

- Frequência de amostragem: amostragem a cada um segundo;

- Quantidade de fasores a cada amostragem: um fasor por canal;

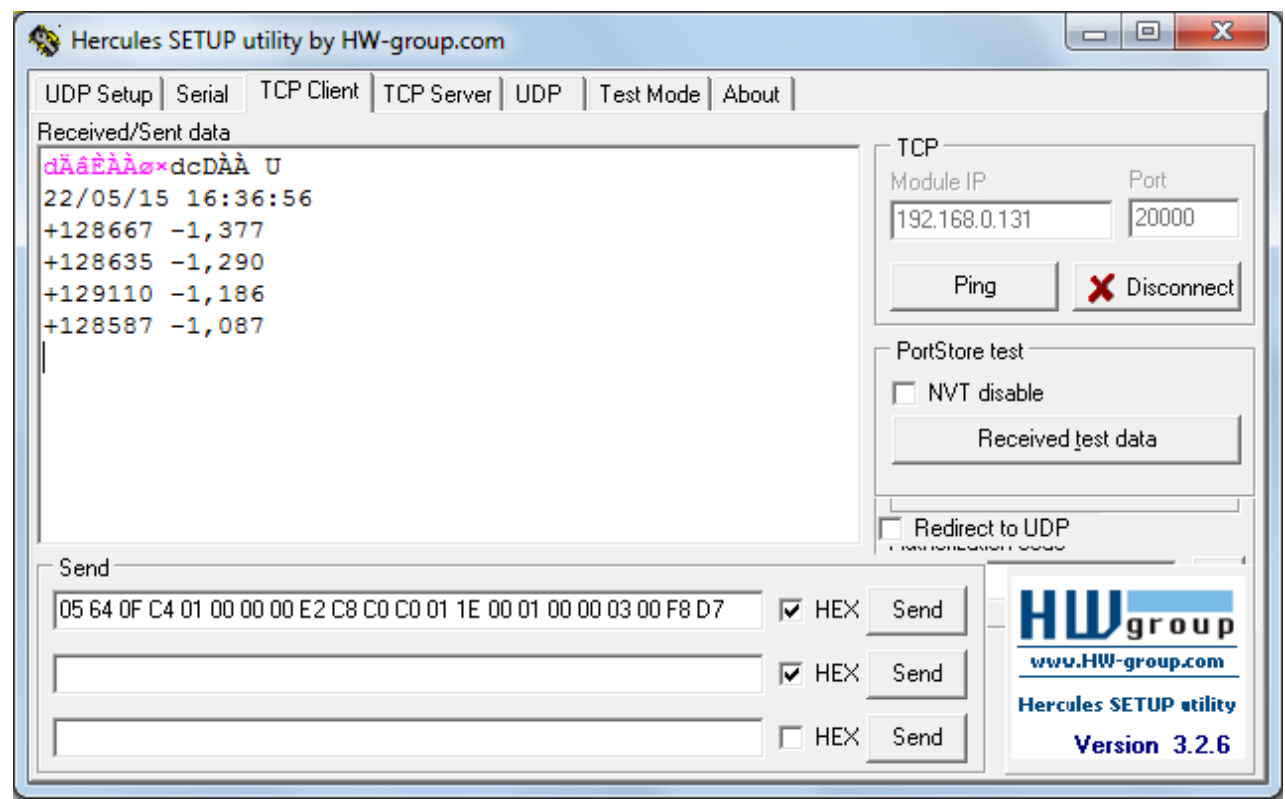

Figura 6.18 - Leitura de quatro fasores de tensão no canal A.

- Mensagem de requisição DNP3 (formato hexadecimal): 0564 0F C4 01000000 E2 C8 C0 C0 $011 \mathrm{E} 000100000300$ F8 D7; 
- Endereço da requisição: 0x0000 (fasor mais recente) a 0x0003;

- Dados da mensagem de resposta (formato ASCII, Figura 6.18):

Fasor 0 - Data: 22/05/15, Hora: 16:36:56, Módulo: $128667 \mathrm{mV}$, Ângulo: -1,377 rad Fasor 1 - Data: 22/05/15, Hora: 16:36:55, Módulo: $128635 \mathrm{mV}$, Ângulo: -1,290 rad Fasor 2 - Data: 22/05/15, Hora: 16:36:54, Módulo: $129110 \mathrm{mV}$, Ângulo: -1,186 rad Fasor 3 - Data: 22/05/15, Hora: 16:36:53, Módulo: $128587 \mathrm{mV}$, Ângulo: -1,087 rad

\subsection{4 - Leitura de fasores de tensão canal C}

- Características gerais do teste

- Fonte de tensão: rede elétrica monofásica;

- Frequência de amostragem: amostragem a cada um segundo;

- Quantidade de fasores a cada amostragem: um fasor por canal;

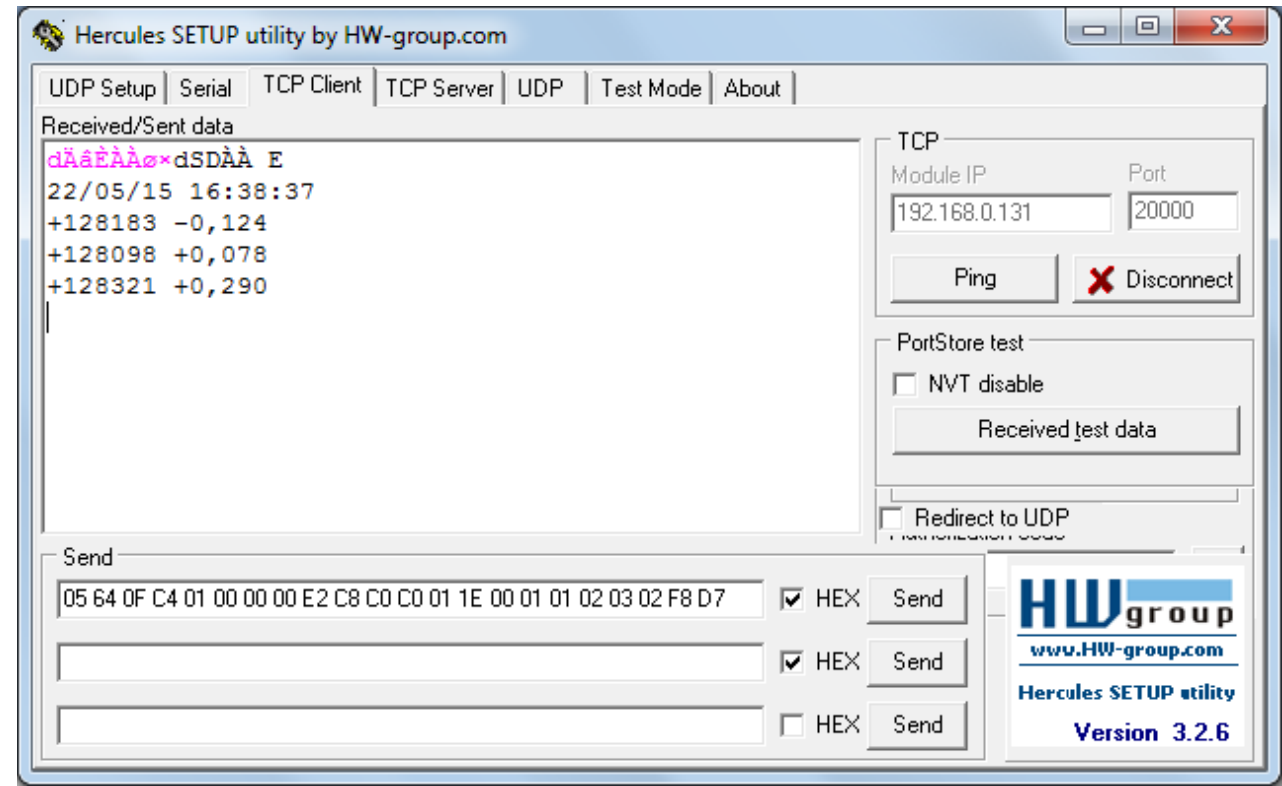

Figura 6.19 - Leitura de quatro fasores de tensão no canal C.

- Mensagem de requisição DNP3 (formato hexadecimal): 0564 0F C4 01000000 E2 C8 C0 C0 01 1E 000101020302 F8 D7;

- Endereço da requisição: 0x0201 a 0x0203;

- Dados da mensagem de resposta (formato ASCII, Figura 6.19):

Fasor 1 - Data: 22/05/15, Hora: 16:38:37, Módulo: 128183 mV, Ângulo: -0,124 rad Fasor 2 - Data: 22/05/15, Hora: 16:38:36, Módulo: $128098 \mathrm{mV}$, Ângulo: +0,078 rad Fasor 3 - Data: 22/05/15, Hora: 16:38:35, Módulo: $128321 \mathrm{mV}$, Ângulo: +0,290 rad 


\subsection{5 - Leitura de fasores de corrente canal B}

- Características gerais do teste

- Fonte de tensão: rede elétrica monofásica;

- Carga resistiva de $110 \Omega$;

- Frequência de amostragem: amostragem a cada um segundo;

- Quantidade de fasores a cada amostragem: um fasor por canal;

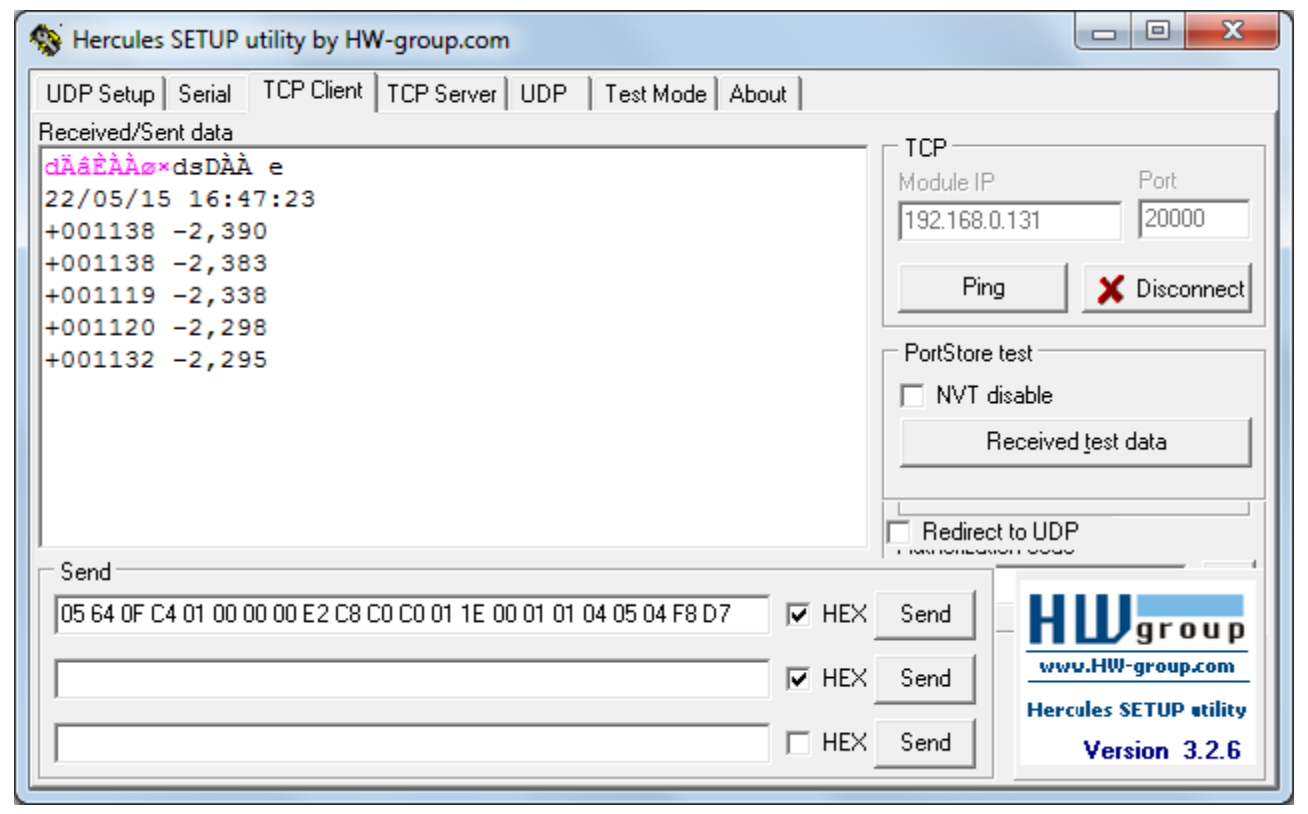

Figura 6.20 - Leitura de cinco fasores de corrente no canal B.

- Mensagem de requisição DNP3 (formato hexadecimal): 0564 0F C4 01000000 E2 C8 C0 C0 011 E 000101040504 F8 D7;

- Endereço da requisição: 0x0401 a 0x0405;

- Dados da mensagem de resposta (formato ASCII, Figura 6.20):

Fasor 1 - Data: 22/05/15, Hora: 16:47:23, Módulo: 1183 mA, Ângulo: -2,390 rad Fasor 2 - Data: 22/05/15, Hora: 16:47:22, Módulo: 1138 mA, Ângulo: -2,383 rad Fasor 3 - Data: 22/05/15, Hora: 16:47:21, Módulo: $1119 \mathrm{~mA}$, Ângulo: -2,338 rad Fasor 4 - Data: 22/05/15, Hora: 16:47:20, Módulo: $1120 \mathrm{~mA}$, Ângulo: -2,298 rad Fasor 5 - Data: 22/05/15, Hora: 16:47:19, Módulo: 1132 mA, Ângulo: -2,295 rad

\subsection{6 - Configuração e leitura da quantidade de fasores por amostragem}

\section{- Características gerais do teste}


- Primeira mensagem de requisição DNP3 (formato hexadecimal): 056412 C4 01000000 76 D2 C0 C0 02 1E 022801000207000500 FC D8;

- Endereço da requisição: 0x0702;

- Dado da mensagem de requisição: 5 (cinco fasores por canal a cada amostragem);

- Segunda mensagem de requisição DNP3 (formato hexadecimal): 0564 OF C4 01000000 E2 C8 C0 C0 01 1E 002801000207 FC D8;

- Endereço da requisição: 0x0702;

- Dados da mensagem de resposta (formato ASCII): 5 (cinco fasores por canal a cada amostragem, Figura 6.21).

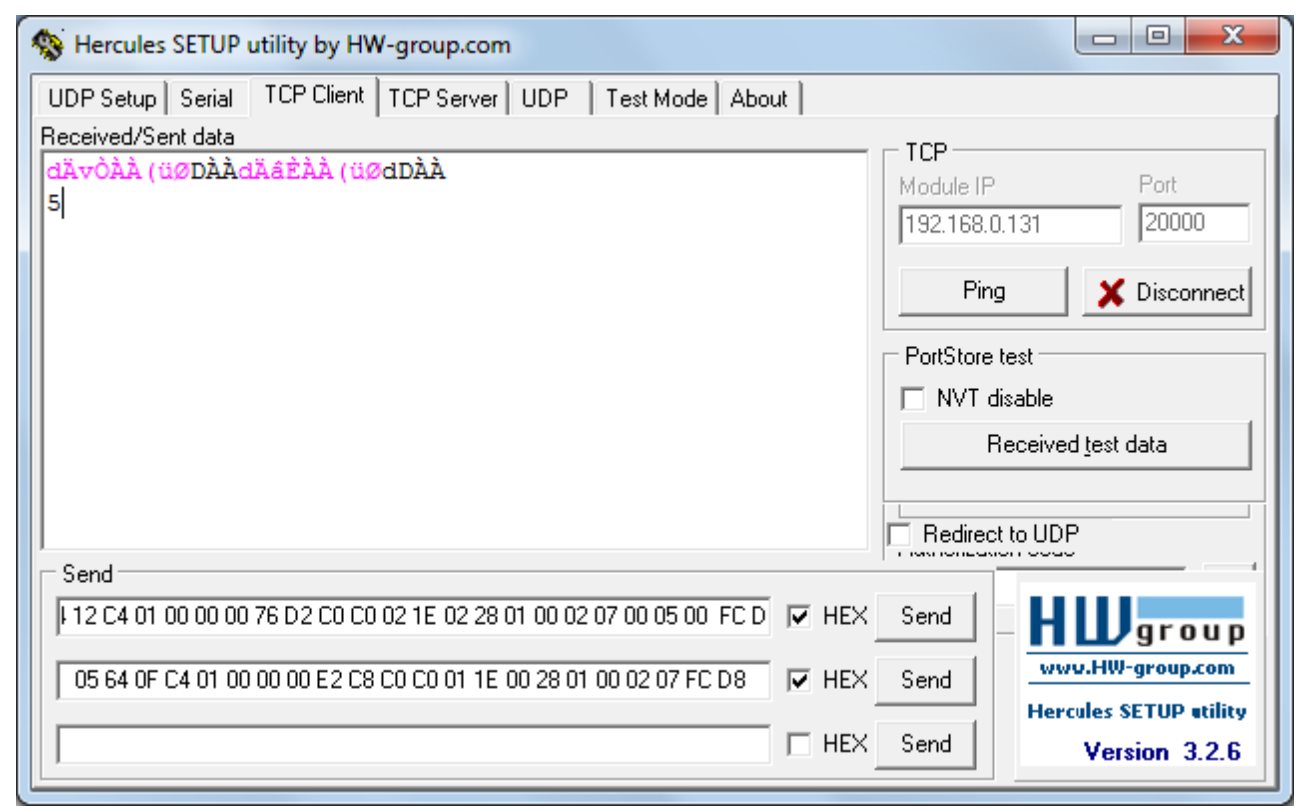

Figura 6.21 - Escrita e leitura da quantidade de fasores por amostragem.

\subsection{7 - Leitura de fasores de corrente no canal B}

- Características gerais do teste

- Fonte de tensão: rede elétrica monofásica;

- Carga resistiva de $110 \Omega$;

- Frequência de amostragem: amostragem a cada um segundo;

- Quantidade de fasores a cada amostragem: cinco fasores por canal;

- Mensagem de requisição DNP3 (formato hexadecimal): 0564 0F C4 01000000 E2 C8 C0

C0 01 1E 000100040304 F8 D7; 


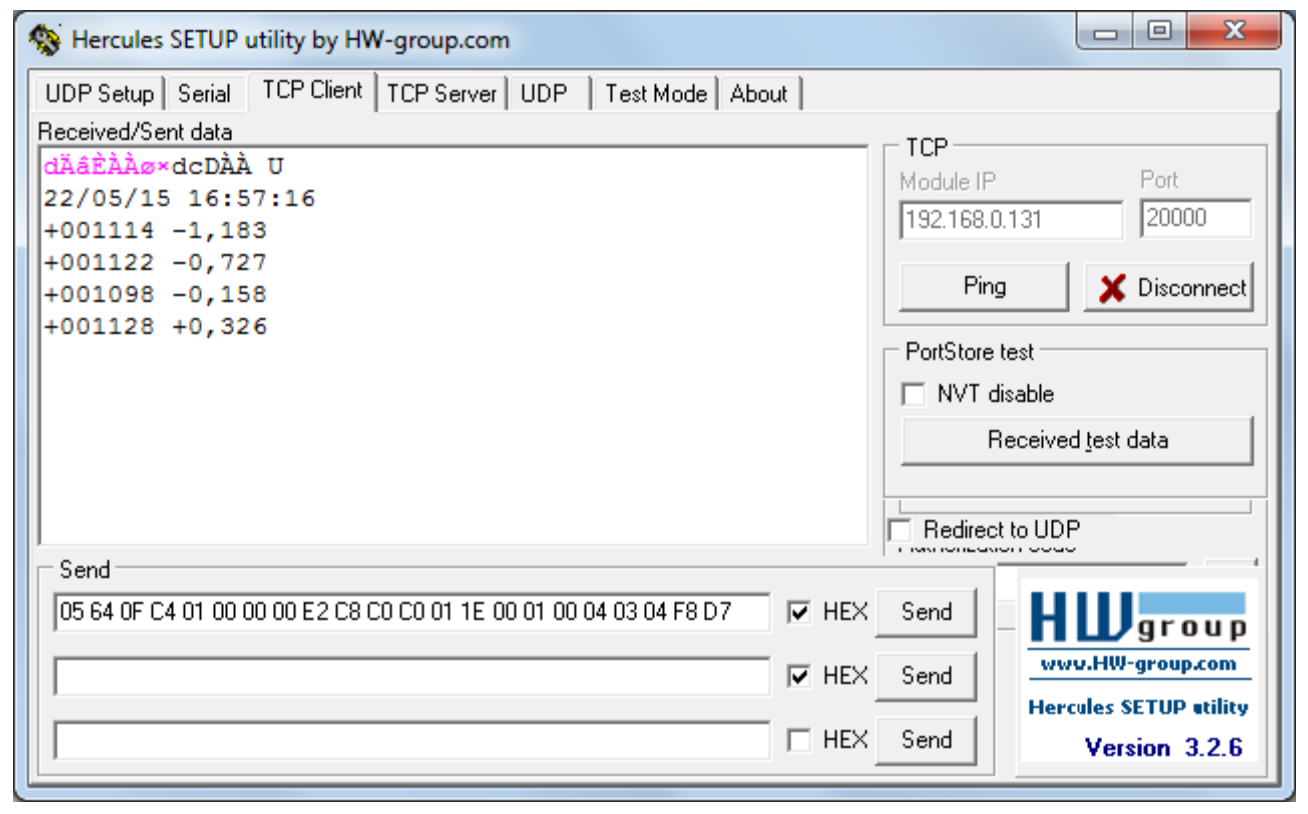

Figura 6.22 - Leitura de quatro fasores de corrente no canal B.

- Endereço da requisição: 0x0400 a 0x0403;

- Dados da mensagem de resposta (formato ASCII, Figura 6.22):

Fasor 1 - Data: 22/05/15, Hora: 16:57:16, Módulo: 1114 mA, Ângulo: -1,183 rad

Fasor 2 - Data: 22/05/15, Hora: -132 ms em relação ao Fasor 1, Módulo: 1122 mA, Ângulo: $-0,727 \mathrm{rad}$

Fasor 3 - Data: 22/05/15, Hora: -264 ms em relação ao Fasor 2, Módulo: 1098 mA, Ângulo: $-0,158 \mathrm{rad}$

Fasor 4 - Data: 22/05/15, Hora: -396 ms em relação ao Fasor 3, Módulo: 1128 mA, Ângulo: $+0,326 \mathrm{rad}$

\subsection{8 - Configuração e leitura da frequência de amostragem}

\section{- Características gerais do teste}

- Primeira mensagem de requisição DNP3 (formato hexadecimal): 056412 C4 01000000 76 D2 C0 C0 02 1E 022801000107000300 FC D8;

• Endereço da requisição: 0x0701;

- Dado da mensagem de requisição: 3 (amostragem a cada três segundos);

- Segunda mensagem de requisição DNP3 (formato hexadecimal): 0564 0F C4 01000000 E2 C8 C0 C0 01 1E 002801000107 FC D8;

- Endereço da requisição: 0x0701;

- Dado da mensagem de resposta (formato ASCII): 3 (amostragem a cada três segundos, Figura 6.23). 


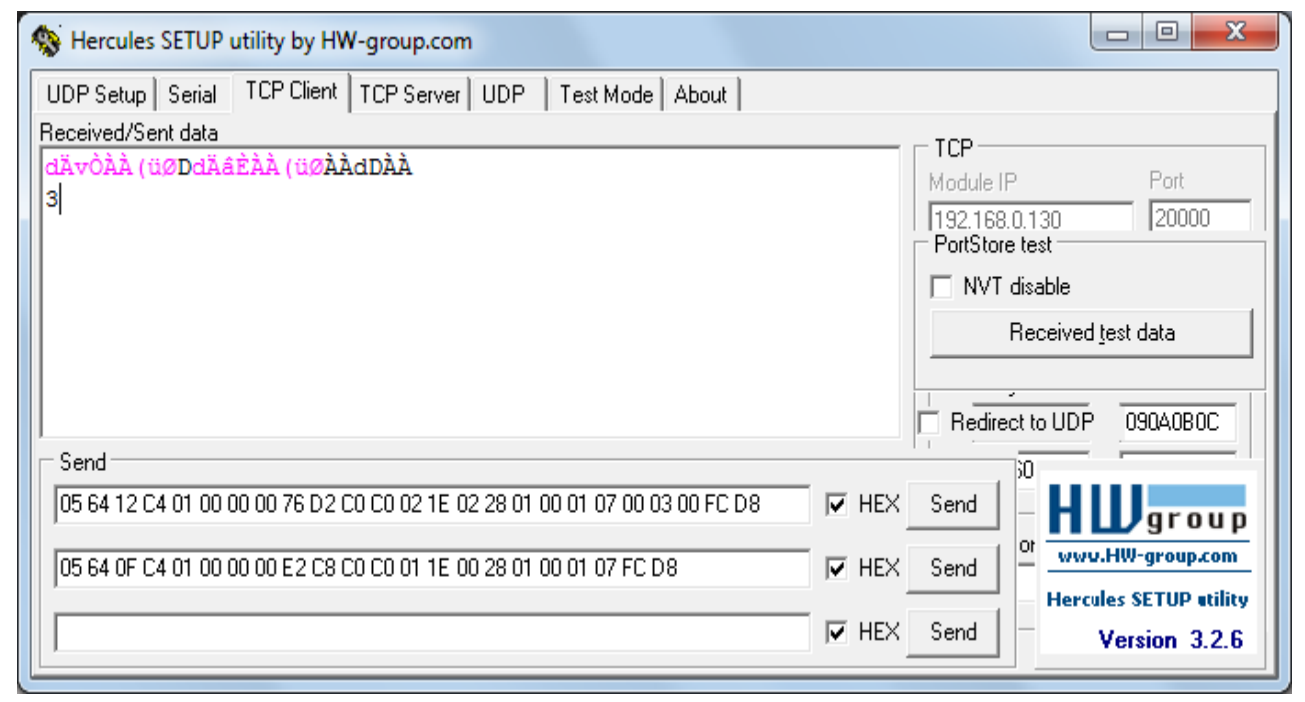

Figura 6.23 - Escrita e leitura da frequência de amostragem.

\subsection{9 - Configuração e leitura da quantidade de fasores por amostragem}

\section{- Características gerais do teste}

- Pimeira mensagem de requisição DNP3 (formato hexadecimal): 056412 C4 0100000076 D2 C0 C0 02 1E 022801000207000100 FC D8;

- Endereço da requisição: 0x0702;

- Dado da mensagem de requisição: 1 (um fasor por canal a cada amostragem);

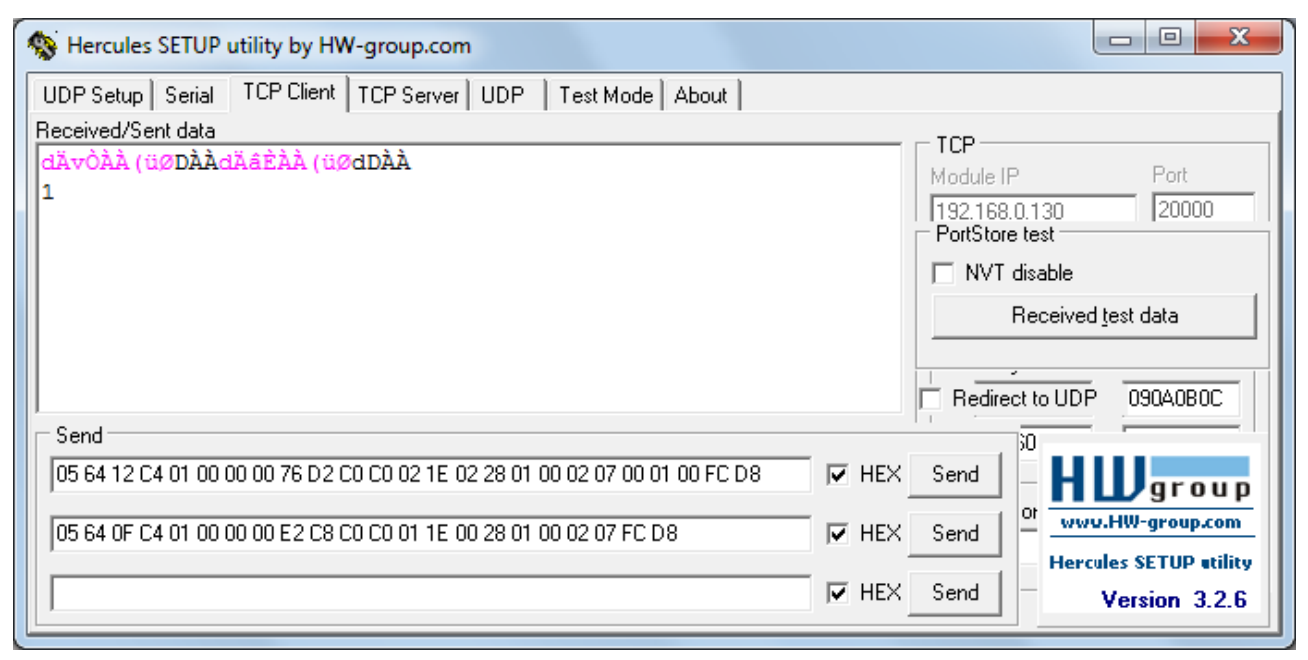

Figura 6.24 - Escrita e leitura da nova quantidade de fasores por amostragem.

- Segunda mensagem de requisição DNP3 (formato hexadecimal): 0564 OF C4 01000000 E2 C8 C0 C0 01 1E 002801000207 FC D8;

• Endereço da requisição: 0x0702; 
- Dados da mensagem de resposta (formato $A S C I I$ ): 1 (um fasor por canal a cada amostragem, Figura 6.24).

\subsubsection{0 - Leitura de fasores de corrente no canal A}

- Características gerais do teste

- Fonte de tensão: rede elétrica monofásica;

- Carga resistiva de 19,5 $\Omega$;

- Frequência de amostragem: amostragem a cada três segundos;

- Quantidade de fasores a cada amostragem: um fasor por canal;

- Primeira mensagem de requisição DNP3 (formato hexadecimal): 0564 OF C4 01000000 E2 C8 C0 C0 01 1E 000100030203 F8 D7;

- Endereço da requisição: 0x0300 a 0x0303;

- Dado da mensagem de resposta (formato ASCII, Figura 6.25):

Fasor 0 - Data: 29/05/15, Hora: 16:31:41, Módulo: 6569 mA, Ângulo: +0,146 rad Fasor 1 - Data: 29/05/15, Hora: 16:31:38, Módulo: 6566 mA, Ângulo: +0,246 rad Fasor 2 - Data: 29/05/15, Hora: 16:31:35, Módulo: $6592 \mathrm{~mA}$, Ângulo: $+0,230 \mathrm{rad}$ Fasor 3 - Data: 29/05/15, Hora: 16:31:32, Módulo: 6603 mA, Ângulo: +0,089 rad

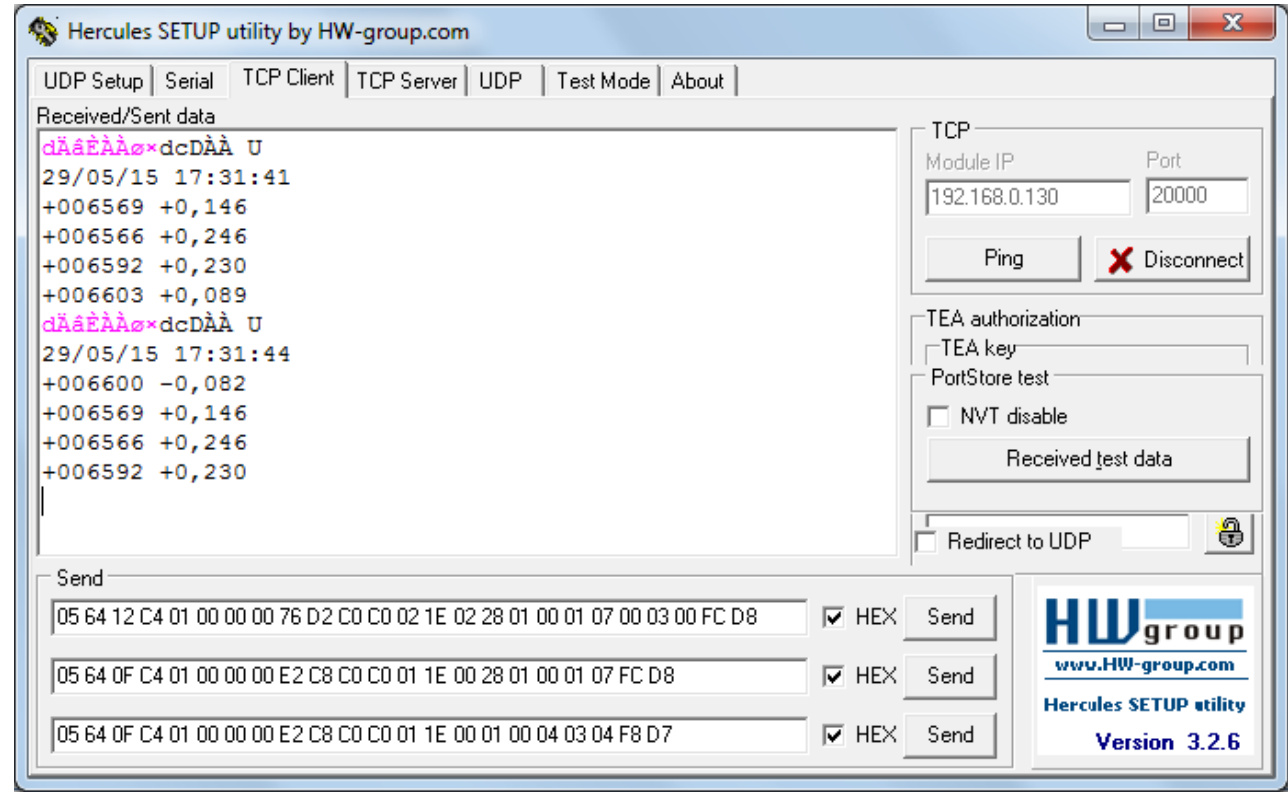

Figura 6.25 - Leitura de novos fasores de corrente no canal B.

- Segunda mensagem de requisição DNP3 (formato hexadecimal): 0564 OF C4 01000000

E2 C8 C0 C0 01 1E 000100030203 F8 D7;

- Endereço da requisição: 0x0300 a 0x0303;

- Dado da mensagem de resposta (formato ASCII, Figura 6.25): 
Fasor 0 - Data: 29/05/15, Hora: 16:31:44, Módulo: 6600 mA, Ângulo: -0,082 rad Fasor 1 - Data: 29/05/15, Hora: 16:31:41, Módulo: 6569 mA, Ângulo: +0,146 rad Fasor 2 - Data: 29/05/15, Hora: 16:31:38, Módulo: 6566 mA, Ângulo: +0,246 rad Fasor 3 - Data: 29/05/15, Hora: 16:31:35, Módulo: 6592 mA, Ângulo: +0,230 rad

\subsubsection{1 - Leitura de frequências para os canais de tensão A, B e C}

\section{- Características gerais do teste}

- Fonte de tensão: rede elétrica monofásica;

- Mensagem de requisição DNP3 (formato hexadecimal): 0564 0F C4 01000000 E2 C8 C0 C0 01 1E 000100060206 F8 D7;

- Endereço da requisição: 0x0600 a 0x0602;

- Dados da mensagem de resposta (formato ASCII, Figura 6.26):

Frequência canal A - Data: 22/05/15, Hora: 17:01:19, Valor: $59999 \mathrm{~Hz}$ Frequência canal B - Data: 22/05/15, Hora: 17:01:19, Valor: 59999 Hz Frequência canal C - Data: 22/05/15, Hora: 17:01:19, Valor: 59999 Hz

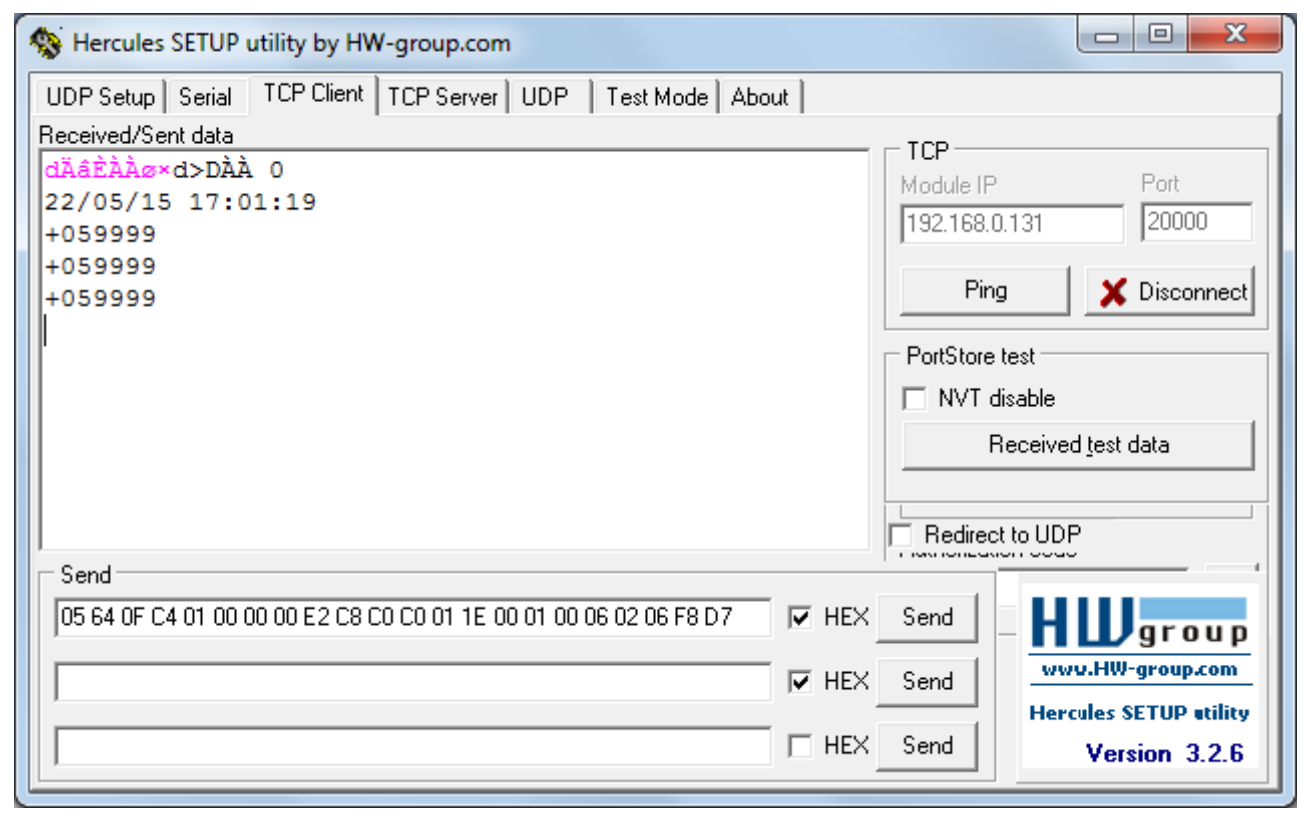

Figura 6.26 - Leitura das frequências para os três canais de tensão.

\subsubsection{2 - Leitura de tensões RMS para os canais A, B e C e correntes RMS para os canais} A e B

\section{- Características gerais do teste}

- Fonte de tensão: rede elétrica monofásica;

- Carga resistiva de $110 \Omega$ apenas para o canal B; 
- Frequência de amostragem: amostragem a cada um segundo;

- Mensagem de requisição DNP3 (formato hexadecimal): 0564 0F C4 01000000 E2 C8 C0 C0 01 1E 000103060706 F8 D7;

• Endereço da requisição: 0x0603 a 0x0607;

- Dado da mensagem de resposta (formato ASCII, Figura 6.27):

Tensão RMS canal A - Data: 22/05/15, Hora: 17:17:38, Valor: $127986 \mathrm{mV}$ Tensão RMS canal B - Data: 22/05/15, Hora: 17:17:38, Valor: $127829 \mathrm{mV}$ Tensão RMS canal C - Data: 22/05/15, Hora: 17:17:38, Valor: $127813 \mathrm{mV}$ Corrente RMS canal A - Data: 22/05/15, Hora: 17:17:38, Valor: 0 mA Corrente RMS canal B - Data: 22/05/15, Hora: 17:17:38, Valor: 1113 mA

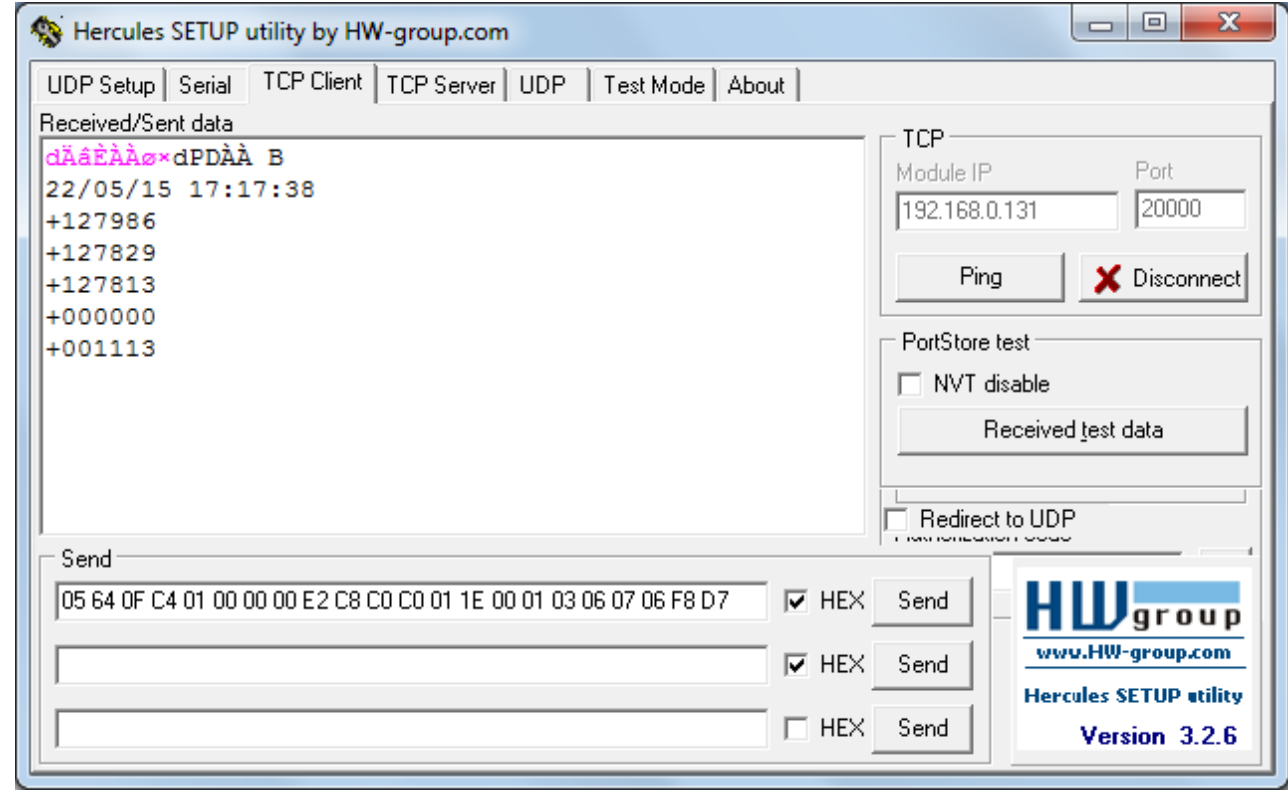

Figura 6.27 - Leitura das tensões RMS para os três canais e das correntes RMS para os canais A e B.

\subsubsection{3 - Leitura de corrente RMS para o canal C}

- Características gerais do teste

- Fonte de tensão: rede elétrica monofásica;

- Nenhuma carga conectada ao canal C;

- Frequência de amostragem: amostragem a cada um segundo;

- Mensagem de requisição DNP3 (formato hexadecimal): 0564 0F C4 01000000 E2 C8 C0

C0 011 E 002801000806 FC D8;

- Endereço da requisição: 0x0608;

- Dado da mensagem de resposta (formato ASCII, Figura 6.28):

Corrente RMS canal C - Data: 22/05/15, Hora: 17:19:54, Valor: 0 mA 


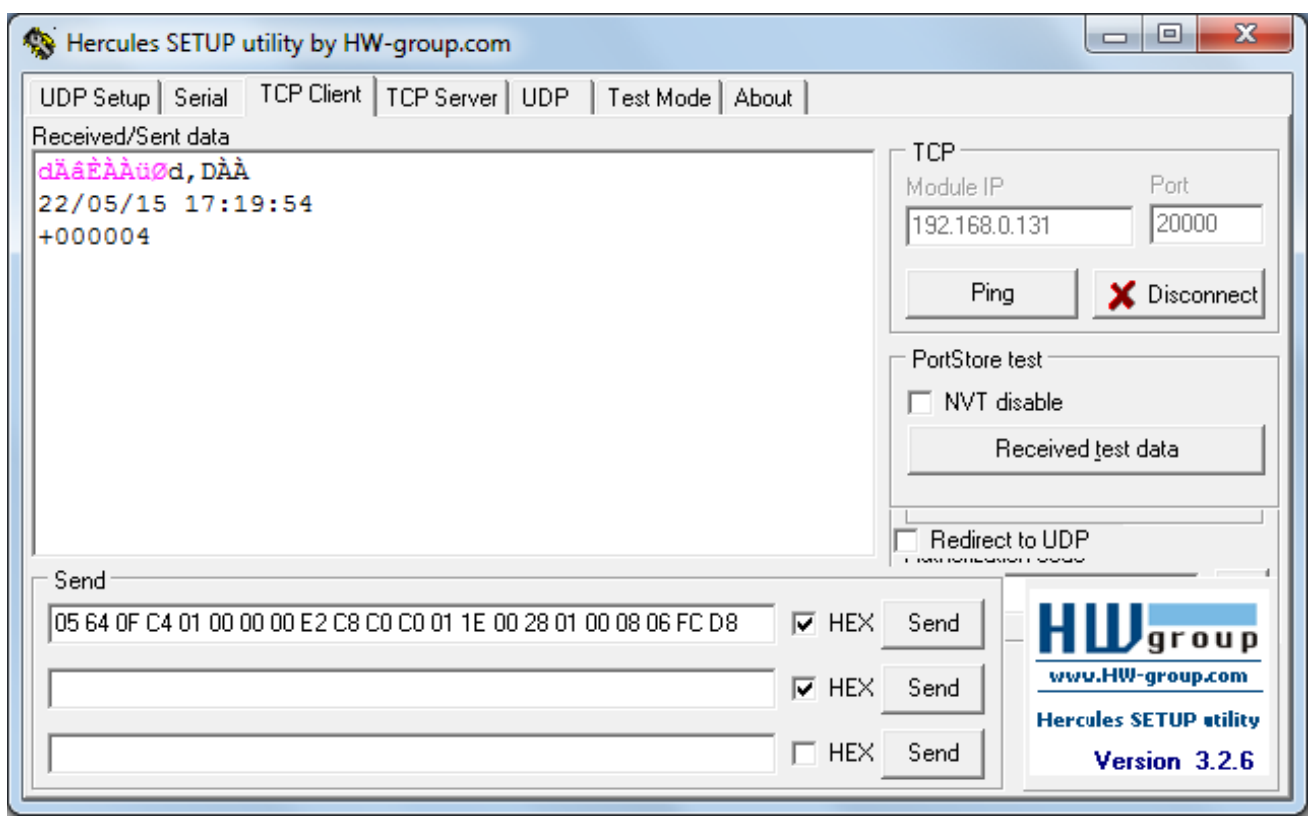

Figura 6.28 - Leitura da corrente RMS para o canal C.

\subsubsection{4 - Leitura das potências ativas para os canais A, B e C e das potências aparentes para os canais A e B}

- Características gerais do teste

- Fonte de tensão: rede elétrica monofásica;

- Carga resistiva de $110 \Omega$ apenas para o canal B;

- Frequência de amostragem: amostragem a cada um segundo;

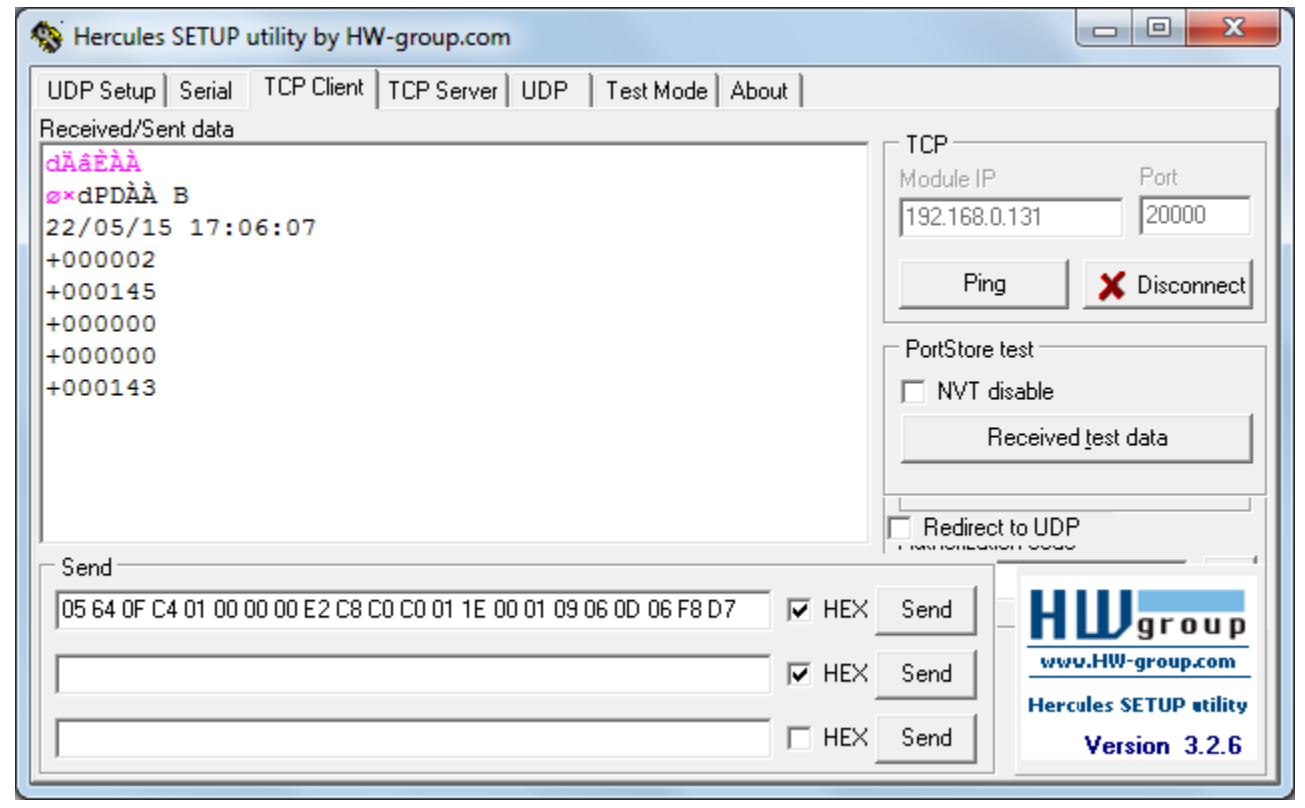

Figura 6.29 - Leitura das potências ativas nos canais A, B e C e das potências aparentes nos canais A e B. 
- Mensagem de requisição DNP3 (formato hexadecimal): 0564 0F C4 01000000 E2 C8 C0 C0 01 1E 00010906 0D 06 F8 D7;

- Endereço da requisição: 0x0609 a 0x060d;

- Dado da mensagem de resposta (formato ASCII, Figura 6.29):

Potência ativa canal A - Data: 22/05/15, Hora: 17:06:07, Valor: 2 W Potência ativa canal B - Data: 22/05/15, Hora: 17:06:07, Valor: $145 \mathrm{~W}$ Potência ativa canal C - Data: 22/05/15, Hora: 17:06:07, Valor: 0W Potência aparente canal A - Data: 22/05/15, Hora: 17:06:07, Valor: 0 VA Potência aparente canal B - Data: 22/05/15, Hora: 17:06:07, Valor: 143 VA

6.2.15 - Leitura da potência aparente para o canal $C$ e das potências reativas para os canais $\mathrm{A}, \mathrm{B}$ e $\mathrm{C}$

\section{- Características gerais do teste}

- Fonte de tensão: rede elétrica monofásica;

- Carga resisitiva de $110 \Omega$ apenas para o canal B;

- Frequência de amostragem: amostragem a cada um segundo;

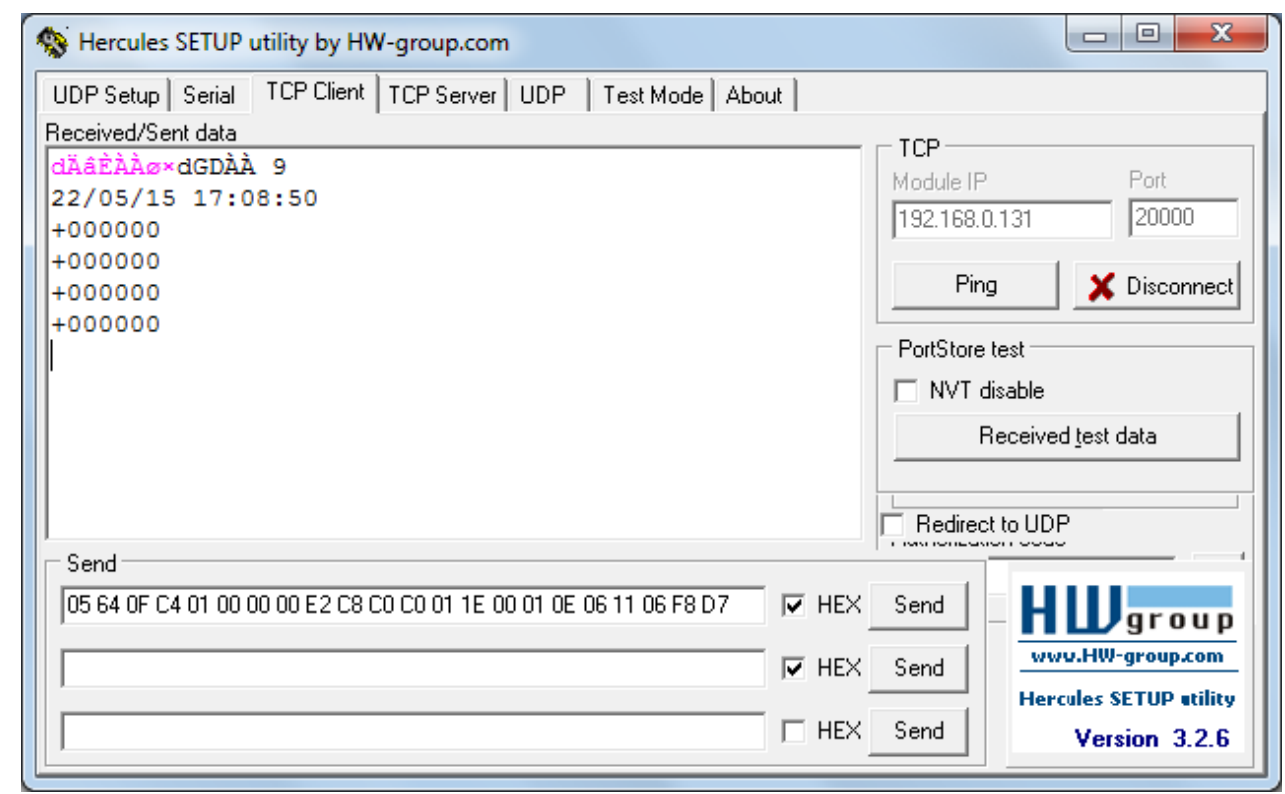

Figura 6.30 - Leitura da potência aparente no canal C e das potências reativas nos canais A, B e C.

- Mensagem de requisição DNP3 (formato hexadecimal): 0564 0F C4 01000000 E2 C8 C0 C0 01 1E 0001 0E 061106 F8 D7;

- Endereço da requisição: 0x060E a 0x0611;

- Dado da mensagem de resposta (formato ASCII, Figura 6.30):

Potência aparente canal C - Data: 22/05/15, Hora: 17:08:50, Valor: 0 VA 
Potência reativa canal A - Data: 22/05/15, Hora: 17:08:50, Valor: 0 VAR Potência reativa canal B - Data: 22/05/15, Hora: 17:08:50, Valor: 0 VAR Potência reativa canal C - Data: 22/05/15, Hora: 17:08:50, Valor: 0 VAR

\subsubsection{6 - Leitura de fasores de tensão no canal $B$, limpeza dos buffers e nova leitura de fasores no canal $B$.}

\section{- Características gerais do teste}

- Fonte de tensão: rede elétrica monofásica;

- Frequência de amostragem: amostragem a cada um segundo;

- Quantidade de fasores a cada amostragem: um fasor por canal;

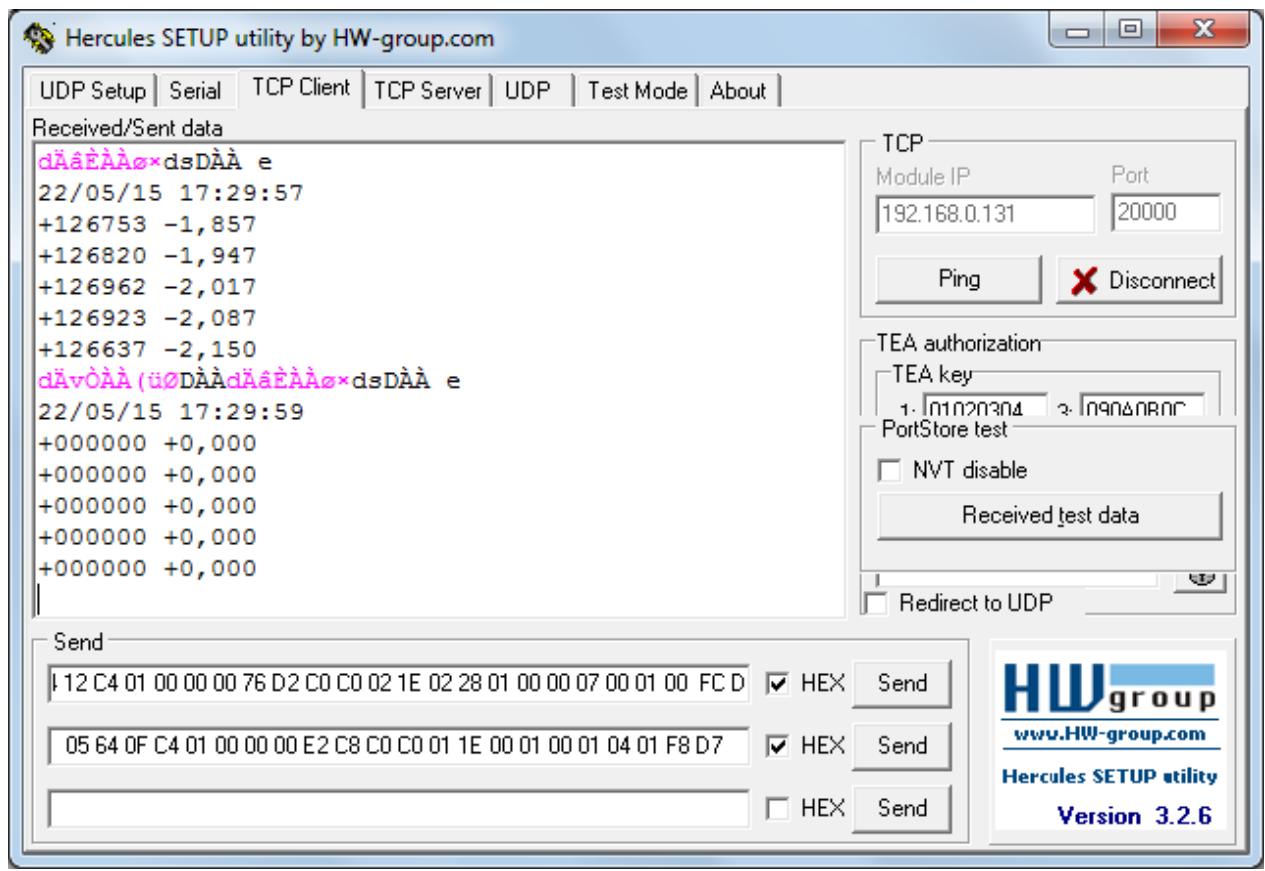

Figura 6.31 - Leitura de fasores de tensão no canal B, limpeza dos buffers e nova leitura.

- Primeira mensagem de requisição DNP3 (formato hexadecimal): 0564 0F C4 01000000 E2 C8 C0 C0 01 1E 000100010401 F8 D7;

- Endereço da requisição: 0x0100 (fasor mais recente) a 0x0104;

- Dados da mensagem de resposta (formato ASCII, Figura 6.31):

Fasor 0 - Data: 22/05/15, Hora: 17:29:57, Módulo: $126753 \mathrm{mV}$, Ângulo: -1,857 rad Fasor 1 - Data: 22/05/15, Hora: 17:29:56, Módulo: $126820 \mathrm{mV}$, Ângulo: -1,947 rad Fasor 2 - Data: 22/05/15, Hora: 17:29:55, Módulo: $126962 \mathrm{mV}$, Ângulo: -2,017 rad Fasor 3 - Data: 22/05/15, Hora: 17:29:54, Módulo: $126923 \mathrm{mV}$, Ângulo: -2,087 rad Fasor 4 - Data: 22/05/15, Hora: 17:29:53, Módulo: 126637 mV, Ângulo: -2,150 rad

- Segunda mensagem de requisição DNP3 (formato hexadecimal): 056412 C4 01000000 76 D2 C0 C0 02 1E 022801000007000100 FC D8; 
- Endereço da requisição: 0x0700;

- Dado da mensagem de requisição: 1 (reseta os buffers);

- Terceira mensagem de requisição DNP3 (formato hexadecimal): 0564 0F C4 01000000

E2 C8 C0 C0 01 1E 000100010401 F8 D7;

- Endereço da requisição: 0x0100 (fasor mais recente) a 0x0104;

- Dados da mensagem de resposta (formato ASCII, Figura 6.31):

Fasor 0 - Data: 22/05/15, Hora: 17:29:59, Módulo: $0 \mathrm{mV}$, Ângulo: $0 \mathrm{rad}$

Fasor 1 - Data: 22/05/15, Hora: 17:29:58, Módulo: $0 \mathrm{mV}$, Ângulo: $0 \mathrm{rad}$

Fasor 2 - Data: 22/05/15, Hora: 17:29:57, Módulo: $0 \mathrm{mV}$, Ângulo: $0 \mathrm{rad}$

Fasor 3 - Data: 22/05/15, Hora: 17:29:56, Módulo: 0 mV, Ângulo: $0 \mathrm{rad}$

Fasor 4 - Data: 22/05/15, Hora: 17:29:55, Módulo: 0 mV, Ângulo: 0 rad

\subsubsection{7 - Leitura das duas identificações mais recentes da causa do distúrbio no canal C}

- Características gerais do teste

- Fonte de tensão: rede elétrica monofásica;

- Carga linear resistiva variando de $110 \Omega$ para $500 \Omega$ apenas para o canal C;

- Frequência de amostragem: amostragem a cada um segundo;

- Frequência para a identificação da causa do distúrbio: identificação a cada 4 segundos;

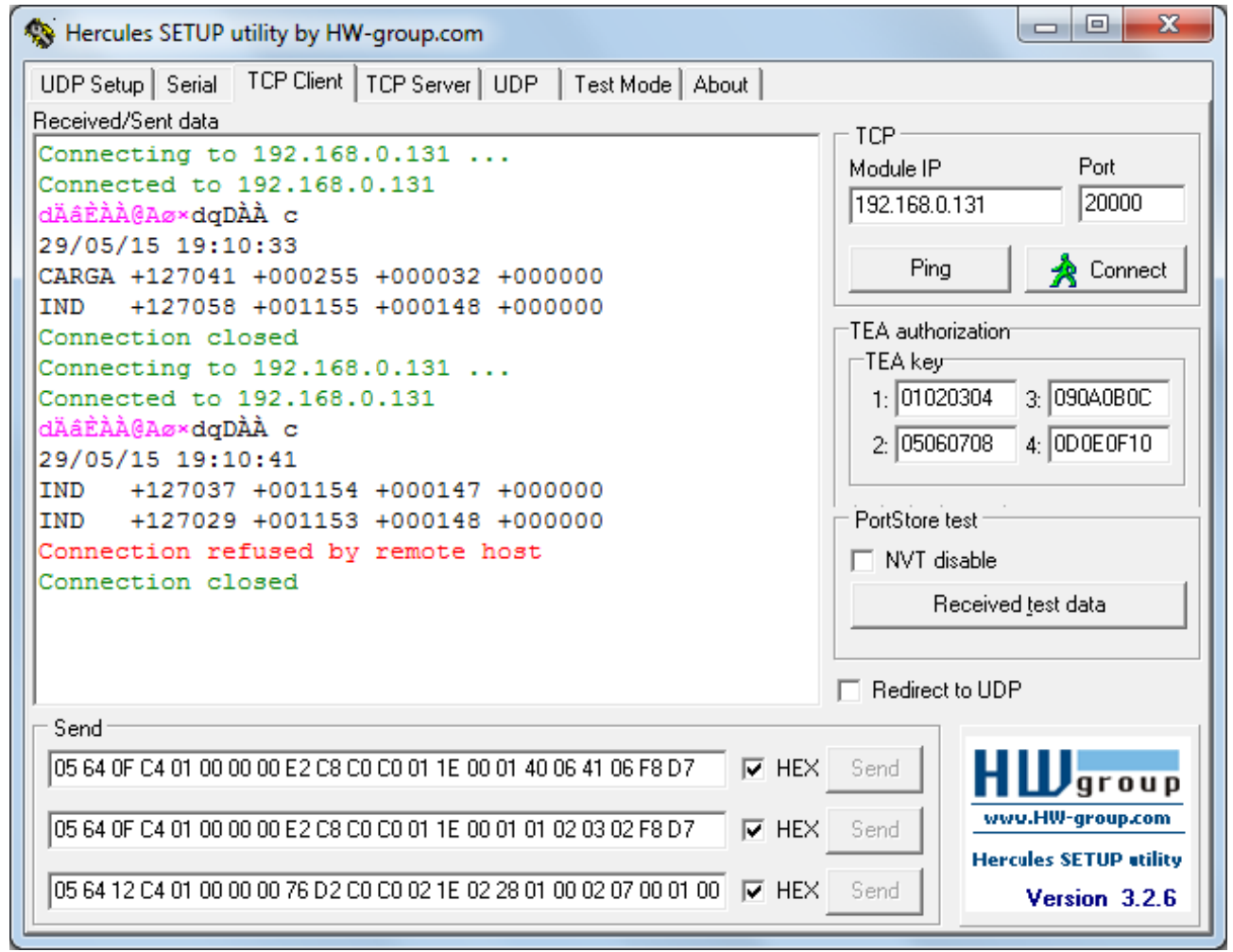

Figura 6.32 - Leitura de identificação da causa de distúrbios canal C. 
- Primeira mensagem de requisição DNP3 (formato hexadecimal): 0564 0F C4 01000000

E2 C8 C0 C0 01 1E 000140064106 F8 D7;

- Endereço da requisição: 0x0640 (fasor mais recente) a 0x0641;

- Dados da mensagem de resposta (formato ASCII, Figura 6.32):

Identificação 0 - Data: 29/05/15, Hora: 19:10:33, Causa: Mudança na carga, $\mathrm{V}_{\mathrm{RMS}}: 127041$ $\mathrm{mV}, \mathrm{I}_{\mathrm{RMS}}$ : $255 \mathrm{~mA}, \mathrm{P}: 32 \mathrm{~W}$, Q: 0 VAR;

Identificação 1 - Data: 29/05/15, Hora: 19:10:29, Causa: Indeterminada, $\mathrm{V}_{\mathrm{RMS}}$ : $127058 \mathrm{mV}$, IRMS: $1155 \mathrm{~mA}, \mathrm{P}: 148 \mathrm{~W}$, Q: 0 VAR;

- Segunda mensagem de requisição DNP3 (formato hexadecimal): 0564 0F C4 01000000

E2 C8 C0 C0 01 1E 000140064106 F8 D7;

- Endereço da requisição: 0x0640 (fasor mais recente) a 0x0641;

- Dados da mensagem de resposta (formato ASCII, Figura 6.32):

Identificação 0 - Data: 29/05/15, Hora: 19:10:41, Causa: Indeterminada, V RMs: $127037 \mathrm{mV}$, $\mathrm{I}_{\mathrm{RMS}}: 1154 \mathrm{~mA}, \mathrm{P}: 147 \mathrm{~W}, \mathrm{Q}: 0 \mathrm{VAR}$

Identificação 1 - Data: 29/05/15, Hora: 19:10:37, Causa: Indeterminada, $\mathrm{V}_{\mathrm{RMS}}$ : $127029 \mathrm{mV}$, IRMS: $1153 \mathrm{~mA}, \mathrm{P}: 148 \mathrm{~W}, \mathrm{Q}: 0 \mathrm{VAR}$.

\subsubsection{8 - Leitura de parâmetros do transformador}

- Características gerais do teste

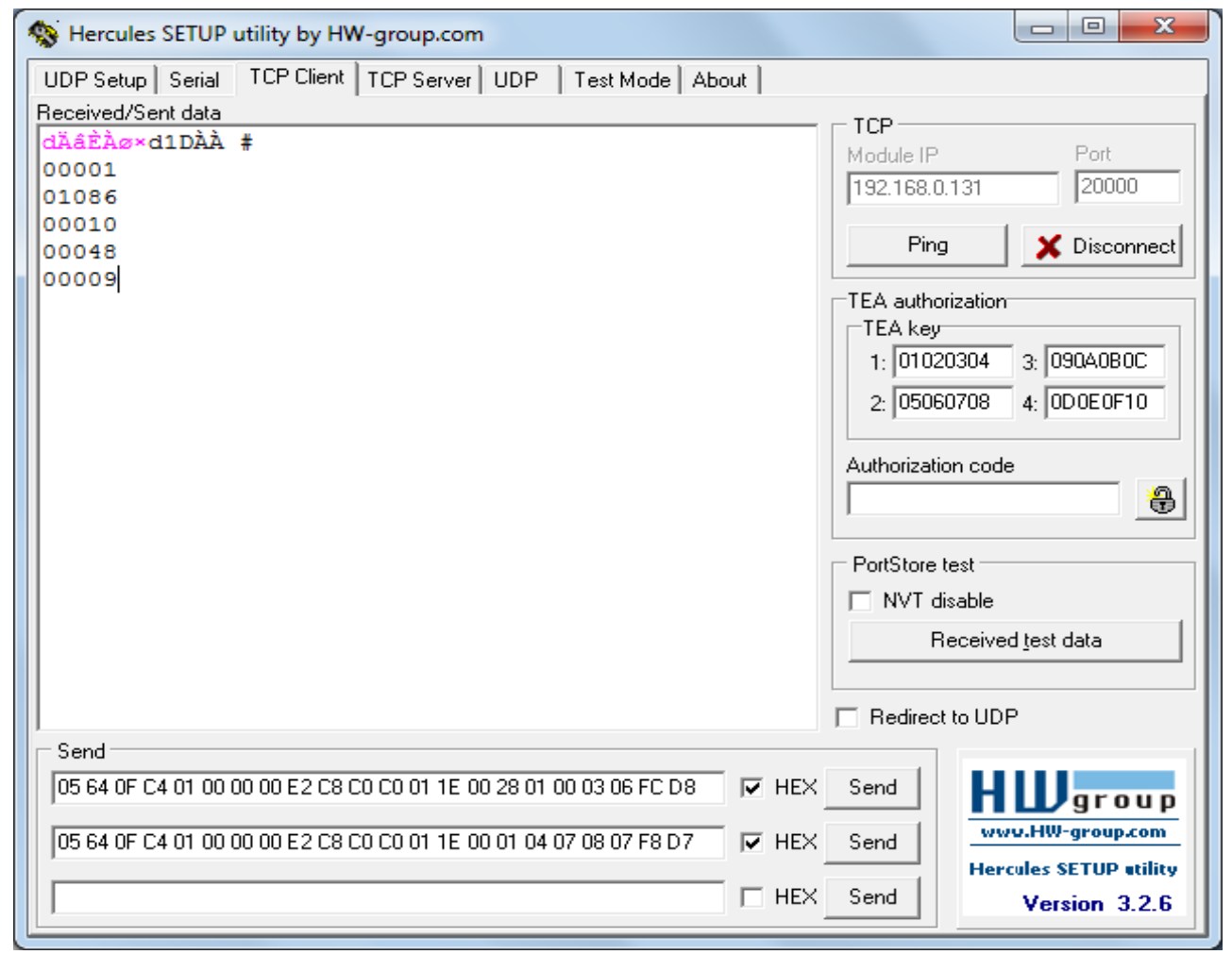

Figura 6.33 - Leitura de parâmetros do transformador. 
- Mensagem de requisição DNP3 (formato hexadecimal): 0564 0F C4 01000000 E2 C8 C0 C0 01 1E 000104070807 F8 D7;

- Endereço da requisição: 0x0704 a 0x0708;

- Dados da mensagem de resposta (formato ASCII, Figura 6.33):

Primeiro parâmetro - Reflexo das grandezas para os terminais primários do transformador habilitado;

Segundo parâmetro - Parâmetro $n l$ do transformador configurado com 1086;

Terceiro parâmetro - Parâmetro $n 2$ do transformador configurado com 10;

Quarto parâmetro - Parâmetro $r l$ do transformador configurado com $48 \mathrm{~m} \Omega$;

Quinto parâmetro - Parâmetro $r 2$ do transformador configurado com $9 \mathrm{~m} \Omega$.

\subsubsection{9 - Leitura de tensão e corrente RMS para o canal A refletidas nos terminais primários do transformador}

- Características gerais do teste

- Fonte de tensão: rede elétrica monofásica com tensão igual a $125 \mathrm{~V}_{\mathrm{RMS}}$;

- Carga linear de 18,65 $\Omega$;

- Parâmetro $n 1$ do transformador configurado com 1086;

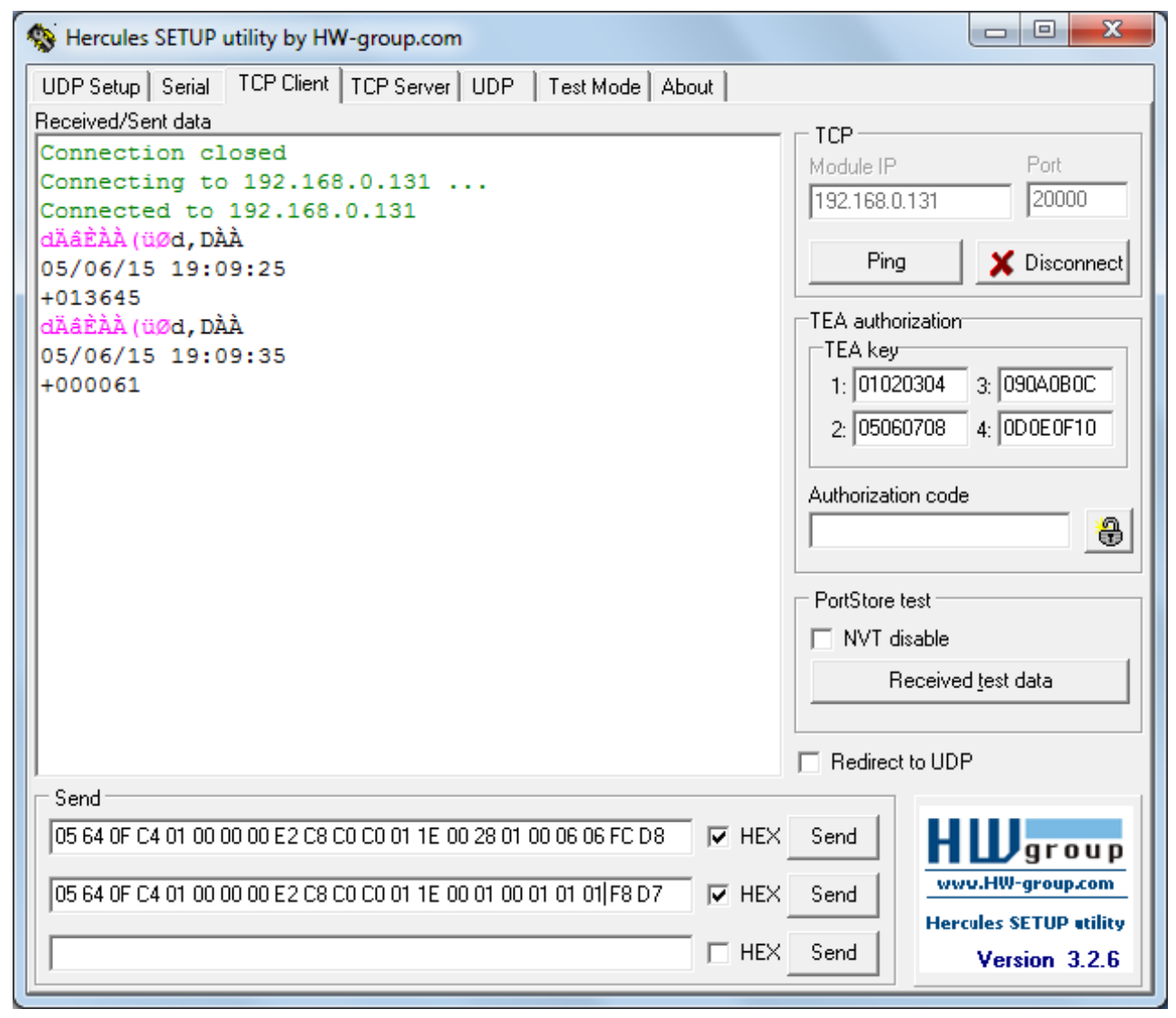

Figura 6.34 - Leitura de tensão e corrente RMS no canal A refletidas nos terminais primários do transformador. 
- Parâmetro $n 2$ do transformador configurado com 10;

- Parâmetro $r l$ do transformador configurado com $48 \mathrm{~m} \Omega$;

- Parâmetro $r 2$ do transformador configurado com $9 \mathrm{~m} \Omega$;

- Parâmetro $L 1$ do transformador configurado com 0,318 m $\Omega$;

- Parâmetro $L 2$ do transformador configurado com 0,0795 m $\Omega$;

- Frequência de amostragem: amostragem a cada um segundo;

- Primeira mensagem de requisição DNP3 (formato hexadecimal): 0564 0F C4 01000000 E2 C8 C0 C0 01 1E 002801000306 EC D2;

- Endereço da requisição: 0x0603;

- Dado da mensagem de resposta (formato ASCII, Figura 6.34):

Tensão RMS canal A - Data: 05/06/15, Hora: 19:09:25, Valor: 13645 V.

- Segunda mensagem de requisição DNP3 (formato hexadecimal): 0564 OF C4 01000000 E2 C8 C0 C0 01 1E 002801000606 FC D8;

- Endereço da requisição: 0x0606;

- Dado da mensagem de resposta (formato ASCII, Figura 6.34):

Corrente RMS canal A - Data: 05/06/15, Hora: 19:09:35, Valor: $61 \mathrm{~mA}$.

\section{- Observações}

Para este teste, o firwmare da PMU foi modificado para que a tensão e a corrente RMS fossem refletidos permanentemente para o enrolamento primário, permitindo a comparação com a simulação mostrada a seguir.

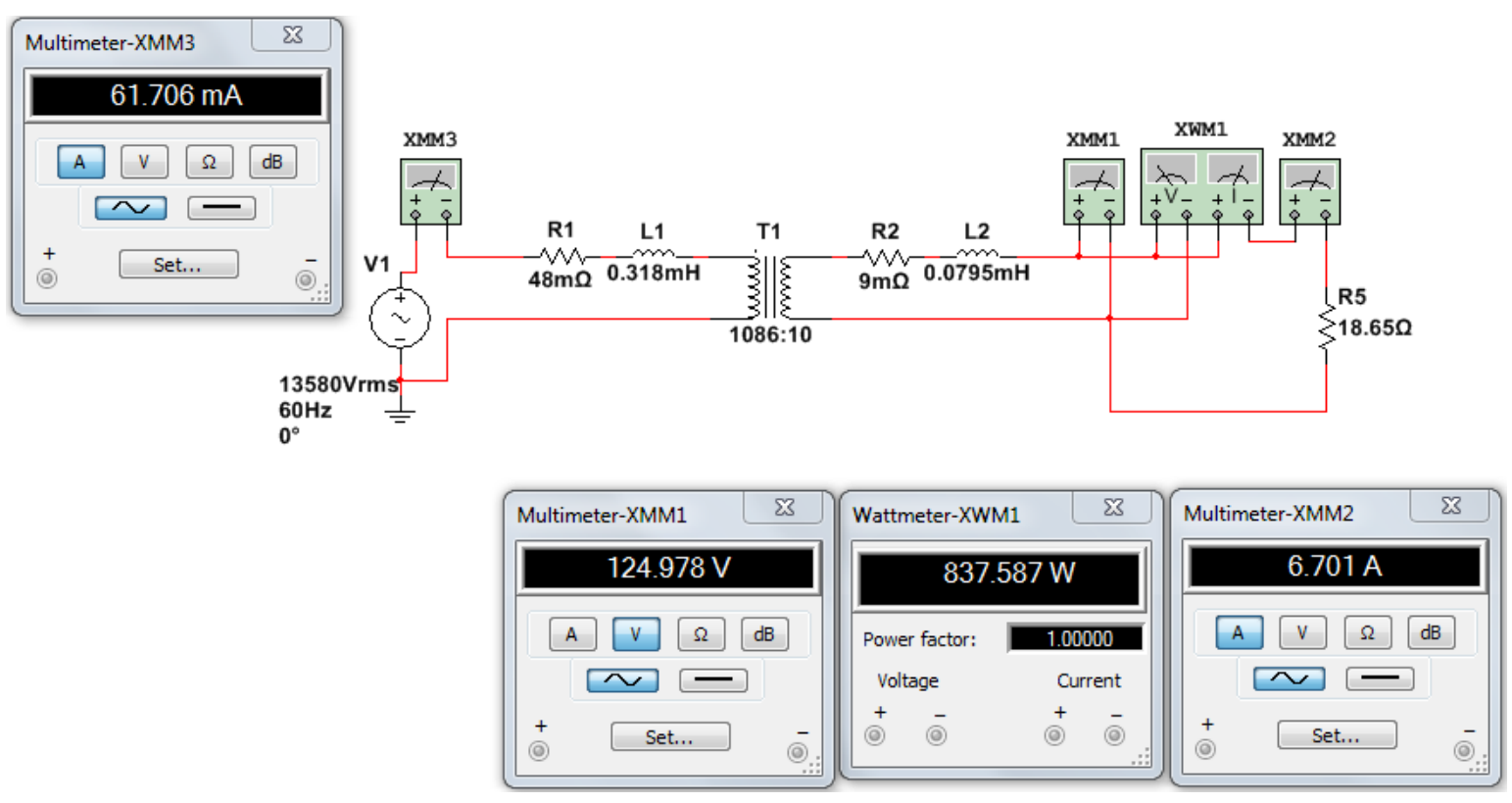

Figura 6.35 - Simulação com um circuito com os parâmetros iguais ao teste em bancada. 
A Figura 6.35 mostra um esquema elétrico simulado por meio do software MULTISIM, onde os parâmetros elétricos do circuito possuem os mesmos valores utilizados no teste em bancada. Para a simulação, os valores RMS da tensão e da corrente refletidas nos terminais primários do transformador são iguais a $13580 \mathrm{~V}$ e 61,7 mA. Quando comparados ao teste em bancada, estes valores apresentaram diferenças de 0,47\% para a tensão e 1,11\% para a corrente, diferenças estas ocasionadas principalmente pela resolução mínima da potência ativa e da corrente calculadas pela $P M U$ proposta.

\subsection{SINCRONISMO NO CÁLCULO FASORIAL ENTRE DIFERENTES PMUs}

Os testes mostrados a seguir verificam o sincronismo entre duas diferentes $P M U s$ na realização do cálculo fasorial. Novamente, para a comunicação entre o dispositivo mestre (mensagem de requsição DNP3) e os dispositivos escravos (mensagem de resposta DNP3) foi utilizado o software HERCULES (2013). Para avaliar o sincronismo entre duas PMUs foram utilizados novamente o Erro Vetorial Total (TVE), o Erro de Magnitude do Módulo (EMM) e o Erro de Ângulo de Fase (EAF), apresentados anteriormente na Seção 6.1.

\subsubsection{Leitura dos quatro fasores mais recentes de tensão no canal A}

- Características gerais do teste

- Fonte de tensão: mesmo ponto de conexão da rede elétrica monofásica para as duas $P M U s$ (baseado na Figura 6.17);

- Frequência de amostragem: amostragem a cada um segundo para as duas $P M U s$;

- Quantidade de fasores a cada amostragem: um fasor por canal para as duas PMUs;

- Análise:

É possivel verificar o sincronismo entre as duas $P M U s$ na realização do cálculo fasorial. O primeiro fasor de tensão da $P M U$ com IP 192.168.0.131 (Figura 6.36), o qual foi calculado em 18:45:41, tem o valor do módulo igual a 127,167 V e ângulo de fase igual a +2,692 rad. Estes valores são parecidos com segundo fasor de tensão da $P M U$ com IP 192.168.0.130, o qual tem o módulo igual a 126,782 V e ângulo de fase igual a +2,691 rad (como mostrado na Tabela 6.12) . O segundo fasor de tensão da $P M U$ com IP 192.168.0.130 foi calculado em 18:45:41, já que o primeiro fasor de tensão foi calculado em 18:45:42. 


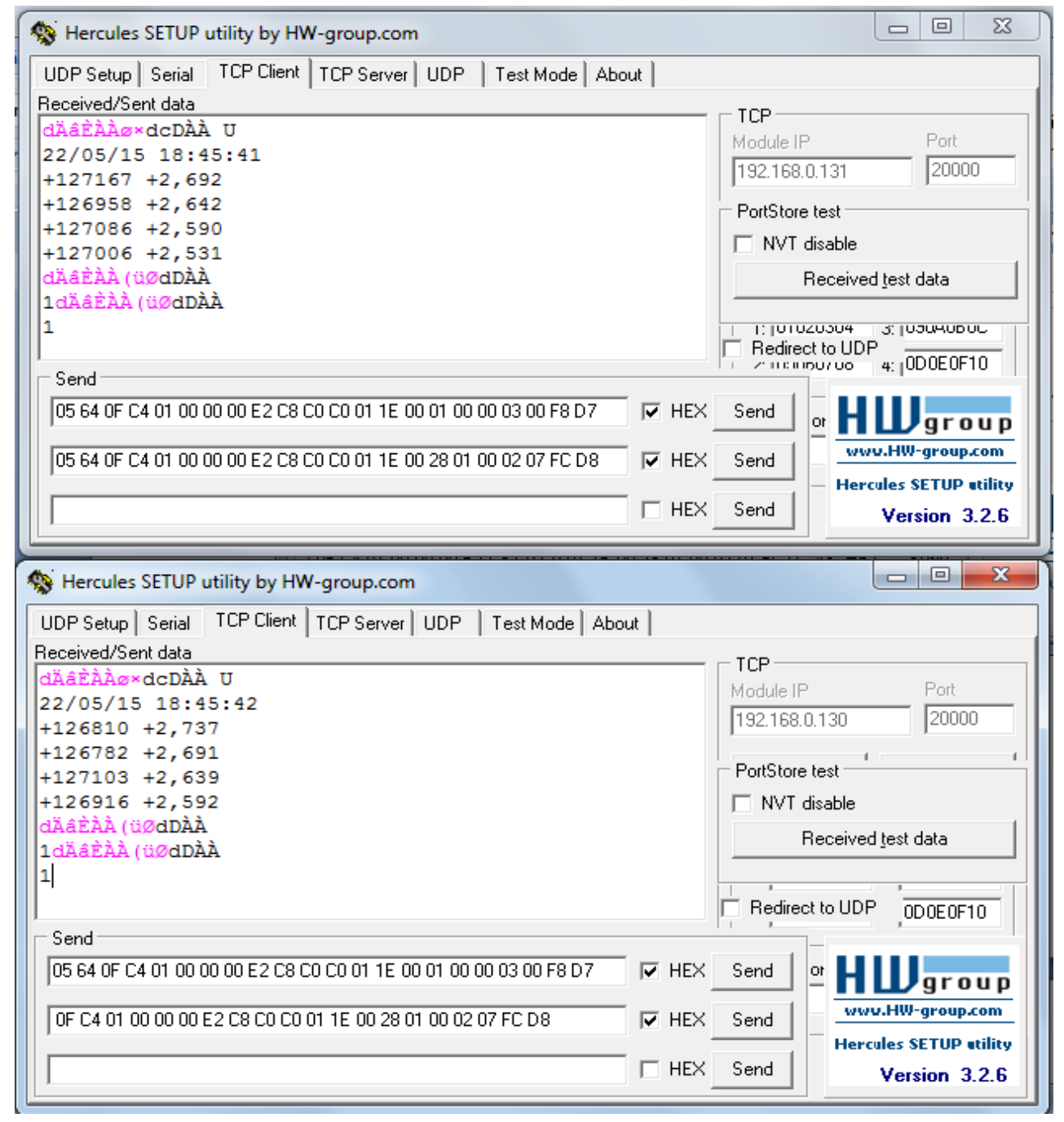

Figura 6.36 - Sincronismo entre duas PMUs na leitura de fasores de tensão no canal A.

A seguir são calculados os valores do Erro Vetorial Total (TVE), Erro de Magnitude do Módulo $(E M M)$ e Erro de Ângulo de Fase $(E A F)$ levando em consideração estes dois fasores:

$$
\begin{aligned}
& -T V E=100 \% \frac{|(127167 m V * \cos (2,692 \mathrm{rad}))-(126782 \mathrm{mV} * \cos (2,691 \mathrm{rad}))|}{|(126782 \mathrm{mV} * \cos (2,691 \mathrm{rad}))|}=0,35 \% \\
& -E M M=100 \% \frac{|127167 \mathrm{mV}-126782 \mathrm{mV}|}{|126782 \mathrm{mV}|}=0,30 \% \\
& -E A F=100 \% \frac{|2,962 \mathrm{rad}-2,961 \mathrm{rad}|}{|2,961 \mathrm{rad}|}=0,03 \%
\end{aligned}
$$

Na Tabela 6.12 são comparados os valores do módulo e ângulo de fase para os instantes 18:45:40 e 18:45:39. Para todos os instantes é possível verificar o sincronismo entre as duas $P M U s$, já que os erros calculados foram inferiores a $1 \%$, atendendo à norma IEEE C37.118 (IEEE, 2005). 
Tabela 6.12 - Sincronimo entre duas PMUs para fasores de tensão no canal A.

\begin{tabular}{|c|c|c|c|c|c|c|c|}
\hline \multirow{2}{*}{ Instantes } & \multicolumn{2}{|c|}{$\begin{array}{c}\text { Fasores para PMU } \\
\text { com IP 192.168.0.131 }\end{array}$} & \multicolumn{2}{c|}{$\begin{array}{c}\text { Fasores para PMU } \\
\text { com IP 192.168.0.130 }\end{array}$} & \multirow{2}{*}{ TVE(\%) } & \multirow{2}{*}{ EMM(\%) } & \multirow{2}{*}{ EAF(\%) } \\
\cline { 2 - 5 } & $\begin{array}{c}\text { Módulo } \\
\text { (V) }\end{array}$ & $\begin{array}{c}\text { Ángulo } \\
\text { (rad) }\end{array}$ & $\begin{array}{c}\text { Módulo } \\
\text { (V) }\end{array}$ & $\begin{array}{c}\text { Angulo } \\
\text { (rad) }\end{array}$ & & & \\
\hline $18: 45: 40$ & 126,958 & $+2,642$ & 127,103 & $+2,639$ & 0,05 & 0,11 & 0,11 \\
\hline $18: 45: 39$ & 127,086 & $+2,590$ & 126,916 & $+2,592$ & 0,01 & 0,13 & 0,08 \\
\hline
\end{tabular}

\subsubsection{Leitura dos fasores de tensão 3 a 7 no canal C}

\section{- Características gerais do teste}

- Fonte de tensão: mesmo ponto de conexão da rede elétrica monofásica para as duas PMUs;

- Frequência de amostragem: amostragem a cada um segundo para as duas PMUs;

- Quantidade de fasores a cada amostragem: um fasor por canal para as duas PMUs;

- Análise: o primeiro fasor de tensão da PMU com IP 192.168.0.131 (Figura 6.37) foi calculado em 18:56:48. O segundo fasor de tensão da $P M U$ com IP 192.168.0.130 foi calculado em 18:56:48, já que o primeiro fasor de tensão foi calculado em 18:56:49.

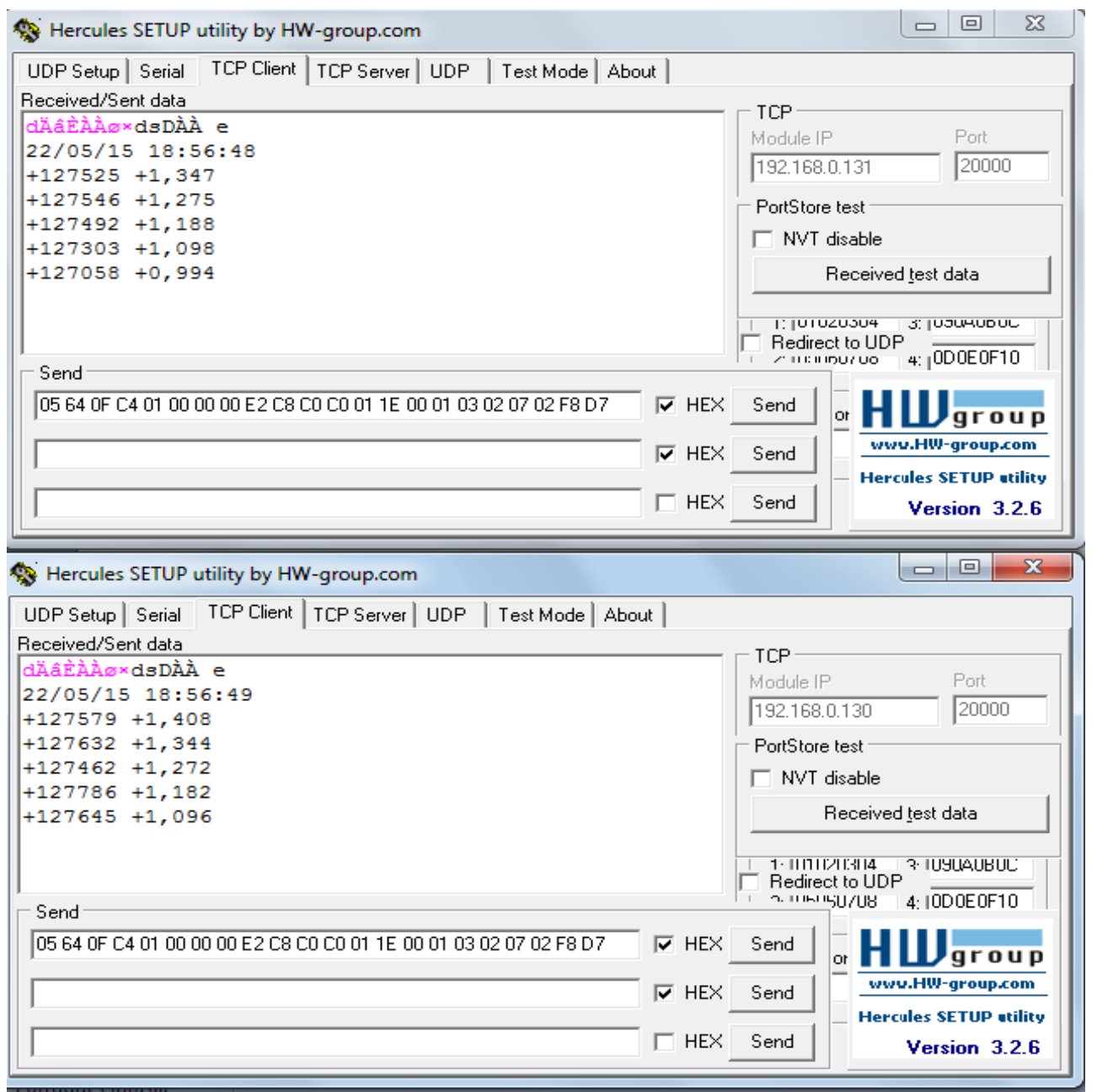

Figura 6.37 - Sincronismo entre duas PMUs na leitura de fasores de tensão no canal C. 
Na Tabela 6.13 são comparados os valores do módulo e ângulo de fase para diferentes instantes juntamente com os cálculos dos erros.

Tabela 6.13 - Sincronimo entre duas PMUs para fasores de tensão no canal C.

\begin{tabular}{|c|c|c|c|c|c|c|c|}
\hline \multirow{2}{*}{ Instantes } & \multicolumn{2}{|c|}{$\begin{array}{c}\text { Fasores para PMU } \\
\text { com IP 192.168.0.131 }\end{array}$} & \multicolumn{2}{c|}{$\begin{array}{c}\text { Fasores para PMU } \\
\text { com IP 192.168.0.130 }\end{array}$} & \multirow{2}{*}{ TVE(\%) } & \multirow{2}{*}{ EMM(\%) } & \multirow{2}{*}{ EAF(\%) } \\
\cline { 2 - 7 } & $\begin{array}{c}\text { Módulo } \\
\text { (V) }\end{array}$ & $\begin{array}{c}\text { Ángulo } \\
\text { (rad) }\end{array}$ & $\begin{array}{c}\text { Módulo } \\
\text { (V) }\end{array}$ & $\begin{array}{c}\text { Ângulo } \\
\text { (rad) }\end{array}$ & & & \\
\hline $18: 56: 48$ & 127,525 & $+1,347$ & 127,632 & $+1,344$ & 1,38 & 0,08 & 0,22 \\
\hline $18: 56: 47$ & 127,546 & $+1,275$ & 127,462 & $+1,272$ & 0,91 & 0,07 & 0,27 \\
\hline $18: 56: 46$ & 127,492 & $+1,188$ & 127,786 & $+1,182$ & 0,89 & 0,23 & 0,51 \\
\hline $18: 56: 45$ & 127,303 & $+1,098$ & 127,645 & $+1,096$ & 0,66 & 0,27 & 0,18 \\
\hline
\end{tabular}

Para o instante 18:56:48 o Erro Vetorial Total (TVE) ficou acima de 1\% principalmente devido ao ângulo de fase estar próximo ao cruzamento do zero.

\subsubsection{Leitura dos fasores de tensão 0 a 4 no canal B (dois fasores por canal)}

\section{- Características gerais do teste}

- Fonte de tensão: mesmo ponto de conexão da rede elétrica monofásica para as duas $P M U s$;

- Frequência de amostragem: amostragem a cada um segundo para as duas $P M U s$;

- Quantidade de fasores a cada amostragem: dois fasores por canal para as duas PMUs;

- Análise:

O primeiro fasor de tensão da $P M U$ com IP 192.168.0.131 foi calculado em 19:07:42 (Figura 6.38). O terceiro fasor de tensão da $P M U$ com IP 192.168.0.130 também foi calculado em 19:07:42, já que o primeiro fasor de tensão foi calculado em 19:07:43 e o segundo fasor foi calculado $132 \mathrm{~ms}$ antes do primeiro.

Na Tabela 6.14 são comparados os valores do módulo e ângulo de fase para diferentes instantes, onde é possível verificar o sincronismo entre as duas $P M U s$ já que os erros calculados foram inferiores a $1 \%$.

Tabela 6.14 - Sincronimo entre duas PMUs no canal B (2 fasores de tensão por canal).

\begin{tabular}{|c|c|c|c|c|c|c|c|}
\hline \multirow{2}{*}{ Instantes } & \multicolumn{2}{|c|}{$\begin{array}{c}\text { Fasores para PMU } \\
\text { com IP 192.168.0.131 }\end{array}$} & \multicolumn{2}{c|}{$\begin{array}{c}\text { Fasores para PMU } \\
\text { com IP 192.168.0.130 }\end{array}$} & \multirow{2}{*}{ TVE(\%) } & \multirow{2}{*}{ EMM(\%) } & \multirow{2}{*}{ EAF(\%) } \\
\cline { 2 - 7 } & $\begin{array}{c}\text { Módulo } \\
\text { (V) }\end{array}$ & $\begin{array}{c}\text { Ângulo } \\
\text { (rad) }\end{array}$ & $\begin{array}{c}\text { Módulo } \\
\text { (V) }\end{array}$ & $\begin{array}{c}\text { Ängulo } \\
\text { (rad) }\end{array}$ & & & \\
\hline $19: 07: 42$ & 126,955 & $-2,972$ & 127,466 & $-2,977$ & 0,45 & 0,37 & 0,17 \\
\hline $\begin{array}{c}132 \mathrm{~ms} \\
\text { antes }\end{array}$ & 126,766 & $-2,495$ & 127,552 & $-2,496$ & 0,75 & 0,62 & 0,04 \\
\hline $19: 07: 41$ & 126,825 & $-2,876$ & 127,415 & $-2,881$ & 0,46 & 0,46 & 0,17 \\
\hline
\end{tabular}




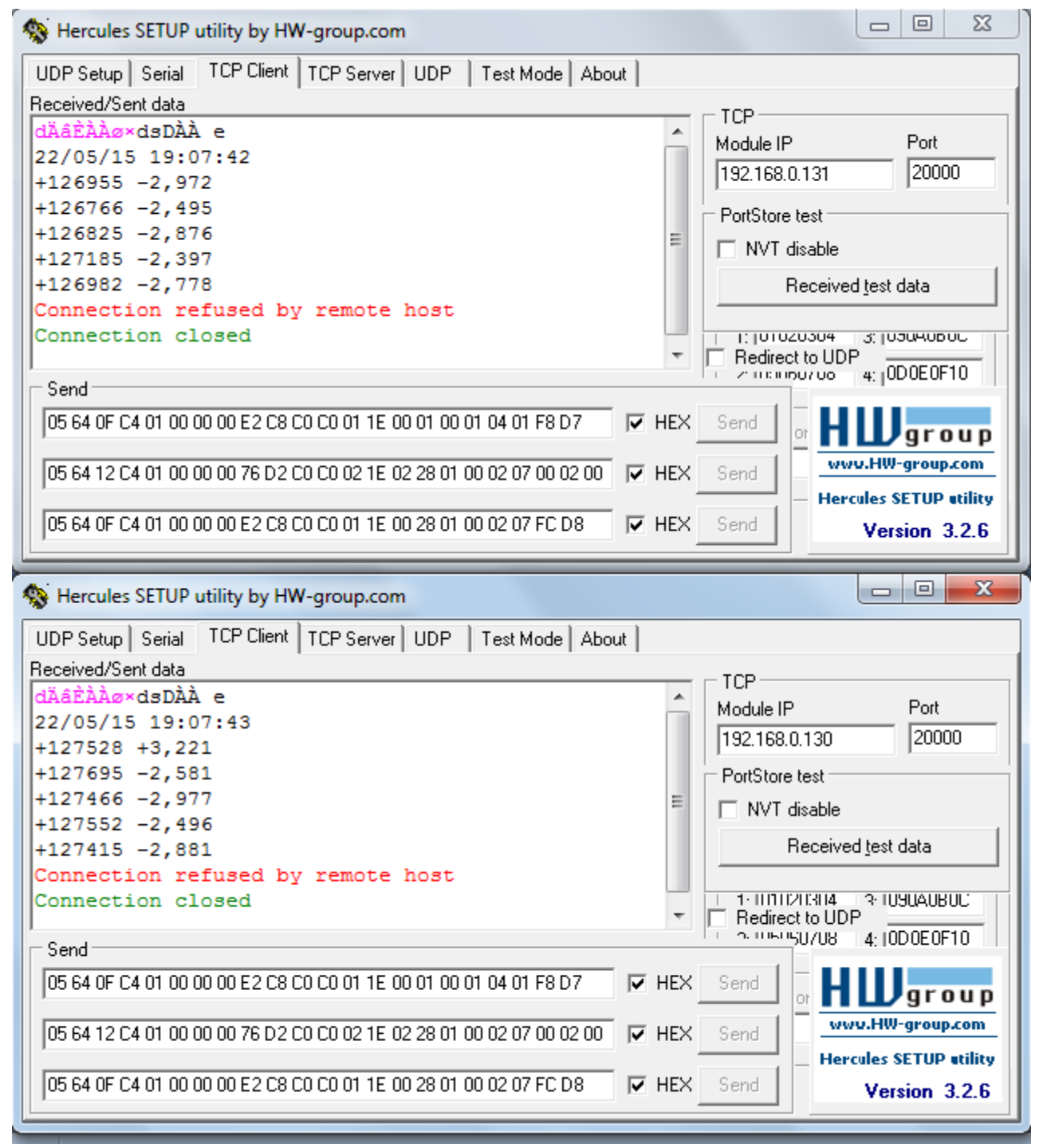

Figura 6.38 - Sincronismo entre duas PMUs na leitura de dois fasores de tensão a cada amostragem no canal $B$.

\subsubsection{Leitura dos fasores 0 a 4 de tensão no canal B (três fasores por canal)}

\section{- Características gerais do teste}

- Fonte de tensão: mesmo ponto de conexão da rede elétrica monofásica para as duas $P M U s$;

- Frequência de amostragem: amostragem a cada um segundo para as duas PMUs;

- Quantidade de fasores a cada amostragem: três fasores por canal para as duas PMUs;

- Análise:

O quarto fasor de tensão da $P M U$ com IP 192.168.0.131 (Figura 6.39) foi calculado em 19:52:28, já que o primeiro fasor foi calculado em 19:52:29 e o segundo e terceiros fasores foram calculados em relação ao primeiro fasor com um antecedência igual a $132 \mathrm{~ms}$ e $246 \mathrm{~ms}$ 
respectivamente. Já o primeiro fasor de tensão da $P M U$ com IP 192.168.0.130 também foi calculado em 19:52:28.

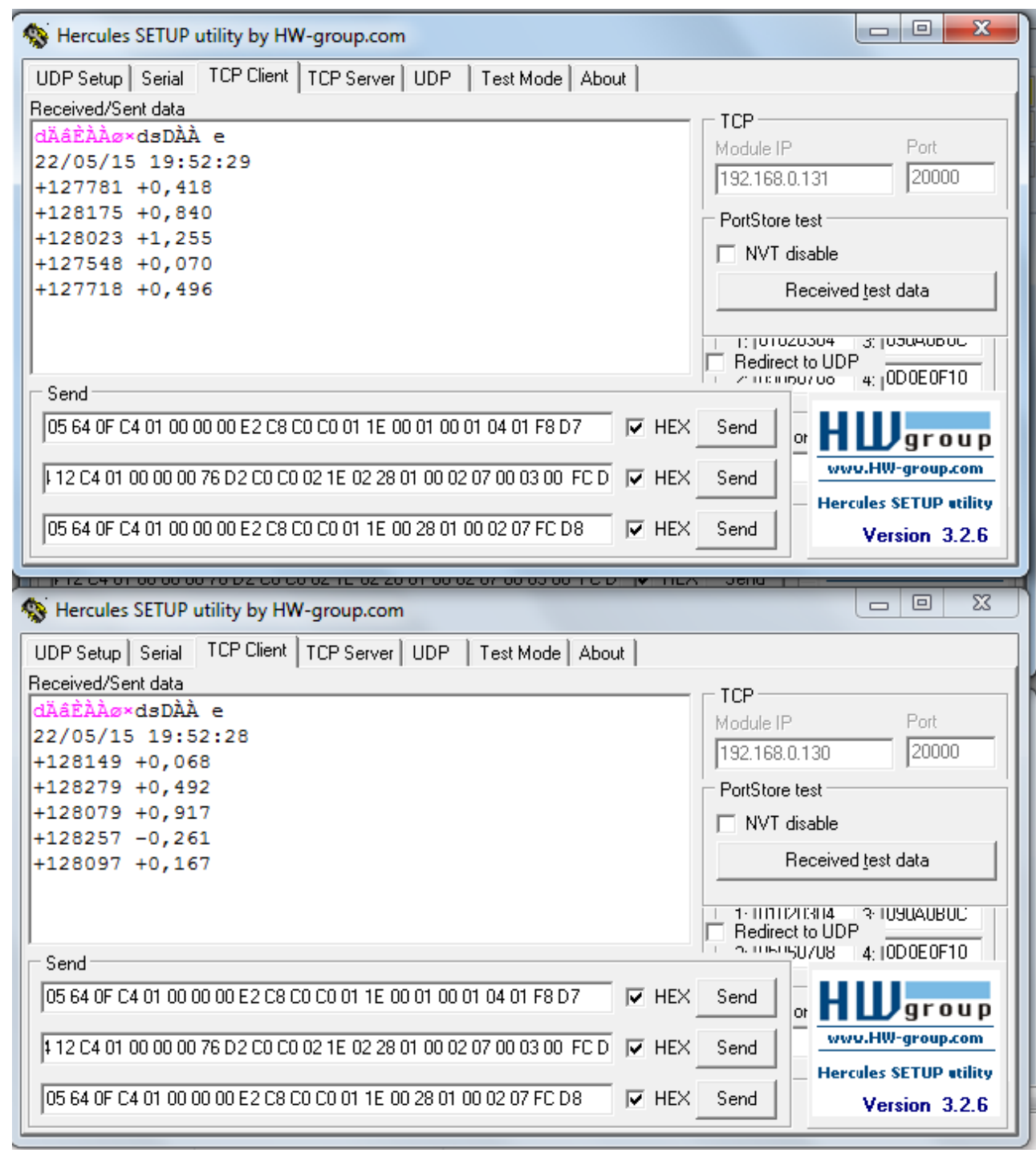

Figura 6.39 - Sincronismo entre duas PMUs na leitura de três fasores de tensão a cada amostragem no canal $B$.

Na Tabela 6.15 são comparados os valores do módulo e ângulo de fase para diferentes instantes, onde é possível verificar novamente o sincronismo entre as duas PMUs com erros inferiores a $1 \%$.

Tabela 6.15 - Sincronimo entre duas PMUs no canal B (3 fasores de tensão por canal).

\begin{tabular}{|c|c|c|c|c|c|c|c|}
\hline \multirow{2}{*}{ Instantes } & \multicolumn{2}{|c|}{$\begin{array}{c}\text { Fasores para PMU } \\
\text { com IP 192.168.0.131 }\end{array}$} & \multicolumn{2}{|c|}{$\begin{array}{c}\text { Fasores para PMU } \\
\text { com IP 192.168.0.130 }\end{array}$} & \multirow{2}{*}{ TVE(\%) } & \multirow{2}{*}{ EMM(\%) } & \multirow{2}{*}{ EAF(\%) } \\
\cline { 2 - 5 } & $\begin{array}{c}\text { Módulo } \\
\text { (V) }\end{array}$ & $\begin{array}{c}\text { Ângulo } \\
\text { (rad) }\end{array}$ & $\begin{array}{c}\text { Módulo } \\
\text { (V) }\end{array}$ & $\begin{array}{c}\text { Ángulo } \\
\text { (rad) }\end{array}$ & & & \\
\hline $19: 52: 28$ & 127,548 & $+0,070$ & 128,149 & $+0,068$ & 0,48 & 0,47 & 0,94 \\
\hline $\begin{array}{c}132 \mathrm{~ms} \\
\text { antes }\end{array}$ & 127,718 & $+0,496$ & 128,279 & $+0,492$ & 0,65 & 0,44 & 0,81 \\
\hline
\end{tabular}




\subsubsection{Leitura dos fasores 0 a 2 de corrente no canal B}

\section{- Características gerais do teste}

- Fonte de tensão: mesmo ponto de conexão da rede elétrica monofásica para as duas PMUs;

- Carga de $110 \Omega$ conectada ao canal B de duas PMUs em série;

- Frequência de amostragem: amostragem a cada um segundo para as duas PMUs;

- Quantidade de fasores a cada amostragem: um fasor por canal para as duas PMUs;

- Análise:

Os primeiros fasores de corrente das PMUs com IPs 192.168.0.131 e 192.168.0.130 (Figura 6.40) foram calculados em 20:19:56.

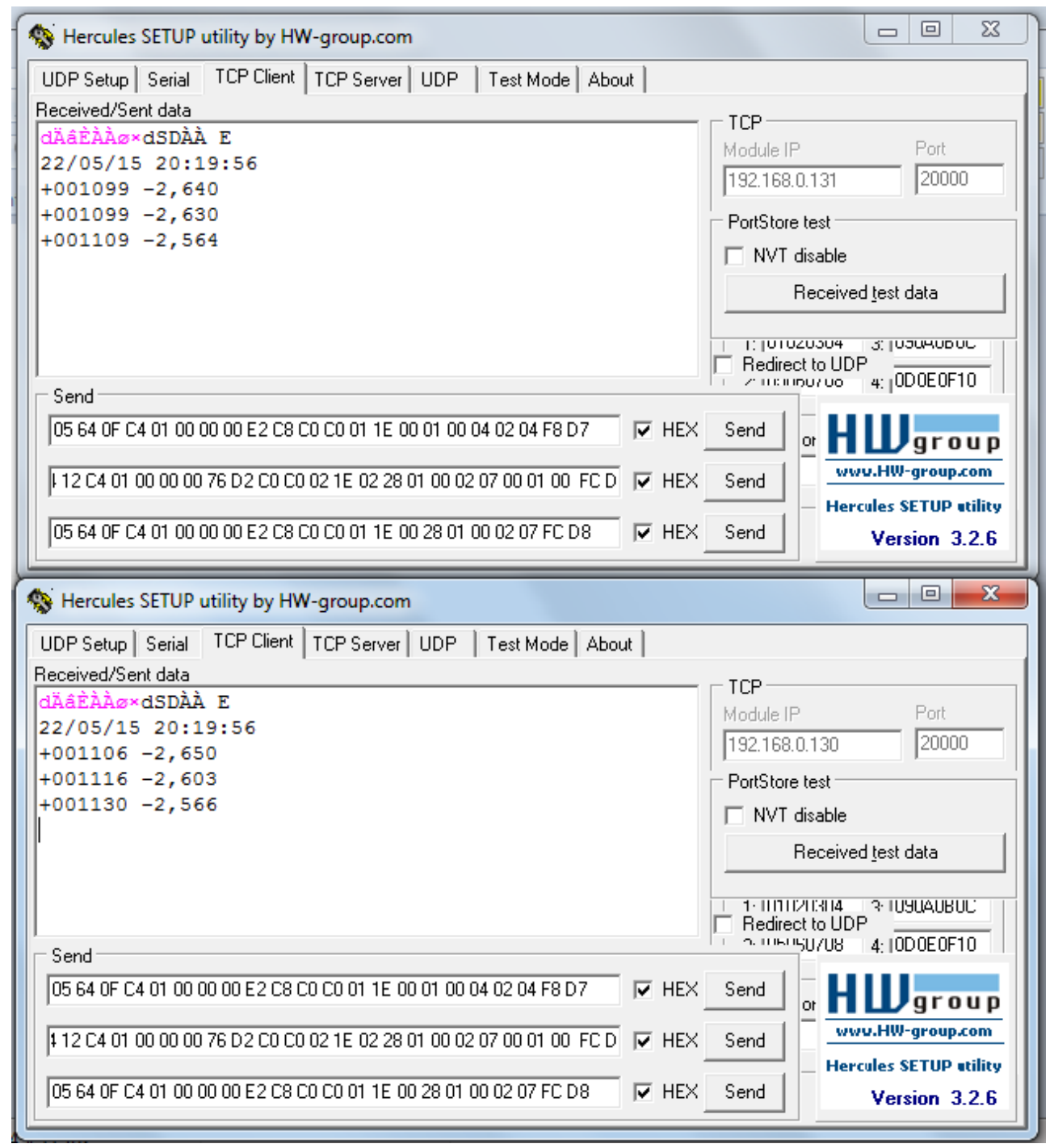

Figura 6.40 - Sincronismo entre duas PMUs na leitura de fasores de corrente no canal B

Na Tabela 6.16 são comparados os valores do módulo e ângulo de fase para diferentes instantes. Os erros em geral ficaram acima do que recomenda a norma principalmente devido 
ao sinal amostrado possuir uma pequena excursão, evidenciando a menor precisão das funções matemáticas realizadas pelo microcontrolador.

Tabela 6.16 - Sincronimo entre duas PMUs para fasores de corrente no canal B.

\begin{tabular}{|c|c|c|c|c|c|c|c|}
\hline \multirow{2}{*}{ Instantes } & \multicolumn{2}{|c|}{$\begin{array}{c}\text { Fasores para PMU } \\
\text { com IP 192.168.0.131 }\end{array}$} & \multicolumn{2}{c|}{$\begin{array}{c}\text { Fasores para PMU } \\
\text { com IP 192.168.0.130 }\end{array}$} & \multirow{2}{*}{ TVE(\%) } & \multirow{2}{*}{ EMM(\%) } & \multirow{2}{*}{ EAF(\%) } \\
\cline { 2 - 7 } & $\begin{array}{c}\text { Módulo } \\
\text { (mA) }\end{array}$ & $\begin{array}{c}\text { Ängulo } \\
\text { (rad) }\end{array}$ & $\begin{array}{c}\text { Módulo } \\
\text { (mA) }\end{array}$ & $\begin{array}{c}\text { Ängulo } \\
\text { (rad) }\end{array}$ & & & \\
\hline $20: 19: 56$ & 1099 & $-2,640$ & 1106 & $-2,650$ & 1,13 & 0,63 & 0,38 \\
\hline $20: 19: 55$ & 1099 & $-2,630$ & 1116 & $-2,603$ & 0 & 1,50 & 1,03 \\
\hline $20: 19: 54$ & 1109 & $-2,564$ & 1130 & $-2,566$ & 1,90 & 1,85 & 0,08 \\
\hline
\end{tabular}

6.3.6 Leitura dos fasores 0 a 2 de corrente no canal A com a mesma frequência de amostragem

- Características gerais do teste

- Fonte de tensão: mesmo ponto de conexão da rede elétrica monofásica para as duas $P M U s$;

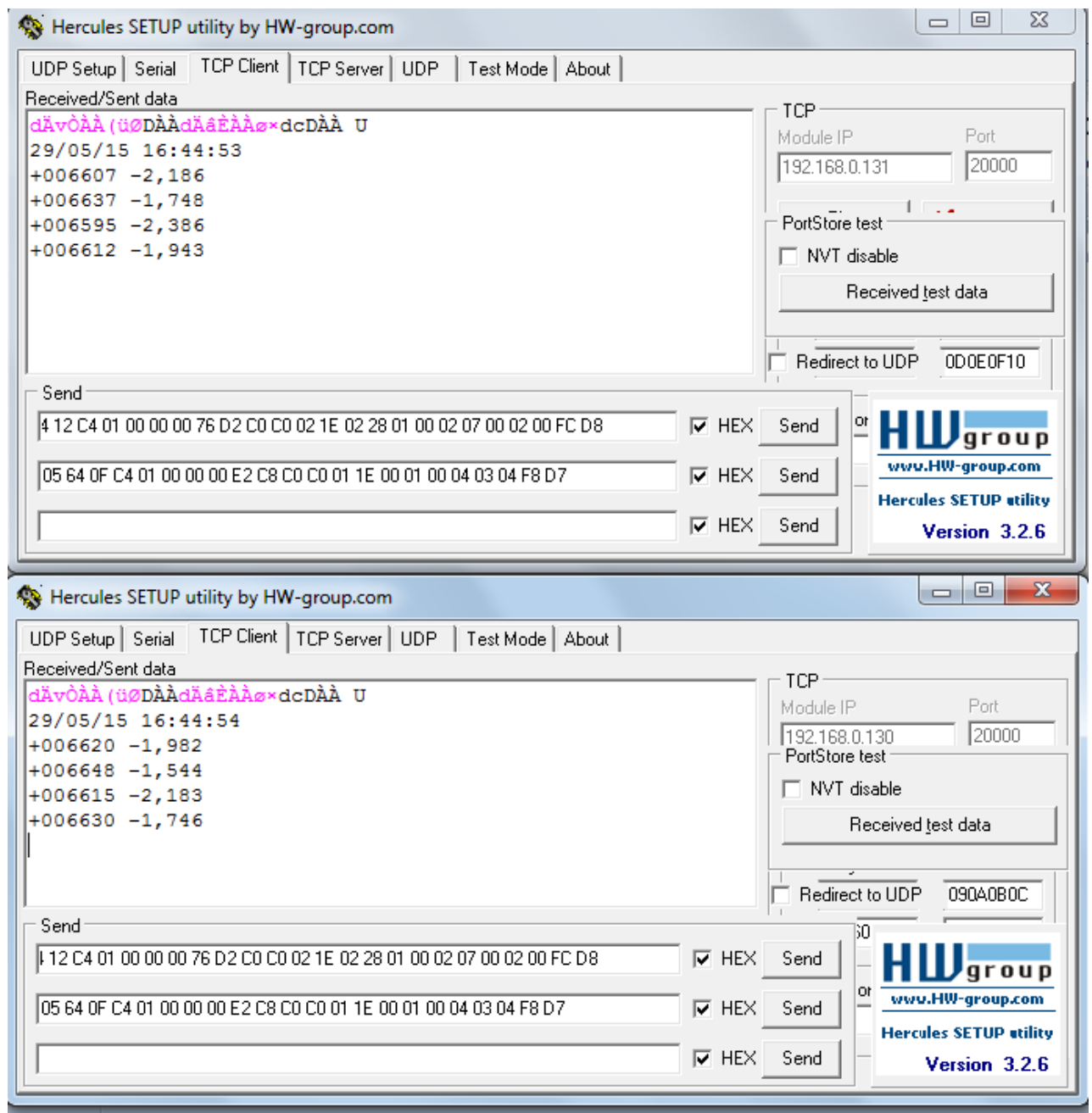

Figura 6.41 - Sincronismo entre duas PMUs na leitura de três fasores de corrente no canal A utilizando frequências de amostragem iguais. 
- Carga de 19,15 $\Omega$ conectada ao canal A de duas PMUs sem série;

- Frequência de amostragem: amostragem a cada um segundo para as duas PMUs;

- Quantidade de fasores a cada amostragem: dois fasores por canal para as duas PMUs;

- Análise:

O primeiro fasor da $P M U$ com IP 192.168.0.131 (Figura 6.41) foi calculado em 16:44:53, sendo o segundo fasor calculado com um antecedência igual a $132 \mathrm{~ms}$ em relação ao primeiro. O terceiro fasor da $P M U$ com IP 192.168.0.130 também foi calculado em 16:44:53 e o quarto fasor desta $P M U$ foi calculado $132 \mathrm{~ms}$ antes do terceiro.

Na Tabela 6.17 é possível verificar o sincronismo entre as duas $P M U s$, onde são comparados os valores do módulo e ângulo de fase para diferentes instantes com erros inferiores a $1 \%$.

Tabela 6.17 - Sincronimo entre duas PMUs para fasores de corrente no canal A.

\begin{tabular}{|c|c|c|c|c|c|c|c|}
\hline \multirow{2}{*}{ Instantes } & \multicolumn{2}{|c|}{$\begin{array}{c}\text { Fasores para PMU } \\
\text { com IP 192.168.0.131 }\end{array}$} & \multicolumn{2}{|c|}{$\begin{array}{c}\text { Fasores para PMU } \\
\text { com IP 192.168.0.130 }\end{array}$} & \multirow{2}{*}{ TVE(\%) } & \multirow{2}{*}{ EMM(\%) } & \multirow{2}{*}{ EAF(\%) } \\
\cline { 2 - 7 } & $\begin{array}{c}\text { Módulo } \\
\text { (mA) }\end{array}$ & $\begin{array}{c}\text { Ângulo } \\
\text { (rad) }\end{array}$ & $\begin{array}{c}\text { Módulo } \\
\text { (mA) }\end{array}$ & $\begin{array}{c}\text { Ângulo } \\
\text { (rad) }\end{array}$ & & & \\
\hline $16: 44: 53$ & 6607 & $-2,186$ & 6615 & $-2,183$ & 0,32 & 0,12 & 0,14 \\
\hline $\begin{array}{c}132 \mathrm{~ms} \\
\text { antes }\end{array}$ & 6637 & $-1,748$ & 6630 & $-1,746$ & 0,95 & 0,11 & 0,11 \\
\hline
\end{tabular}

\subsubsection{Leitura dos fasores 0 a 2 de corrente no canal A com frequências de amostragem diferentes}

- Características gerais do teste

- Fonte de tensão: mesmo ponto de conexão da rede elétrica monofásica para as duas $P M U s$;

- Carga de 19,15 $\Omega$ conectada ao canal A de duas PMUs sem série;

- Frequência de amostragem: amostragem a cada um segundo para a $P M U$ com IP 192.168.0.131 e a cada três segundos para a $P M U$ com IP 192.168.0.130;

- Quantidade de fasores a cada amostragem: um fasor por canal para as duas PMUs;

- Análise:

O segundo fasor da $P M U$ com IP 192.168.0.131 (Figura 6.42) foi calculado em 17:02:05, sendo o quinto fasor foi calculado no instante 17:02:02.

Já o segundo fasor de corrente da PMU com IP 192.168.0.130 também foi calculado em 17:02:05. O terceiro fasor desta $P M U$ foi calculado no instante 17:02:02. 


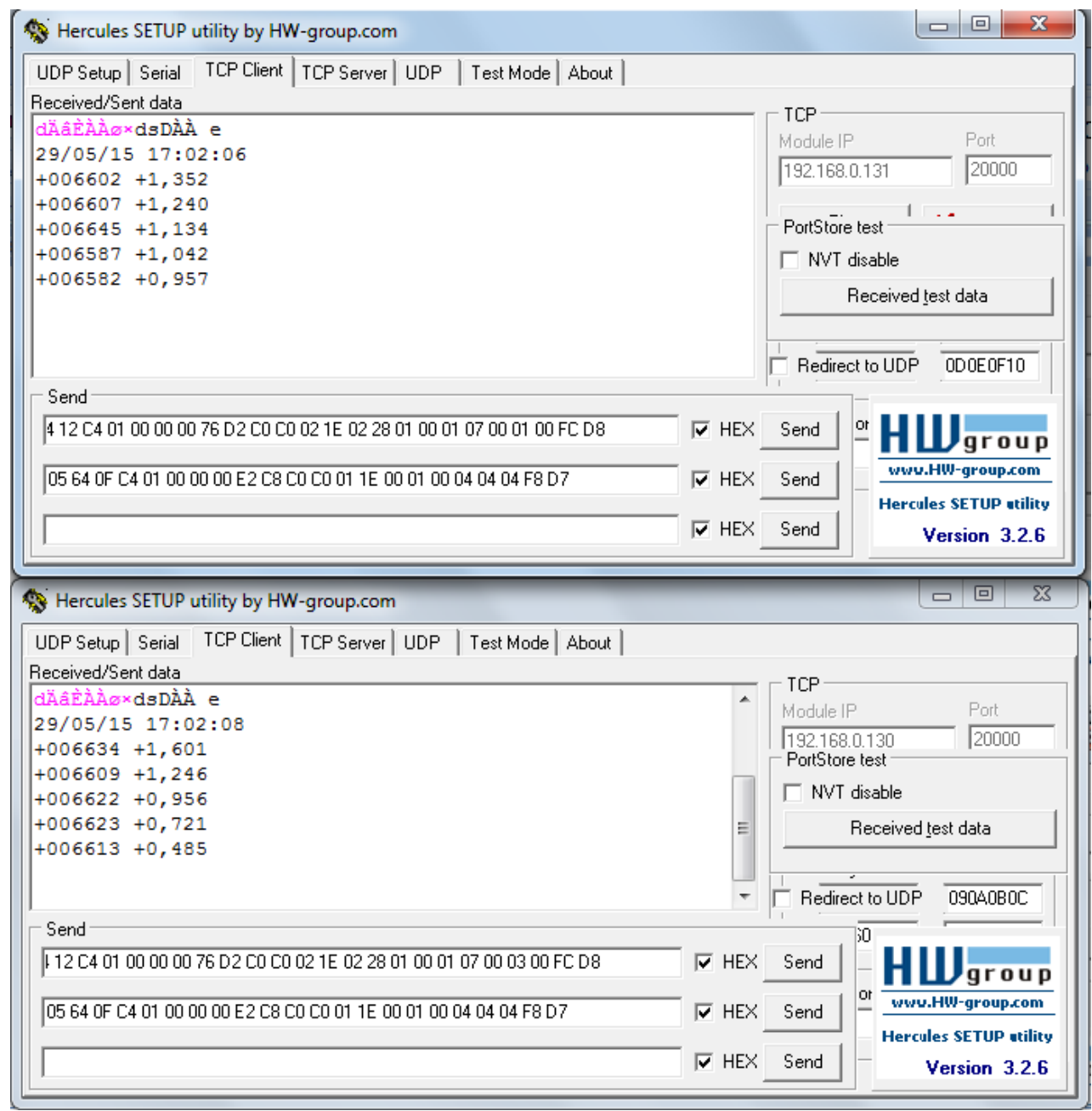

Figura 6.42 - Sincronismo entre duas PMUs na leitura de três fasores de corrente no canal A utilizando frequências de amostragem diferentes.

Na Tabela 6.18 são comparados os valores do módulo e ângulo de fase para diferentes instantes. Para o instante 17:02:05 o Erro Vetorial Total (TVE) ficou acima de 1\% principalmente devido ao ângulo de fase estar próximo ao cruzamento do zero.

Tabela 6.18 - Sincronimo entre PMUs para fasores de corrente no canal A (freq. diferentes).

\begin{tabular}{|c|c|c|c|c|c|c|c|}
\hline \multirow{2}{*}{ Instantes } & \multicolumn{2}{|c|}{$\begin{array}{c}\text { Fasores para PMU } \\
\text { com IP 192.168.0.131 }\end{array}$} & \multicolumn{2}{c|}{$\begin{array}{c}\text { Fasores para PMU } \\
\text { com IP 192.168.0.130 }\end{array}$} & \multirow{2}{*}{ TVE(\%) } & \multirow{2}{*}{ EMM(\%) } & \multirow{2}{*}{ EAF(\%) } \\
\cline { 2 - 5 } & $\begin{array}{c}\text { Módulo } \\
\text { (mA) }\end{array}$ & $\begin{array}{c}\text { Ângulo } \\
\text { (rad) }\end{array}$ & $\begin{array}{c}\text { Módulo } \\
\text { (mA) }\end{array}$ & $\begin{array}{c}\text { Ángulo } \\
\text { (rad) }\end{array}$ & & & \\
\hline $17: 02: 05$ & 6607 & $+1,240$ & 6609 & $+1,246$ & 1,75 & 0,03 & 0,48 \\
\hline $17: 02: 02$ & 6582 & $+0,957$ & 6622 & $+0,956$ & 0,73 & 0,60 & 0,10 \\
\hline
\end{tabular}




\subsection{DESEMPENHO DO SISTEMA DE IDENTIFICAÇÃO DA CAUSA DOS DISTÚRBIOS}

Nesta seção é mostrado o desempenho do sistema fuzzy, implementado na unidade de mediação fasorial otimizada para sistemas de distribuição, quanto à classificação do padrão de saída. Foram obtidas diferentes combinações das variáveis de entrada "Variação da tensão RMS", "Variação da potência ativa" e "Variação da potência reativa", visando explorar o conjunto de regras para o sistema de inferência fuzzy citado no Capítulo 4 (Tabela 6.19).

Tabela 6.19 - Combinações utilizadas para explorar o conjunto de regras

\begin{tabular}{|c|c|c|c|}
\hline $\begin{array}{lll}\Delta \mathbf{P} & \Delta \mathbf{V}\end{array}$ & POSITIVA & NULA & NEGATIVA \\
\hline \multirow{3}{*}{ POSITIVA } & $\begin{array}{c}\Delta \mathrm{Q}>0-\mathrm{REDE} \\
\text { COMBINAÇÃO } 5\end{array}$ & \multirow{3}{*}{$\begin{array}{c}\text { CARGA } \\
\text { COMBINAÇÃO } 3\end{array}$} & \multirow{3}{*}{$\begin{array}{c}\text { CARGA } \\
\text { COMBINAÇÃO } 11\end{array}$} \\
\hline & $\begin{array}{c}\Delta \mathrm{Q}=0-\mathrm{IN} D \\
\text { COMBINACÃO } 9\end{array}$ & & \\
\hline & $\begin{array}{c}\Delta Q<0 \text { - CARGA } \\
\text { COMBINAÇÃO } 15\end{array}$ & & \\
\hline \multirow{3}{*}{ NULA } & \multirow{3}{*}{$\begin{array}{c}\text { CARGA } \\
\text { COMBINAÇÃO } 13\end{array}$} & $\begin{array}{c}\triangle Q>0-\text { CARGA } \\
\text { COMBINAÇÃO } 6\end{array}$ & \multirow{3}{*}{$\begin{array}{c}\text { CARGA } \\
\text { COMBINAÇÃO } 12\end{array}$} \\
\hline & & $\begin{array}{c}\Delta \mathrm{Q}=0 \text { - IND } \\
\text { COMBINAÇÃO } 1\end{array}$ & \\
\hline & & $\begin{array}{c}\Delta Q<0-\text { CARGA } \\
\text { COMBINAÇÃO } 7\end{array}$ & \\
\hline \multirow{3}{*}{ NEGATIVA } & \multirow{3}{*}{$\begin{array}{c}\text { CARGA } \\
\text { COMBINAÇÃO } 10\end{array}$} & \multirow{3}{*}{$\begin{array}{c}\text { CARGA } \\
\text { COMBINAÇÃO } 2\end{array}$} & $\begin{array}{c}\Delta Q>0 \text { - CARGA } \\
\text { COMBINAÇÃO } 14\end{array}$ \\
\hline & & & $\begin{array}{c}\Delta \mathrm{Q}=0 \text { - IND } \\
\text { COMBINAÇÃO } 8\end{array}$ \\
\hline & & & $\begin{array}{c}\Delta \mathrm{Q}<0-\text { REDE } \\
\text { COMBINAÇÃO } 4\end{array}$ \\
\hline
\end{tabular}

Nos testes em laboratório essas combinações foram obtidas utilizando uma fonte com tensão variável, resistências variáveis e capacitores, como mostrado na Figura 6.43. Para a $P M U$ proposta as frequências de amostragem e identificação da causa do distúrbio foram configuradas com 1 e 4 segundos, para possibilitar a variação dos parâmetros elétricos.

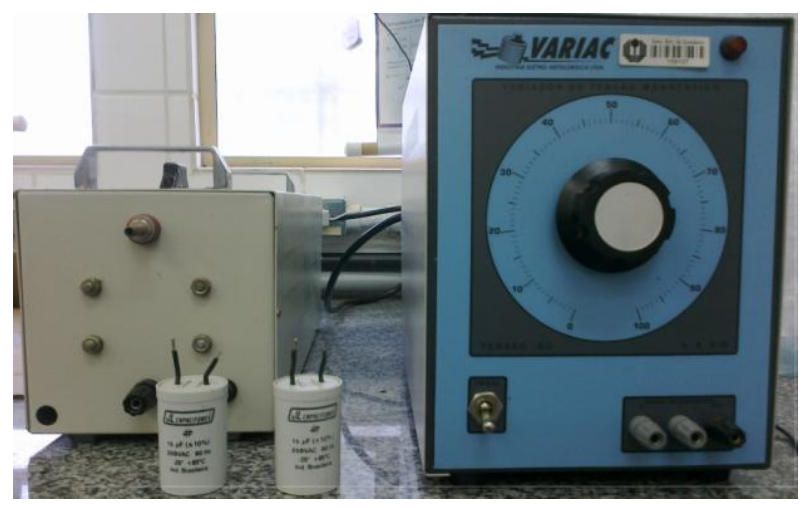

Figura 6.43 - Equipamentos e componentes utilizados nos testes 
Em algumas das combinações relatadas a seguir também há a presença de testes realizados a partir da base de dados de campo de um transformador de distribuição, visando explorar com mais detalhes o sistema de inferência fuzzy. Neste caso os dados, cujo tempo entre as medições é igual a 10 minutos, foram inseridos manualmente no firmware da PMU.

Visando à adequação aos equipamentos existentes na bancada de testes, tais como a fonte variável de baixa tensão, a presença de transformador durante a realização dos testes foi desconsiderada, adotando-se a topologia do circuito mostrado na Figura 6.44. A ausência do transformador não gerou nenhum efeito negativo quanto ao objetivo de explorar o conjunto de regras para o sistema de inferência fuzzy.

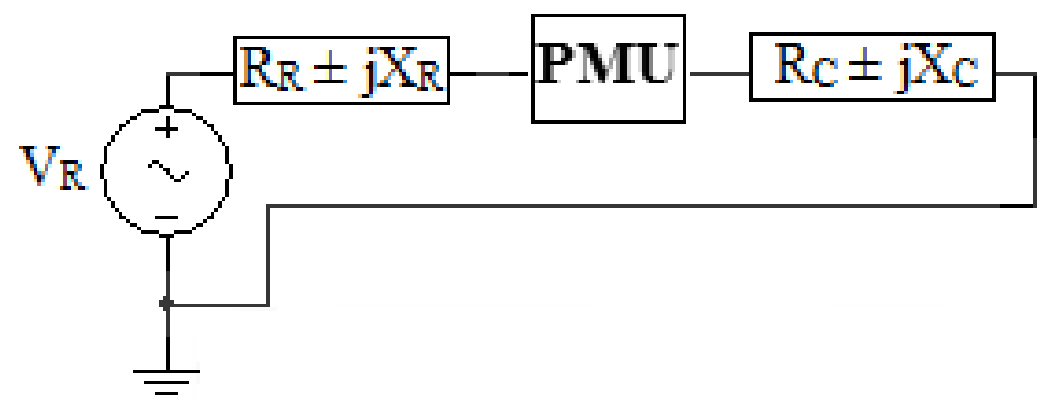

Figura 6.44 - Topologia do circuito adotada para a realização dos testes.

Independente do teste, as informações de saída do sistema de inferência fuzzy e os gráficos utilizados nas combinações apresentadas a seguir foram obtidos por meio do ambiente de desenvolvimento do microcontrolador, sempre relacionado ao canal A da $P M U$.

\subsubsection{Combinação 1}

\section{- Teste realizado em laboratório}

\section{- Características gerais do teste}

- Sem variações nos parâmetros da carga ou da rede;

- Características da rede: fonte de tensão com valor de $127 \mathrm{~V}_{\mathrm{RMS}}$. Impedância igual à zero;

- Características da carga: resistência com valor de 150,4 $\Omega$ em série com capacitor de $15 \mu \mathrm{F}$;

- Variação da tensão RMS medida: $+17 \mathrm{mV}$;

- Variação da potência ativa medida: +2 W;

- Variação da potência reativa medida: -2 VAR. 


\section{- Características funcionais do sistema do sistema de inferência fuzzy}

- Classificações relacionadas à variação da tensão RMS: "NULA" com valor da função de pertinência $\mu V=0,966$ e "POSITIVA" com valor da função de pertinência $\mu V=0,034$;

- Classificações relacionadas à variação da potência ativa: "NULA" com valor da função de pertinência $\mu P=0,5$ e "POSITIVA" com valor da função de pertinência $\mu P=0,5$;

- Classificações relacionadas à variação da potência reativa: "NULA" com valor da função de pertinência $\mu Q=0,5$ e "NEGATIVA" com valor da função de pertinência $\mu Q=0,5$;

- Região fuzzy de saída (agregação final):

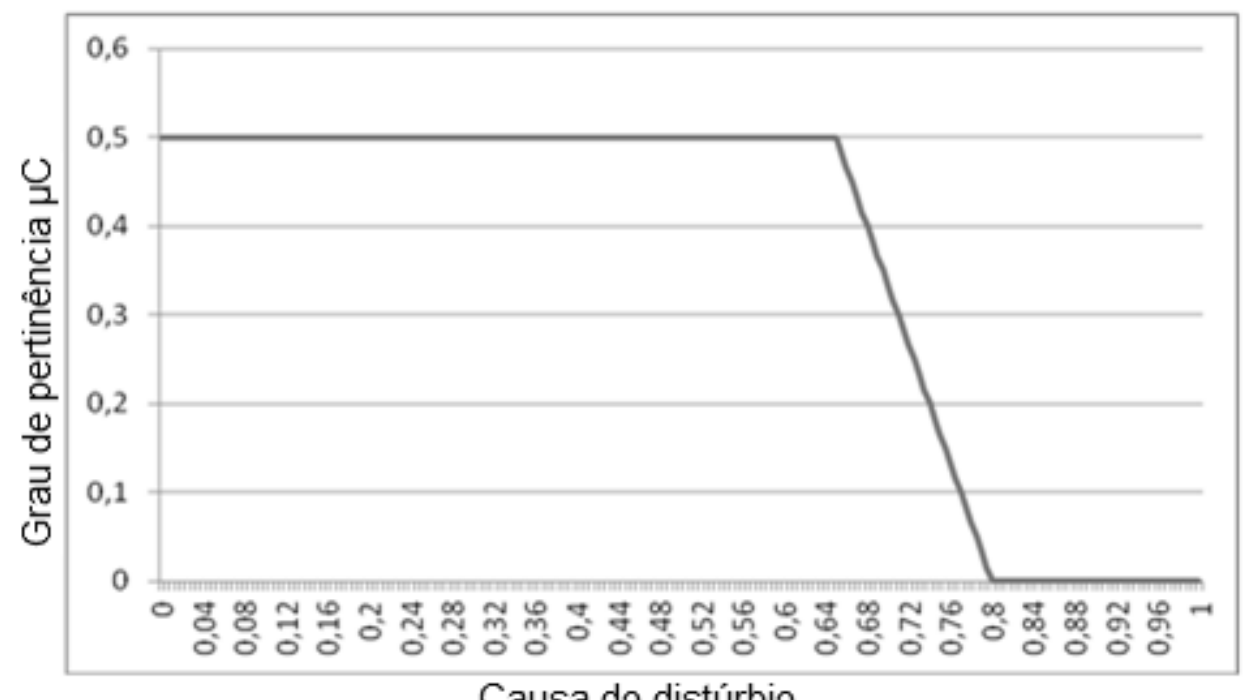

\section{Causa do distúrbio}

Figura 6.45 - Região fuzzy de saída para a combinação 1 obtida em laboratório.

- Regras ativadas: "CARGA" para as combinações $\Delta V=0 / \Delta P=0 / \Delta Q<0, \quad \Delta V=0 / \Delta P>0$, $\Delta V>0 / \Delta P=0$ e $\Delta V>0 / \Delta P>0 / \Delta Q<0$. "INDETERMINADO" para as combinações $\Delta V=0 / \Delta P=0 / \Delta Q=0$ e $\Delta V>0 / \Delta P>0 / \Delta Q=0$.

- Valor defuzzificado: 0,360;

• Classe selecionada: "INDETERMINADO";

- Análise

Neste teste fica claro a ocorrência dos erros ocasionais gerados pela Unidade de Medição Fasorial Otimizada para sistemas de distribuição, já que não houve variação dos parâmetros da carga ou da rede. É possível verificar na Figura 6.45 que a região fuzzy de saída foi computada com contribuições significativas das regras ativadas "CARGA" e 
“INDETERMINADO”. Porém, os ajustes dos termos da variável de saída e das variáveis de entrada, em particular dos termos "Variação Nula", fez com que o sistema de inferência fuzzy classificasse corretamente a saída do sistema como "INDETERMINADO".

\subsubsection{Combinação 2}

- Teste realizado em laboratório

\section{- Características gerais do teste}

- Variações manuais apenas nos parâmetros da carga;

- Características da rede: fonte de tensão com valor de $127 \mathrm{~V}_{\mathrm{RMS}}$. Impedância igual à zero;

- Características iniciais da carga: resistência de $156,4 \Omega$ em série com capacitor de $15 \mu \mathrm{F}$;

- Características finais da carga: resistência de 298,6 $\Omega$ em série com capacitor de $15 \mu \mathrm{F}$;

- Variação da tensão RMS medida: $-5 \mathrm{mV}$;

- Variação da potência ativa medida: $-6 \mathrm{~W}$;

- Variação da potência reativa medida: -25 VAR.

\section{- Características funcionais do sistema do sistema de inferência fuzzy}

- Região fuzzy de saída (agregação final):

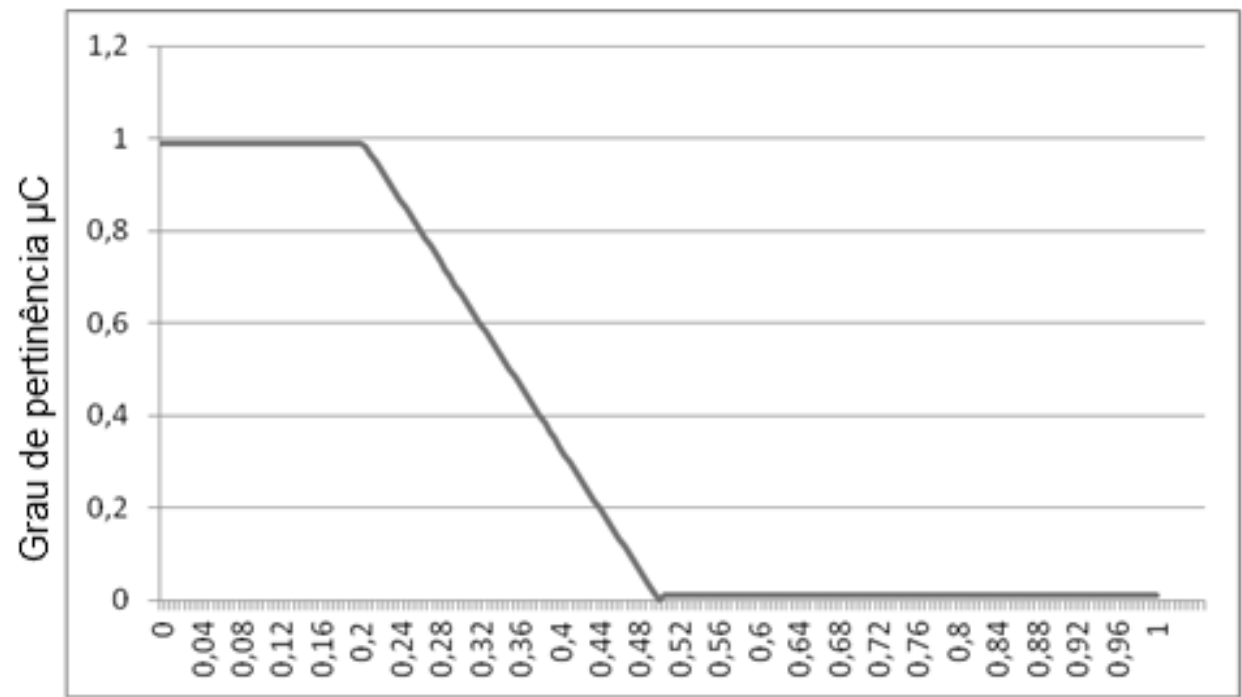

Causa do distúrbio

Figura 6.46 - Região fuzzy de saída para a combinação 2 obtida em laboratório.

- Classificações relacionadas à variação da tensão RMS: "NULA" com valor da função de pertinência $\mu V=0,990$ e "NEGATIVA" com valor da função de pertinência $\mu V=0,010$; 
- Classificações relacionadas à variação da potência ativa: "NEGATIVA" com valor da função de pertinência $\mu P=1$;

- Classificações relacionadas à variação da potência reativa: "NEGATIVA" com valor da função de pertinência $\mu Q=1$;

- Regras ativadas: "REDE" para a combinação $\Delta V<0 / \Delta P<0 / \Delta Q<0$ e "CARGA" para a combinação $\Delta V=0 / \Delta P<0$;

- Valor defuzzificado: 0,19;

- Classe selecionada: "CARGA";

- Análise

Para este teste o sistema de inferência fuzzy classificou corretamente a saída do sistema como "CARGA". Apesar de ter sido ativada no sistema a classe "REDE" para a combinação $\Delta V<0 / \Delta P<0 / \Delta Q<0$, a mesma teve uma baixa contribuição na formação da região fuzzy de saída e na definição do valor pontual (Figura 6.46).

\subsubsection{Combinação 3}

6.4.3.1 - Teste realizado em laboratório

- Características gerais do teste

- Variações manuais apenas nos parâmetros da carga;

- Características da rede: fonte de tensão com valor de $127 \mathrm{~V}_{\mathrm{RMS}}$. Impedância igual à zero;

- Características iniciais da carga: resistência de 298,6 $\Omega$ em série com capacitor de $15 \mu \mathrm{F}$;

- Características finais da carga: resistência de 150,4 $\Omega$ em série com capacitor de $15 \mu \mathrm{F}$;

- Variação da tensão RMS medida: $-10 \mathrm{mV}$;

- Variação da potência ativa medida: $+4 \mathrm{~W}$;

- Variação da potência reativa medida: +32 VAR.

\section{- Características funcionais do sistema do sistema de inferência fuzzy}

- Classificações relacionadas à variação da tensão RMS: "NULA" com valor da função de pertinência $\mu V=0,980$ e "NEGATIVA" com valor da função de pertinência $\mu V=0,020$; 
- Classificações relacionadas à variação da potência ativa: "POSITIVA" com valor da função de pertinência $\mu P=1$;

- Classificações relacionadas à variação da potência reativa: "POSITIVA" com valor da função de pertinência $\mu Q=1$;

- Regras ativadas: "CARGA" para as combinações $\Delta V<0 / \Delta P>0$ e $\Delta V=0 / \Delta P>0$;

- Valor defuzzificado: 0,185;

- Classe selecionada: "CARGA";

- Região fuzzy de saída (agregação final):

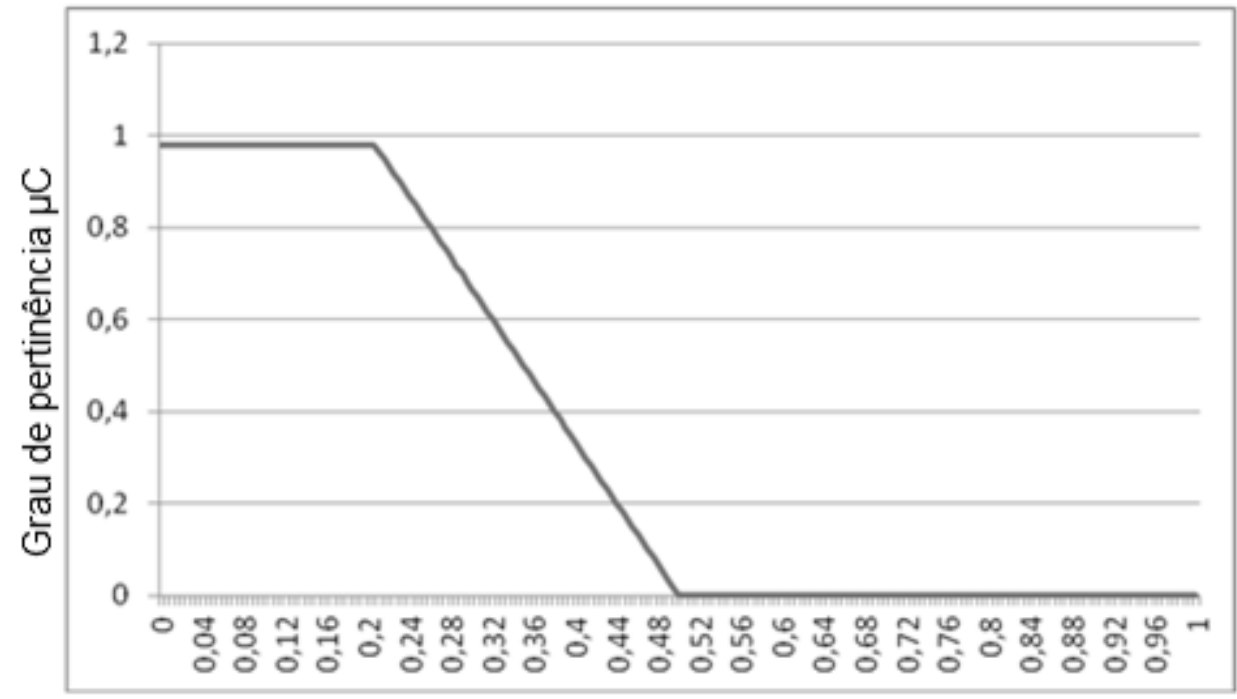

Causa do distúrbio

Figura 6.47 - Região fuzzy de saída para a combinação 3 obtida em laboratório.

- Análise

Para este teste a região fuzzy de saída (Figura 6.47) teve a contribuição apenas da regra ativada "CARGA", fazendo com que o sistema de inferência fuzzy classificasse corretamente a saída do sistema.

\subsubsection{2 - Teste realizado com a base de dados de campo}

\section{- Características gerais do teste}

- Variação da tensão RMS medida: $-130 \mathrm{mV}$;

- Variação da potência ativa medida: $+3 \mathrm{~W}$;

- Variação da potência reativa medida: -1 VAR. 


\section{- Características funcionais do sistema do sistema de inferência fuzzy}

- Classificações relacionadas à variação da tensão RMS: "NEGATIVA" com valor da função de pertinência $\mu V=0,26$ e "NULA" com valor da função de pertinência $\mu V=0,74$;

- Classificações relacionadas à variação da potência ativa: "NULA" com valor da função de pertinência $\mu P=0,25$ e "POSITIVA" com valor da função de pertinência $\mu P=0,75$;

- Classificações relacionadas à variação da potência reativa: "NEGATIVA" com valor da função de pertinência $\mu Q=0,25$ e "NULA" com valor da função de pertinência $\mu Q=0,75$;

- Região fuzzy de saída (agregação final):

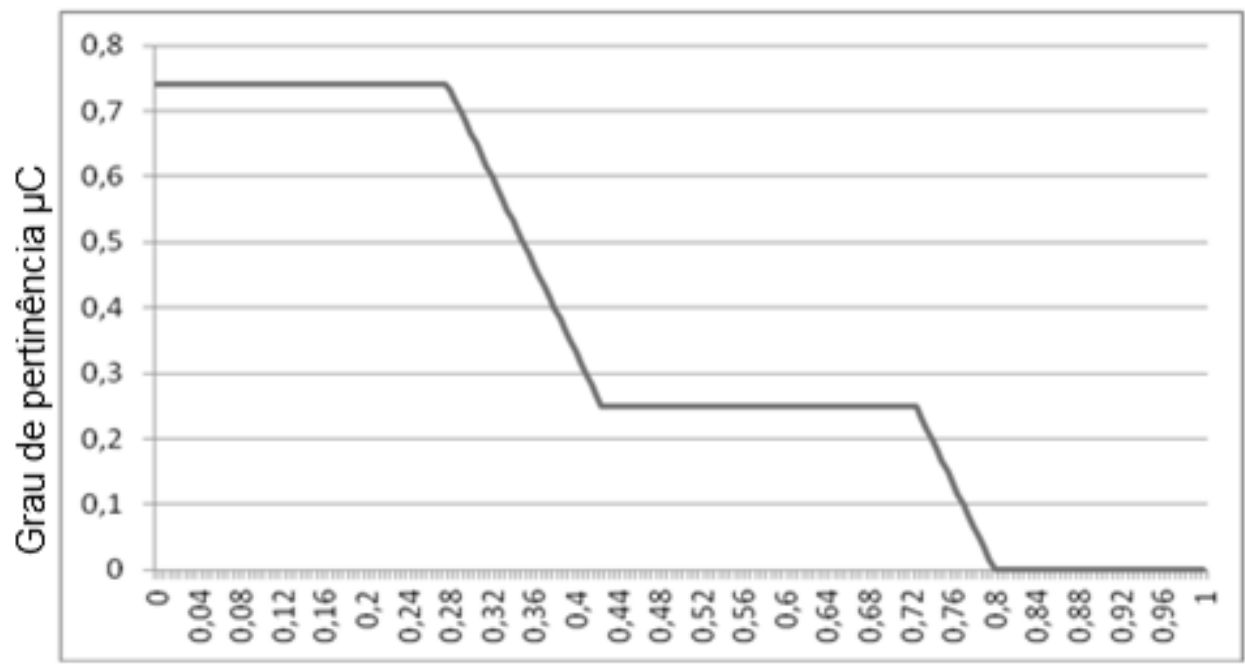

Causa do distúrbio

Figura 6.48 - Região fuzzy de saída para a Combinação 3 obtida com a base de dados.

- Regras ativadas: "CARGA" para as combinações $\Delta V<0 / \Delta P=0, \quad \Delta V<0 / \Delta P>0$, $\Delta V=0 / \Delta P=0 / \Delta Q<0$ e $\Delta V=0 / \Delta P>0$. “INDETERMINADO” para a combinação $\Delta V=0 / \Delta P=0 / \Delta Q=0$

- Valor defuzzificado: 0,285;

- Classe selecionada: "CARGA".

- Análise

Para este teste o sistema de inferência fuzzy classificou a saída do sistema como "CARGA". Apesar de ter sido ativada no sistema a classe "INDETERMINADO" para a combinação $\Delta V=0 / \Delta P=0 / \Delta Q=0$, a mesma teve uma menor contribuição na formação da região fuzzy de saída (Figura 6.48). 


\subsubsection{Combinação 4}

\subsubsection{1 - Teste realizado em laboratório}

\section{- Características gerais do teste}

- Variações manuais apenas nos parâmetros da rede;

- Características iniciais da rede: fonte de tensão igual a $129 \mathrm{~V}_{\mathrm{RMS}}$. Impedância igual a zero;

- Características finais da rede: fonte de tensão igual a 123,12 $\mathrm{V}_{\mathrm{RMS}}$. Impedância igual a zero;

- Características da carga: resistência com valor de 86,1 $\Omega$ em série com capacitor de $15 \mu \mathrm{F}$;

- Variação da tensão RMS medida: $-5860 \mathrm{mV}$;

- Variação da potência ativa medida: $-4 \mathrm{~W}$;

- Variação da potência reativa medida: -8 VAR.

\section{- Características funcionais do sistema do sistema de inferência fuzzy}

- Classificações relacionadas à variação da tensão RMS: "NEGATIVA" com valor da função de pertinência $\mu V=1$;

- Classificações relacionadas à variação da potência ativa: "NEGATIVA" com valor da função de pertinência $\mu P=1$;

- Classificações relacionadas à variação da potência reativa: "NEGATIVA" com valor da função de pertinência $\mu Q=1$;

- Região fuzzy de saída (agregação final):

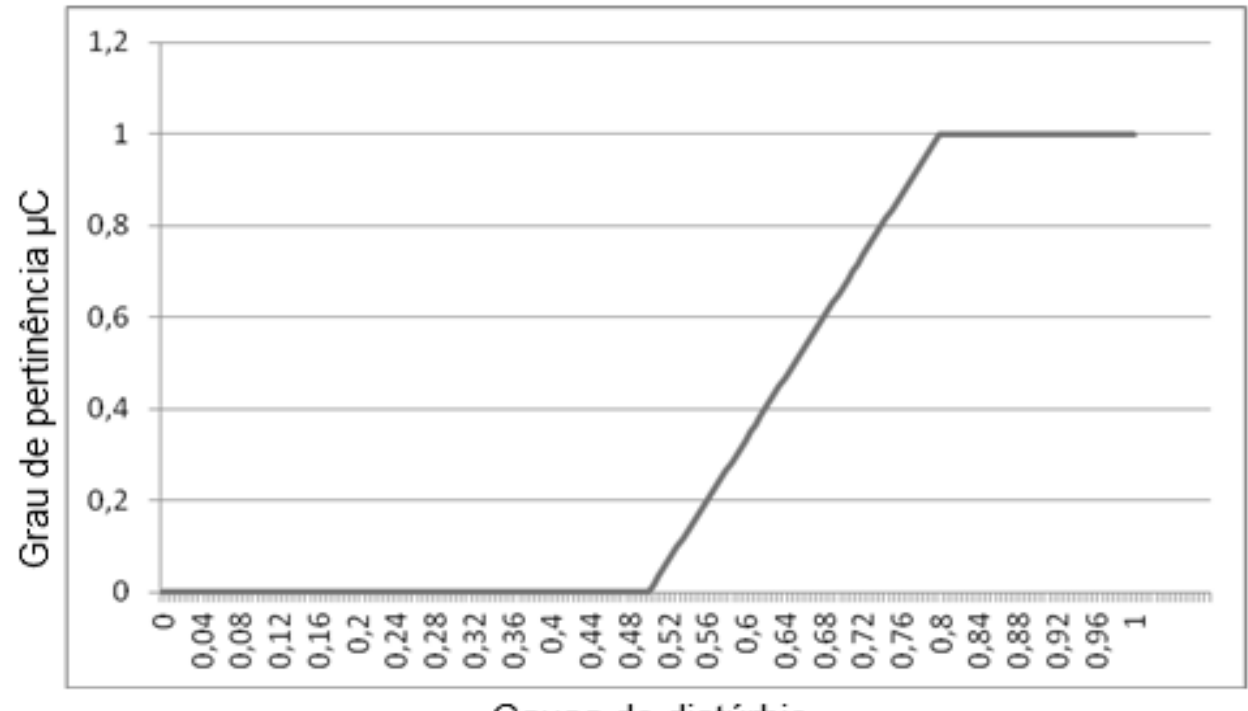

Causa do distúrbio

Figura 6.49 - Região fuzzy de saída para a Combinação 4 obtida em laboratório. 
- Regras ativadas: "REDE” para a combinação $\Delta V<0 / \Delta P<0 / \Delta Q<0$;

- Valor defuzzificado: 0,815;

- Classe selecionada: "REDE".

- Análise

Para este teste a região fuzzy de saída (Figura 6.49) teve a contribuição apenas da regra ativada "REDE", fazendo com que o sistema de inferência fuzzy classificasse corretamente a saída do sistema.

6.4.4.2 - Teste realizado com a base de dados de campo

- Características gerais do teste

- Variação da tensão RMS medida: $-430 \mathrm{mV}$;

- Variação da potência ativa medida: $-380 \mathrm{~W}$;

- Variação da potência reativa medida: -95 VAR.

- Características funcionais do sistema do sistema de inferência fuzzy

- Classificações relacionadas à variação da tensão RMS: "NEGATIVA" com valor da função de pertinência $\mu V=0,86$ e "NULA" com valor da função de pertinência $\mu V=0,14$;

- Região fuzzy de saída (agregação final):

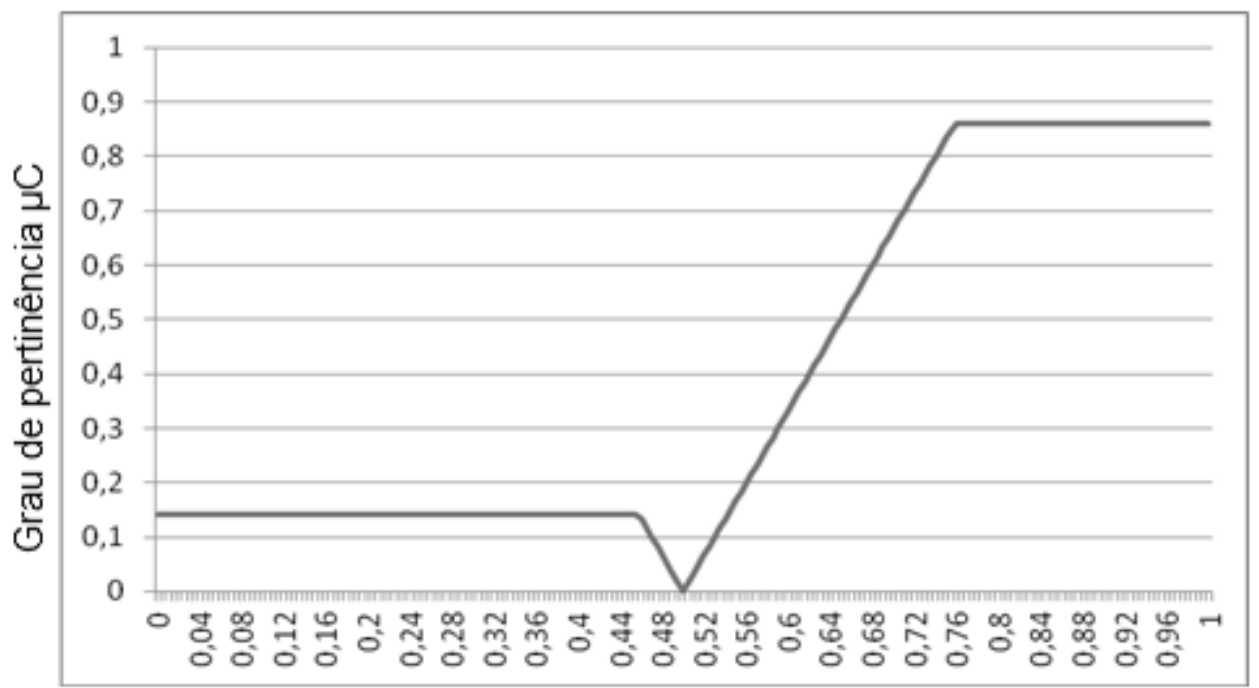

Causa do distúrbio

Figura 6.50 - Região fuzzy de saída para a Combinação 4 obtida com a base de dados. 
- Classificações relacionadas à variação da potência ativa: "NEGATIVA" com valor da função de pertinência $\mu P=1$;

- Classificações relacionadas à variação da potência reativa: "NEGATIVA" com valor da função de pertinência $\mu Q=1$;

- Regras ativadas: "REDE" para a combinação $\Delta V<0 / \Delta P<0 / \Delta Q<0$ e "CARGA" para a combinação $\Delta V=0 / \Delta P<0$;

- Valor defuzzificado: 0,705;

- Classe selecionada: "REDE".

- Análise

Para este teste o sistema de inferência fuzzy (Figura 6.50) classificou a saída do sistema como "REDE". Apesar de ter sido ativada no sistema a classe "CARGA" para a combinação $\Delta V=0 / \Delta P<0$, a mesma teve uma menor contribuição na formação da região fuzzy de saída.

\subsubsection{Combinação 5}

6.4.5.1 - Teste realizado em laboratório

- Características gerais do teste

- Variações manuais apenas nos parâmetros da rede;

- Características iniciais da rede: fonte de tensão com valor de $123,12 \mathrm{~V}_{\mathrm{RMS}}$. Impedância igual à zero;

- Características finais da rede: fonte de tensão com valor de 131,70 $\mathrm{V}_{\mathrm{RMS}}$. Impedância igual à zero;

- Características da carga: resistência com valor de $86,1 \Omega$ em série com capacitor de $15 \mu \mathrm{F}$;

- Variação da tensão RMS medida: +8591 mV;

- Variação da potência ativa medida: +6 W;

- Variação da potência reativa medida: +8 VAR.

- Características funcionais do sistema do sistema de inferência fuzzy

- Classificações relacionadas à variação da tensão RMS: "POSITIVA" com valor da função de pertinência $\mu V=1$; 
- Classificações relacionadas à variação da potência ativa: "POSITIVA" com valor da função de pertinência $\mu P=1$;

- Classificações relacionadas à variação da potência reativa: "POSITIVA" com valor da função de pertinência $\mu Q=1$;

- Regras ativadas: "REDE" para a combinação $\Delta V>0 / \Delta P>0 / \Delta Q>0$;

- Valor defuzzificado: 0,815;

- Classe selecionada: "REDE";

- Região fuzzy de saída (agregação final):

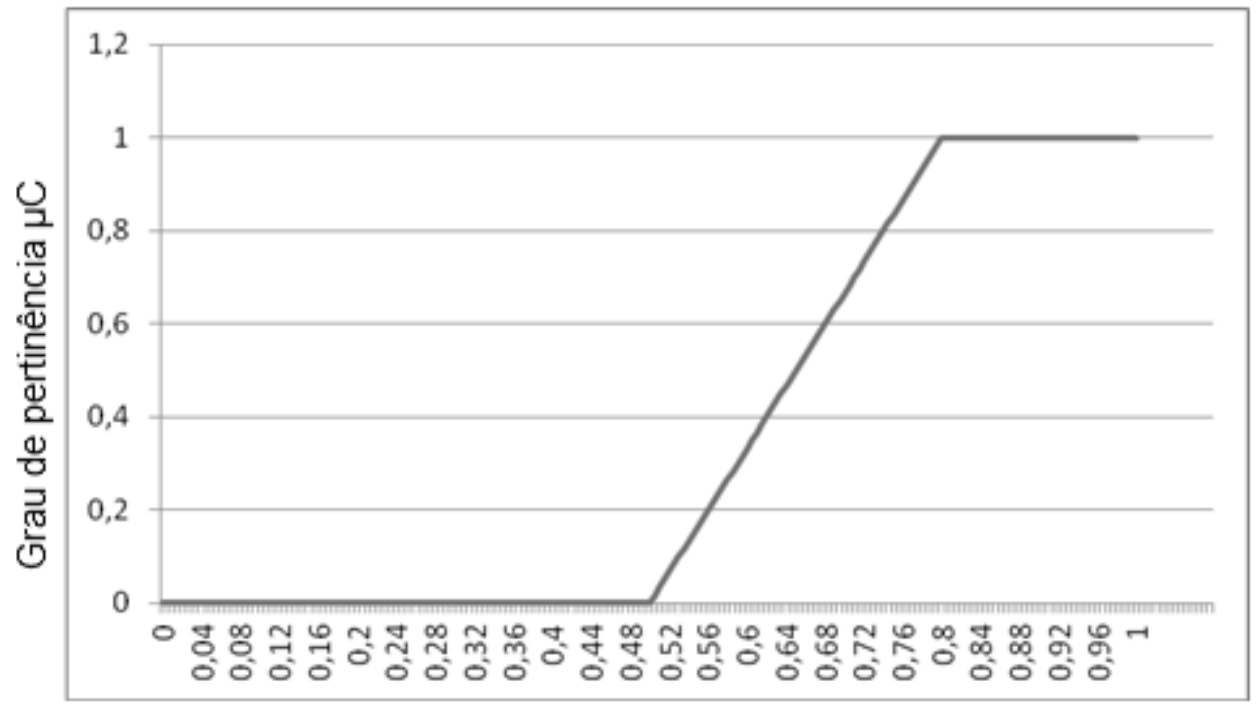

Causa do distúrbio

Figura 6.51 - Região fuzzy de saída para a Combinação 5 obtida em laboratório.

- Análise

Para este teste a região fuzzy de saída (Figura 6.51) teve a contribuição apenas da regra ativada "REDE", fazendo com que o sistema de inferência fuzzy classificasse corretamente a saída do sistema.

6.4.5.2 - Teste realizado com a base de dados de campo

\section{- Características gerais do teste}

- Variação da tensão RMS medida: +390 mV;

- Variação da potência ativa medida: $+79 \mathrm{~W}$;

- Variação da potência reativa medida: +263 VAR. 
- Características funcionais do sistema do sistema de inferência fuzzy

- Classificações relacionadas à variação da tensão RMS: "NULA" com valor da função de pertinência $\mu V=0,22$ e "POSITIVA" com valor da função de pertinência $\mu V=0,78$;

- Classificações relacionadas à variação da potência ativa: "POSITIVA" com valor da função de pertinência $\mu P=1$;

- Classificações relacionadas à variação da potência reativa: "POSITIVA" com valor da função de pertinência $\mu Q=1$;

- Região fuzzy de saída (agregação final):

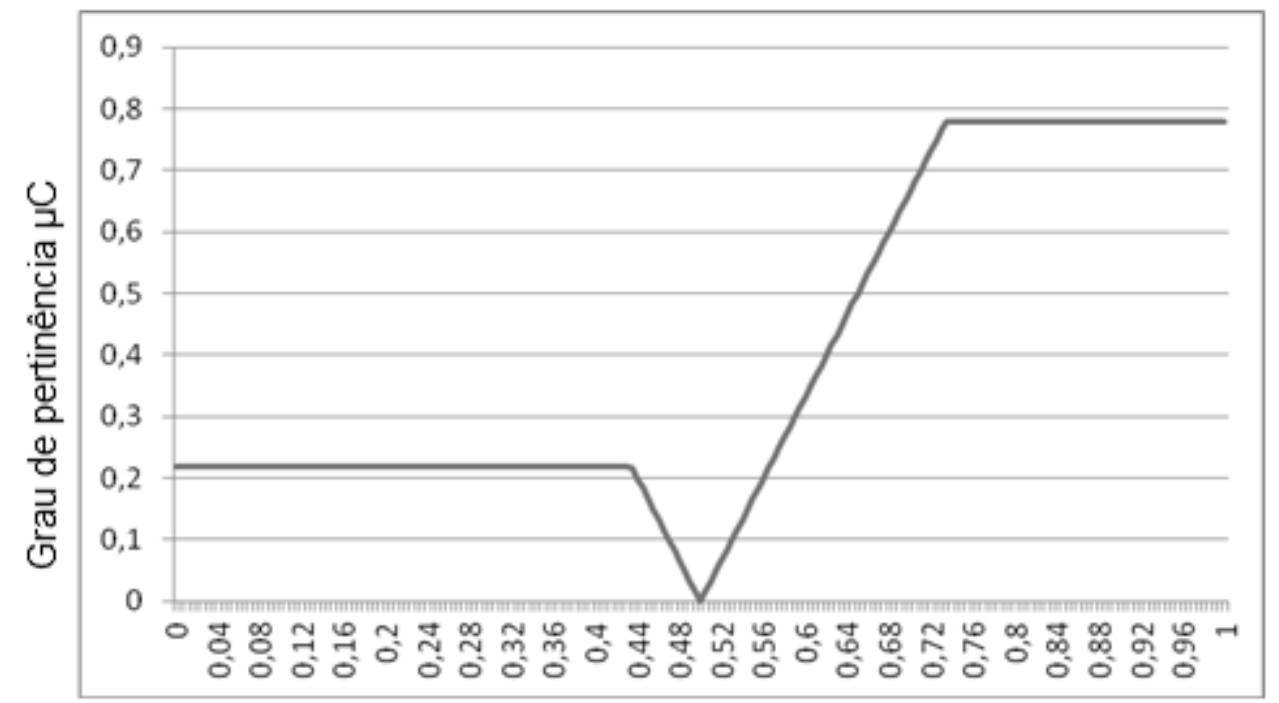

Causa do distúrbio

Figura 6.52 - Região fuzzy de saída para a Combinação 5 obtida com a base de dados

- Regras ativadas: "REDE" para a combinação $\Delta V>0 / \Delta P>0 / \Delta Q>0$ e "CARGA" para a combinação $\Delta V=0 / \Delta P>0$;

- Valor defuzzificado: 0,655;

- Classe selecionada: "REDE".

\section{- Análise}

Para este teste o sistema de inferência fuzzy classificou a saída do sistema como "REDE". Apesar de ter sido ativada no sistema a classe "CARGA" para a combinação $\Delta V=0 / \Delta P>0$, a mesma teve uma menor contribuição na formação da região fuzzy de saída (Figura 6.52). 


\subsubsection{Combinação 6}

- Teste realizado em laboratório

\section{- Características gerais do teste}

- Variações manuais apenas nos parâmetros da carga;

- Características da rede: fonte de tensão com valor de $127 \mathrm{~V}_{\mathrm{RMS}}$. Impedância igual à zero;

- Características iniciais da carga: resistência com valor de $125 \Omega$;

- Características finais da carga: resistência de $125 \Omega$ em paralelo com capacitor de $15 \mu \mathrm{F}$;

- Variação da tensão RMS medida: +81 mV;

- Variação da potência ativa medida: $0 \mathrm{~W}$;

- Variação da potência reativa medida: +96 VAR.

\section{- Características funcionais do sistema do sistema de inferência fuzzy}

- Classificações relacionadas à variação da tensão RMS: "NULA" com valor da função de pertinência $\mu V=0,838$ e "POSITIVA" com valor da função de pertinência $\mu V=0,162$;

- Classificações relacionadas à variação da potência ativa: "NULA" com valor da função de pertinência $\mu P=1$;

- Classificações relacionadas à variação da potência reativa: "POSITIVA" com valor da função de pertinência $\mu Q=1$;

- Região fuzzy de saída (agregação final):

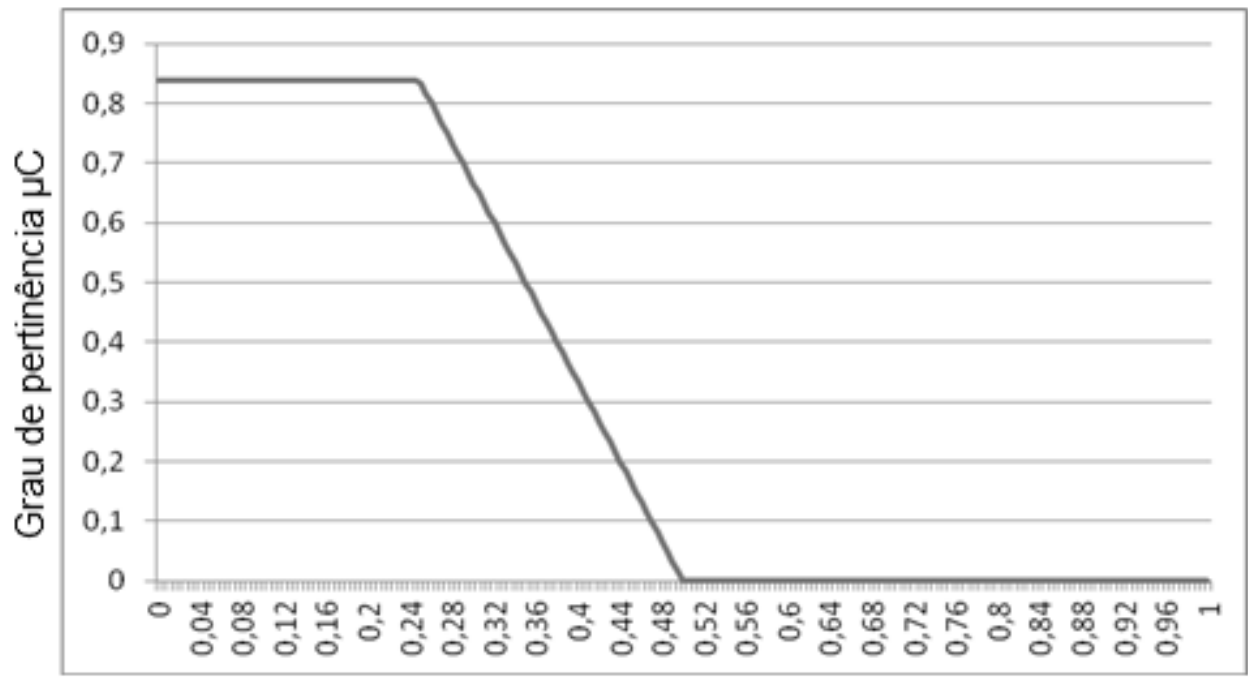

Causa do distúrbio

Figura 6.53 - Região fuzzy de saída para a Combinação 6 obtida em laboratório 
- Regras ativadas: "CARGA" para as combinações $\Delta V=0 / \Delta P=0 / \Delta Q>0$ e $\Delta V>0 / \Delta P=0$;

- Valor defuzzificado: 0,190;

- Classe selecionada: "CARGA".

- Análise

Para este teste a região fuzzy de saída (Figura 6.53) teve a contribuição apenas da regra ativada "CARGA", fazendo com que o sistema de inferência fuzzy classificasse corretamente a saída do sistema.

\subsubsection{Combinação 7}

- Teste realizado em laboratório

\section{- Características gerais do teste}

- Variações manuais apenas nos parâmetros da carga;

- Características da rede: fonte de tensão com valor de $127 \mathrm{~V}_{\mathrm{RMS}}$. Impedância igual à zero;

- Características iniciais da carga: resistência de $125 \Omega$ em paralelo com capacitor de $15 \mu \mathrm{F}$;

- Características finais da carga: resistência com valor de $125 \Omega$;

- Variação da tensão RMS medida: $-123 \mathrm{mV}$;

- Variação da potência ativa medida: $0 \mathrm{~W}$;

- Variação da potência reativa medida: -92 VAR.

- Características funcionais do sistema do sistema de inferência fuzzy

- Classificações relacionadas à variação da tensão RMS: "NULA" com valor da função de pertinência $\mu V=0,754$ e "NEGATIVA" com valor da função de pertinência $\mu V=0,246$;

- Classificações relacionadas à variação da potência ativa: "NULA" com valor da função de pertinência $\mu P=1$;

- Classificações relacionadas à variação da potência reativa: "NEGATIVA" com valor da função de pertinência $\mu Q=1$;

- Regras ativadas: "CARGA” para as combinações $\Delta V=0 / \Delta P=0 / \Delta Q<0$ e $\Delta V<0 / \Delta P=0$;

- Valor defuzzificado: 0,195;

- Classe selecionada: "CARGA".

- Região fuzzy de saída (agregação final): 


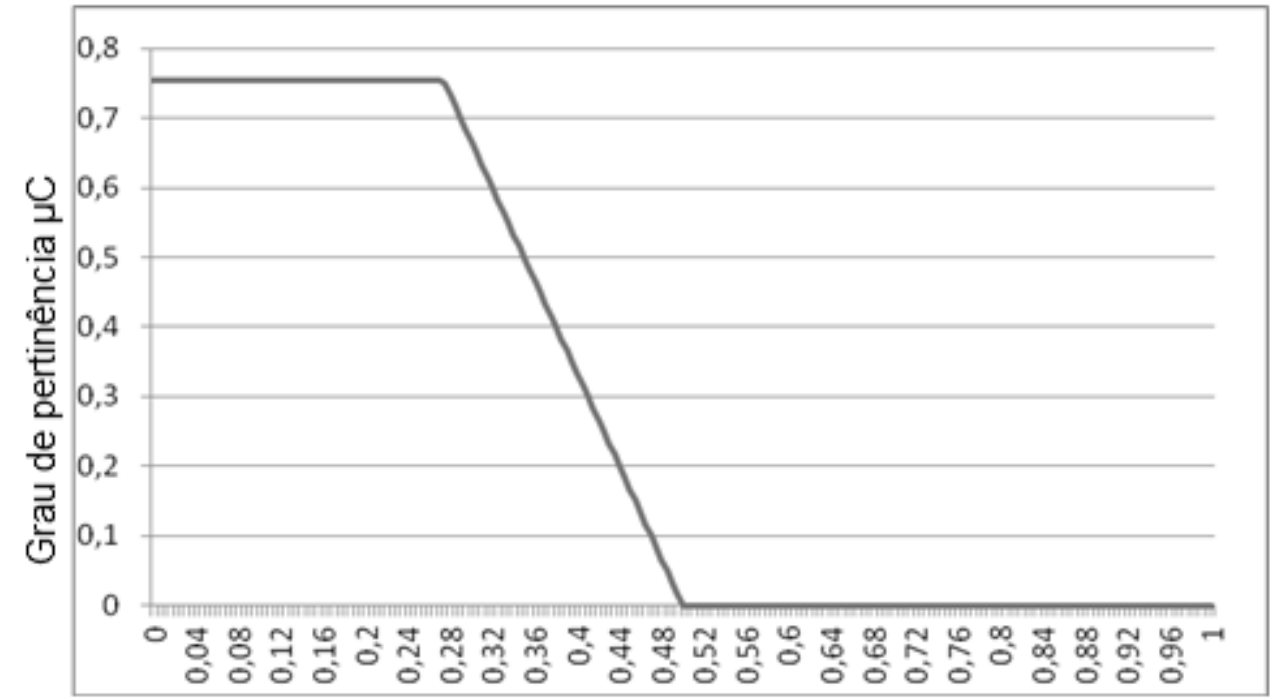

Causa do distúrbio

Figura 6.54 - Região fuzzy de saída para a Combinação 7 obtida em laboratório.

- Análise

Para este teste a região fuzzy de saída teve a contribuição apenas da regra ativada "CARGA", fazendo com que o sistema de inferência fuzzy classificasse corretamente a saída do sistema (Figura 6.54).

\subsubsection{Combinação 8}

- Teste realizado em laboratório

- Características gerais do teste

- Variações manuais apenas nos parâmetros da rede;

- Características iniciais da rede: fonte de tensão igual a 127,96 $\mathrm{V}_{\mathrm{RMS}}$. Impedância igual à zero;

- Características finais da rede: fonte de tensão igual a 126,93 $\mathrm{V}_{\mathrm{RMS}}$. Impedância igual à zero;

- Características da carga: resistência com valor de $100 \Omega$;

- Variação da tensão RMS medida: -1028 mV;

- Variação da potência ativa medida: $-2 \mathrm{~W}$;

- Variação da potência reativa medida: 0 VAR.

- Características funcionais do sistema do sistema de inferência fuzzy 
- Classificações relacionadas à variação da tensão RMS: "NEGATIVA" com valor da função de pertinência $\mu V=1$;

- Classificações relacionadas à variação da potência ativa: "NEGATIVA" com valor da função de pertinência $\mu P=0,5$ e "NULA", com valor da função de pertinência $\mu P=0,5$;

- Classificações relacionadas à variação da potência reativa: "NULA" com valor da função de pertinência $\mu Q=1$;

- Região fuzzy de saída (agregação final):

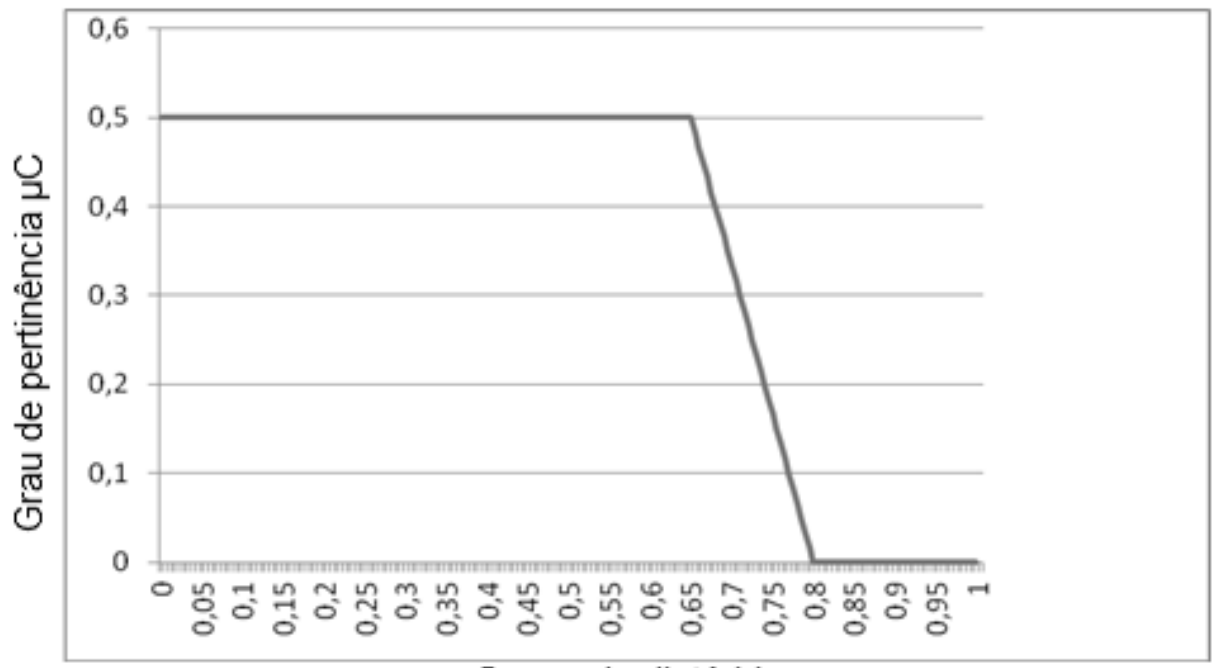

Causa do distúrbio

Figura 6.55 - Região fuzzy de saída para a Combinação 8 obtida em laboratório.

- Regras ativadas: "CARGA" para a combinação $\Delta \mathrm{V}<0 / \Delta \mathrm{P}=0$ e "INDETERMINADO" para a combinação $\Delta V<0 / \Delta P<0 / \Delta Q=0$;

- Valor defuzzificado: 0,36;

- Classe selecionada: "INDETERMINADO".

- Análise

É possível verificar na Figura 6.55 que a região fuzzy de saída foi computada com contribuições significativas das regras ativadas "CARGA" e "INDETERMINADO". Porém, os ajustes dos termos da variável de saída e das variáveis de entrada, em particular dos termos "Variação Nula", fez com que o sistema de inferência fuzzy classificasse corretamente a saída do sistema como "INDETERMINADO". 


\subsubsection{Combinação 9}

- Teste realizado em laboratório

- Características gerais do teste

- Variações manuais apenas nos parâmetros da rede;

- Características iniciais da rede: fonte de tensão com valor de 128,41 V $\mathrm{V}_{\mathrm{RMS}}$. Impedância igual à zero;

- Características finais da rede: fonte de tensão com valor de $129,55 \mathrm{~V}_{\mathrm{RMS}}$. Impedância igual à zero;

- Características da carga: resistência com valor de $100 \Omega$;

- Variação da tensão RMS medida: $+1141 \mathrm{mV}$;

- Variação da potência ativa medida: $+2 \mathrm{~W}$;

- Variação da potência reativa medida: 0 VAR.

- Características funcionais do sistema do sistema de inferência fuzzy

- Classificações relacionadas à variação da tensão RMS: "POSITIVA" com valor da função de pertinência $\mu V=1$;

- Classificações relacionadas à variação da potência ativa: "NULA" com valor da função de pertinência $\mu P=0,5$ e "POSITIVA" com valor da função de pertinência $\mu P=0,5$;

- Região fuzzy de saída (agregação final):

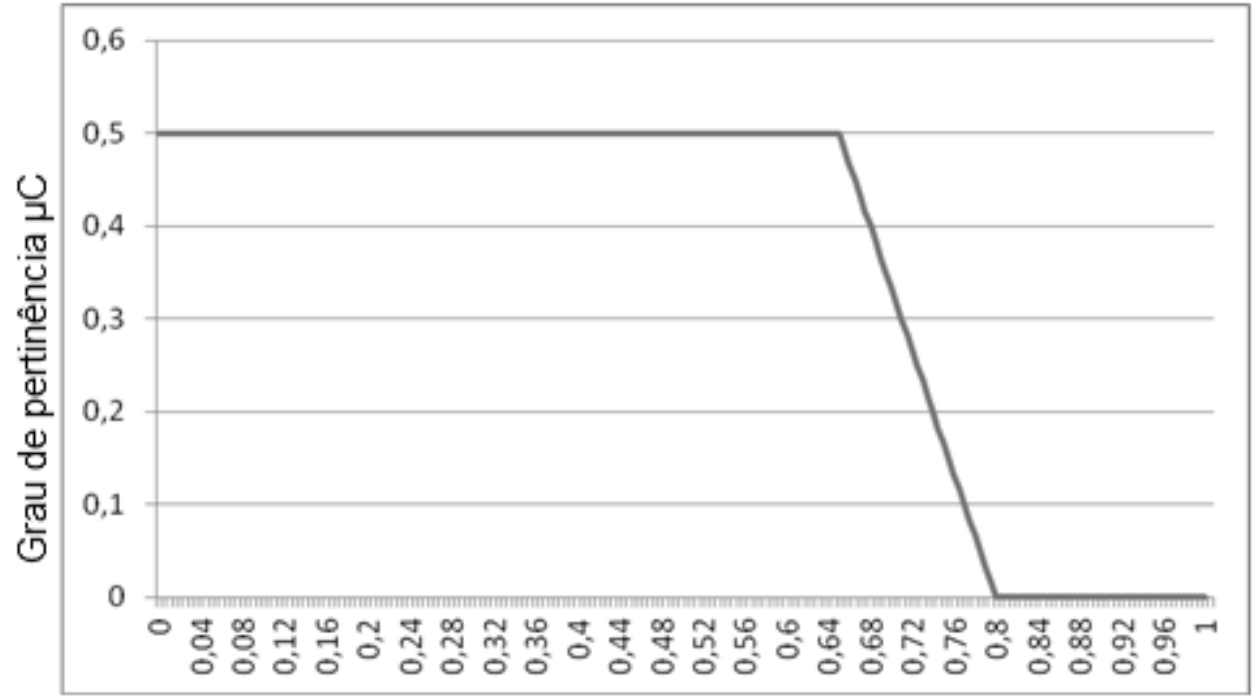

Causa do distúrbio

Figura 6.56 - Região fuzzy de saída para a Combinação 9 obtida em laboratório. 
- Classificações relacionadas à variação da potência reativa: "NULA" com valor da função de pertinência $\mu Q=1$;

- Regras ativadas: "CARGA" para a combinação $\Delta V>0 / \Delta P=0$ e "INDETERMINADO" para a combinação $\Delta V>0 / \Delta P>0 / \Delta Q=0$;

- Valor defuzzificado: 0,36;

- Classe selecionada: "INDETERMINADO".

\section{- Análise}

É possível verificar na Figura 6.56 que a região fuzzy de saída foi computada com contribuições significativas das regras ativadas "CARGA" e "INDETERMINADO". Porém, os ajustes dos termos da variável de saída e das variáveis de entrada, em particular dos termos "Variação Nula", fez com que o sistema de inferência fuzzy classificasse corretamente a saída do sistema como "INDETERMINADO".

\subsubsection{Combinação 10}

6.4.10.1 - Teste realizado em laboratório

- Características gerais do teste

- Variações manuais apenas nos parâmetros da carga;

- Características da rede: fonte de tensão com valor de $127 \mathrm{~V}_{\mathrm{RMS}}$ em série com capacitor de 15 $\mathrm{uF}$;

- Características iniciais da carga: resistência com valor de $120 \Omega$ em paralelo com capacitor de $15 \mu \mathrm{F}$;

- Características finais da carga: resistência de $200 \Omega$ em paralelo com capacitor de $15 \mu \mathrm{F}$;

- Variação da tensão RMS medida: +5234 mV;

- Variação da potência ativa medida: $-4 \mathrm{~W}$;

- Variação da potência reativa medida: 5 VAR.

- Características funcionais do sistema do sistema de inferência fuzzy

- Classificações relacionadas à variação da tensão RMS: "POSITIVA" com valor da função de pertinência $\mu V=1$; 
- Classificações relacionadas à variação da potência ativa: "NEGATIVA" com valor da função de pertinência $\mu P=1$;

- Classificações relacionadas à variação da potência reativa: "POSITIVA" com valor da função de pertinência $\mu Q=1$;

- Regras ativadas: "CARGA” para a combinação $\Delta V>0 / \Delta P<0$;

- Valor defuzzificado: 0,18;

- Classe selecionada: "CARGA";

- Região fuzzy de saída (agregação final):

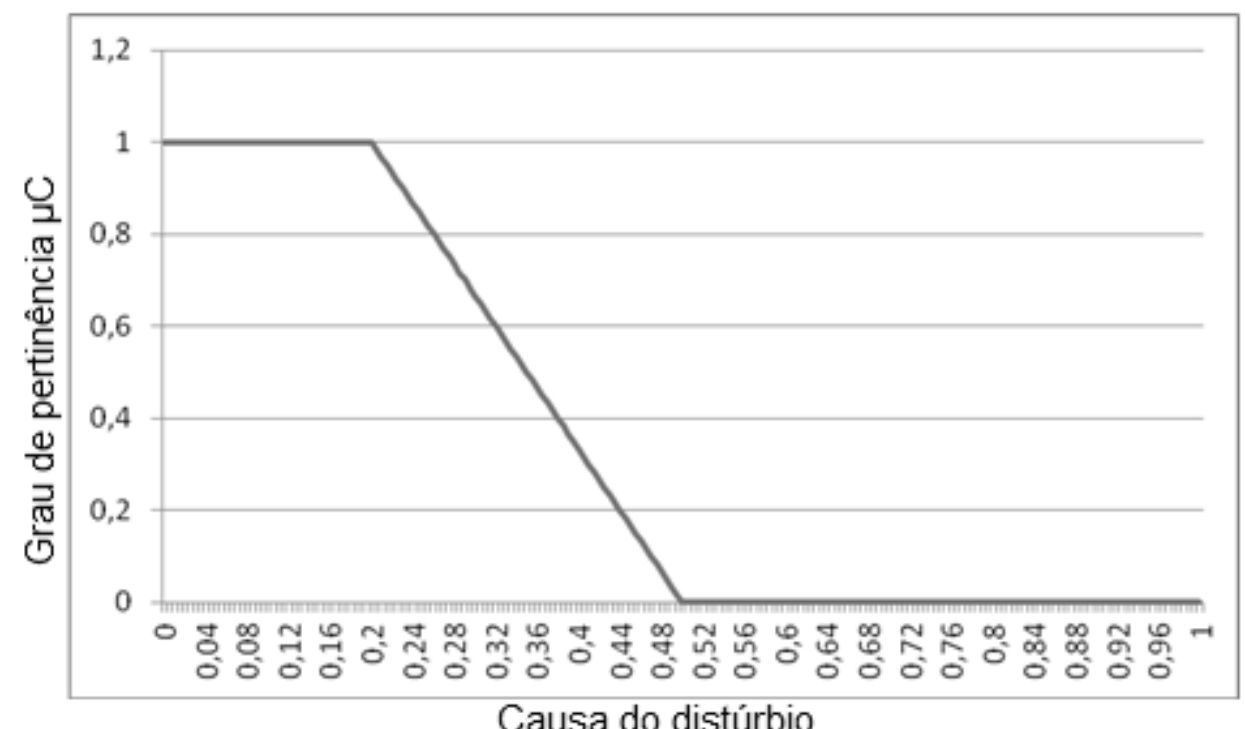

Figura 6.57 - Região fuzzy de saída para a Combinação 10 obtida em laboratório.

- Análise

Para este teste a região fuzzy de saída (Figura 6.57) teve a contribuição apenas da regra ativada "CARGA", fazendo com que o sistema de inferência fuzzy classificasse corretamente a saída do sistema.

6.4.10.2 - Teste realizado com a base de dados de campo

\section{- Características gerais do teste}

- Variação da tensão RMS medida: +260 mV;

- Variação da potência ativa medida: $-3338 \mathrm{~W}$;

- Variação da potência reativa medida: -1305 VAR. 
- Características funcionais do sistema do sistema de inferência fuzzy

- Classificações relacionadas à variação da tensão RMS: "NULA" com valor da função de pertinência $\mu V=0,48$ e "POSITIVA" com valor da função de pertinência $\mu V=0,52$;

- Classificações relacionadas à variação da potência ativa: "NEGATIVA" com valor da função de pertinência $\mu P=1$;

- Classificações relacionadas à variação da potência reativa: "NEGATIVA" com valor da função de pertinência $\mu Q=1$;

- Região fuzzy de saída (agregação final):

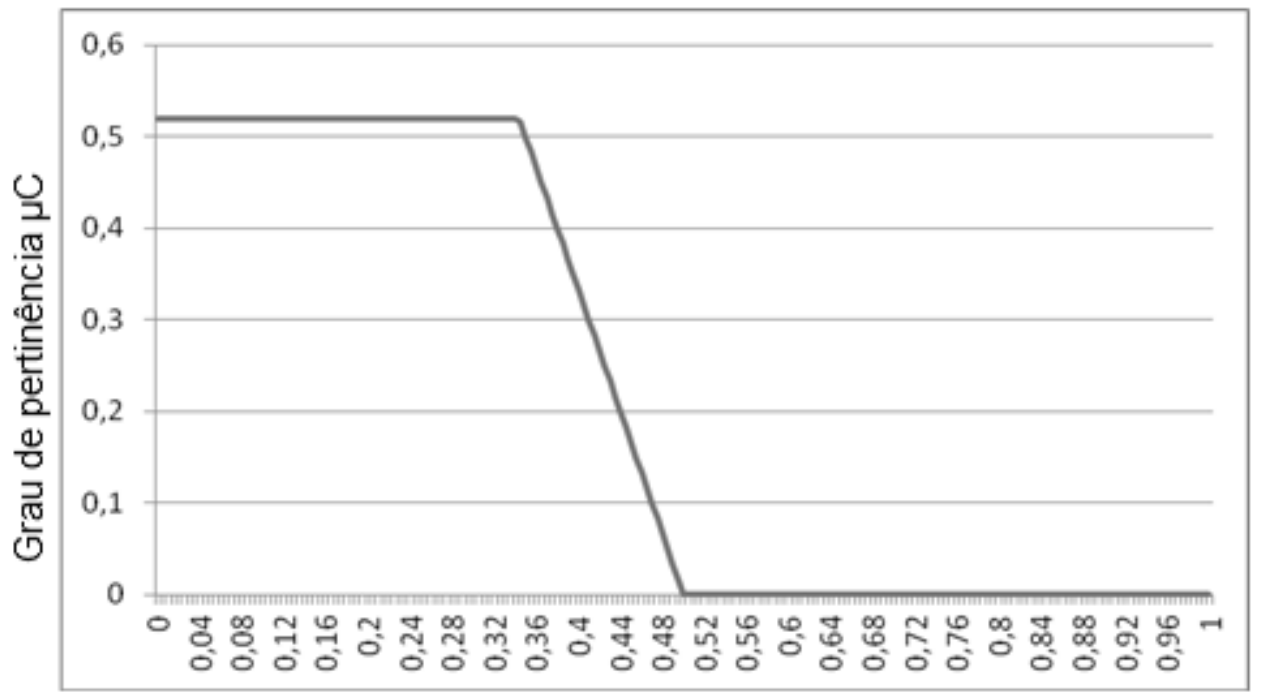

Causa do distúrbio

Figura 6.58 - Região fuzzy de saída para a Combinação 10 obtida com a base de dados.

- Regras ativadas: "CARGA” para as combinações $\Delta V=0 / \Delta P<0$ e $\Delta V>0 / \Delta P<0$;

- Valor defuzzificado: 0,21;

- Classe selecionada: "CARGA".

- Análise

Para este teste a região fuzzy de saída (Figura 6.58) teve a contribuição apenas da regra ativada "CARGA", fazendo com que o sistema de inferência fuzzy classificasse corretamente a saída do sistema.

\subsubsection{Combinação 11}

- Teste realizado em laboratório 


\section{- Características gerais do teste}

- Variações apenas nos parâmetros da carga;

- Características da rede: fonte de tensão de $127 \mathrm{~V}_{\mathrm{RMS}}$ em série com capacitor de $15 \mathrm{uF}$;

- Características iniciais da carga: resistência de $200 \Omega$ em paralelo com capacitor de $15 \mu \mathrm{F}$;

- Características finais da carga: resistência de $158 \Omega$ em paralelo com capacitor de $15 \mu \mathrm{F}$;

- Variação da tensão RMS medida: -2808 mV;

- Variação da potência ativa medida: $+2 \mathrm{~W}$;

- Variação da potência reativa medida: -2 VAR.

- Características funcionais do sistema do sistema de inferência fuzzy

- Classificações relacionadas à variação da tensão RMS: "NEGATIVA" com valor da função de pertinência $\mu V=1$;

- Classificações relacionadas à variação da potência ativa: "NULA" com valor da função de pertinência $\mu P=0,5$ e "POSITIVA" com valor da função de pertinência $\mu P=0,5$;

- Classificações relacionadas à variação da potência reativa: "NEGATIVA" com valor da função de pertinência $\mu Q=0,5$ e "NULA" com valor da função de pertinência $\mu Q=0,5$;

- Regras ativadas: "CARGA" para as combinações $\Delta V<0 / \Delta P=0$ e $\Delta V<0 / \Delta P>0$;

- Valor defuzzificado: 0,21;

- Classe selecionada: "CARGA";

- Região fuzzy de saída (agregação final):

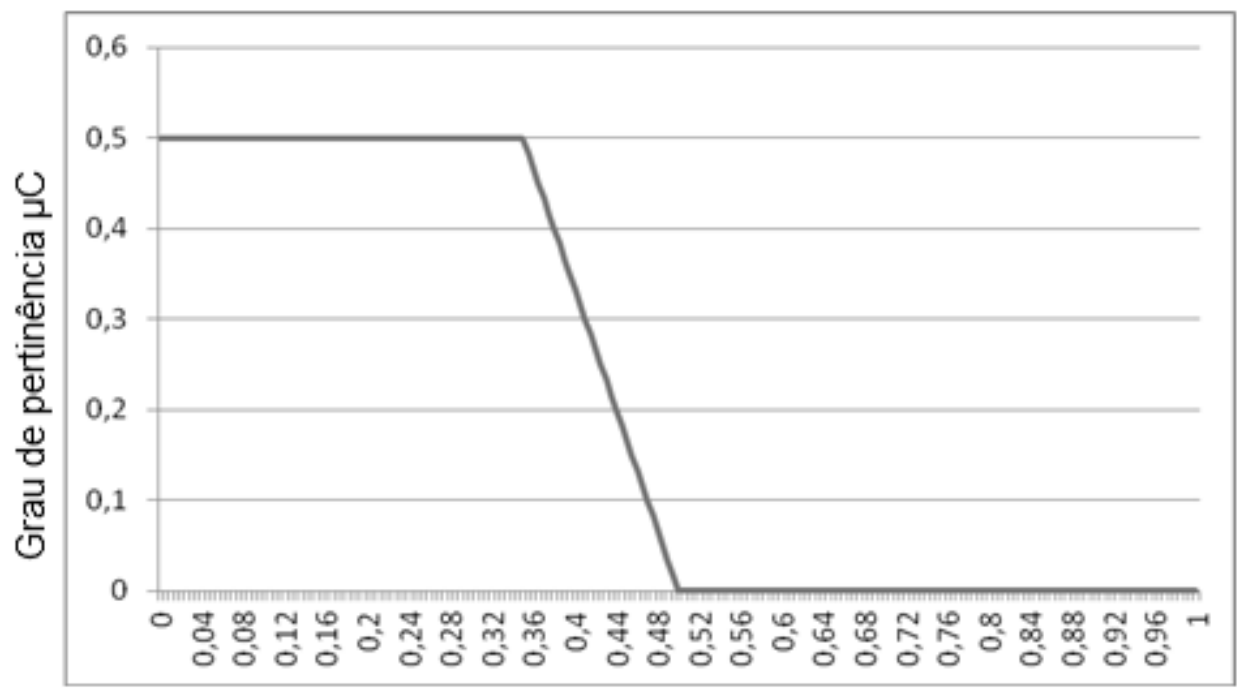

Causa do distúrbio

Figura 6.59 - Região fuzzy de saída para a Combinação 11 obtida em laboratório 


\section{- Análise}

Para este teste a região fuzzy de saída (Figura 6.59) teve a contribuição apenas da regra ativada "CARGA", fazendo com que o sistema de inferência fuzzy classificasse corretamente a saída do sistema.

\subsubsection{Combinação 12}

\subsubsection{1 - Teste realizado em laboratório}

- Características gerais do teste

- Variações apenas nos parâmetros da carga;

- Características da rede: fonte de tensão de $127 \mathrm{~V}_{\mathrm{RMS}}$ em série com capacitor de $15 \mathrm{uF}$;

- Características iniciais da carga: capacitor com valor de $15 \mu \mathrm{F}$;

- Características finais da carga: capacitor com valor de $30 \mu \mathrm{F}$;

- Variação da tensão RMS medida: -19055 mV;

- Variação da potência ativa medida: $0 \mathrm{~W}$;

- Variação da potência reativa medida: -3 VAR.

- Características funcionais do sistema do sistema de inferência fuzzy

- Região fuzzy de saída (agregação final):

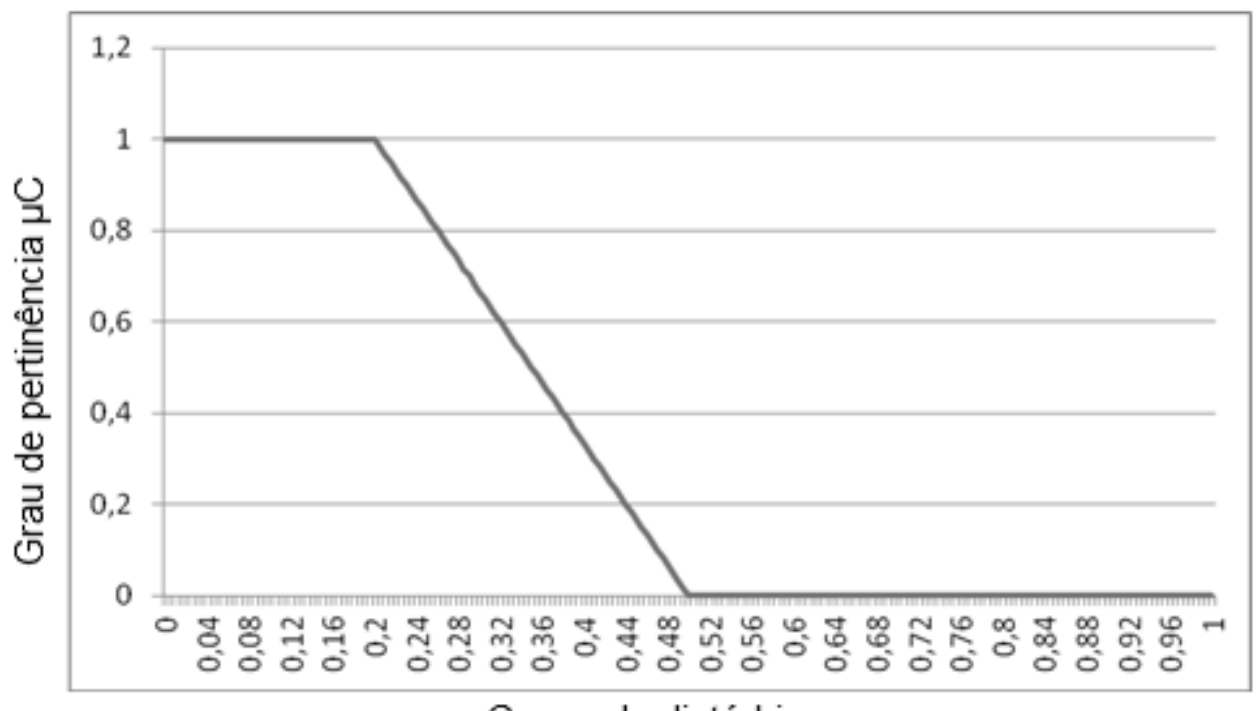

Causa do distúrbio

Figura 6.60 - Região fuzzy de saída para a Combinação 12 obtida em laboratório. 
- Classificações relacionadas à variação da tensão RMS: "NEGATIVA" com valor da função de pertinência $\mu V=1$;

- Classificações relacionadas à variação da potência ativa: "NULA" com valor da função de pertinência $\mu P=1$;

- Classificações relacionadas à variação da potência reativa: "NEGATIVA" com valor da função de pertinência $\mu Q=0,75$ e "NULA" com valor da função de pertinência $\mu Q=0,25$;

- Regras ativadas: "CARGA" para a combinação $\Delta V<0 / \Delta P=0$;

- Valor defuzzificado: 0,18;

- Classe selecionada: "CARGA”.

\section{- Análise}

Para este teste a região fuzzy de saída (Figura 6.60) teve a contribuição apenas da regra ativada "CARGA", fazendo com que o sistema de inferência fuzzy classificasse corretamente a saída do sistema.

\subsubsection{2 - Teste realizado com a base de dados de campo}

\section{- Características gerais do teste}

- Variação da tensão RMS medida: $-321 \mathrm{mV}$;

- Variação da potência ativa medida: $-1 \mathrm{~W}$;

- Variação da potência reativa medida: 292 VAR.

\section{- Características funcionais do sistema do sistema de inferência fuzzy}

- Classificações relacionadas à variação da tensão RMS: "NEGATIVA" com valor da função de pertinência $\mu V=0,66$ e "NULA" com valor da função de pertinência $\mu V=0,34$;

- Classificações relacionadas à variação da potência ativa: "NEGATIVA" com valor da função de pertinência $\mu P=0,25$ e "NULA" com valor da função de pertinência $\mu P=0,75$;

- Classificações relacionadas à variação da potência reativa: "POSITIVA" com valor da função de pertinência $\mu Q=1$;

- Regras ativadas: "CARGA" para as combinações $\Delta V<0 / \Delta P<0 / \Delta Q>0, \quad \Delta V<0 / \Delta P=0$, $\Delta V=0 / \Delta P<0, \Delta V=0 / \Delta P=0 / \Delta Q>0 ;$

- Valor defuzzificado: 0,2; 
- Classe selecionada: "CARGA";

- Região fuzzy de saída (agregação final):

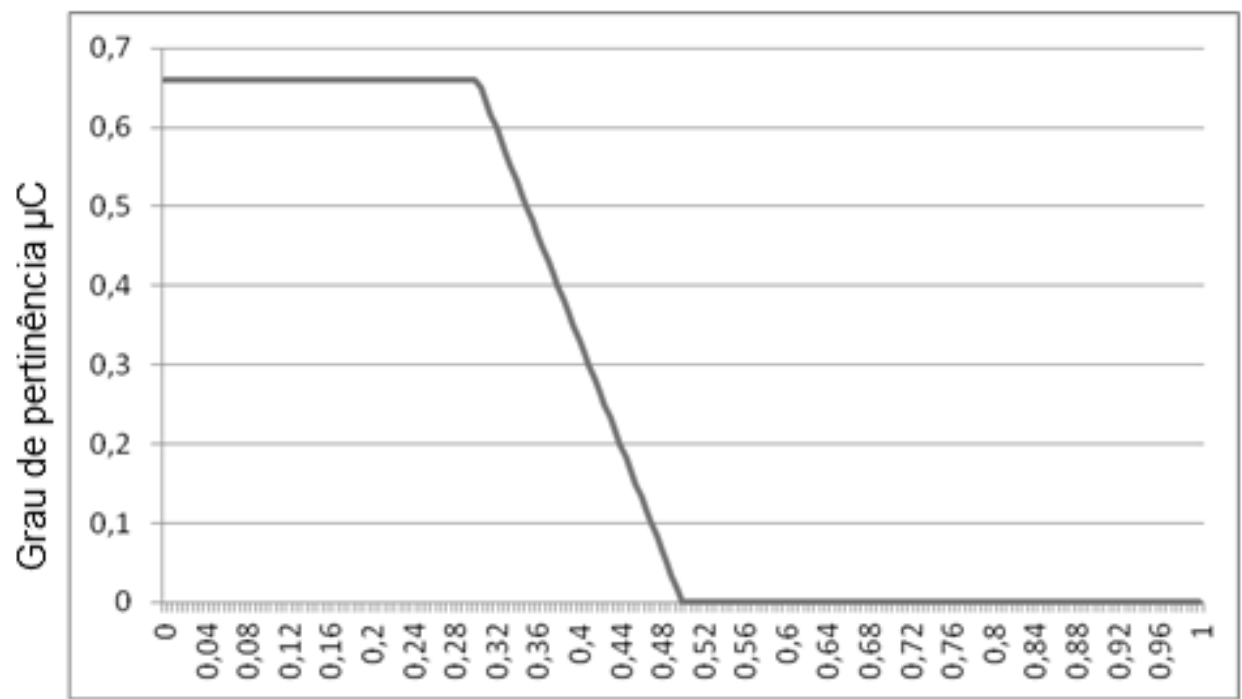

Causa do distúrbio

Figura 6.61 - Região fuzzy de saída para a Combinação 12 obtida com a base de dados.

- Análise

Para este teste a região fuzzy de saída (Figura 6.61) teve a contribuição apenas da regra ativada "CARGA", fazendo com que o sistema de inferência fuzzy classificasse corretamente a saída do sistema.

\subsubsection{Combinação 13}

6.4.13.1 - Teste realizado em laboratório

- Características gerais do teste

- Variações apenas nos parâmetros da carga;

- Características da rede: fonte de tensão de $127 \mathrm{~V}_{\mathrm{RMS}}$ em série com capacitor de $15 \mathrm{uF}$;

- Características iniciais da carga: capacitor com valor de $30 \mu \mathrm{F}$;

- Características finais da carga: capacitor com valor de $15 \mu \mathrm{F}$;

- Variação da tensão RMS medida: 18630 mV;

- Variação da potência ativa medida: $0 \mathrm{~W}$;

- Variação da potência reativa medida: 2 VAR. 
- Características funcionais do sistema do sistema de inferência fuzzy

- Classificações relacionadas à variação da tensão RMS: "POSITIVA" com valor da função de pertinência $\mu V=1$;

- Classificações relacionadas à variação da potência ativa: "NULA" com valor da função de pertinência $\mu P=1$;

- Classificações relacionadas à variação da potência reativa: "NULA" com valor da função de pertinência $\mu Q=0,5$ e "POSITIVA" com valor da função de pertinência $\mu Q=0,5$;

- Região fuzzy de saída (agregação final):

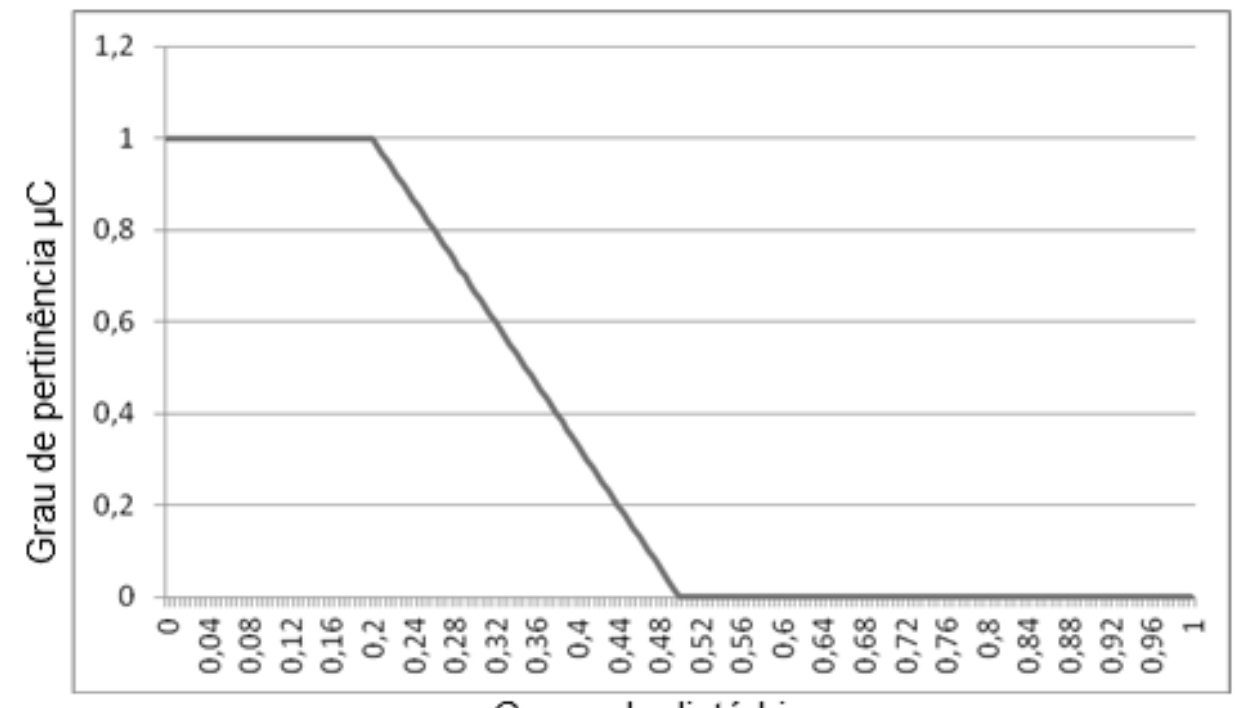

Causa do distúrbio

Figura 6.62 - Região fuzzy de saída para a Combinação 13 obtida em laboratório.

- Regras ativadas: "CARGA" para a combinação $\Delta V>0 / \Delta P=0$;

- Valor defuzzificado: 0,18;

- Classe selecionada: "CARGA".

- Análise

Para este teste a região fuzzy de saída (Figura 6.62) teve a contribuição apenas da regra ativada "CARGA", fazendo com que o sistema de inferência fuzzy classificasse corretamente a saída do sistema.

6.4.13.2 - Teste realizado com a base de dados de campo 
- Variação da tensão RMS medida: 300 mV;

- Variação da potência ativa medida: $-2 \mathrm{~W}$;

- Variação da potência reativa medida: -60 VAR.

\section{- Características funcionais do sistema do sistema de inferência fuzzy}

- Classificações relacionadas à variação da tensão RMS: "NULA" com valor da função de pertinência $\mu V=0,4$ e "POSITIVA" com valor da função de pertinência $\mu V=0,6$;

- Classificações relacionadas à variação da potência ativa: "NEGATIVA" com valor da função de pertinência $\mu P=0,5$ e "NULA" com valor da função de pertinência $\mu P=0,5$;

- Classificações relacionadas à variação da potência reativa: "NEGATIVA" com valor da função de pertinência $\mu Q=1$;

- Região fuzzy de saída (agregação final):

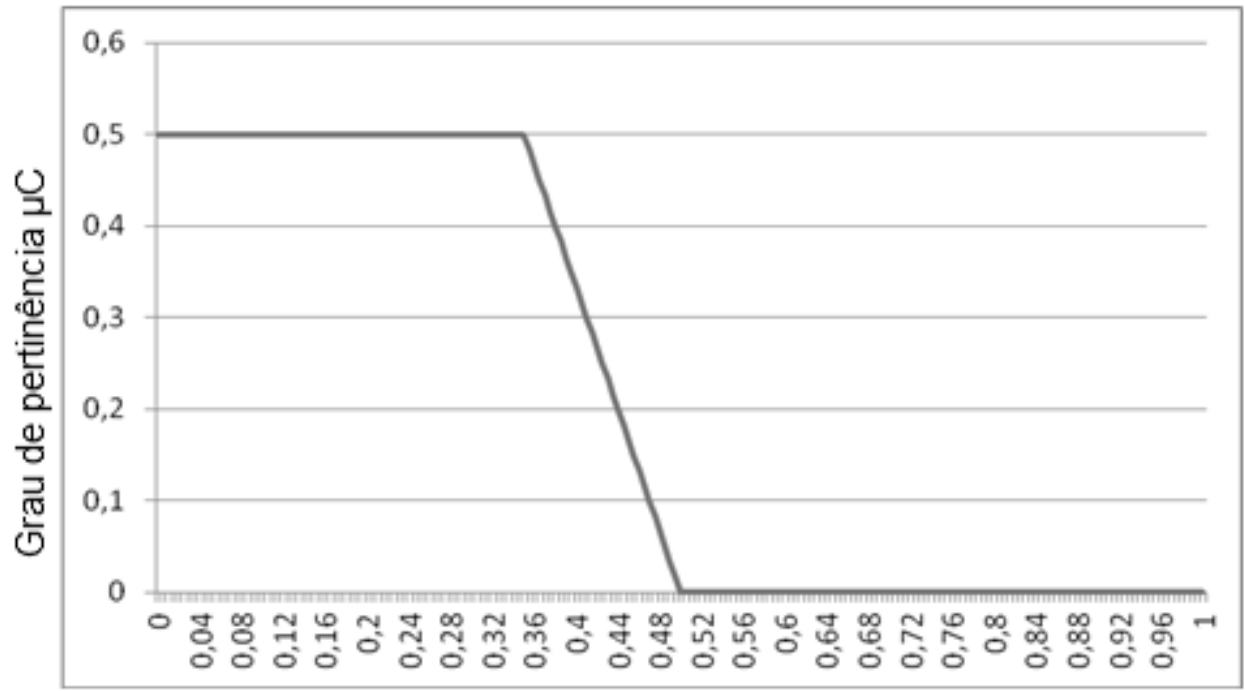

Causa do distúrbio

Figura 6.63 - Região fuzzy de saída para a Combinação 13 obtida com a base de dados.

- Regras ativadas: "CARGA" para as combinações $\Delta V=0 / \Delta P=0 / \Delta Q<0, \quad \Delta V=0 / \Delta P<0$, $\Delta V>0 / \Delta P=0$ e $\Delta V>0 / \Delta P<0$

- Valor defuzzificado: 0,210;

- Classe selecionada: "CARGA".

- Análise

Para este teste a região fuzzy de saída (Figura 6.63) teve a contribuição apenas da regra ativada "CARGA", fazendo com que o sistema de inferência fuzzy classificasse corretamente a saída do sistema. 


\subsubsection{Combinação 14}

\subsubsection{1 - Teste realizado em laboratório}

\section{- Características gerais do teste}

- Variações apenas nos parâmetros da carga;

- Características da rede: fonte de tensão de $127 \mathrm{~V}_{\mathrm{RMS}}$ em série com capacitor de $15 \mathrm{uF}$ e resistência de $500 \Omega$;

- Características iniciais da carga: capacitor de $15 \mu \mathrm{F}$ em série com resistor de $960 \Omega$;

- Características finais da carga: capacitor de $15 \mu \mathrm{F}$ em série com resistor de $30 \Omega$;

- Variação da tensão RMS medida: -39839 mV;

- Variação da potência ativa medida: $-8 \mathrm{~W}$;

- Variação da potência reativa medida: 6 VAR.

- Características funcionais do sistema do sistema de inferência fuzzy

- Classificações relacionadas à variação da tensão RMS: "NEGATIVA" com valor da função de pertinência $\mu V=1$;

- Classificações relacionadas à variação da potência ativa: "NEGATIVA" com valor da função de pertinência $\mu P=1$;

- Região fuzzy de saída (agregação final):

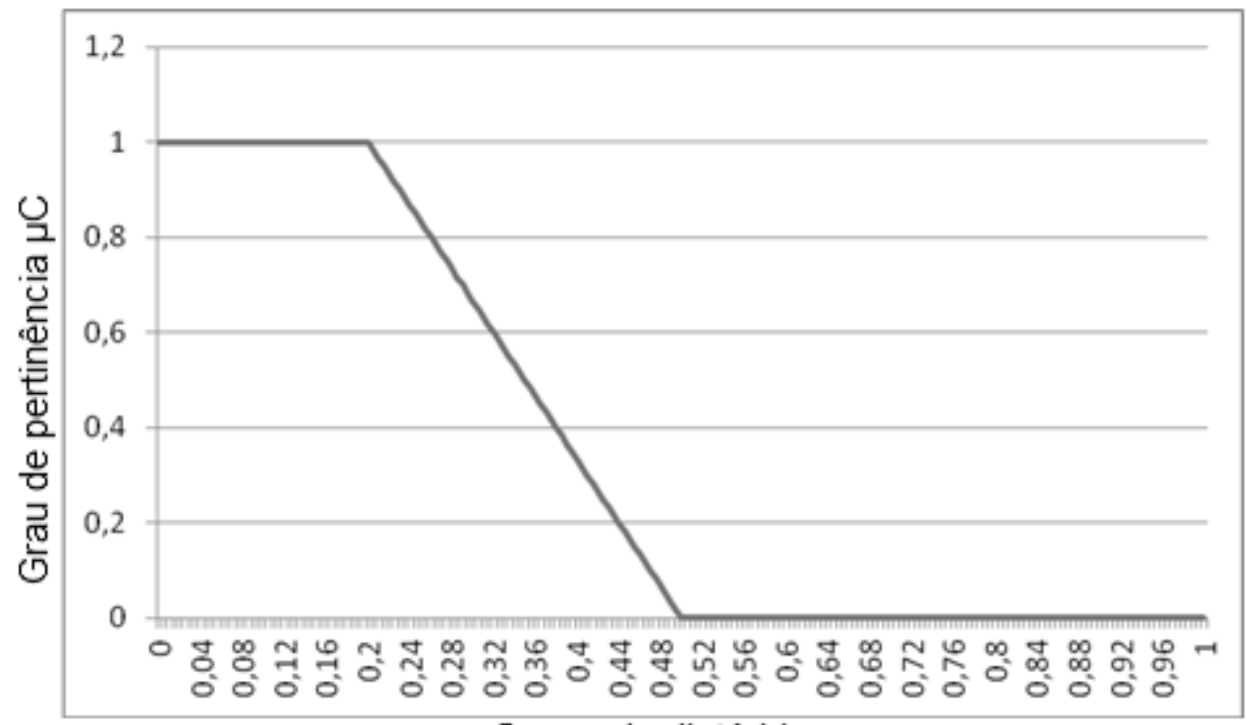

Causa do distúrbio

Figura 6.64 - Região fuzzy de saída para a Combinação 14 obtida em laboratório 
- Classificações relacionadas à variação da potência reativa: "POSITIVA" com valor da função de pertinência $\mu Q=1$;

- Regras ativadas: "CARGA" para a combinação $\Delta V<0 / \Delta P<0 / \Delta Q>0$;

- Valor defuzzificado: 0,18;

- Classe selecionada: "CARGA".

- Análise

Para este teste a região fuzzy de saída (Figura 6.64) teve a contribuição apenas da regra ativada "CARGA", fazendo com que o sistema de inferência fuzzy classificasse corretamente a saída do sistema.

6.4.14.2 - Teste realizado com a base de dados de campo

\section{- Características gerais do teste}

- Variação da tensão RMS medida: $-250 \mathrm{mV}$;

- Variação da potência ativa medida: -166 W;

- Variação da potência reativa medida: 621 VAR.

- Características funcionais do sistema do sistema de inferência fuzzy

- Classificações relacionadas à variação da tensão RMS: "NULA" com valor da função de pertinência $\mu V=0,5$ e "NEGATIVA" com valor da função de pertinência $\mu V=0,5$;

- Classificações relacionadas à variação da potência ativa: "NEGATIVA" com valor da função de pertinência $\mu P=1$;

- Classificações relacionadas à variação da potência reativa: "POSITIVA" com valor da função de pertinência $\mu Q=1$;

- Regras ativadas: "CARGA" para as combinações $\Delta V=0 / \Delta P<0$ e $\Delta V<0 / \Delta P<0 / \Delta Q>0$;

- Valor defuzzificado: 0,210;

- Classe selecionada: "CARGA";

- Região fuzzy de saída (agregação final): 


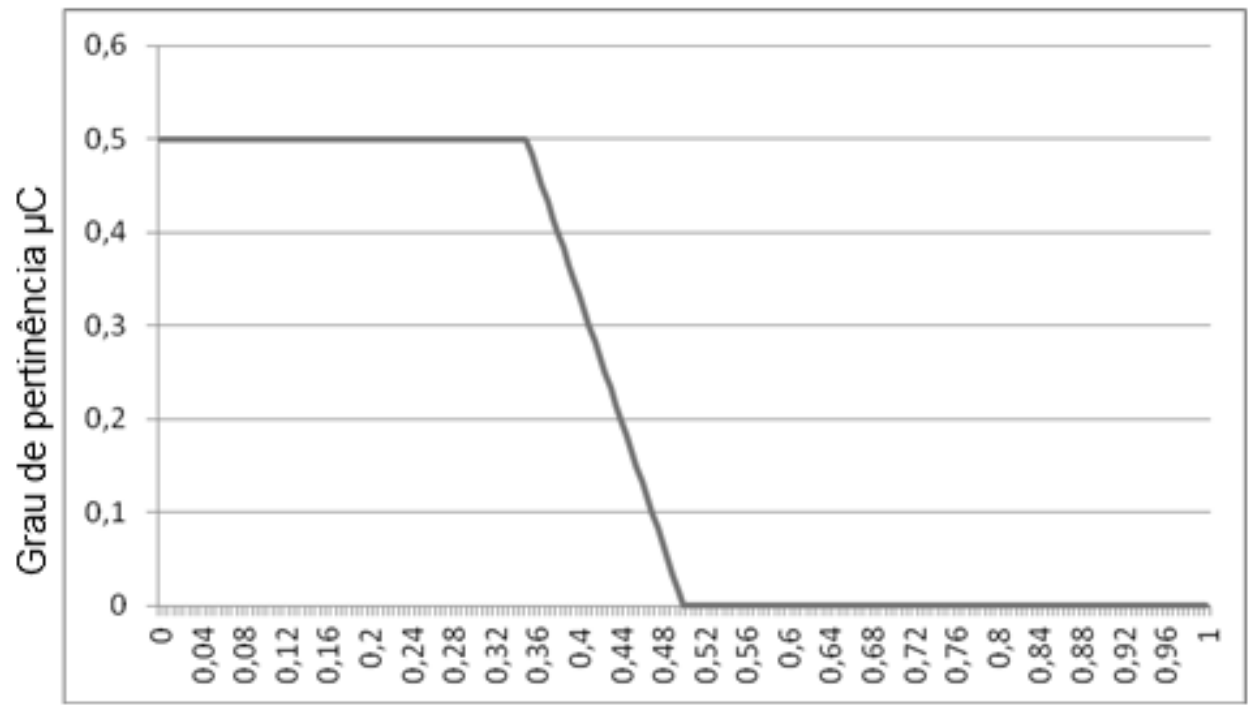

Causa do distúrbio

Figura 6.65 - Região fuzzy de saída para a Combinação 14 obtida com a base de dados

- Análise

Para este teste a região fuzzy de saída (Figura 6.65) teve a contribuição apenas da regra ativada "CARGA", fazendo com que o sistema de inferência fuzzy classificasse corretamente a saída do sistema.

\subsubsection{Combinação 15}

6.4.15.1 - Teste realizado em laboratório

\section{- Características gerais do teste}

- Variações apenas nos parâmetros da carga;

- Características da rede: fonte de tensão de $127 \mathrm{~V}_{\mathrm{RMS}}$ em série com capacitor de $15 \mu \mathrm{F}$ e resistência de $251 \Omega$;

- Características iniciais da carga: capacitor de $15 \mu \mathrm{F}$ em série com resistor de $56 \Omega$;

- Características finais da carga: capacitor de $15 \mu \mathrm{F}$ em série com resistor de $960 \Omega$;

- Variação da tensão RMS medida: 45539 mV;

- Variação da potência ativa medida: $6 \mathrm{~W}$;

- Variação da potência reativa medida: -13 VAR.

- Características funcionais do sistema do sistema de inferência fuzzy 
- Classificações relacionadas à variação da tensão RMS: "POSITIVA" com valor da função de pertinência $\mu V=1$;

- Classificações relacionadas à variação da potência ativa: "POSITIVA" com valor da função de pertinência $\mu P=1$;

- Classificações relacionadas à variação da potência reativa: "NEGATIVA" com valor da função de pertinência $\mu Q=1$;

- Regras ativadas: "CARGA" para a combinação $\Delta V>0 / \Delta P>0 / \Delta Q<0$;

- Valor defuzzificado: 0,18;

- Classe selecionada: “CARGA”.

- Região fuzzy de saída (agregação final):

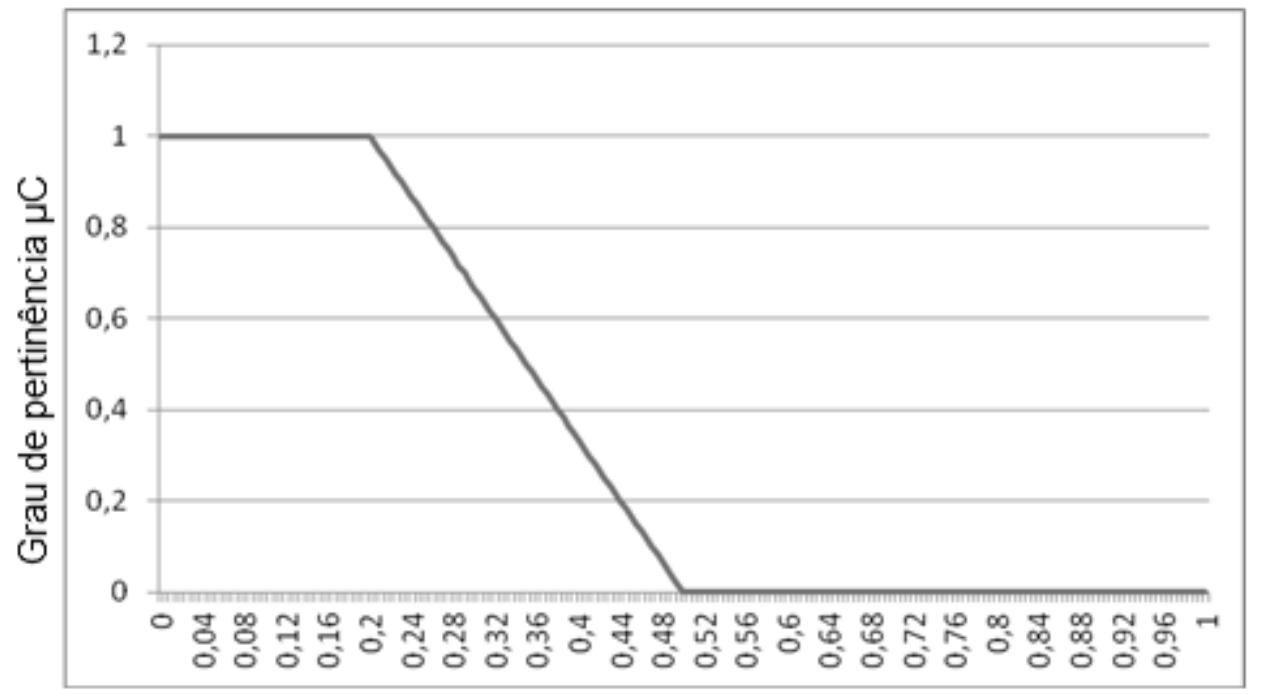

Causa do distúrbio

Figura 6.66 - Região fuzzy de saída para a Combinação 15 obtida em laboratório.

- Análise

Para este teste a região fuzzy de saída (Figura 6.66) teve a contribuição apenas da regra ativada "CARGA", fazendo com que o sistema de inferência fuzzy classificasse corretamente a saída do sistema.

6.4.15.2 - Teste realizado com a base de dados de campo

- Características gerais do teste

- Variação da tensão RMS medida: $350 \mathrm{mV}$;

- Variação da potência ativa medida: $220 \mathrm{~W}$; 
- Variação da potência reativa medida: -182 VAR.

- Características funcionais do sistema do sistema de inferência fuzzy

- Classificações relacionadas à variação da tensão RMS: "NULA" com valor da função de pertinência $\mu V=0,3$ e "POSITIVA" com valor da função de pertinência $\mu V=0,7$;

- Classificações relacionadas à variação da potência ativa: "POSITIVA" com valor da função de pertinência $\mu P=1$;

- Classificações relacionadas à variação da potência reativa: "NEGATIVA" com valor da função de pertinência $\mu Q=1$;

- Região fuzzy de saída (agregação final):

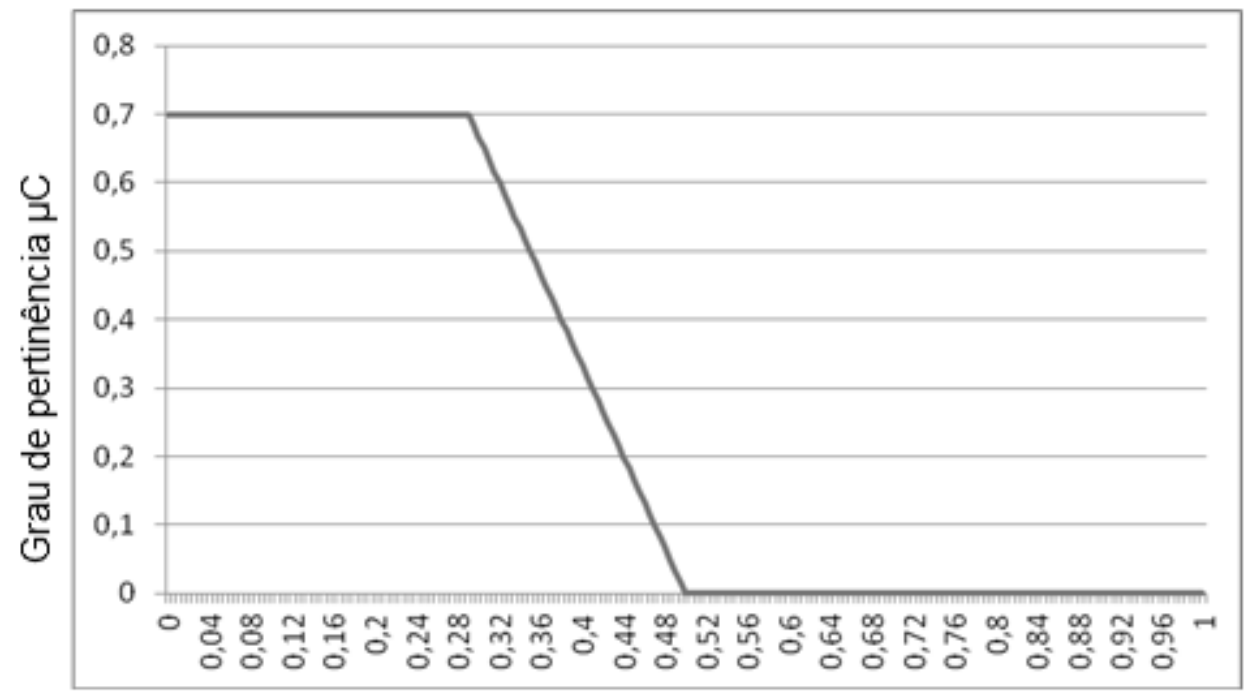

Causa do distúrbio

Figura 6.67 - Região fuzzy de saída para a Combinação 15 obtida com a base de dados.

- Regras ativadas: "CARGA" para as combinações $\Delta V=0 / \Delta P>0$ e $\Delta V>0 / \Delta P>0 / \Delta Q<0$;

- Valor defuzzificado: 0,2;

- Classe selecionada: "CARGA".

- Análise

Para este teste a região fuzzy de saída (Figura 6.67) teve a contribuição apenas da regra ativada "CARGA", fazendo com que o sistema de inferência fuzzy classificasse corretamente a saída do sistema. 


\subsection{DESEMPENHO DO ALGORITMO DE ESTIMAÇÃO DE PARÂMETROS ELÉTRICOS}

Os testes mostrados a seguir verificam o desempenho da $P M U$ na estimação dos parâmetros elétricos da carga e da rede de distribuição. Para a comunicação entre o dispositivo mestre e o dispositivo escravo foi utilizado o software HERCULES (2013).

No caso dos testes envolvendo a estimação de parâmetros de cargas, os mesmos foram realizados em laboratório com a utilização de resistências variáveis e capacitores, como mostrado anteriormente na Figura 6.41. Para verificar o desempenho da $P M U$, os resultados obtidos em bancada foram comparados com os resultados teóricos obtidos com o auxílio do software MULTISIM, onde o mesmo circuito montado em bancada foi simulado.

Devido à dificuldade de se montar em bancada os parâmetros típicos de uma rede de distribuição foram simulados, por meio do software MULTISIM, dois conjuntos de cargas para os testes envolvendo a estimação destes parâmetros.

Assim, no firmware da Unidade de Medição Fasorial Otimizada, o indicador que mostra que a causa de distúrbio é a rede foi manualmente ativado e os valores relacionados à corrente e as potências ativa, reativa e aparente obtidos para a primeira carga foram inseridos para serem utilizados pelo algoritmo responsável pela estimação dos parâmetros, apresentado anteriormente na Seção 4.5. Em seguida foi a vez do indicador que mostra que a causa de distúrbio é a carga ser manualmente ativado e serem inseridos os valores relacionados à segunda carga, possibilitando assim a estimação dos parâmetros da rede pelo algoritmo.

\subsection{1 - Primeira estimação dos parâmetros da carga para o canal A}

\section{- Características gerais do teste}

- Características da rede: fonte de tensão de $127 \mathrm{~V}_{\mathrm{RMS}}$;

- Características iniciais da carga: resistor de $60 \Omega$ em paralelo com capacitor de $15 \mu \mathrm{F}$;

- Características finais da carga: resistor de $70 \Omega$ em paralelo com capacitor de $15 \mu \mathrm{F}$;

- Mensagem de requisição DNP3 (formato hexadecimal): 0564 0F C4 01000000 E2 C8 C0 C0 01 1E 000150065106 F8 D7;

- Endereço da requisição: 0x0650 a 0x0651;

- Dados da mensagem de resposta (formato ASCII, Figura 6.68): Resistência da carga: 58,929

$\Omega$, Reatância da carga: $-24,619 \Omega$. 


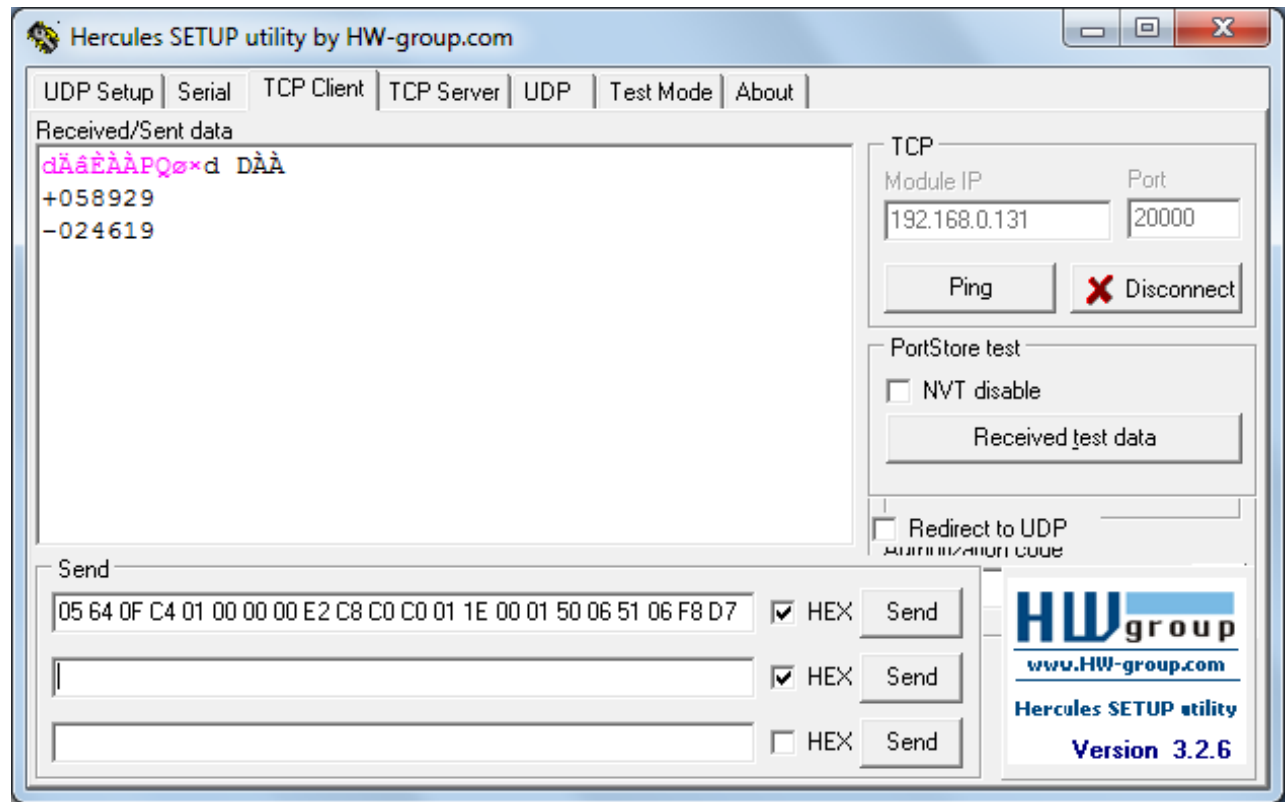

Figura 6.68 - Primeira leitura de parâmetros finais da carga no canal A.

\section{- Análise}

Na simulação apresentada na Figura 6.69, a impedância série equivalente da carga é obtida utilizando as Equações (3.37) e (3.38), apresentadas anteriormente no Capítulo 3:

$$
\begin{gathered}
-R_{C}=\frac{P}{\left(I_{R M S}\right)^{2}}=\frac{230,414}{(1,973)^{2}}=59,191 \Omega \\
\text { - } X_{C}=\frac{Q}{\left(I_{R M S}\right)^{2}}=\frac{-98,558}{(1,973)^{2}}=-25,319 \Omega
\end{gathered}
$$

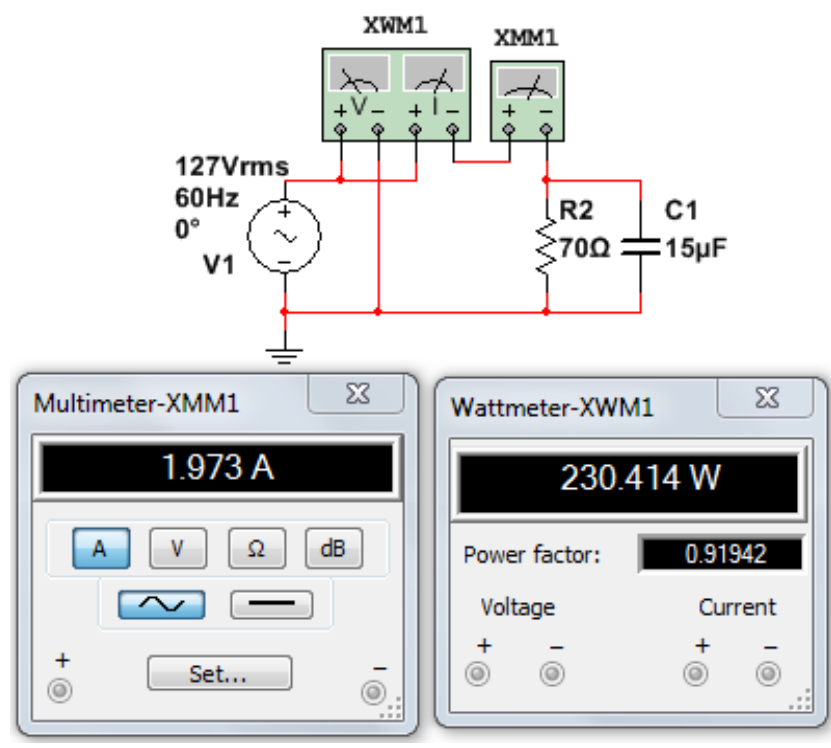

Figura 6.69 - Primeira simulação para obtenção dos parâmetros da carga no canal A. 
É possível verificar que os valores obtidos no teste em laboratório para a resistência e reatância que formam a carga ficaram muito próximos aos valores obtidos por simulação, ratificando assim o funcionamento esperado do equipamento quanto à estimação de parâmetros de cargas.

\subsection{2 - Segunda estimação de parâmetros da carga para o canal A}

\section{- Características gerais do teste}

- Características da rede: fonte de tensão de $127 \mathrm{~V}_{\mathrm{RMS}}$;

- Características iniciais da carga: resistor de $60 \Omega$ em paralelo com capacitor de $15 \mu \mathrm{F}$;

- Características finais da carga: resistor de $110,6 \Omega$ em paralelo com capacitor de $15 \mu \mathrm{F}$;

- Mensagem de requisição DNP3 (formato hexadecimal): 0564 0F C4 01000000 E2 C8 C0

C0 $011 \mathrm{E} 000150065106$ F8 D7;

- Endereço da requisição: 0x0650 a 0x0651;

- Dados da mensagem de resposta (formato ASCII, Figura 6.70):

Resistência da carga: $58,929 \Omega$, Reatância da carga: $-24,619 \Omega$;

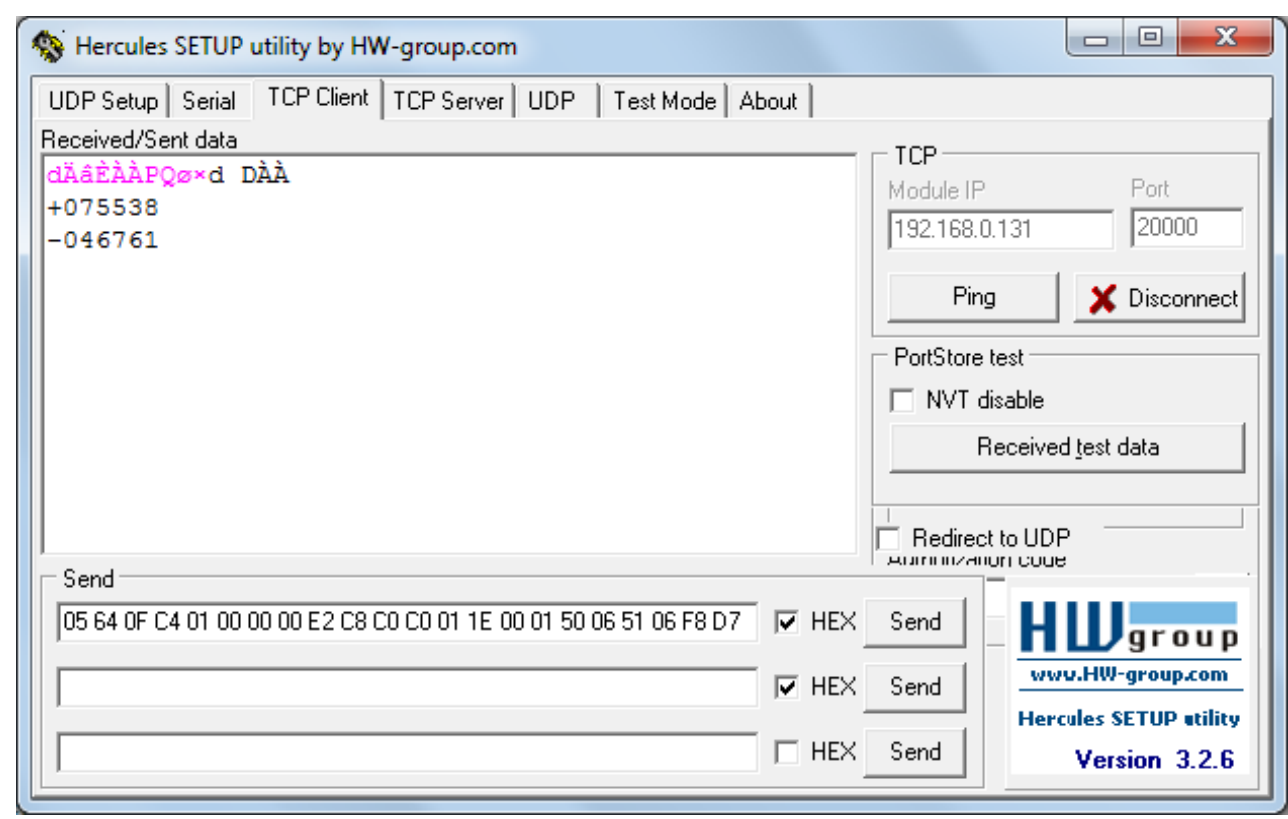

Figura 6.70 - Segunda leitura de parâmetros finais da carga no canal A.

- Análise

Na simulação apresentada na Figura 6.71, a impedância série equivalente da carga é obtida utilizando-se novamente as Equações (3.37) e (3.38). 


$$
\begin{aligned}
& -R_{C}=\frac{P}{\left(I_{R M S}\right)^{2}}=\frac{145,832}{(1,372)^{2}}=77,472 \Omega \\
& -X_{C}=\frac{Q}{\left(I_{R M S}\right)^{2}}=\frac{-95,481}{(1,372)^{2}}=-50,723 \Omega
\end{aligned}
$$

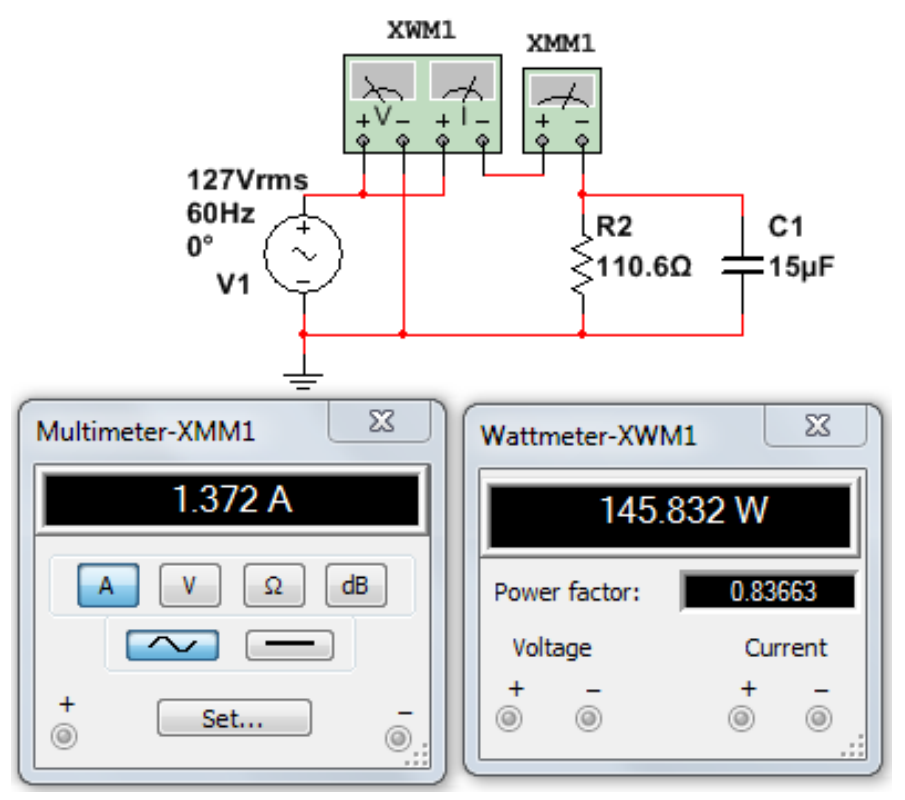

Figura 6.71 - Segunda simulação para obtenção dos parâmetros da carga no canal A.

Diferentemente do teste 6.5.1, os valores obtidos no teste em laboratório para a resistência e reatância que formam a carga não ficaram tão próximos aos valores obtidos por simulação. Isso ocorreu principalmente devido à baixa precisão do transformador de corrente para sinais com baixa amplitude.

\subsection{3 - Terceira estimação de parâmetros da carga para o canal A}

\section{- Características gerais do teste}

- Características da rede: fonte de tensão de $127 \mathrm{~V}_{\mathrm{RMS}}$;

- Características iniciais da carga: resistor de $70 \Omega$;

- Características finais da carga: resistor de 56,8 $\Omega$;

- Mensagem de requisição DNP3 (formato hexadecimal): 0564 0F C4 01000000 E2 C8 C0

C0 01 1E 000150065106 F8 D7;

- Endereço da requisição: 0x0650 a 0x0651;

- Dados da mensagem de resposta (formato ASCII, Figura 6.72):

Resistência da carga: 57,025 $\Omega$, Reatância da carga: $0 \Omega$; 


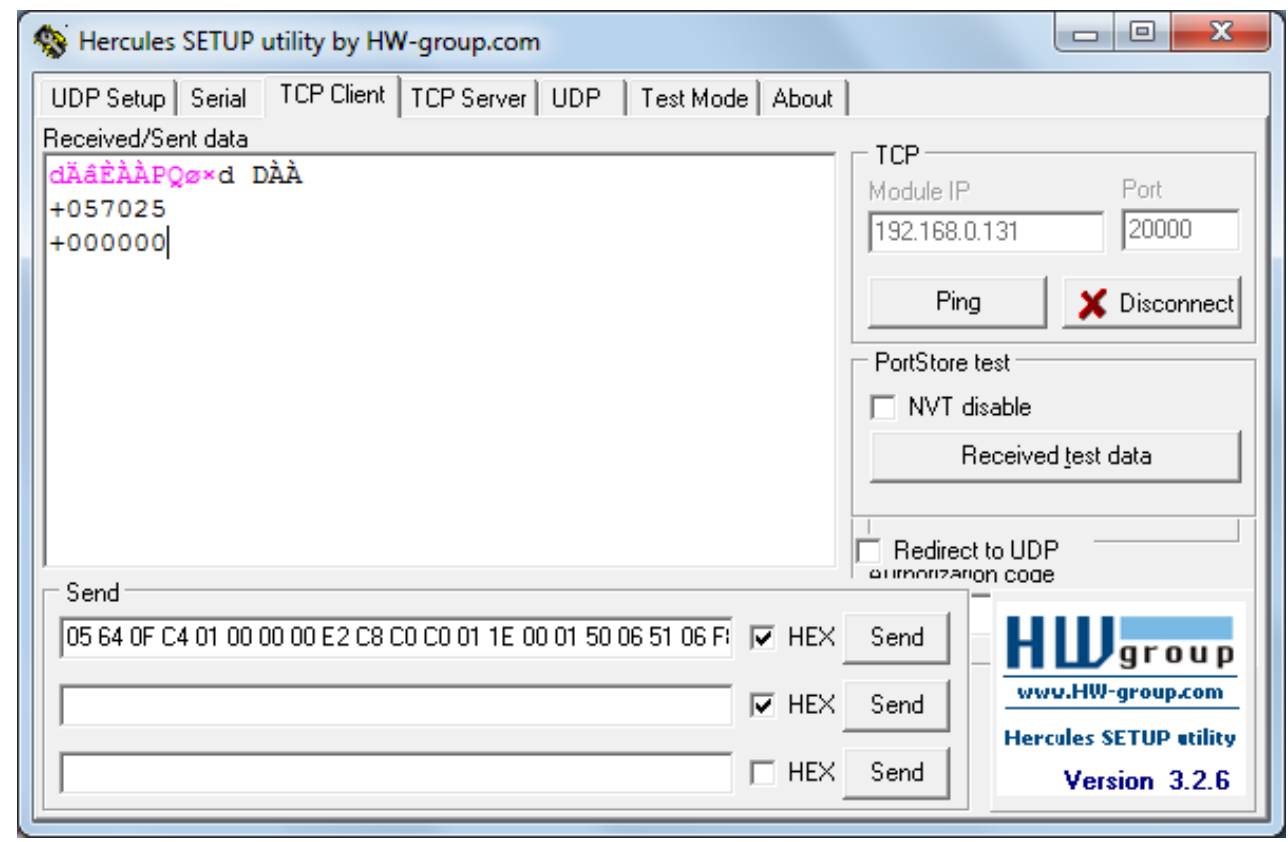

Figura 6.72 - Terceira leitura de parâmetros da carga no canal A.

- Análise

Na simulação apresentada na Figura 6.73, a impedância série equivalente da carga é calculada a seguir:

$$
\begin{aligned}
& -R_{C}=\frac{P}{\left(I_{R M S}\right)^{2}}=\frac{283,961}{(2,236)^{2}}=56,795 \Omega \\
& -X_{C}=\frac{Q}{\left(I_{R M S}\right)^{2}}=\frac{0}{(2,236)^{2}}=0 \Omega
\end{aligned}
$$

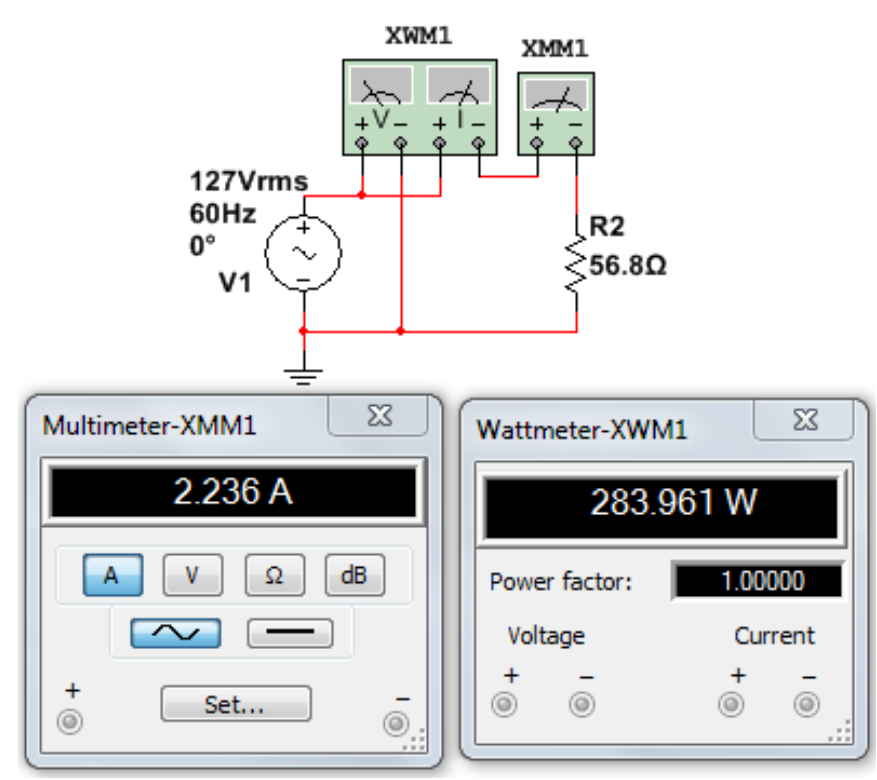

Figura 6.73 - Terceira simulação para obtenção dos parâmetros da carga no canal A. 
É possível verificar que os valores obtidos no teste em laboratório para a resistência e reatância que formam a carga ficaram bem próximos aos valores obtidos por simulação, ratificando novamente o funcionamento esperado do equipamento.

\subsection{4 - Quarta estimação de parâmetros da carga para o canal A}

\section{- Características gerais do teste}

- Características da rede: fonte de tensão de $127 \mathrm{~V}_{\mathrm{RMS}}$;

- Características iniciais da carga: resistor de $50 \Omega$ em série com capacitor de $45 \mu \mathrm{F}$;

- Características finais da carga: resistor de 35,6 $\Omega$ em série com capacitor de $45 \mu \mathrm{F}$;

- Mensagem de requisição DNP3 (formato hexadecimal): 0564 0F C4 01000000 E2 C8 C0

C0 01 1E 000150065106 F8 D7;

- Endereço da requisição: 0x0650 a 0x0651;

- Dados da mensagem de resposta (formato ASCII, Figura 6.74):

Resistência da carga: $35,809 \Omega$, Reatância da carga: $-56,073 \Omega$;

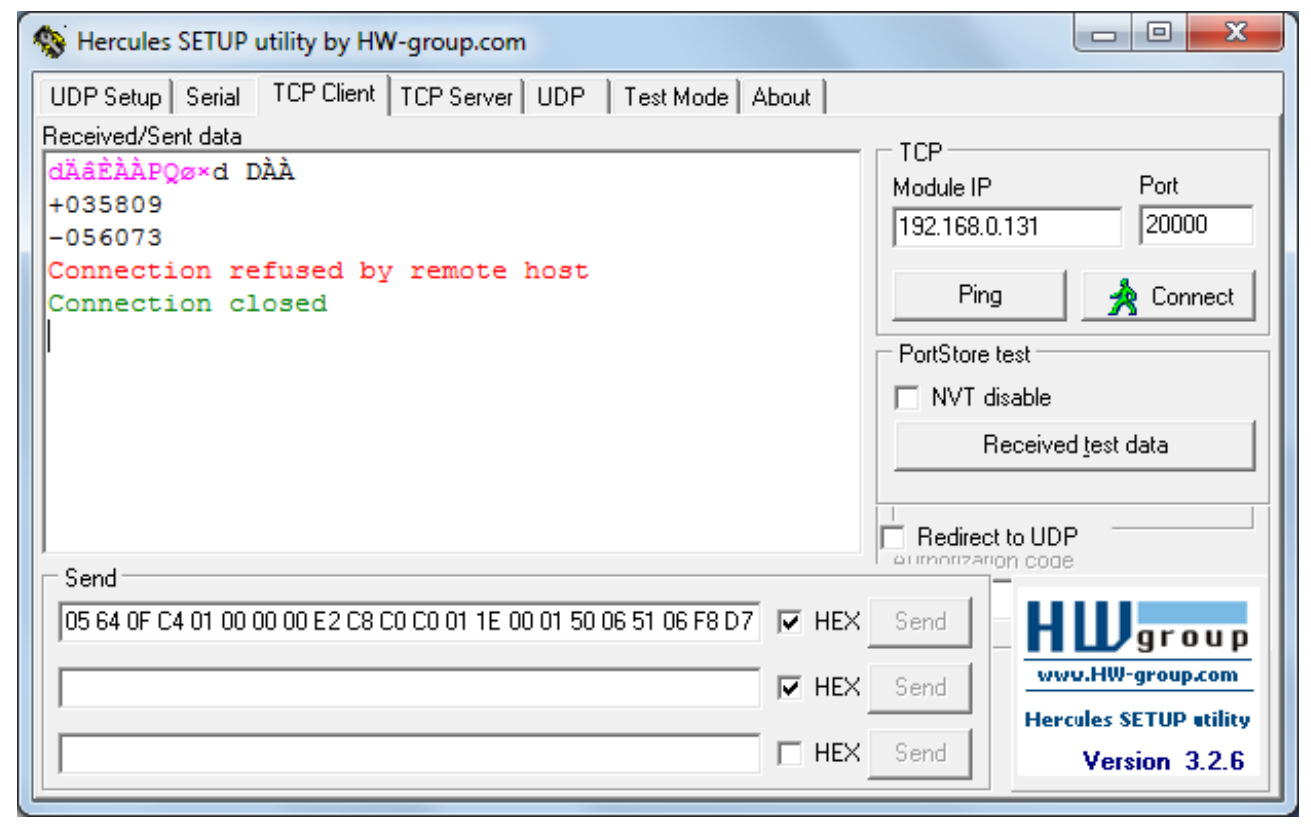

Figura 6.74 - Quarta leitura de parâmetros da carga no canal A.

- Análise

Na simulação apresentada na Figura 6.75, a impedância série equivalente da carga é obtida utilizando-se novamente as Equações (3.37) e (3.38): 


$$
\begin{gathered}
-R_{C}=\frac{P}{\left(I_{R M S}\right)^{2}}=\frac{123,401}{(1,862)^{2}}=35,593 \Omega \\
-X_{C}=\frac{Q}{\left(I_{R M S}\right)^{2}}=\frac{-201,695}{(1,862)^{2}}=-58,175 \Omega
\end{gathered}
$$

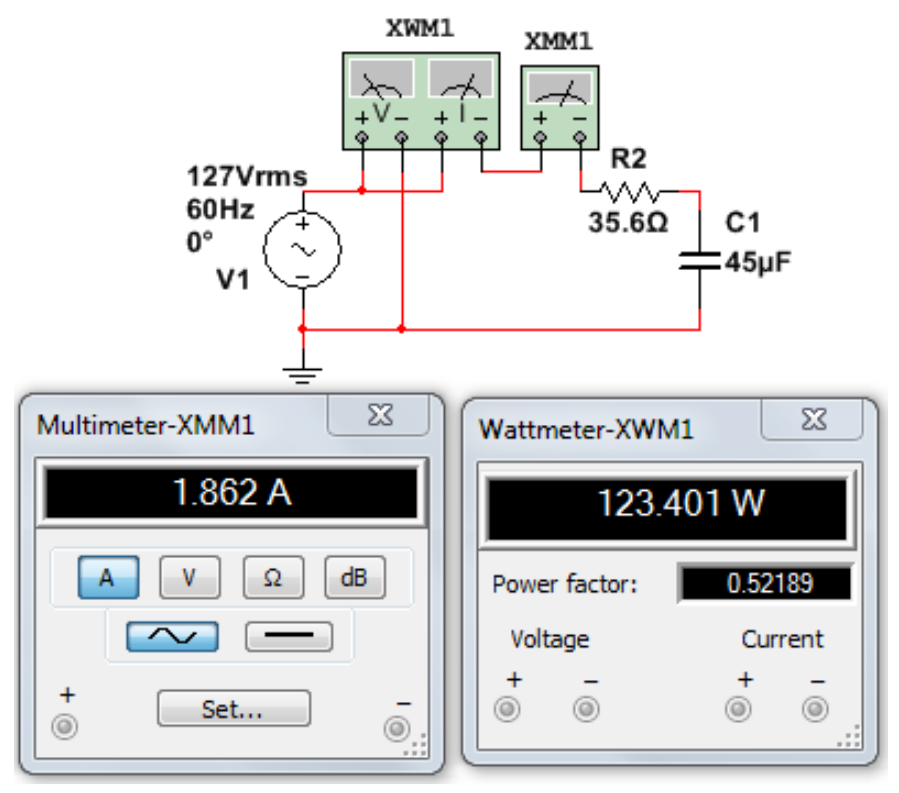

Figura 6.75 - Quarta simulação para obtenção dos parâmetros da carga no canal A.

É possível verificar que os valores obtidos no teste em laboratório para a resistência e reatância que formam a carga ficaram novamente bem próximos aos valores obtidos por simulação. Desta forma, o resultado deste teste juntamente com os resultados dos testes anteriores demonstra a boa precisão obtida pela Unidade de Medição Fasorial Otimizada quanto à estimação de parâmetros de cargas, independente da configuração de seus componentes resistivo e reativo.

\subsection{5 - Estimação dos parâmetros da rede para o canal A}

\section{- Características gerais do teste}

- Características finais da rede: fonte de tensão de $13800 \mathrm{~V}_{\mathrm{RMS}}$, resistor de 7,2 $\Omega$ em série com indutor de 175,65 $\mathrm{mH}$. A PMU está acoplada à rede por meio de um transformador com as seguintes quantidades de espiras: $n_{1}=1086$ e $n_{2}=10$;

- Características iniciais da carga: resistor de 1,6 $\Omega$ em série com indutor de $2 \mathrm{mH}$ (Fig 6.76);

- Parâmetros iniciais obtidos por simulação: I=71547 mA, S=9076 VA, P=8191 W, Q=3910 VAR, Fator de potência=0,90244; 


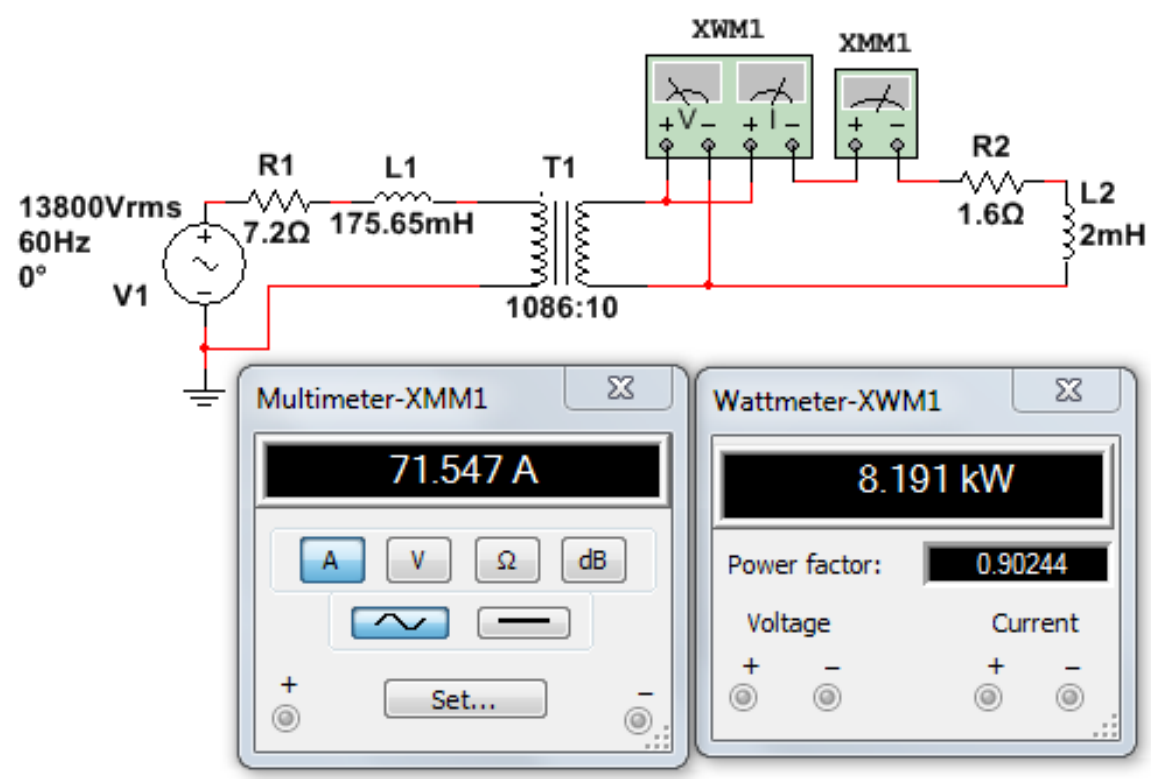

Figura 6.76 - Simulação para obtenção dos parâmetros iniciais da carga no canal A.

- Características finais da carga: resistor de 1,5 $\Omega$ em série com indutor de 1,875 $\mathrm{mH}$ (Figura $6.77)$;

- Parâmetros finais obtidos por simulação: $\mathrm{I}=76307$ mA, S=9680 VA, P=8736 W, Q=4170 VAR, Fator de potência=0,90244;

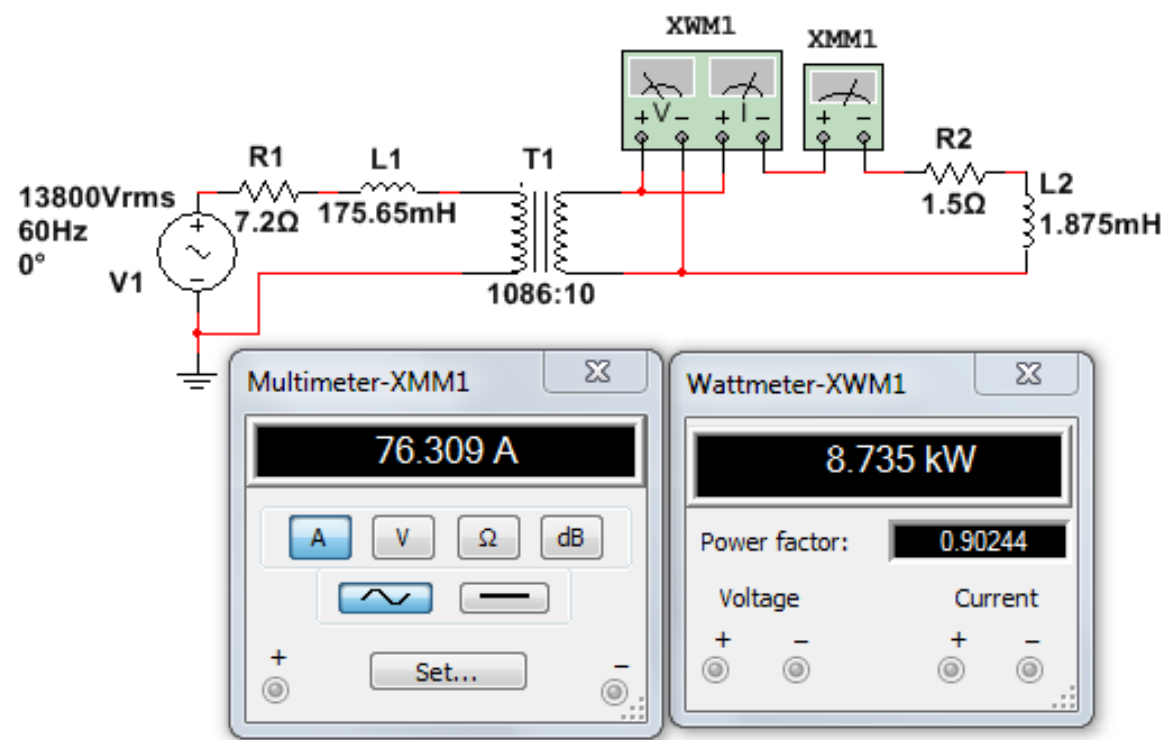

Figura 6.77 - Simulação para obtenção dos parâmetros finais da carga no canal A.

- Primeira mensagem de requisição DNP3 (formato hexadecimal): 0564 OF C4 01000000 E2 C8 C0 C0 $011 \mathrm{E} 000150065106 \mathrm{E} 27 \mathrm{~B}$;

- Endereço da requisição: 0x0650 a 0x0651;

- Dados da mensagem de resposta (formato ASCII, Figura 6.78):

Resistência final da carga: $1,5 \Omega$, Reatância da carga: $0,716 \Omega$; 
- Segunda mensagem de requisição DNP3 (formato hexadecimal): 0564 0F C4 01000000 E2 C8 C0 C0 01 1E 000152065406 E2 7B;

- Endereço da requisição: 0x0652 a 0x0654;

- Dados da mensagem de resposta (formato ASCII, Figura 6.78):

Resistência da rede: $23,587 \Omega$, Reatância da rede: $35,381 \Omega$, Tensão da rede: $13802 \mathrm{~V}$.

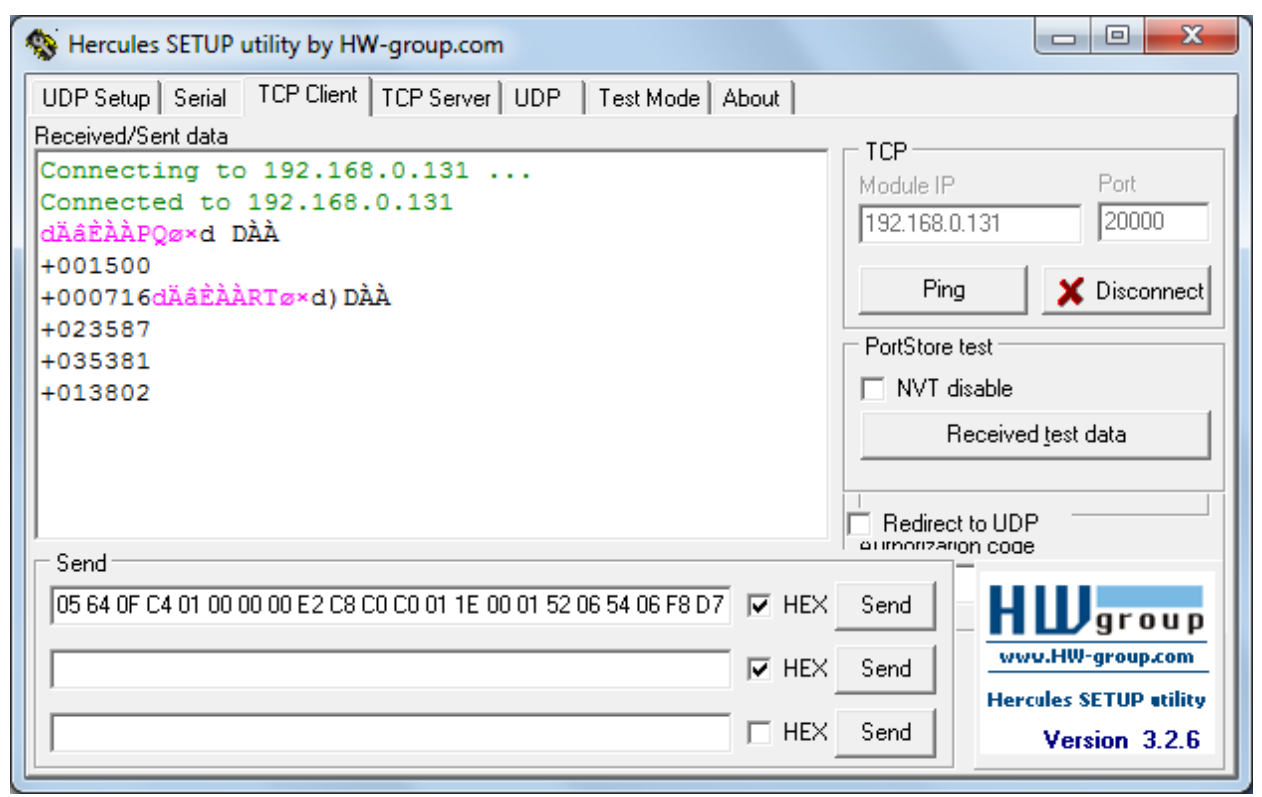

Figura 6.78 - Leitura dos parâmetros da carga e da rede no canal A.

- Análise

O valor da resistência da carga $\left(R_{C}\right)$ igual a $1,5 \Omega$, obtido pela Unidade de Medição Fasorial Otimizada, é igual ao do circuito simulado na Figura 6.77. O mesmo acontece para a reatância da carga $\left(X_{C}\right)$, cujo valor para o indutor de $1,875 \mathrm{mH}$ obtido por meio da Equação (3.36) é igual a $0,708 \Omega$.

$-X=2 * \pi * f * L=2 * \pi * 60 * 1,875 m H=0,708 \Omega$

Os valores obtidos pela Unidade de Medição Fasorial Otimizada para a fonte da rede $\left(V_{R}\right)$, a resistência da rede $\left(R_{R}\right)$ e para a reatância da rede $\left(X_{R}\right)$ e os valores do circuito na Figura 6.77 são mostrados na Tabela 6.20 .

Tabela 6.20 - Valores dos parâmetros da rede para canal A.

\begin{tabular}{|c|c|c|}
\hline Parâmetros & $\begin{array}{c}\text { Circuito da Figura } \\
\mathbf{6 . 7 6}\end{array}$ & $\begin{array}{c}\text { Enviados pela } \\
\text { PMU }\end{array}$ \\
\hline$V_{R}(\mathrm{~V})$ & 13800 & 13802 \\
\hline$R_{R}(\Omega)$ & 7,200 & 23,587 \\
\hline$X_{R}(\Omega)$ & 66,218 & 35,381 \\
\hline
\end{tabular}


A proximidade entre os valores da impedância da rede obtidos pela Unidade de Medição Fasorial Otimizada e os valores obtidos por meio do circuito simulado na Figura 6.77 é ratificado quando se compara também o módulo da impedância da rede.

Desta forma, o valor do módulo da impedância da rede, considerando o circuito da Figura 6.77, pode ser obtido por meio da Equação (6.4).

$$
\text { - } Z_{R}=\sqrt{{R_{R}{ }^{2}+X_{R}^{2}}^{2}}=\sqrt{(7,2)^{2}+(66,218)^{2}}=66,609 \Omega
$$

Utilizando novamente a Equação (6.4), o valor do módulo da impedância da rede considerando os valores da resistência e da reatância calculados pela Unidade de Medição Fasorial Otimizada é igual a $42,522 \Omega$, como mostrado abaixo, sendo próximo ao valor $\left(Z_{R}=\right.$ $66,609 \Omega$ ) simulado no circuito da Figura 6.77.

$$
\text { - } Z_{R}=\sqrt{{R_{R}{ }^{2}+X_{R}^{2}}^{2}}=\sqrt{(23,587)^{2}+(35,381)^{2}}=42,522 \Omega
$$

\subsection{6 - Estimação dos parâmetros da rede para o canal B}

\section{- Características gerais do teste}

- Características finais da rede: fonte de tensão de $13800 \mathrm{~V}_{\mathrm{RMS}}$, resistor de 7,2 $\Omega$ em série com indutor de 175,65 $\mathrm{mH}$. A $P M U$ está acoplada à rede por meio de um transformador com as seguintes quantidades de espiras: $n_{1}=1086$ e $n_{2}=10$;

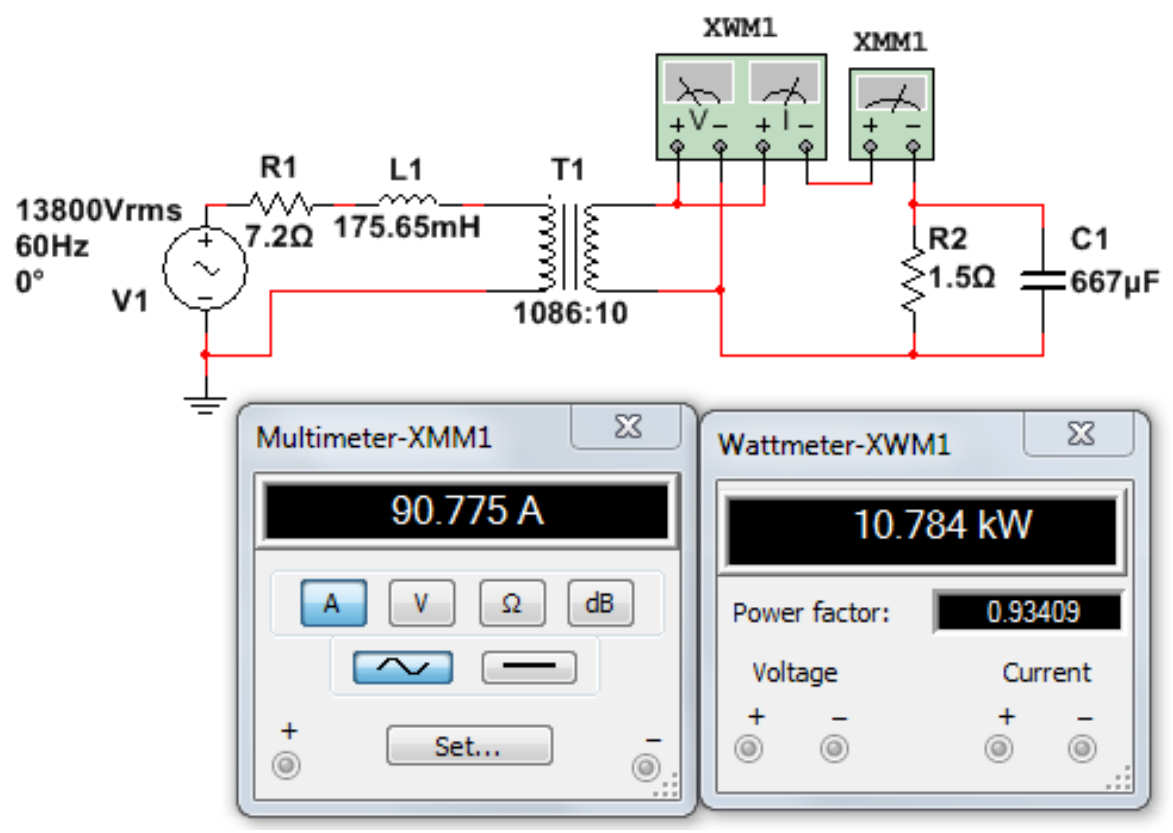

Figura 6.79 - Simulação para obtenção dos parâmetros iniciais da carga no canal B. 
- Características iniciais da carga: resistor de 1,5 $\Omega$ em paralelo com capacitor de $667 \mu \mathrm{F}$ (Figura 6.79);

- Parâmetros iniciais obtidos por simulação: I=90776 mA, S=11548 VA, P=10787 W, Q=4122 VAR, Fator de potência=0,93409;

- Características finais da carga: resistor de 1,6 $\Omega$ em paralelo com capacitor de $625 \mu \mathrm{F}$ (Figura 6.80);

- Parâmetros finais obtidos por simulação: I=85092 mA, S=10823 VA, P=10110 W, Q=-3862 VAR, Fator de potência=0,93417;

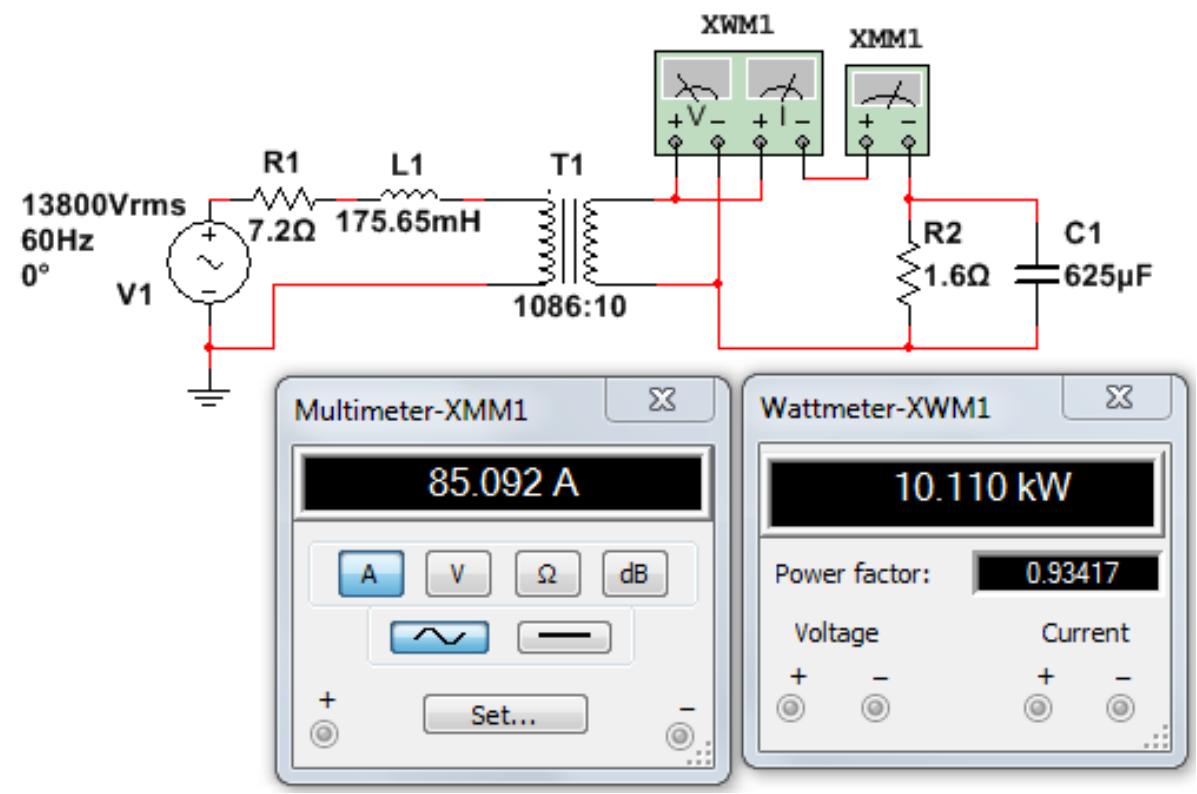

Figura 6.80 - Simulação para obtenção dos parâmetros finais da carga no canal B.

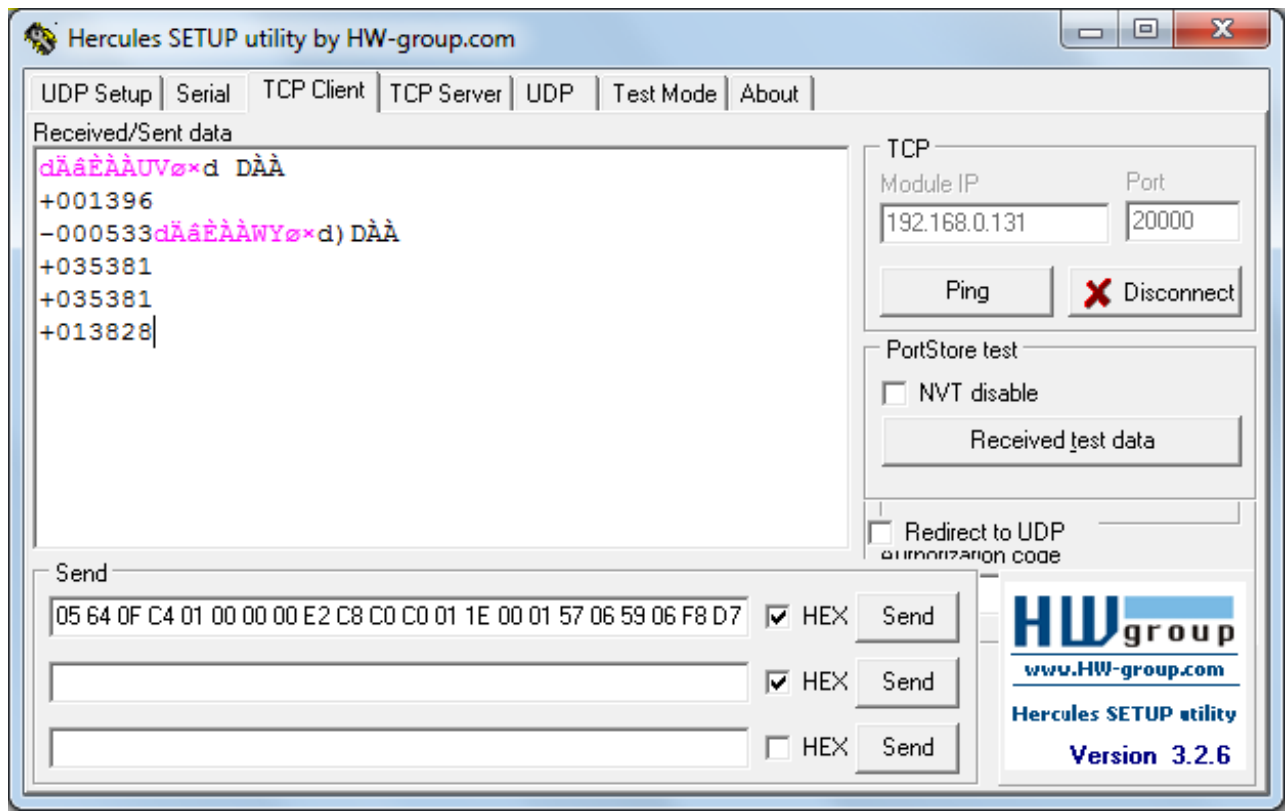

Figura 6.81 - Leitura dos parâmetros da carga e da rede no canal B. 
- Primeira mensagem de requisição DNP3 (formato hexadecimal): 0564 OF C4 01000000

E2 C8 C0 C0 $011 \mathrm{E} 000155065606 \mathrm{E} 27 \mathrm{~B}$;

- Endereço da requisição: 0x0655 a 0x0656;

- Dados da mensagem de resposta (formato ASCII, Figura 6.81):

Resistência final da carga: $1,396 \Omega$, Reatância da carga: $-0,533 \Omega$;

- Segunda mensagem de requisição DNP3 (formato hexadecimal): 0564 OF C4 01000000

E2 C8 C0 C0 01 1E 000157065906 E2 7B;

- Endereço da requisição: 0x0657 a 0x0659;

- Dados da mensagem de resposta (formato ASCII, Figura 6.81):

Resistência da rede: $35,381 \Omega$, Reatância da rede: $35,381 \Omega$, Tensão da rede: $13828 \mathrm{~V}$.

- Análise

Os parâmetros da impedância série da carga, equivalente à associação paralela entre a resistência de $1,6 \Omega$ e a capacitância de $625 \mu \mathrm{F}$ presentes na Figura 6.80, podem ser obtidos utilizando as Equações 3.37 e 3.38 abaixo e são iguais aos valores obtidos pela Unidade de Medição Fasorial Otimizada, mostrados na Figura 6.81:

$$
\begin{gathered}
-R_{C}=\frac{P}{\left(I_{R M S}\right)^{2}}=\frac{10112}{(85,094)^{2}}=1,396 \Omega \\
-X_{C}=\frac{Q}{\left(I_{R M S}\right)^{2}}=\frac{-3862}{(85,094)^{2}}=-0,553 \Omega
\end{gathered}
$$

Os valores obtidos pela Unidade de Medição Fasorial Otimizada para a fonte da rede $\left(V_{R}\right)$, a resistência da rede $\left(R_{R}\right)$ e para a reatância da rede $\left(X_{R}\right)$ e os valores do circuito na Figura 6.80 são mostrados na Tabela 6.21.

Tabela 6.21 - Valores dos parâmetros da rede para o canal B.

\begin{tabular}{|c|c|c|}
\hline Parâmetros & $\begin{array}{c}\text { Circuito da Figura } \\
\mathbf{6 . 7 6}\end{array}$ & $\begin{array}{c}\text { Enviados pela } \\
\text { PMU }\end{array}$ \\
\hline$V_{R}(\mathrm{~V})$ & 13800 & 13828 \\
\hline$R_{R}(\Omega)$ & 7,200 & 35,381 \\
\hline$X_{R}(\Omega)$ & 66,218 & 35,381 \\
\hline
\end{tabular}

Os valores obtidos pela Unidade de Medição Fasorial Otimizada estão na mesma ordem de grandeza dos valores destes mesmos parâmetros presentes no circuito simulado na Figura 6.80. Utilizando novamente a Equação (6.4), o valor do módulo da impedância da rede considerando os valores da resistência e da reatância calculados pela Unidade de Medição 
Fasorial Otimizada é igual a 50,036 $\Omega$, como mostrado abaixo, sendo próximo ao valor $\left(Z_{R}=\right.$ $66,609 \Omega$ ) simulado no circuito da Figura 6.80.

$$
\text { - } Z_{R}=\sqrt{{R_{R}{ }^{2}+X_{R}^{2}}^{2}}=\sqrt{(35,381)^{2}+(35,381)^{2}}=50,036 \Omega
$$

\subsection{7 - Estimação dos parâmetros da rede para o canal C}

\section{- Características gerais do teste}

- Características finais da rede: fonte de tensão de $13800 \mathrm{~V}_{\mathrm{RMS}}$, resistor de 7,2 $\Omega$ em série com indutor de 175,65 $\mathrm{mH}$. A PMU está acoplada à rede por meio de um transformador com as seguintes quantidades de espiras: $n_{1}=1086$ e $n_{2}=10$;

- Características iniciais da carga: resistor de 1,5 $\Omega$ em paralelo com capacitor de $667 \mu \mathrm{F}$ (Figura 6.79);

- Parâmetros iniciais obtidos por simulação: I=90776 mA, S=11548 VA, P=10787 W, Q=4122 VAR, Fator de potência=0,93409;

- Características finais da carga: resistor de 1,6 $\Omega$ em paralelo com capacitor de $618 \mu \mathrm{F}$ (Figura 6.82);

- Parâmetros finais obtidos por simulação: I=84970 mA, S=10809 VA, P=10112 W, Q=-3818 VAR, Fator de potência=0,93552;

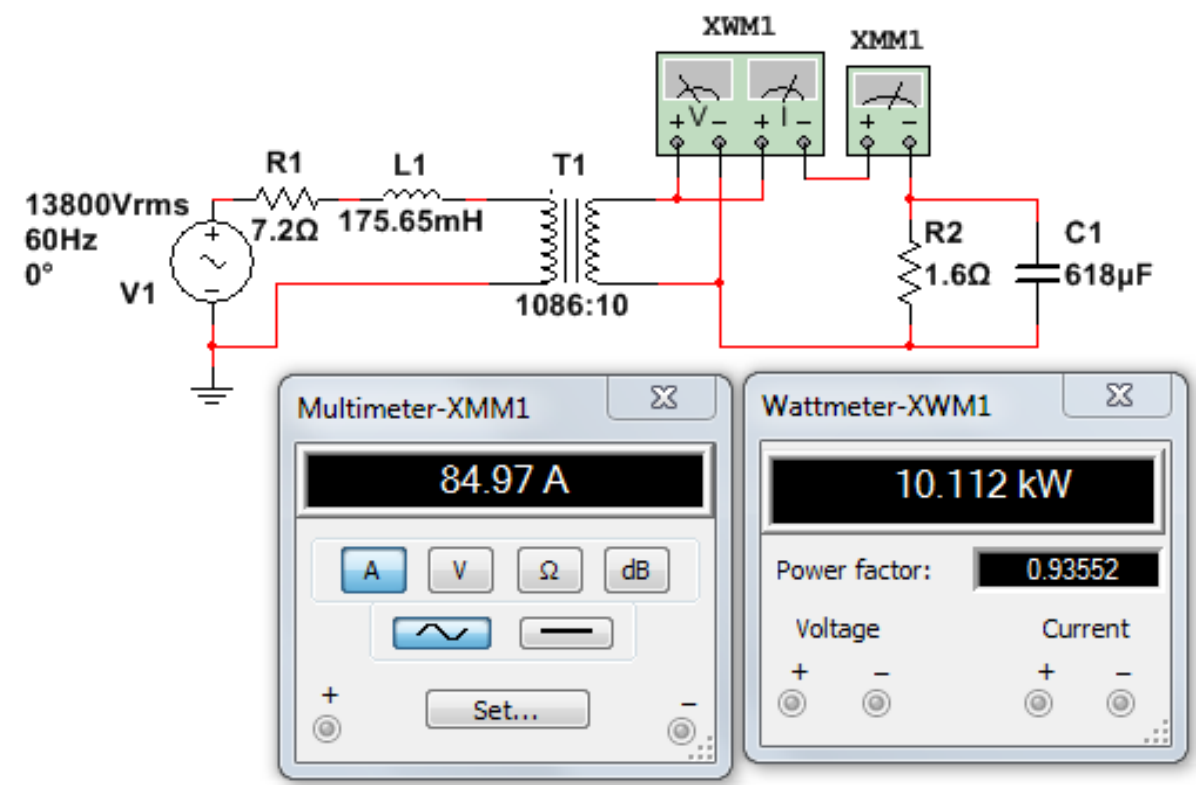

Figura 6.82 - Simulação para obtenção dos parâmetros finais da carga no canal C. 
- Primeira mensagem de requisição DNP3 (formato hexadecimal): 0564 OF C4 01000000

E2 C8 C0 C0 01 1E 0001 5A 06 5B 06 E2 7B;

- Endereço da requisição: 0x065A a 0x065B;

- Dados da mensagem de resposta (formato ASCII, Figura 6.83):

Resistência final da carga: $1400 \mathrm{~m} \Omega$, Reatância da carga: $-528 \mathrm{~m} \Omega$;

- Segunda mensagem de requisição DNP3 (formato hexadecimal): 0564 0F C4 01000000

E2 C8 C0 C0 01 1E 0001 5C 06 5E 06 E2 7B;

- Endereço da requisição: 0x065C a 0x065E;

- Dados da mensagem de resposta (formato ASCII, Figura 6.83):

Resistência da rede: $353818 \mathrm{~m} \Omega$, Reatância da rede: $955310 \mathrm{~m} \Omega$, Tensão da rede: $13832 \mathrm{~V}$.

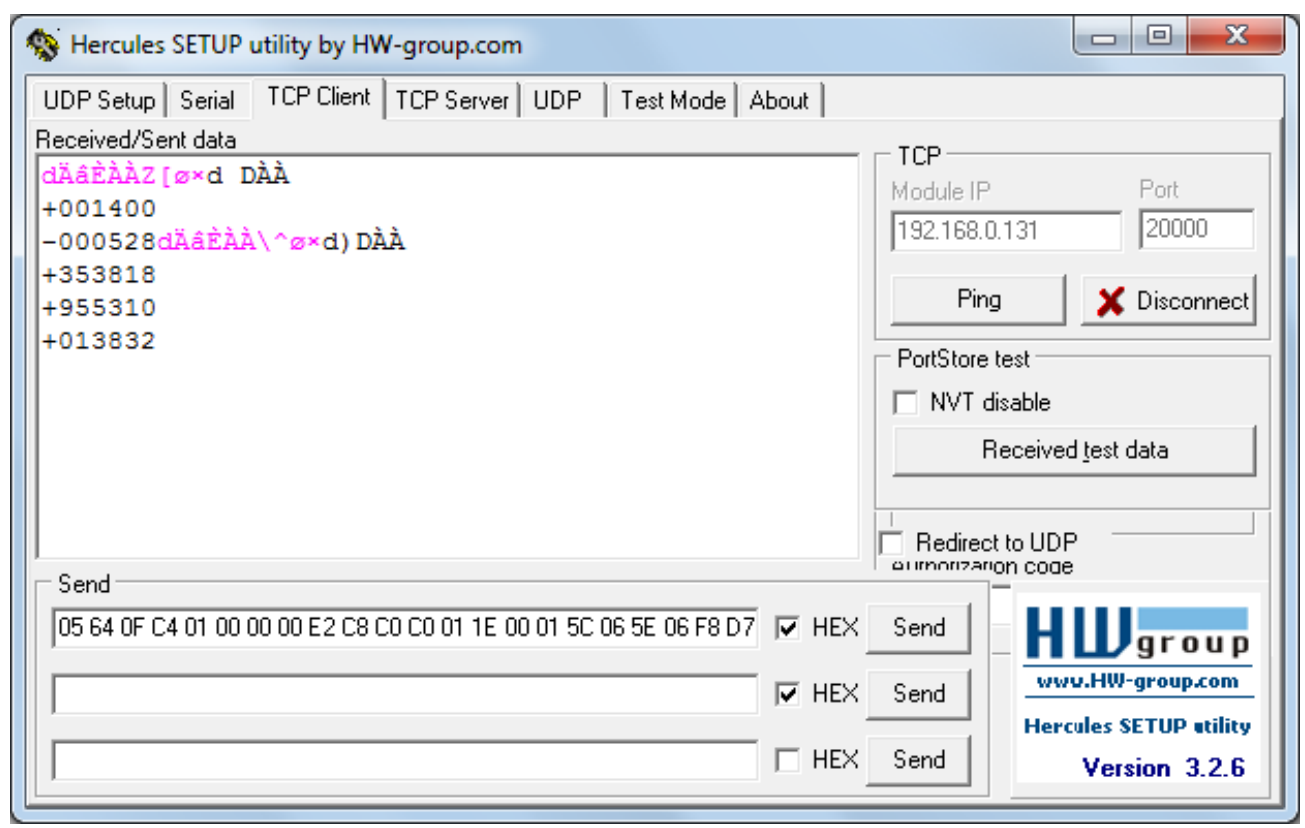

Figura 6.83 - Leitura dos parâmetros da carga e da rede no canal C

- Análise

Os parâmetros da impedância série da carga, equivalente à associação paralela entre a resistência de 1,6 $\Omega$ e a capacitância de $618 \mu \mathrm{F}$ presentes na Figura 6.82, são obtidos utilizando novamente as Equações 3.37 e 3.38 abaixo e são iguais aos valores obtidos pela Unidade de Medição Fasorial Otimizada, mostrados na Figura 6.83.

$$
\begin{gathered}
-R_{C}=\frac{P}{\left(I_{R M S}\right)^{2}}=\frac{10112}{(84,970)^{2}}=1,400 \Omega \\
-X_{C}=\frac{Q}{\left(I_{R M S}\right)^{2}}=\frac{-3818}{(84,970)^{2}}=-0,528 \Omega
\end{gathered}
$$


As características iniciais da carga são iguais ao do Teste 6.5.6. Os valores obtidos pela Unidade de Medição Fasorial Otimizada para a fonte da rede $\left(V_{R}\right)$, a resistência da rede $\left(R_{R}\right)$ e para a reatância da rede $\left(X_{R}\right)$ e os valores do circuito na Figura 6.82 são mostrados na Tabela 6.22 .

Tabela 6.22 - Valores dos parâmetros da rede para o canal C.

\begin{tabular}{|c|c|c|}
\hline Parâmetros & $\begin{array}{c}\text { Circuito da Figura } \\
\mathbf{6 . 7 6}\end{array}$ & $\begin{array}{c}\text { Enviados pela } \\
\text { PMU }\end{array}$ \\
\hline$V_{R}(\mathrm{~V})$ & 13800 & 13832 \\
\hline$R_{R}(\Omega)$ & 7,200 & 353,818 \\
\hline$X_{R}(\Omega)$ & 66,218 & 955,310 \\
\hline
\end{tabular}

Os valores obtidos pelo equipamento proposto para a resistência da rede $\left(R_{R}\right)$ e para a reatância da rede $\left(X_{R}\right)$ não estão na mesma ordem de grandeza dos valores destes mesmos parâmetros presentes no circuito simulado na Figura 6.82. Isso ocorre devido à diferença no valor dos fatores de potência entre as cargas inicial e final, condição essa que deve ser contemplada para o bom funcionamento do algoritmo responsável pela estimação dos parâmetros elétricos da carga e da rede e que foi citado anteriormente na Seção 4.5. 


\section{Capítulo 7}

\section{EstimaÇÃo Remota de PARÂMetros E Modelagem de CARgaS}

Com a utilização da informação da causa do distúrbio e dos últimos valores para a tensão e corrente RMS, potência ativa e potência reativa, juntamente com a técnica apresentada na Seção 7.1 neste capítulo, os parâmetros elétricos da carga e da rede podem ser estimados com boa precisão remotamente em um servidor, já que é necessário um poder computacional superior ao apresentado pelo microcontrolador presente na Unidade de Medição Fasorial Otimizada. Aproveitando-se também do maior poder computacional presente em um servidor, as cargas também podem ser modeladas matematicamente, como comentado na Seção 7.2.

\subsection{ESTIMAÇÃO REMOTA EM UM SERVIDOR DOS PARÂMETROS ELÉTRICOS DA CARGA E DA REDE}

É possível estimar os parâmetros da rede e da carga baseando-se no circuito da Figura 4.9, onde são obtidas as Equações (7.1) e (7.2).

$$
\begin{gathered}
V_{R^{\prime}}-V_{C}=I\left(R_{R^{\prime}}+j X_{R^{\prime}}\right) \\
I=\frac{P_{C}+j Q_{C}}{V_{C}}
\end{gathered}
$$

Substituindo o parâmetro "I" da Equação (7.2) na Equação (7.1) e separando os termos real e imaginário, são obtidas as Equações (7.3) e (7.4).

$$
\begin{gathered}
V_{C} V_{R R^{\prime}}-P_{C} R_{R^{\prime}}+Q_{C} X_{R^{\prime}}=V_{C}^{2} \\
V_{C} V_{R I^{\prime}}-P_{C} X_{R^{\prime}}-Q_{C} R_{R^{\prime}}=0
\end{gathered}
$$

Utilizando as Equações (7.3) e (7.4) e considerando $N$ medidas temporais da tensão RMS $\left(V_{C}\right)$, potência ativa $\left(P_{C}\right)$ e potência reativa $\left(Q_{C}\right)$ oriundas da ocorrência de distúrbios 
devido a mudanças na carga, um sistema de equações lineares (7.5) é obtido, onde os parâmetros elétricos $V_{R R}, V_{R I}, R_{R}$, e $X_{R}$, podem ser estimados. Os erros relacionados a essas estimações podem ser minimizados com a utilização de uma grande variedade de medidas e adoção de alguma técnica de otimização matemática.

$$
\left(\begin{array}{cccc}
V_{C}(1) & 0 & -P_{C}(1) & Q_{C}(1) \\
V_{C}(2) & 0 & -P_{C}(2) & Q_{C}(2) \\
\vdots & \vdots & \vdots & \vdots \\
V_{C}(N) & 0 & -P_{C}(N) & Q_{C}(N) \\
0 & V_{C}(1) & -Q_{C}(1) & -P_{C}(1) \\
0 & V_{C}(2) & -Q_{C}(2) & -P_{C}(2) \\
\vdots & \vdots & \vdots & \vdots \\
0 & V_{C}(N) & -Q_{C}(N) & -P_{C}(N)
\end{array}\right) \cdot\left(\begin{array}{l}
V_{R R^{\prime}} \\
V_{R I^{\prime}} \\
R_{R^{\prime}} \\
X_{R^{\prime}}
\end{array}\right)=\left(\begin{array}{l}
V_{C}{ }^{2}(1) \\
V_{C}{ }^{2}(2) \\
\cdot \\
\cdot \\
V_{C}{ }^{2}(N) \\
0 \\
0 \\
\cdot \\
0
\end{array}\right)
$$

O módulo da tensão $V_{R^{\prime}}$ pode ser obtida por meio da Equação (7.6).

$$
V_{R^{\prime}}=\sqrt{V_{R R^{\prime}}{ }^{2}+V_{R I^{\prime}}{ }^{2}}
$$

Como citado anteriormente, os parâmetros elétricos da rede estão refletidos nos lado secundário do transformador. Utilizando as Equações (3.29), (3.34) e (3.35), citadas anteriormente no Capítulo 3, estes parâmetros podem ser refletidos para o lado primário do transformador, como mostrado a seguir:

$$
\begin{aligned}
& -V_{R}=\frac{n 1}{n 2} V_{R^{\prime}} \\
& \text { - } R_{R}=\left(\frac{n 1}{n 2}\right)^{2} R_{R^{\prime}} \\
& \text { - } X_{R}=\left(\frac{n 1}{n 2}\right)^{2} X_{R^{\prime}}
\end{aligned}
$$

Já as Equações (3.37) e (3.38), mostradas no Capítulo 3, podem estimar os parâmetros da carga. 


$$
\begin{aligned}
& -R_{C}=\frac{P_{C}}{\left(I_{R M S}\right)^{2}} \\
& -X_{C}=\frac{Q_{C}}{\left(I_{R M S}\right)^{2}}
\end{aligned}
$$

Como exemplo, na Tabela 7.1 são apresentadas algumas medições da tensão RMS, potência ativa e potência reativa pertencentes a uma base de dados de campo de um transformador de distribuição. As variações entre as medições ocorreram devido a mudanças na carga.

Tabela 7.1 - Medições provenientes de um transformador de distribuição.

\begin{tabular}{|c|c|c|c|c|c|}
\hline INTERAÇÃO & DATA & HORA & V $_{\text {RMS }}(\mathbf{V})$ & $\mathbf{P}(\mathbf{W})$ & $\mathbf{Q}($ var) \\
\hline 1 & $20 / 07 / 2011$ & $10: 30: 00$ & 128,18 & 6412 & $-2472,70$ \\
\hline 2 & $20 / 07 / 2011$ & $10: 40: 00$ & 128,10 & 6500 & $-2105,50$ \\
\hline 3 & $20 / 07 / 2011$ & $10: 50: 00$ & 128,53 & 6027 & -2449 \\
\hline 4 & $20 / 07 / 2011$ & $11: 00: 00$ & 128,90 & 5717 & $-2597,90$ \\
\hline
\end{tabular}

Estas medições foram utilizadas no Sistema de equações (7.5) e na Equação (7.6) com o auxílio do software $M A T L A B$ (2011), com o qual possível levantar os parâmetros $V_{R}=132,34$ $\mathrm{V}, R_{R}=0,00389 \Omega$ e $X_{R}=0,00957 \Omega$. Se for considerada uma relação $\left(\mathrm{n}_{1} / \mathrm{n}_{2}\right)=108,9$ e utilizando as Equações (3.29), (3.34) e (3.35), são obtidos os parâmetros $V_{R}=14147,15 \mathrm{~V}$, $R_{R}=44,45 \Omega$ e $X_{R}=109,36 \Omega$.

É importante ressaltar que os valores para os parâmetros elétricos da rede calculados por este método e também pelo método descrito na Seção 4.5 levam em conta o "ponto de vista" de apenas uma PMU, estando estes valores relacionados à corrente consumida pela carga conectada a esta PMU. Porém, mesmo não sendo consideradas outras cargas conectadas a outros pontos da rede, a ordem de grandeza dos valores estimados para os parâmetros já permite verificar se há grandes perdas (impedâncias altas) na rede ou se houve a inclusão de um sistema de geração distribuída próximo a PMU (impedâncias próximas a zero).

\subsection{MODELAGEM MATEMÁTICA DA CARGA EM UM SERVIDOR REMOTO}

O termo "carga" assume diferentes significados, dependendo do contexto em que for usado, sendo as principais definições (IEEE, 1993): 
- Um equipamento conectado ao sistema de potência que consome energia;

- A energia total consumida por todos os equipamentos conectados ao sistema de potência;

- Uma porção do sistema, que não é representada detalhadamente, mas é tratada como se fosse um único elemento consumidor de potência, conectado a um barramento.

Em especial, a última definição estabelece que, uma vez escolhido um barramento de carga, tudo que estiver conectado a jusante deste barramento está agregado num equivalente, classificado como carga e esta é medida em termos da potência consumida por este equivalente. A tensão elétrica medida no barramento de carga é definida como a variável de perturbação do fenômeno, ou a variável de entrada do modelo (VISCONTI, 2010).

Através dos valores disponibilizados pela Unidade de Medição Fasorial Otimizada da tensão RMS, potência ativa e potência reativa, armazenados antes e depois da ocorrência de distúrbios elétricos, o servidor remoto pode adotar um dos modelos estáticos apresentados a seguir para as cargas conectadas em cada uma das fases. Quando ocorrem variações pequenas ou lentas de tensão e/ou frequência, o sistema retorna ao regime permanente rapidamente, e nestes casos é possível modelar a carga por modelos estáticos sem perda de generalidade (IEEE, 1993).

\subsubsection{Modelo Impedância Constante (Z)}

O modelo impedância constante expressa a variação da potência proporcionalmente ao quadrado de desvios da tensão de seu ponto de operação pré-distúrbio, como mostram as Equações (7.7) e (7.8) (VISCONTI, 2010).

$$
\begin{aligned}
& P_{C}=P_{0 C}\left(\frac{V_{C}}{V_{0 C}}\right)^{2} \\
& Q_{C}=Q_{0 C}\left(\frac{V_{C}}{V_{0 C}}\right)^{2}
\end{aligned}
$$

onde $P_{C}, Q_{C}$ e $V_{C}$ são as leituras da potência ativa, potência reativa e tensão RMS na carga após a ocorrência dos distúrbios elétricos. $P_{C O}, Q_{C O}$ e $V_{C O}$ são as leituras da potência ativa, potência reativa e tensão RMS antes da ocorrência dos distúrbios elétricos. 
Para que o modelo Impedância Constante possa ser levantado por um servido remoto, é necessário que sejam utilizadas as grandezas elétricas $\left(V_{C}, P_{C}\right.$ e $\left.Q_{C}\right)$ ocorridas após a identificação "rede" como causa dos distúrbios elétricos, já que isto indica que não houve modificações nos parâmetros da impedância da carga.

De acordo com (IEEE, 1993), esta é considerada uma prática simplificada demais.

\subsubsection{Modelo Corrente Constante (I)}

O modelo corrente constante expressa variações na potência proporcionais aos desvios de tensão quando da ocorrência de distúrbios causados por modificações na carga, como mostram as Equações (7.9) e (7.10) (VISCONTI, 2010).

$$
\begin{gathered}
P_{C}=P_{0 C}\left(\frac{V_{C}}{V_{0 C}}\right) \\
Q_{C}=Q_{0 C}\left(\frac{V_{C}}{V_{0 C}}\right)
\end{gathered}
$$

\subsubsection{Modelo Potência Constante (P)}

O modelo potência constante expressa variações na potência independente de variações de tensão quando da ocorrência de distúrbios causados por modificações na carga, como mostram as Equações (7.11) e (7.12) (VISCONTI, 2010).

$$
\begin{gathered}
P_{C}=P_{0 C} \\
Q_{C}=Q_{0 C}
\end{gathered}
$$

\subsubsection{Modelo Polinomial (ZIP)}

O modelo mais conhecido para caracterizar o comportamento estático de cargas, largamente empregado em estudos de fluxo de potência e de estabilidade de tensão, é o modelo ZIP, apresentado nas Equações (7.13) e (7.14) (VISCONTI, 2010). 
O significado físico deste modelo associa o comportamento da potência que flui para a carga como uma composição de três parcelas: uma parcela da carga representada por um modelo de impedância constante (a parcela $\alpha *$ da potência, proporcional ao quadrado da tensão), uma parcela do modelo de corrente constante (a parcela $\beta *$ da potência, diretamente proporcional à tensão) e uma parcela de potência constante (a parcela $\gamma_{*}$ da potência, que não varia com a tensão).

Assim, as Equações (7.13) e (7.14) representam a potências ativa e reativa em função de desvios da tensão de seus valores iniciais de operação, estabelecendo uma relação não linear entre essas grandezas.

$$
\begin{aligned}
& P_{C}=P_{0 C}\left[\alpha_{Z p}\left(\frac{V_{C}}{V_{0 C}}\right)^{2}+\beta_{I p}\left(\frac{V_{C}}{V_{0 C}}\right)+\gamma_{P p}\right] \\
& Q_{C}=Q_{0 C}\left[\alpha_{Z q}\left(\frac{V_{C}}{V_{0 C}}\right)^{2}+\beta_{I q}\left(\frac{V_{C}}{V_{0 C}}\right)+\gamma_{P q}\right]
\end{aligned}
$$

O conjunto de parâmetros a ser estimado é $\theta=\left[\alpha_{*}, \beta_{*}, \gamma_{*}\right]$, que, como visto anteriormente, representa respectivamente os percentuais de impedância constante (Z), corrente constante (I) e potência constante (P) da composição da carga. Estes parâmetros estão sujeitos à seguinte restrição:

$$
\alpha_{*}+\beta_{*}+\gamma_{*}=1 \text { ou } \gamma_{*}=1-\alpha_{*}-\beta_{*}
$$

Em resumo, o conjunto de parâmetros a ser estimado para os modelos são $\theta_{p}=\left[\alpha_{Z p}, \beta_{I p}\right.$, $\left.\gamma_{P p}\right]$ e $\theta_{q}=\left[\alpha_{Z q}, \beta_{I q}, \gamma_{P q}\right]$, respectivamente para potência ativa e reativa.

\subsubsection{Modelo Exponencial}

Este modelo não tem significado físico, diferentemente do modelo polinomial ZIP apresentado. As Equações (7.16) e (7.17) relacionam respectivamente as potências ativa e reativa como funções não-lineares das variações de tensão (VISCONTI, 2010).

$$
P_{C}=P_{0 C}\left(\frac{V_{C}}{V_{0 C}}\right)^{n p}
$$




$$
Q_{C}=Q_{0 C}\left(\frac{V_{C}}{V_{0 C}}\right)^{n q}
$$

Os parâmetros a serem estimados são $n p$ e $n q$, que podem assumir, segundo o compêndio apresentado em (IEEE, 1995), valores numa faixa de $n p=[0,72 ; 1,3]$ e $n q=[2,96$; $4,38]$ para cargas tipicamente residenciais, $n p=[0,99 ; 1,51]$ e $n q=[3,15 ; 3,95]$ para cargas tipicamente comerciais e $\mathrm{np}=0,18$ e $\mathrm{nq}=6$ para cargas tipicamente industriais. 


\section{Capítulo 8}

\section{CONClusões e Trabalhos Futuros}

Neste capítulo são apresentadas as conclusões finais desse trabalho de maneira a conduzir seu fechamento. Além disso, a partir dos desenvolvimentos realizados e resultados obtidos serão apresentadas propostas para trabalhos futuros que façam uso, total ou parcialmente, do conteúdo exposto neste trabalho.

Para tanto, este capítulo está organizado em duas seções. A Seção 8.1 será responsável por apresentar as conclusões do trabalho, enquanto que na Seção 8.2 a proposta de trabalhos futuros será conduzida.

\subsection{CONCLUSÕES}

Por meio dos resultados apresentados no Capítulo 6 é possível observar o atendimento esperado às características funcionais propostas à Unidade de Medição Fasorial Otimizada, isto é, com funcionalidades adequadas para sua utilização com sistemas de distribuição, tais como:

- Coleta para cada fase das amostras de tensão e corrente e o posterior cálculo fasorial, o qual apresentou uma precisão adequada como mostrado nos testes realizados na Seção 6.1, sendo que os erros com percentuais acima do recomendado ocorreram para correntes com amplitudes abaixo de dois ampères;

- Aquisição para cada fase de outras grandezas elétricas como frequência da fase, potências ativa, reativa e aparente, tensão e corrente RMS, sendo estas informações disponibilizadas juntamente com os fasores de tensão a corrente por meio do protocolo otimizado DNP3 sobre TCP/IP, como mostrado nos testes realizados na Seção 6.2;

- Quando solicitada, a reflexão no lado primário do transformador das tensões e correntes fasoriais medidas nos terminais de baixa tensão, levando-se em consideração o número de espiras, as resistências e as reatâncias de dispersão presentes nos enrolamentos primários e secundários no transformador. Um ensaio com a utilização da modelagem do transformador foi apresentada na Seção 6.2; 
- Sincronização na medição fasorial por meio do sinal GPS, a qual foi comprovada por meio de vários ensaios apresentados na Seção 6.3 utilizando duas diferentes PMUs. Verificou-se novamente que erros com percentuais acima do recomendado ocorreram para sinais de corrente com amplitudes muito baixas.

- Identificação da causa (rede ou carga) de variações nas medições com o auxílio de um sistema de inferência fuzzy, onde na Seção 6.4 foram geradas em laboratório as diferentes combinações das variáveis de entrada "Variação da tensão RMS", "Variação da potência ativa" e "Variação da potência reativa" que exploraram todo o conjunto de regras que caracterizam o sistema.

- Estimação dos parâmetros elétricos da carga e da rede de distribuição por meio da utilização de um algoritmo que utiliza as informações providas pelo sistema de identificação da causa de distúrbios presente na $P M U$ e das medições da tensão RMS, corrente RMS, potência ativa e potência reativa, como mostrado nos testes realizados na Seção 6.5.

Aliado as funcionalidades propostas, o baixo custo, característica fundamental do equipamento proposto, foi alcançada principalmente pela escolha da plataforma computacional formada pelo microcontrolador PIC32MX795F512L e pelo circuito de aquisição polifásico ADE7758, como mostra o orçamento presente no Anexo B.

É importante ressaltar na Tabela B.1 que os itens Microcontrolador, Transceiver Ethernet, Conector RJ45, Ressonador $8 \mathrm{MHz}$, Cristal $25 \mathrm{MHz}$, Conector USB e Placa $\mu \mathrm{C}+\mathrm{GPS}$ visam substituir a placa de desenvolvimento Cerebot MX7CK, apresentada anteriormente na Seção 3.5 e que foi de grande utilidade para o desenvolvimento do projeto. Porém, a utilização desta placa de desenvolvimento na fabricação da versão final do produto é economicamente inviável já que possui outros periféricos desnecessários ao funcionamento do mesmo.

Quando comparado aos equipamentos destinados a redes de transmissão, como os modelos GE Multilin N60 (GE, 2015) e Arbiter 1133A (ARBITER SYSTEMS, 2015), a Unidade de Medição Fasorial Otimizada proposta neste trabalho possui características funcionais mais simples relacionadas ao número de fasores calculados por segundo e a faixa operacional de tensão e corrente. No entanto estas características são suficientes visando à utilização do equipamento em redes de distribuição de energia elétrica, além de serem somadas a características funcionais exclusivas presentes no mesmo que já foram comentadas anteriormente e outras relacionadas à sua instalação, tais como: 
- Interface direta com os terminais secundários do transformador de distribuição, dispensando a necessidade de componentes adicionais como transformadores de corrente;

- Invólucro mecânico resistente a diferentes condições ambientais;

- Circuitos de proteção adequados à rede de distribuição em baixa tensão.

O custo total dos componentes da Unidade de Medição Fasorial Sincronizada para Sistemas de Distribuição é inferior à proposta de uma $P M U$ monofásica citada em Miller (2010) e comentada anteriormente no Capítulo 2, cujo custo de componentes próximo a U\$ 200,00 nos Estados Unidos é igual à R\$1.126,80 se os mesmos fossem importados para o Brasil, considerando a relação de conversão de $\mathrm{R} \$ 3,13$ para cada U\$ 1,00 e custos com importação e frete próximos a $80 \%$ do valor do equipamento. No entanto, como este equipamento é monofásico, são necessárias três unidades do mesmo para monitorar uma rede de distribuição trifásica.

A vantagem econômica do equipamento proposto, mesmo sem a adição dos custos relacionados ao processo produtivo, impostos e comercialização, fica mais evidente quando comparado ao custo de um equipamento já disponível no mercado, como o modelo Multilin N60 da General Eletric. Se este equipamento fosse importado para o Brasil, o seu preço ficaria próximo à $\mathrm{R} \$ 49.686,00$ considerando novamente a relação de conversão de $\mathrm{R} \$ 3,13$ para cada U\$ 1,00 e custos com importação e frete próximos a 80\% do valor do equipamento.

Assim, os objetivos traçados para esse trabalho foram atingidos e os resultados obtidos fazem com que a continuidade do estudo proposto neste trabalho ou mesmo novas linhas de pesquisa correlacionadas ao tema abordado possam ser delineados. A fim de pontuar algumas dessas linhas, a Seção 8.2 é conduzida.

\subsection{TRABALHOS FUTUROS}

Dentre os futuros trabalhos, correlacionados aos temas focados nesta tese, pontua-se os seguintes:

- Pesquisa sobre a substituição de componentes eletrônicos do produto visando reduzir o custo final do mesmo, porém sem prejuízo à suas funcionalidades;

- Ampliação do cálculo de sincrofasores para componentes harmônicos no firmware da Unidade de Medição Fasorial Sincronizada, por meio de modificações na quantidade de amostras utilizadas no cálculo da DFT; 
- Utilização, em um servidor remoto, de ferramentas com maior capacidade computacional para inferir com precisão os componentes harmônicos de um sinal discretizado.

- Desenvolvimento de técnicas que compensem regiões operacionais não lineares do transdutor de corrente, mantendo assim uma boa precisão na medição de correntes com amplitudes pequenas;

- Evolução do sistema para identificação da causa do distúrbio elétrico, principalmente quanto à adoção de outras topologias de sistemas inteligentes e outras variáveis de entrada;

- Aprimoramento da técnica de estimação dos parâmetros elétricos da carga e da rede de distribuição a ser executada em um servidor, principalmente quanto ao desenvolvimento de um processo mais simplificado para a estimação dos parâmetros elétricos da rede;

- Aprimoramento, no firmware da Unidade de Medição Fasorial Otimizada, do algoritmo responsável pela estimação dos parâmetros elétricos da carga e da rede de distribuição, principalmente quanto à adoção de outras condições necessárias para a estimação dos parâmetros elétricos da rede além do fator de potência e de altas correntes;

- Realização de testes em campo junto a concessionárias de distribuição de energia elétrica;

- Pesquisa sobre outras potenciais aplicações onde a Unidade de Medição Fasorial Otimizada proposta neste trabalho pudesse ser empregada. 


\section{REFERÊNCIAS BIBLIOGRÁFICAS}

ABBASY, N.H., ISMAIL, H.M. A Unified Approach for the Optimal PMU Location for Power System State Estimation. IEEE Transactions on Power Systems, 2009. v. 24, n. 2, p. 806-91, 2009.

ABI-ACKEL, M.V., CAMPOS, I.L.P. Sistema de controle, medição e monitoramento da rede secundária de distribuição de energia elétrica. US 20140300210, 10 maio 2013.

AGÊNCIA NACIONAL DE ENERGIA ELÉTRICA. Procedimentos de Distribuição de Energia Elétrica no Sistema Elétrico Nacional (PRODIST) - Módulo 3 - Acesso ao Sistema de Distribuição. Brasília, 2012. p. 65.

ANEEL. Perdas de Energia. 2015. Acesso em 14 abr 2015. Disponível em: <http://www.aneel.gov.br/area.cfm?idArea $=801>$.

AGOSTINI, M.N. Estudos de Aplicação de Medição Fasorial Sincronizada em Sistemas de Energia Elétrica. Relatório de Pós-Doutorado -LabPlan/UFSC, Florianópolis, Junho de 2006.

AGOSTINI, M.N. Curso sobre Medição Fasorial - Teoria e Prática. LabPlan/UFSC, Florianópolis, Novembro de 2007.

ALEXANDER, C., SADIKU, M., MUSA, S. Análise de Circuitos Elétricos com Aplicações. Porto Alegre, Brasil: AMGH Editora, 2014.

AMARAL, M. B. Modelagem Estática de Carga por Meio de Medição Direta: Proposição de um Metodologia Sistematizada, seus Impactos e Benefícios. Dissertação de Mestrado - Programa de Pós-Graduação em Engenharia Elétrica - Universidade Federal de Juiz de Fora, MG, Setembro de 2004.

ANALOG DEVICES. Poly Phase Multifunction Energy Metering IC with Per Phase Information - ADE7758 Datasheet. United States of America, Rev. E, 2011.

ANALOG DEVICES. Evaluation Board Documentation ADE7758 Energy metering IC EVAL ADE7758EB. United States of America, Rev. PrB, 2003.

ANDRADE, S. R. C. Sistemas de Medição Fasorial Sincronizada: Aplicação para Melhoria da Operação de Sistemas Elétricos de Potência. Dissertação de Mestrado Programa de Pós-Graduação em Engenharia Elétrica (PPGEE) - Universidade Federal de Minas Gerais, Belo Horizonte, Junho de 2008.

ANDRADE, S.R.C., VALE, M.H.M., SANTOS A.F.C.R. Aplicação da Tecnologia de Medição Fasorial Sincronizada nos Processos de Planejamento Elétrico da Operação. In: XI SIMPÓSIO DE ESPECIALISTAS EM PLANEJAMENTO DA OPERAÇÃO E EXPANSÃO ELÉTRICA. Belém, PA, Março de 2009. p. Não paginado.

ARBITER SYSTEMS. Cátalogo online da Arbiter Systems. Acesso em: 06 jul 2015. Disponível em <http://www.arbiter.com/catalog/product/model-1133a-power-sentinel>. 
AREFI, A., HAGHIFAM, M.R., FATHI, S.H. Distribution Harmonic State Estimation Based on a Modified PSO Considering Parameters Uncertainty. In: IEEE POWERTECH. Trondheim, Jun. 2011. p. 1-7.

ASE2000. Trial Version: Applied Systems Enginnering, 1999.

AVAGo TECHNOLOGIES. ACPL-064L, ACPL-M61L, ACPL-W61L, ACPL-K64L Ultra Low Power 10 MBd Digital CMOS Optocouplers Datasheet. United States of America, Maio de 2013.

BORGHETTI, A., NUCCI, C.A., PAOLONE, M., CIAPPI, G., SOLARI, A. Synchronized Phasors Monitoring During the Islanding Maneuver of an Active Distribution Network. IEEE Transactions on Smart Grid, 2011. v. 2, n. 1, p. 82-91, 2011.

CAPARÓ, J. L. C. Modelagem de Transformadores de Distribuição para Aplicação em Algoritmos de Fluxo de Potência Trifásico. Dissertação de Mestrado - Programa de PósGraduação em Engenharia Elétrica - Universidade Estadual Paulista, Ilha Solteira, Dezembro de 2005.

CASALI, F. Field Experience of Phasors Measurement in a Distribution Network with Increased Level of LV-Connected PV. In: 22ND INTERNATIONAL CONFERENCE ON ELECTRICITY DISTRIBUTION. Stockholm, 2013. paper No. 0190.

CHERRI, A.C., JÚNIOR, D.J.A., SILVA, I.N. Inferência fuzzy para o problema de corte de estoque com sobras aproveitáveis de material. Sociedade Brasileira de Pesquisa Operacional, 2011, v. 31, n .1, p.173-195, 2011.

CPFL ENERGIA. Protocolo DNP3 Aplicado à Comunicação em Sistemas de Energia Elétrica. São Paulo, 2011.

DECKER, I.C., DOTTA, D., AGOSTINI, M.N., ZISMATH, S.L., SILVA, A.S. Performance of a Synchronized Phasor Measurements in the Brazilian System. In: IEEE - POWER ENGINEERING SOCIETY GENERAL MEETING. Montreal, 2006. p. 18-22.

DECKER, I.C., AGOSTINI, M.N., DOTTA, D., MEYER, B.T., TEODORO, F.H., ZISMATH, S.L. Estudo e Avaliação do Desempenho de um Protótipo de Sistema de Medição Fasorial Sincronizada Instalado no Sistema de Transmissão da Eletrosul. Revista Eletroevolução, 2010. n. 59, p. 16-23, 2010.

DILIGENT INCORPORATED. Cerebot MX7cK $\mathbf{c K}^{\mathbf{T M}}$ Board Reference Manual. United States of America, Junho de 2013.

DING, F., BOOTH, C.D. Applications of PMUs in Power Distribution Networks with Distributed Generation. In: UPEC 2011 - 46TH INTERNATIONAL UNIVERSITIES' POWER ENGINEERING CONFERENCE. Soest, 2011. p. 1-5.

EHRENSPERGER, J.G. Sistemas de medição fasorial sincronizada: análise do estado da arte e aplicações no monitoramento de sistemas de energia elétrica. Dissertação de Mestrado - Departamento de Engenharia Elétrica da Universidade Federal de Santa Catarina, Florianópolis, 2004.

EL-HAWARY, M.E. The Smart Grid - State-of-the-art and Future Trends. Electric Power Components and Systems, 2014. v. 42, n. 3, p. 239-250, 2014. 
EPCOS. SIOV metal oxide varistors. Leaded varistors, Superior R-MP, S20 series. United States of America, April 2011.

EURAMET. Standard tests and requirements for Rate-of-Change of Frequency (ROCOF) measurements in SmartGrids. EMPIR Call 2015 - Health, SI, Normative and Research Potential, 2015, v. 1, n. STR-n12, 2015.

EUROPEAN PATENT OFFICE. Disponível em <http://www.epo.org/index.html>. Acesso em: 23 jul.2015.

FALCÃO, D.M. Integração de Tecnologias para Viabilização da Smart Grid. In: III SIMPÓSIO BRASILEIRO DE SISTEMAS ELÉTRICOS (SBSE). Belém, 2010. p. 1-5.

FALCÃO, D.M. Smart Grid e Microrredes: O Futuro já é Presente. In: VIII SIMPÓSIO DE AUTOMAÇÃO DE SISTEMAS ELÉTRICAS (SIMPASE). Rio de Janeiro, 2009. p. Não paginado.

FLAUZINO, R. A. Identificação e Localização de Faltas de Alta Impedância em Sistemas de Distribuição Baseadas em Decomposição por Componentes Ortogonais e Inferência Fuzzy. Tese de Doutorado - Programa de Pós-Graduação em Engenharia Elétrica da Escola de Engenharia de São Carlos (EESC/USP), São Carlos, 2007.

FRAZÃO, R. J. A. Métodos Alternativos para Estimação de Estado em Sistemas de Energia Elétrica. Dissertação de Mestrado - Programa de Pós-Graduação em Engenharia de Eletricidade da Universidade Federal do Maranhão (UFMA), São Luis, Janeiro de 2012.

GE. Catálogo online da GE. Acesso em: 06 jul 2015. Disponível em <www.gedigitalenergy.com/multilin/catalog/n60.htm>.

GIANNAKIS, G., KELATOS, V., GATSIS, N., SEUNG-JUN KIM, HAO ZHU, WOLLENBERG, B. Monitoring and Optimization for Power Grids: A Signal Processing Perspective. IEEE Signal Processing Magazine, 2013. v. 30, n. 5, p. 107-128, 2013.

GOMES, P., GUARINI, A. P., SOUZA, M. M. P., MASSAUD, A. G., FERREIRA, C., VICENTE, J. M. E., MENDES, P. P. C., RIBEIRO, A. M. C. Modelagem de Carga para Estudos Dinâmicos. In: XIX Seminário Nacional de Produção e Transmissão de Energia Elétrica. Rio de Janeiro, 2007. p. Não paginado.

GÖNEN, T. Electric Power Distribution System Engineering. United States of America: McGraw-Hill series in electrical engineering, 1986.

GRIGOletTO, V. O. Protocolos de Comunicação para Automação de sistemas de Energia - Análise Teórica e Aplicação Prática. Monografia - Escola de Engenharia de São Carlos da Universidade de São Paulo (EESC), São Carlos, 2012.

HATAWAY, G., FLERCHINGER, B., MOXLEY, R. Synchrophasors for Distribution Applications. PowerSouth Energy Cooperative and Schweitzer Engineering Laboratories Inc. Pullman, 2012.

HERCULES. Version 3.2.6: HW Group, 2013.

ICE COMPONENTS. CT07-1000 Current Sense Xfmr Datasheet. United States of America, 2011. 
IEEE Task Force on Load Representation for Dynamic Performance. Load Representation for Dynamic Performance Analysis. IEEE Transactions on Power Systems, 1993. v. 8, n. 2, pp. 472-482, 1993.

IEEE Task Force on Load Representation for Dynamic Performance. Bibliography on Load Models for Power Flow and Dynamic Performance Simulation. IEEE Transactions on Power Systems, 1995, v. 10, n. 1, pp. 523-528, 1995.

IEEE. IEEE Standard for Synchrophasors for Power Systems - ANSI/IEEE C37.118. 2005.

INSTITUTO NACIONAL DE PROPRIEDADE INDUSTRIAL. Disponível em <http://www.inpi.gov.br>. Acesso em: 23 jul.2015.

JASSBI, J.J., SERRA, P.J.A., RIBEIRO, R.A., DONATTI, A. A Comparison of Mamdani and Sugeno Inference Systems for a Space Fault Detection Application. In: AUTOMATION CONGRESS WAC '06 WORLD. Budapest, 2006. p. 1-8.

KERSTING, W. H. Distribution system modeling and analysis. 3. ed. Boca Raton, United States of America: CRC Press, 2002.

LATIPAT. Disponível em <http://lp.espacenet.com>. Acesso em: 23 jul.2015.

LAVERTY, D.M., VANFRETTI, L., BEST, R.J., BROGAN,P., ALKHATIB,I. MORROW, D.J. The OpenPMU Platform for Open-Source Phasor Measurements. IEEE Transactions on Instrumentation and Measurement, 2013. v. 62 , n. 4, p. 700 - 709, 2013.

LECUN,Y., BENGIO, Y., HINTON, G. Deep Learning. Nature, 2015. n. 521, p. 436 - 444, 2015.

LI, H.Y., YUNUS, B. Assessment of Switched Communication Network Availability for State Estimation of Distribution Networks With Generation. IEEE Transactions on Power Delivery, 2007. v. 22, n.3, p. 1424 - 1432, 2007.

LIMA, C. A. F., SANTOS, J. J. E., NAVAS, J. R. P., CONSELVAN, D. S., SOBRINHO, A. S. F. Cabeça de Série do Sistema de Religamento \& Corte de Unidades Consumidoras com Tecnologia Bluetooth. In: ANAIS DO IV SIMPÓSIO BRASILEIRO DE SISTEMAS ELÉTRICOS (SBSE). Goiania, 2012. p. Não paginado.

MARINI, R.L.V. Uso de Medição Fasorial Sincronizada Visando a Melhoria da Estabilidade de Sistemas Elétricos de Potência. Dissertação de Mestrado - Programa de Pós-Graduação em Engenharia da Universidade Federal de Santa Catarina, Florianópolis, Julho de 2005.

MATLAB. Version 7.12: The Math Works Inc, 2011.

MENDEL, J. Uncertain rule-based fuzzy inference systems: Introduction and new directions. United States of America: Prentice-Hall, 2001.

KERSTING, W. H. Distribution system modeling and analysis. 3. ed. Boca Raton, United States of America: CRC Press, 2002. 
MICROCHIP TECHNOLOGY INCORPORATED. 32-Bit Language Tools Libraries DS51685 Datasheet. United States of America, Rev.B, 2008a.

MICROCHIP TECHNOLOGY INCORPORATED. The Microchip TCP/IP Stack DS00833 Datasheet. United States of America, Rev.C, 2008b.

MICROCHIP TECHNOLOGY INCORPORATED. Section 14 - Timers DS61105 Datasheet. United States of America, Rev.E, 2010a.

MICROCHIP TECHNOLOGY INCORPORATED. Section 29 - Real-Time Clock and Calendar (RTCC) DS61125 Datasheet. United States of America, Rev.E, 2010b.

MICROCHIP TECHNOLOGY INCORPORATED. Section 23 - Serial Peripheral Interface (SPI) DS61106 Datasheet. United States of America, Rev.G, 2011.

MICROCHIP TECHNOLOGY INCORPORATED. Section 8 - Interrupts DS61108 Datasheet. United States of America, Rev.G, 2012a.

MICROCHIP TECHNOLOGY INCORPORATED. Section 21 - UART DS61107 Datasheet. United States of America, Rev.G, 2012 b.

MICROCHIP TECHNOLOGY INCORPORATED. PIC32MX5XX/6XX/7XX DS60001156 Datasheet. United States of America, Rev.H, 2013a.

MICROCHIP TECHNOLOGY INCORPORATED. Section 35 - Ethernet Controller DS60001155 Datasheet. United States of America, Rev.C, $2013 \mathrm{~b}$.

MILLER, B. R. Concept for Next Generation Phasor Measurement: A Low-Cost, SelfContained, and Wireless Design. Master Thesis - Tennessee Research and Creative Exchange, University of Tennessee, Knoxville, December 2010.

MPLAB IDE. Version 8.63: Microchip Technology Incorporated, 2010.

MPLAB C Compiler for PIC32 MCUs. Version 2.02: Microchip Technology Incorporated, 2011.

MULTISIM. Version 11.0: National Instruments, 2010.

NASCIMENTO, R.J., BATISTELA, N.J., KUO-PENG P., JANUÁRIO, M., RIGONI, M., SPREEDEMAN, R., RESMINI, F.N., FURLAN, A.G.L. Estudo e Modelagem de Transformadores. In: V CONGRESSO DE INOVAÇÃO TECNOLÓGICA EM ENERGIA ELÉTRICA (CITENEL). Belém, 2009. p. Não paginado.

NEVES, M. S. Modelagem de carga em Sistemas de Energia Elétrica: Modelo Matemático e sua Validação com Testes em Campo. Dissertação de Mestrado Programa de Pós-Graduação em Engenharia Elétrica da Universidade Federal de Juiz de Fora (UFJF), Juiz de Fora, Agosto de 2008.

OLIVEIRA, P. R.P. DNP 3.0 - Distributed Network Protocol, 2008.

PAZ, M. C. R. Formulação Integrada para a Localização de Faltas em Sistemas de Distribuição. Dissertação de Mestrado - Programa de Pós-Graduação em Engenharia Elétrica da Universidade Federal do Rio Grande do Sul (UFRGS), Porto Alegre, Agosto de 2010. 
PEDRYCZ, W., GOMIDE, F. A. C. An Introduction to Fuzzy Sets - Analysis and Design. MIT Press, 1998.

PROTEUS Design Suite. Version 7.10: Labcenter Electronics Ltd, 2011.

PUBLITEK EUROPEAN EDITORS. Low-Cost Microcontroller-Based Phasor Measurement Units Improve Smart Grid Reliability. Bath, 2014.

RECOM. RAC01-02 Datasheet. United States of America, Rev. 3, 2014.

RICHARDSON RFPD. 1575.42 MHz GPS Active Antenna - RANG001312G. United States of America, Rev. 2P, March 2011.

ROSS, T.J. Fuzzy Logic with Engineering Applications. 2. ed. West Sussex, England: John Wiley, 2004.

SANCHEZ-AYALA, G., AGUERC, J.R., ELIZONDO, D., LELIC, M. Current Trends on Applications of PMUs in Distribution Systems. In: IEEE INNOVATIVE SMART GRID TECHNOLOGIES (ISGT). Washington, 2013. p. 1-6.

SANTOS, M.M., AGOSTINI, M.N. Sistemas de Medição Fasorial Sincronizada. Revista Mensal do Conselho Regional de Engenharia, Arquitetura e Agronomia do Rio Grande do Sul, 2011. n. 81, p.31, 2011.

SILVA, I. N. Estimadores Fuzzy Linguísticos (Aplicação em Classificação de Padrões). Notas de aula da disciplina SEL5755 - Sistemas Fuzzy, 2013a.

SILVA, I. N. Estimadores Fuzzy Linguísticos (Aplicação em Aproximação Funcional). Notas de aula da disciplina SEL5755 - Sistemas Fuzzy, 2013b.

SMSC CORPORATION. LAN8720A/LAN8720Ai - Small Footprint RMII 10/100 Ethernet Transceiver with HP Auto-MDIX Support Datasheet. United States of America, Rev.1.4, 2012.

STRAHL. Catálogo online da Strahl. 2014. Acesso em: 10 dez 2014. Disponível em: $<$ http://www.strahl.com>.

THE UNITED STATES PATENT AND TRADEMAK OFFICE. Disponível em <http://www. uspto.govr>. Acesso em: 23 jul.2015.

TORRES, G. Redes de Computadores: versão revisada e atualizada. 2. ed. Rio de Janeiro, Brasil: Nova Terra, 2009.

U-BLOX AG. GPS.G7-HW-12012 - MAX-7 GPS/GNSS modules Datasheet. Swiss, Rev.A, 2013a.

U-BLOX AG. GPS.G7-SW-12001-B - Receiver Description - Including Protocol Specification V14. Swiss, Rev.B, 2013 b.

VA TECH SAT. Firmware Description DNPMxx - Distributed NetworkProtocol VA1. Edinburgh, 2002.

VISCONTI, I. F. Modelos de Cargas Baseados em Medições para Simulações Dinâmicas em Sistemas Elétricos de Potência. Dissertação de Mestrado - Programa de PósGraduação em Engenharia Elétrica da PUC-Rio, Rio de Janeiro, Abril de 2010. 
VON MEIER, A., CULLER, D., MCEACHERN, A. Micro-Synchrophasors for Distribution Systems. In: IEEE INOVATE SMART GRID TECHNOLOGIES CONFERENCE (ISGT). Washington, 2014. p. 1-5.

WACHE, M., MURRAY, D.C. Application of Synchrophasor Measurements for Distribution Networks. In: IEEE POWER AND ENERGY SOCIETY GENERAL MEETING. San Diego, July 2011. p. 1-4.

WILSON, R.E. Methods and Uses of Precise Time in Power Systems. IEEE Transactions on Power Delivery, 2007. v. 7, n. 1, p. 1424 - 1432, 2007.

XIE, X., XIN, X., XIAO, J., WU, J., HAN, Y. Applications in Chinese Power System. IEEE Power \& Energy Magazine, 2006. v. 4, n. 1, p. 54-63, 2006.

YEN, J., LANGARI, R. Fuzzy Logic: Intelligence, control, and Information. United States of America: Prentice Hall, 1998.

ZADEH, L.A. Fuzzy sets. Information and Control, 1965. v. 8, p. 29-44, 1965.

ZADEH, L.A. Outline of new approach to the analysis of complex systems and decisions. IEEE Transactions on Systems, Man and Cybernetics, 1973. v. 3, p. 28-44, 1973. 


\section{ANEXOA}

\section{CONCEITOS RELACIONAdOS À Lógica FuzzY}

\section{A.1 - Fundamentos sobre conjuntos e lógica fuzzy}

Na teoria de conjuntos clássica, um elemento ou pertence a uma classe ou não. Dado um universo de discurso $U$ e um elemento particular $x \in U$, o grau de pertinência $\mu_{A}(x)$ com relação a um conjunto $A \subseteq U$ é dado por:

$$
\mu_{A}(x)= \begin{cases}1, & \text { se } x \in A \\ 0, & \text { se } x \notin A\end{cases}
$$

A função $\mu_{A}(x): U \rightarrow\{0,1\}$ é chamada de função característica na teoria clássica de conjuntos. Pode-se observar em (A.1) que a função característica, assim definida, pode assumir apenas valores discretos.

Frequentemente, uma generalização desta ideia é utilizada, por exemplo, para manipulação de dados com erros limitados. Todos os números pertencentes a um intervalo pré-definido terão um grau de pertinência 1, os números que não pertencerem a este intervalo possuirão um grau de pertinência nulo como pode ser observado na Figura A.1(a). Na Figura A.2(b) o caso preciso é apresentado e deste se tem que o grau de pertinência é um somente em determinado valor, sendo nulo para os demais valores (FLAUZINO, 2007).
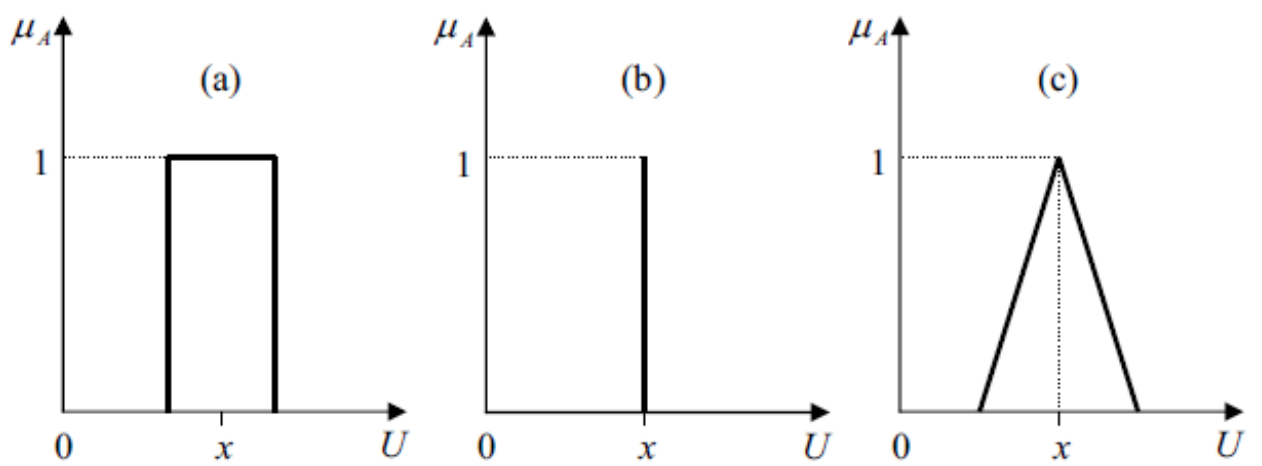

Figura A.1 - Funções de pertinência (FLAUZINO, 2007). 
Zadeh (1973) propôs uma caracterização mais ampla, na medida em que sugere que alguns elementos são mais membros de um conjunto do que outros. $\mathrm{O}$ grau de pertinência pode então assumir qualquer valor entre o intervalo $[0,1]$, sendo que o valor 0 indica uma completa exclusão e um valor 1 representa completa pertinência, ou seja, a função característica passa a ser contínua no seu domínio. Esta generalização aumenta o poder de expressão da função característica.

Na Figura A.3(c), esta abordagem descrita é apresentada na forma de uma função de pertinência triangular com pico em $x$, sugerindo a ideia de que quanto mais próximo de $x$, mais o elemento se identifica com o conceito representado por $x$.

A partir desta definição, o conceito de elemento e o conceito de conjunto podem ser expandidos e novas denominações mais amplas assumidas, como apresentado a seguir.

Formalmente, seja $U$ uma coleção de objetos denominados genericamente por $\{u\}$. O domínio $U$ é chamado de universo de discurso, podendo ser contínuo ou discreto. Um conjunto fuzzy $A$ em um universo de discurso $U$ é definido por uma função de pertinência $\mu_{A}$ que assume valores em um intervalo [0,1], como apresentado em (A.2).

$$
\mu_{A}: U \rightarrow[0,1]
$$

O conjunto suporte de um conjunto fuzzy $A$ é o subconjunto dos pontos $u$ de $U$ tal que $\mu_{A}(u)>0$. Um conjunto fuzzy cujo conjunto suporte é um único ponto de $U \operatorname{com} \mu_{A}=1$ é chamado de um conjunto unitário fuzzy. A partir desta definição, os conjuntos clássicos passam a ser um caso específico na teoria de conjuntos fuzzy. Na Figura A.1(c) tem-se uma função de pertinência do tipo triangular, no entanto, pode-se utilizar qualquer função $f: \mathfrak{R} \rightarrow$ $[0,1]$ para a representação de um determinado conjunto fuzzy.

\section{A.2 - Definição de operações e operadores da lógica fuzzy}

Sejam $A$ e $B$ dois conjuntos fuzzy definidos em um universo de discurso $U$ com funções de pertinência $\mu_{A}$ e $\mu_{B}$, respectivamente. As operações envolvendo conjuntos fuzzy, tais como a união $(A \cup B)$, a intersecção $(A \cap B)$ e o complemento $(\neg A)$, são definidas respectivamente de maneira formal pelas expressões (A.3), (A.4) e (A.5) (FLAUZINO, 2007).

$$
\begin{gathered}
\mu_{A \cup B}(u)=\mu_{A}(u) \& \mu_{B}(u) \\
\mu_{A \cap B}(u)=\mu_{A}(u) \Gamma \mu_{B}(u)
\end{gathered}
$$




$$
\mu_{\neg A}(u)=1-\mu_{A}(u)
$$

onde $\Gamma$ é uma norma triangular ( $t$-norma) e \& é uma co-norma triangular ( $s$-norma). Estas normas também são utilizadas para definir os conectivos "E”( $\Gamma)$ e “OU”(\&), empregados para compor os relacionamentos lógicos entre os termos das variáveis linguísticas de entrada, os quais são mostrados com mais detalhes no item A.3.

Como exemplo de $s$-norma tem-se a Expressão (A.6) e como exemplo da $t$-norma temse a Expressão (A.7).

$$
\begin{gathered}
\mu_{A \cup B}(u)=\max \left\{\mu_{A}(u), \mu_{B}(u)\right\} \\
\mu_{A \cap B}(u)=\min \left\{\mu_{A}(u), \mu_{B}(u)\right\}
\end{gathered}
$$

O emprego do operador "max" representando a s-norma e o emprego do operador "min" representando a $t$-norma foi proposto inicialmente por Zadeh (1965). No entanto, inúmeras outras $s$-norma e $t$-norma podem ser empregadas na definição dos sistemas fuzzy (PEDRYCZ \& GOMIDE, 1998).

\section{A.3 - Regras de inferência fuzzy}

Para expressar conceitos ou relacionamentos através de elementos da linguagem natural é muito comum o uso de elementos qualitativos ao invés de valores quantitativos. Elementos linguísticos típicos incluem expressões do tipo "mais ou menos", "alto", "não muitos", "médios", etc. Estas ideias são capturadas pela definição de variáveis linguísticas.

Uma variável linguística tem por característica assumir valores dentro de um conjunto de termos linguísticos, ou seja, palavras ou frases. Assim, ao invés de assumir instâncias numéricas, estas variáveis assumem instâncias linguísticas. Por exemplo, uma variável linguística "Temperatura" poderá assumir como valor um dos termos do conjunto \{"baixa", "média", "alta"\}. Para se atribuir um significado aos termos linguísticos, associa-se a cada um destes termos um conjunto fuzzy definido sobre um universo de discurso comum, que neste exemplo será a "Temperatura". A Figura A.2 ilustra três possíveis termos linguísticos para variável linguística representando a temperatura (FLAUZINO, 2007). 


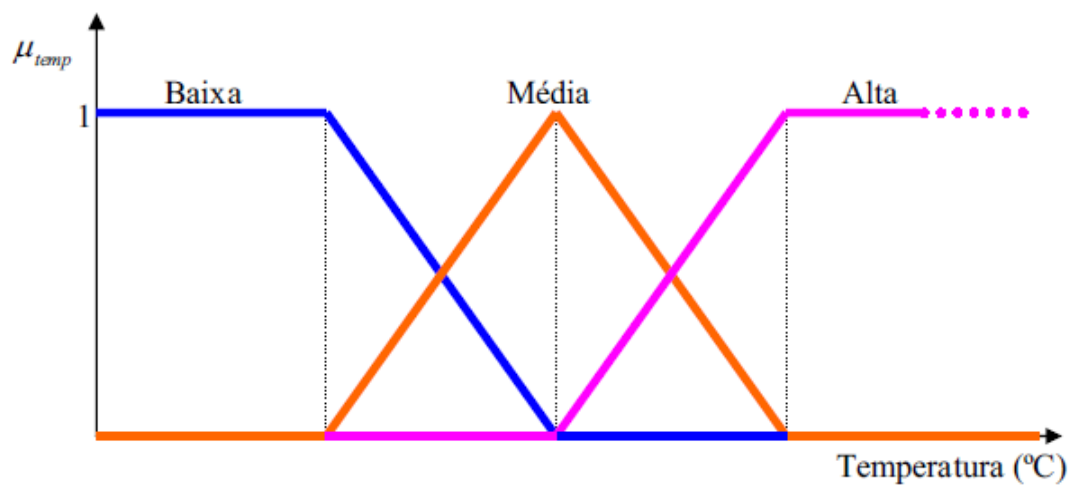

Figura A.2 - Representação da variável linguística temperatura (FLAUZINO, 2007).

A forma mais comum de expressar o conhecimento é por meio de regras do tipo condição-ação. Neste tipo de regra, um conjunto de condições descrevendo uma parcela observável das entradas do processo é associado com uma ação de saída que irá manter ou levar o sistema às condições desejadas, ou ainda, expressar o conhecimento especialista envolvido em um sistema e permitir que a modelagem seja mais flexível e comporte informações qualitativas do processo.

Tipicamente, uma condição é uma proposição linguística (envolvendo variáveis linguísticas de entrada), onde são utilizados conectivos, como por exemplo "o erro é grande e positivo". Da mesma maneira, uma ação típica de controle é uma descrição linguística, como por exemplo "aumente um pouco a vazão". A ideia embutida junto às regras fuzzy de representar o conhecimento por meio de um conjunto de termos linguísticos associados às variáveis de saída e entrada do processo é absorvida pelos sistemas de inferência fuzzy. As ações de controle ou as saídas do modelo são expressas de forma similar para cada variável de controle (saídas). Regras do tipo se-então são frequentemente chamadas de declarações condicionais fuzzy ou simplesmente regras fuzzy. Dependendo do propósito, controle ou modelagem, podem ser chamadas ainda de regras de controle fuzzy ou regras de modelagem fuzzy. Uma regra fuzzy típica pode ser dada por:

$$
\mu_{R}=\mu_{(A \rightarrow B)}(x, y)
$$

onde $A$ e $B$ são conjuntos fuzzy pertencentes respectivamente aos universos de discursos $X$ e $Y$, e o operador $(\rightarrow)$ denota uma função de implicação fuzzy. A função de pertinência $\mu_{\mathrm{RA} \rightarrow \mathrm{B}}$ pode ser obtida por meio dos seguintes operadores (SILVA, 2013b):

- Mamdani: $\mu_{R_{A \rightarrow B}}(x, y)=\min \left\{\mu_{A}(x), \mu_{B}(y)\right\}$

- Zadeh: $\mu_{R_{A \rightarrow B}}(x, y)=\max \left\{1-\mu_{A}(x), \min \left\{\mu_{A}(x), \mu_{B}(y)\right\}\right\}$ 
- Larsen: $\mu_{R_{A \rightarrow B}}(x, y)=\mu_{A}(x) * \mu_{B}(y)$

- Aritmético: $\mu_{R_{A \rightarrow B}}(x, y)=\min \left\{1,1-\mu_{A}(x)+\mu_{B}(y)\right\}$

- Booleano: $\mu_{R_{A \rightarrow B}}(x, y)=\max \left\{1-\mu_{A}(x), \mu_{B}(y)\right\}$

A ação de controle consistirá então da união de todas as funções fuzzy ativadas. $\mathrm{O}$ valor final, ou seja, aquele que será apresentado pelas saídas do sistema fuzzy, será determinado pelo processo de defuzzificação. Uma descrição detalhada dos processos envolvidos com a inferência fuzzy pode ser encontrada em Pedrycz \& Gomide (1998).

\section{A.4 - Agregação}

Em uma base de regras, quando mais de uma regra é acionada, as contribuições das diversas regras após a inferência são combinadas pelo operador de agregação. Por exemplo, supondo-se que $B_{1}{ }^{\prime}, \ldots, B_{n}$ ' são todos os resultados derivados das diversas regras acionadas, todos relacionados a uma mesma variável linguística, o resultado da implicação de todas as regras $B$ ' será:

$$
B^{\prime}=\bigcup_{i}^{n} B_{i}^{\prime}
$$

onde o símbolo $U$ representa o operador agregação (FLAUZINO, 2007). Normalmente, fazse a agregação pelo máximo (operador max), ou seja, entre os diversos consequentes de um mesmo conjunto gerado na implicação, seleciona-se o de maior grau de pertinência (CHERRI et al, 2011). A Figura A.3 ilustra o processo de agregação quando existem duas regras, $A_{i} \rightarrow B_{i}$ e $A_{j} \rightarrow B_{j}$. $A$ 'é o fator de entrada, representado como um conjunto fuzzy.
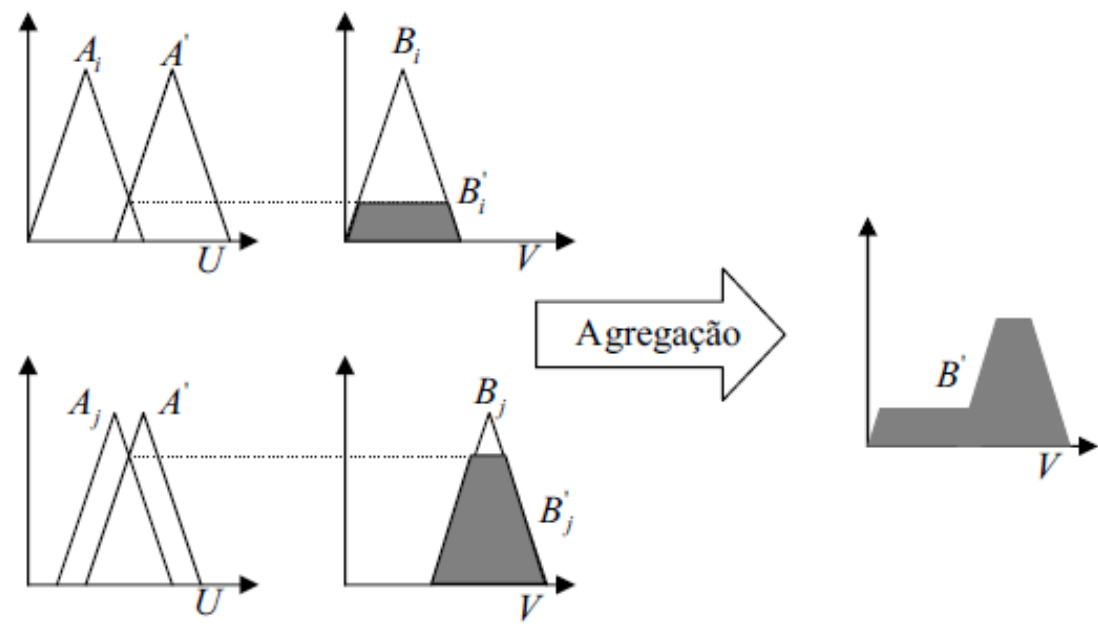

Figura A.3 - Mecanismo de inferência fuzzy (FLAUZINO, 2007). 


\section{A.5 - Defuzzificação da região fuzzy de saída}

De posse desta região fuzzy de saída, computada a partir das contribuições individuais de cada regra ativada, aplica-se então um operador de defuzzificação a fim de fornecer um valor pontual (crisp) de saída o qual pertence ao universo de discurso da respectiva variável fuzzy de saída (SILVA, 2013b).

A seguir são apresentados alguns operadores de defuzzificação:

- Método do Centro de Área (CDA):

$$
C D A=\frac{\sum_{k=1}^{N} \mu\left(v_{K}\right) v_{K}}{\sum_{k=1}^{N} \mu\left(v_{K}\right)}
$$

onde $N$ é o número de discretizações do universo de discurso.

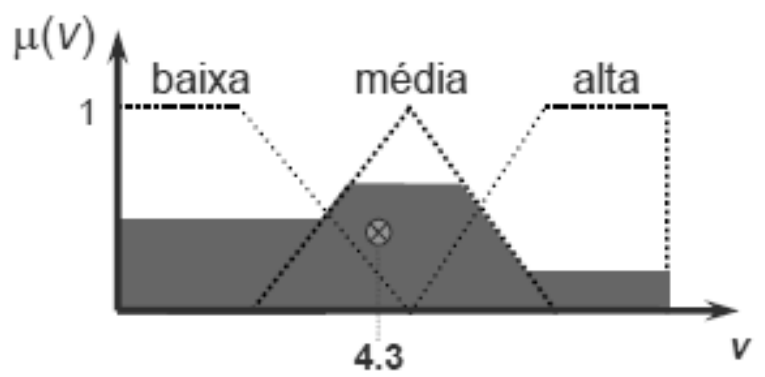

Figura A.4 - Método do Centro de Área (SILVA, 2013b).

- Método das Médias dos Máximos (MDM):

$$
M D M=\sum_{k=1}^{M} \frac{v_{K}}{M}
$$

onde $v_{k}$ são os valores que contém graus de pertinência máximos e $M$ é a quantidade destes elementos.

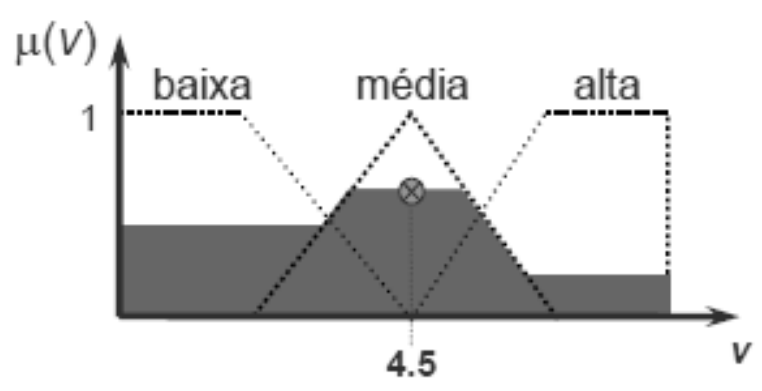

Figura A.5 - Método das Médias dos Máximos (SILVA, 2013b). 
- Método do Primeiro Máximo (MPM):

$$
M P M=\min \left\{\max \left\{\mu_{V}\right\}\right\}
$$

onde $M P M$ é o valor do universo de discurso onde ocorre o primeiro maior máximo.

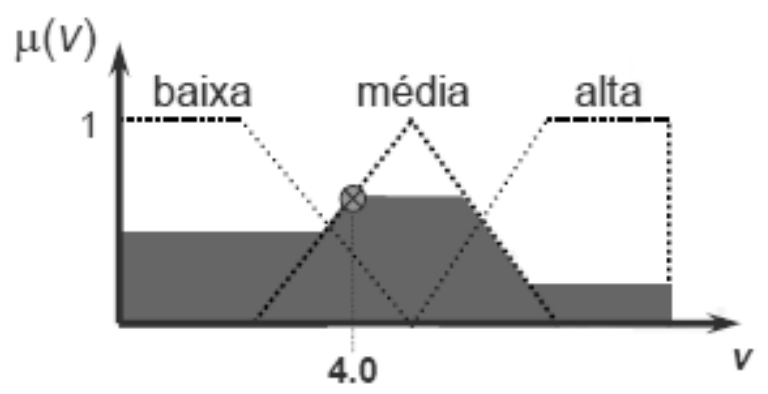

Figura A.6 - Método do Primeiro Máximo (SILVA, 2013b).

Após o procedimento de defuzzificação da região fuzzy final, uma determinada classe pode ser fornecida como resposta através do termo que produzir o maior grau de ativação em relação ao valor defuzzificado (SILVA, 2013a). Tomando como exemplo a Figura A.6, a classe selecionada foi o termo "média". 


\section{ANEXO B}

\section{CUSTO MATERIAL DO PROTÓTIPO}

$\mathrm{Na}$ Tabela B.1 os componentes foram cotados para a montagem de 10 e 100 unidades da Unidade de Medição Fasorial Otimizada.

Tabela B.1 - Lista de Materiais do Protótipo.

\begin{tabular}{|c|c|c|c|c|c|c|}
\hline Componente & Modelo & Fabricante & $\begin{array}{l}\text { Distribui } \\
\text { dor }\end{array}$ & Qtd & $\begin{array}{c}\text { Cotação } \\
\text { para } 10 \\
\text { unidades }\end{array}$ & $\begin{array}{l}\text { Cotação } \\
\text { para } 100 \\
\text { unidades }\end{array}$ \\
\hline Microcontrolador & $\begin{array}{c}\text { PIC32MX795F5 } \\
\text { 12L-80I/PT }\end{array}$ & MICROCHIP & Mouser & 1 & U\$ 9,41 & U\$ 7,81 \\
\hline $\begin{array}{c}\text { Transceiver } \\
\text { Ethernet }\end{array}$ & $\begin{array}{c}\text { LAN8720AI-CP- } \\
\text { TR }\end{array}$ & MICROCHIP & Mouser & 1 & U\$ 1,26 & U\$ 0,95 \\
\hline Conector RJ45 & $\mathrm{J} 00-0065 \mathrm{NL}$ & PULSE & Mouser & 1 & U\$ 4,98 & U\$ 4,74 \\
\hline Conector USB & ZX62D-B-5PAB & HIROSE & Mouser & 1 & $\mathrm{U} \$ 0,62$ & U\$ 0,59 \\
\hline Cristal $32768 \mathrm{~Hz}$ & $\begin{array}{c}\text { NC38LF- } \\
32.768 \mathrm{kHz}\end{array}$ & FOX & Mouser & 1 & $\mathrm{U} \$ 1,26$ & U\$ 1,13 \\
\hline $\begin{array}{c}\text { Ressonador } \\
8 \mathrm{MHz}\end{array}$ & $\begin{array}{c}\text { DSC1030BC1- } \\
008.0000\end{array}$ & MICREL & Mouser & 1 & $\mathrm{U} \$ 1,43$ & U\$ 1,17 \\
\hline Cristal $25 \mathrm{MHz}$ & $\begin{array}{c}\text { ABMM2- } \\
25.000 M H Z-E 2 T\end{array}$ & ABR & Mouser & 1 & U\$ 1,02 & U\$ 0,65 \\
\hline Cristal $10 \mathrm{MHz}$ & $\begin{array}{c}\text { ABL- } \\
\text { 10.000MHZ-B2 }\end{array}$ & ABRACON & Mouser & 1 & $U \$ 0,33$ & U\$ 0,27 \\
\hline $\begin{array}{c}\text { Cl Medidor de } \\
\text { Energia Poli }\end{array}$ & ADE7758ARWZ & $\begin{array}{l}\text { ANALOG } \\
\text { DEVICES }\end{array}$ & Mouser & 1 & U\$ 10,17 & U\$ 8,64 \\
\hline $\begin{array}{l}\text { Fotoacoplador de } \\
\text { alta velocidade }\end{array}$ & $\begin{array}{l}\text { ACPL-M61L- } \\
000 E\end{array}$ & AVAGO & Mouser & 5 & U\$1,72 & U\$ 1,35 \\
\hline $\begin{array}{c}\text { Transformador de } \\
\text { Corrente }\end{array}$ & CT07-1000 & $\begin{array}{c}\text { ICE } \\
\text { COMPONENTS }\end{array}$ & Mouser & 3 & U\$ 7,10 & U\$ 5,47 \\
\hline Varistor & $\begin{array}{c}\text { B72220P3271K } \\
101 \\
\end{array}$ & EPCOS & Mouser & 3 & U\$ 1,28 & U\$ 1,01 \\
\hline $\begin{array}{c}\text { Fonte chaveada } \\
5 \mathrm{~V}\end{array}$ & RAC02-05SC & RECOM & Mouser & 2 & U\$ 12,60 & U\$ 11,11 \\
\hline Módulo GPS & MAX-7Q & U-BLOX & Alibaba & 1 & U\$ 11,20 & U\$ 10,00 \\
\hline Antena GPS & RANG001312G & RICHARDSON & Arrow & 1 & U\$ 12,00 & U\$ 12,00 \\
\hline $\begin{array}{l}\text { Componentes } \\
\text { convencionais }\end{array}$ & Vários & Vários & Mouser & 1 & U\$ 10,00 & U\$ 8,00 \\
\hline Placa $\mu \mathrm{C}+$ GPS & - & NV & NV & 1 & $\mathrm{R} \$ 18,00$ & $\mathrm{R} \$ 13,00$ \\
\hline Placa aquisição & - & NV & NV & 1 & $R \$ 20,00$ & $\mathrm{R} \$ 15,00$ \\
\hline Mecânica plástica & 3068 & STRAHL & $\begin{array}{l}\text { Eletro } \\
\text { center }\end{array}$ & 1 & $\mathrm{R} \$ 90,00$ & $\mathrm{R} \$ 70,00$ \\
\hline Prensa-cabos & 704 & STRAHL & $\begin{array}{l}\text { Eletro } \\
\text { center }\end{array}$ & 5 & $\mathrm{R} \$ 2,52$ & $\mathrm{R} \$ 2,00$ \\
\hline \multicolumn{5}{|c|}{ Valor total dos componentes nacionais (R\$ - 06/07/15) } & 140,60 & 108,00 \\
\hline \multicolumn{5}{|c|}{ Valor total dos componentes importados (U\$ FOB - 06/07/15) } & 122,62 & 104,33 \\
\hline \multicolumn{5}{|c|}{ Valor total dos componentes importados (U\$ CIF - 06/07/15) * } & 220,72 & 187,79 \\
\hline \multicolumn{5}{|c|}{ Valor total dos componentes importados $(R \$-06 / 07 / 15)$ ** } & 690,85 & 587,78 \\
\hline \multicolumn{5}{|c|}{ Valor total dos componentes (R\$ - 06/07/15) } & 831,45 & 695,78 \\
\hline
\end{tabular}

${ }^{*} \mathrm{CIF}=1,8 \mathrm{FOB}$, levando-se em conta taxas de importação e frete

** Cotação do dólar comercial: U\$ 1,00 = R\$ 3,13 
A maioria dos componentes citados nesta tabela foi importada, com custo de aquisição cotado junto aos distribuidores em dólares FOB (Free On Board), isto é, sem levar em consideração taxas relacionadas com frete, seguro e impostos. Posteriormente é apresentado na tabela o valor total dos componentes importados convertidos para dólares CIF (Cost, Insurance and Freight), onde foram considerados os custos anteriormente desprezados. Por fim, é apresentado na tabela o custo final em reais, considerando a cotação do câmbio no dia 6 de julho de 2015. 